\title{
CENSO DE REDUCCIONES INDIGENAS SELECCIONADAS: ANALISIS SOCIODEMOGRAFICO
}

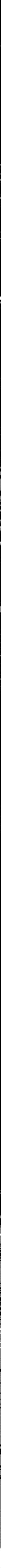

Whiversidad de La Frontera - Instituto Nacional de Estadisticas

Cannidación Instituto Indígena - Programa de Apoyo y Extensión on Saludi Materno Infantil - Centro Latinoamericano de Demografía 
Esta publicación forma parte del Proyecto Estudio Biodemográfico y Social de la Población en Reducciones Indígenas. El volumen comprende el análisis de resultados del Censo de Reducciones Indígenas Seleccionadas, que fue llevado a cabo entre el 24 de octubre y el 6 de diciembre de 1988 en cuatro distritos de la Comuna de Temuco, Provincia de Cautín, IX Región de Chile.

Participaron en las diversas etapas de realización de este proyecto la Universidad de La Frontera (UFRO), la Pontificia Universidad Católica de Chile Sede Temuco (UCT), la Fundación Instituto Indígena (FII), el Instituto Nacional de Estadísticas (INE), el Programa de Apoyo y Extensión en Salud Materno Infantil (PAESMI) y el Centro Latinoamericano de Demografía (CELADE).

La presente publicación pone a disposición un conjunto de antecedentes que permite el conocimiento de las condiciones de vida de una población indígena campesina, desde un punto de vista interdisciplinario y con el objetivo global de sistematizar aspectos claves para el planteamiento de políticas.

Como objetivo más específico, se considera de particular importancia el tratar de dar respuesta a numerosas interrogantes sobre las actuales condiciones de vida de una población mapuche campesina que, a contar de la segunda mitad del siglo XIX, fue radicada en territorios definidos como "reducciones indígenas".

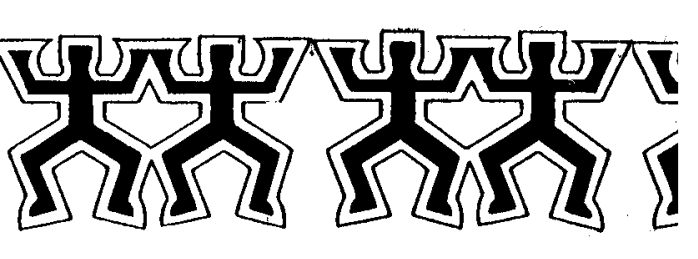




\section{CENSO DE REDUCCIONES INDIGENAS SELECCIONADAS: ANALISIS SOCIODEMOGRAFICO}

Distritos Labranza, Molco, Maquehue y Metrenco

Provincia de Cautín, IX Región, Chile

Octubre-Diciembre 1988

Universidad de La Frontera - Instituto Nacional de Estadísticas

Fundación Instituto Indígena - Programa de Apoyo y Extension en Salud Materno Infantil - Centro Latinoamericano de Demografía

Santiago, Chile

1990 
Serie CELADE: LC/DEM/G 96/OI 93

Esta publicación ha sido posible gracias al apoyo de los Gobiernos de Canadá y Francia a través de los Programas de Cooperación e Intercambio con el Centro Latinoamericano de Demografía (CELADE). Se desea expresar un especial reconocimiento a los residentes de las reducciones censadas por la colaboración brindada a la presente investigación por medio de su favorable acogida a las entrevistas.

La compilación, revisión y edición de este documento estuvo a cargo de Jorge Martínez P., Consultor del CELADE.

Las opiniones y datos que figuran en este volumen son responsabilidad de los autores, sin que las instituciones sean necesariamente partícipes de ellos.

Fotografía portada: Juan Pablo Orrego Silva 


\section{INDICE}

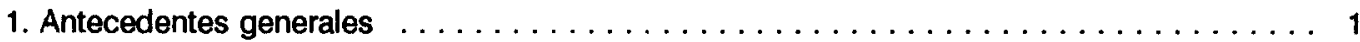

1.1. Etapas del proyecto $\ldots \ldots \ldots \ldots \ldots \ldots \ldots \ldots \ldots \ldots \ldots \ldots \ldots \ldots$

1.1.1. Primera etapa . . . . . . . . . . . . . . . . . . 1

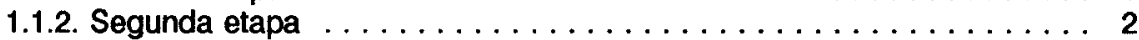

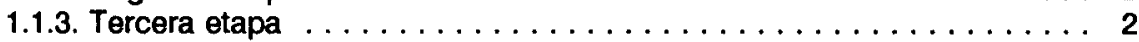

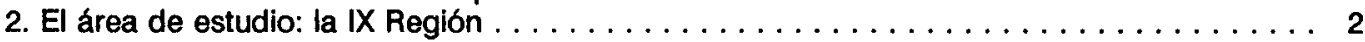

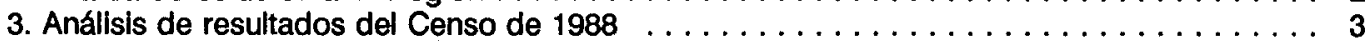

I. CARACTERISTICAS DEMOgRAFICAS $\ldots \ldots \ldots \ldots \ldots \ldots \ldots \ldots \ldots \ldots \ldots$

Jorge Rodriguez, Jorge Martínez, Juan Chackiel

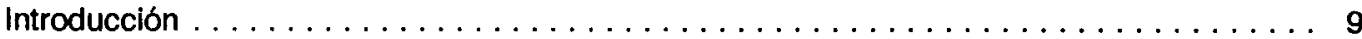

1. Aspectos generales de la población $\ldots \ldots \ldots \ldots \ldots \ldots \ldots \ldots \ldots \ldots \ldots \ldots \ldots \ldots \ldots$

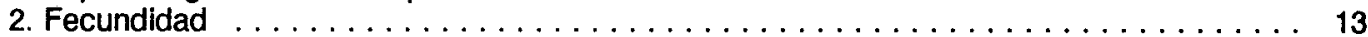

2.1. Paridez media o fecundidad retrospectiva $\ldots \ldots \ldots \ldots \ldots \ldots \ldots \ldots \ldots$

2.2. Fecundidad actual (TGF) $\ldots \ldots \ldots \ldots \ldots \ldots \ldots \ldots \ldots \ldots \ldots \ldots \ldots \ldots$

2.3. Tasas de reproducción ....................... 22

2.4. Diferencias socioculturales de la fecundidad . . . . . . . . . . . 24

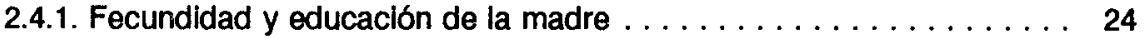

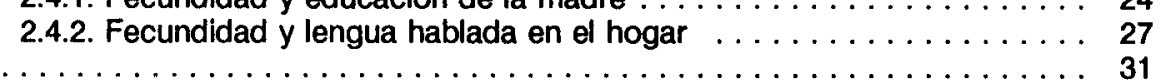

3.1. Mortalidad y esperanza de vida . . . . . . . . . . . . . . . 31

3.2. Mortalidad infantil . . . . . . . . . . . . . . . . . 34

4. Migración

4.1. Importancia de la migración derivada de la comparación entre la población en

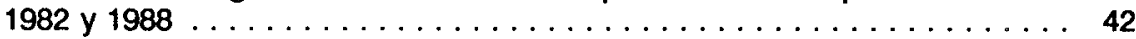

4.2. Importancia de la migración derivada del análisis de la estructura de edad y sexo de la población .........................43

5. Crecimiento y composición de la población por edad y sexo $\ldots \ldots \ldots \ldots \ldots \ldots \ldots$

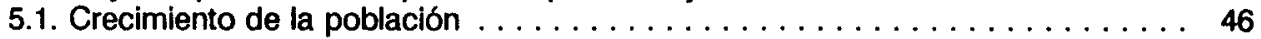

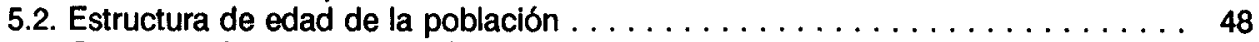

Conclusiones

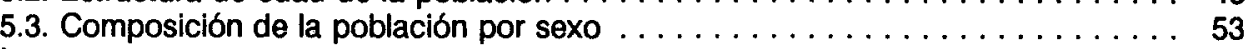

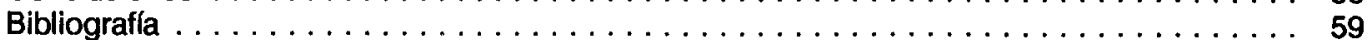

Anexos . . . . . . . . . . . .

II. MORTALIDAD Y ATENCION DE SALUd MATERNO INFANTIL $\ldots \ldots \ldots \ldots, \ldots 77$

Susana Schkolnik, Ana M. Oyarce

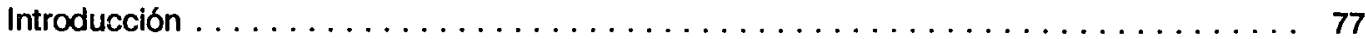

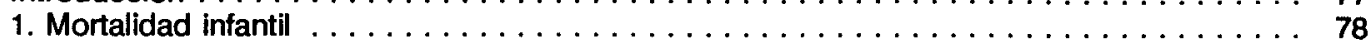

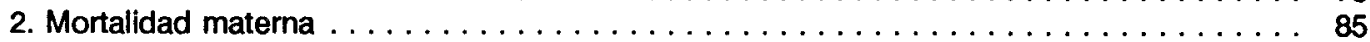

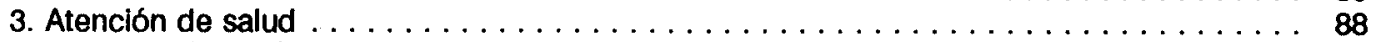

3.1. Atención en el parto . . . . . . . . . . . . . . . . . . 90

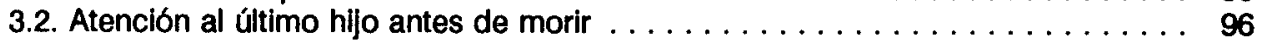

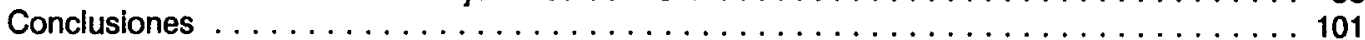

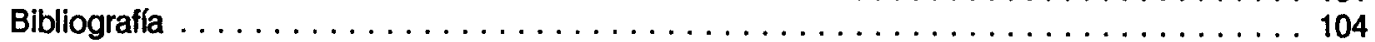

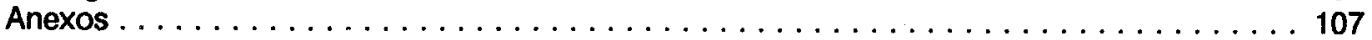


Gabriela Pérez

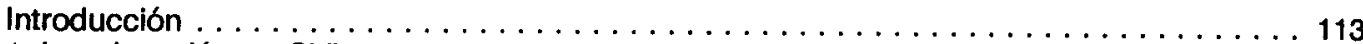

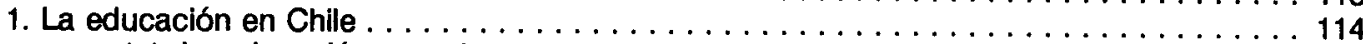

1.1. La educación entre los mapuches . . . . . . . . . . . . . . . . . 115

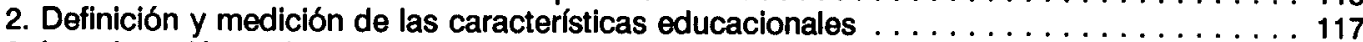

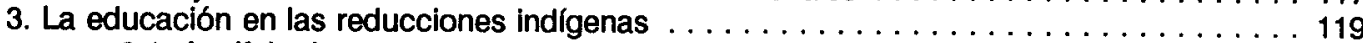

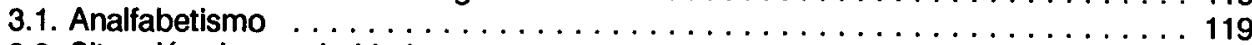

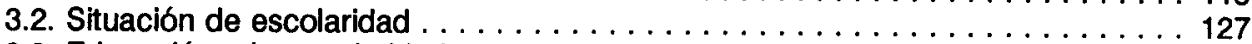

3.3. Educación y lengua hablada . . . . . . . . . . . . . . . . . . . . 134

3.4. La situación de escolaridad al interior de la IX Región . . . . . . . . . . 138

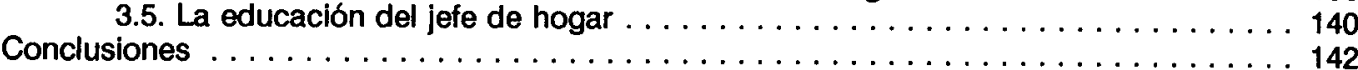

Bibliografía .................................. 144

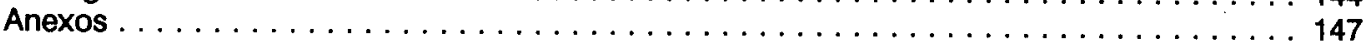

IV. CARACteristicas ECONOMICAS $\ldots \ldots \ldots \ldots \ldots$

Gabriela Pérez, Jorge Martínez

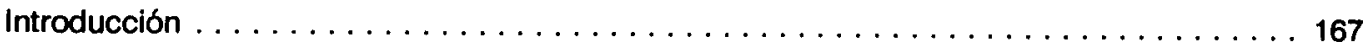

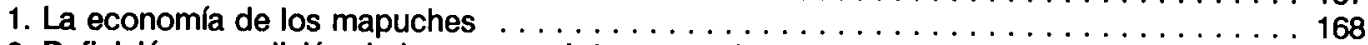

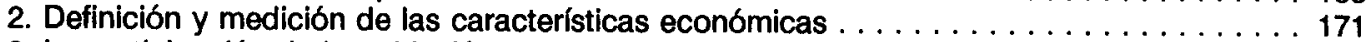

3. La participación de la población en la actividad económica $\ldots \ldots \ldots \ldots \ldots \ldots \ldots \ldots \ldots$

3.1. Diferencias entre distritos $\ldots \ldots \ldots \ldots \ldots \ldots \ldots \ldots \ldots \ldots \ldots \ldots \ldots \ldots \ldots$

3.2. Diferencias con el contexto nacional y regional $\ldots \ldots \ldots \ldots \ldots \ldots \ldots \ldots \ldots$

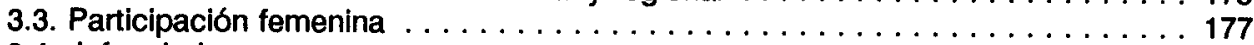

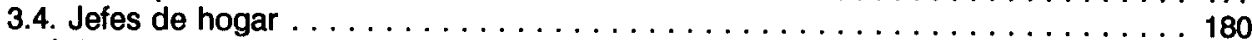

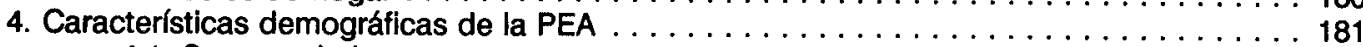

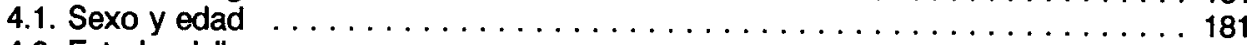

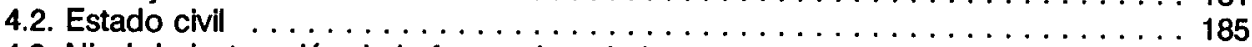

4.3. Nivel de instrucción de la fuerza de trabajo . . . . . . . . . . . . 186

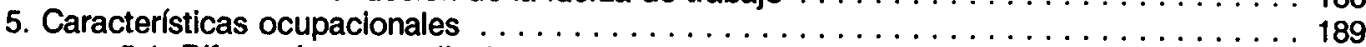

5.1. Diferencias entre distritos $\ldots \ldots \ldots \ldots \ldots \ldots \ldots \ldots \ldots \ldots \ldots \ldots \ldots \ldots \ldots \ldots$

5.2. Comparación entre las reducciones seleccionadas y las reducciones de la IX

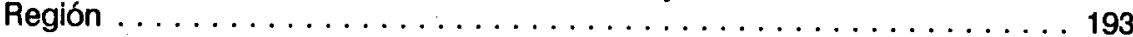

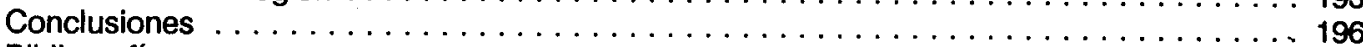

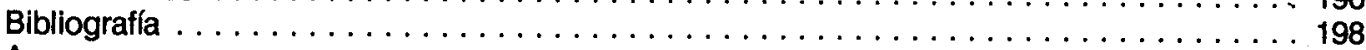

Anexos ................................ 199

V. VIVIENDA, HOGAR Y FAMILIA $\ldots \ldots \ldots \ldots \ldots \ldots \ldots \ldots \ldots \ldots \ldots \ldots \ldots$

Ana M. Oyarce

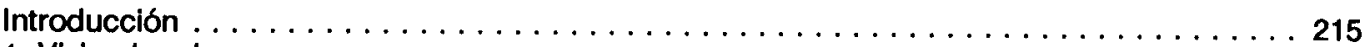

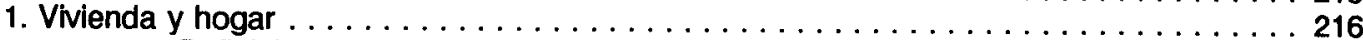

1.1. Definiciones de las categorias de vivienda y hogar $\ldots \ldots \ldots \ldots \ldots \ldots \ldots 216$

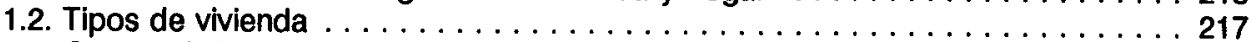

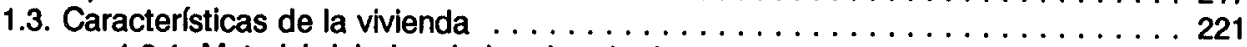

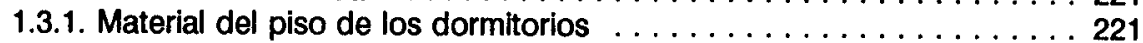

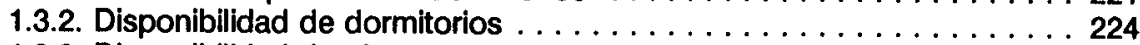

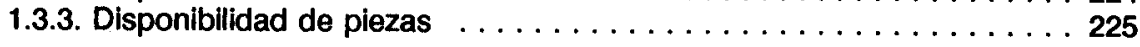


1.3.4. Disponibilidad de pieza de cocina . . . . . . . . . . . . . . 227

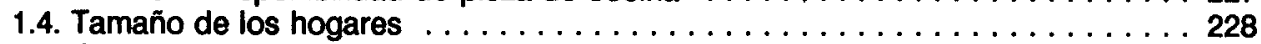

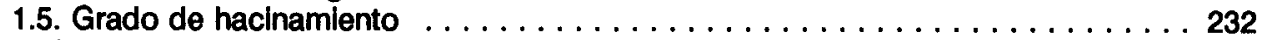

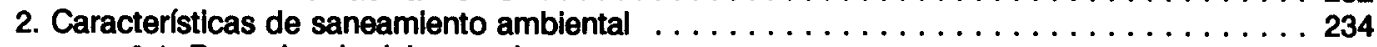

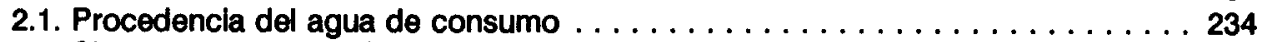

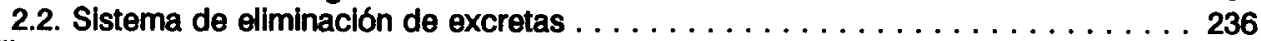

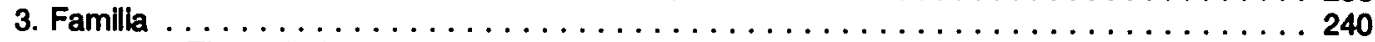

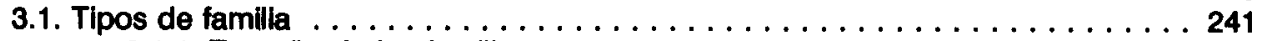

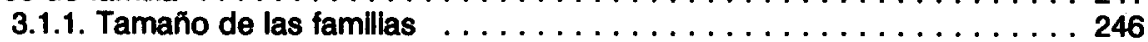

3.2. Estructura y composición de la familia $\ldots \ldots \ldots \ldots \ldots \ldots \ldots \ldots \ldots \ldots 250$

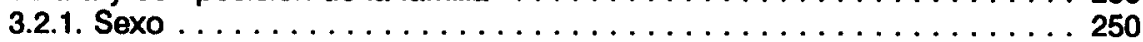

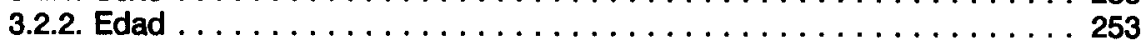

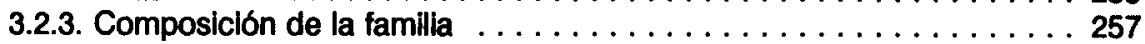

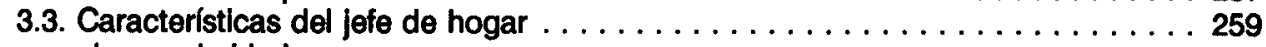

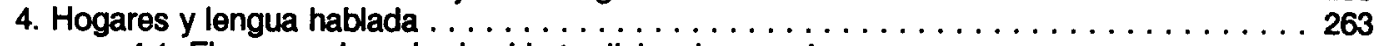

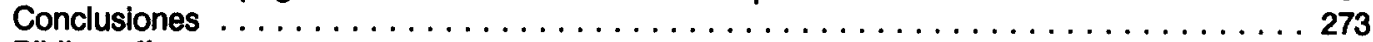

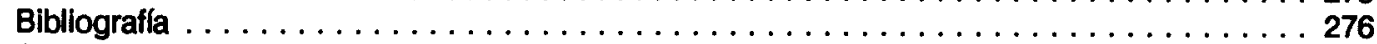

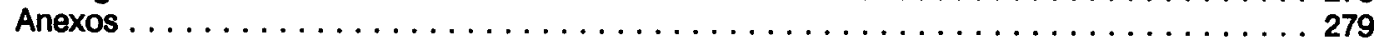

ANEXO 1: Particlpantes en la investigación censal $\ldots \ldots \ldots \ldots \ldots \ldots \ldots$

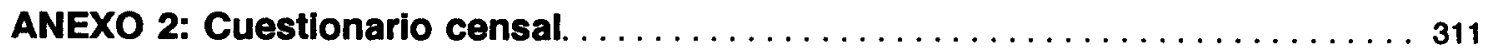




\section{INTRODUCCION}

\section{Antecedentes generales}

Esta publicación corresponde a la fase final de la Segunda Etapa del Proyecto Estudio Biodemográfico y Social de la Población en Reducciones Indigenas. Esta etapa ha comprendido la realización del Censo de Reducciones Indigenas Seleccionadas, que fue llevado a cabo entre el 24 de octubre y el 6 de diciembre de 1988 en los distritos de Labranza, Molco, Maquehue y Metrenco, ubicados en la Comuna de Temuco, Provincia de Cautin, IX Región de Chile (mapas 1,2 y 3).

Han participado en las diversas etapas de realización de este proyecto, según sus áreas de competencia y disponibilidad, la Universidad de La Frontera (UFRO), la Pontificia Universidad Católica de Chile Sede Temuco (UCT), la Fundación Instituto Indigena (FII), el Instituto Nacional de Estadisticas (INE), el Programa de Apoyo y Extensión en Salud Materno Infantil (PAESMI) y el Centro Latinoamericano de Demografía (CELADE).

\subsection{Etapas del proyecto}

E1 Proyecto Estudio Biodemográfico y Social de la Población en Reducciones Indigenas ha contemplado el diseño de tres etapas, que en forma resumida son las siguientes:

1.1.1. Primera etapa: diagnóstico preliminar de las condiciones de vida de la población mapuche residente en reducciones indigenas en la IX Región del país.' Este estudio se basó en la información

Oyarce, Ana M.; Romaggi, Marisabel y Vidal, Aldo (1989), Cómo viven los mapuches. Análisis del Censo de Población de Chile de 1982. PAESMI, Santiago, Serie Docs. de Trabajo $\mathrm{N}^{2} 01$, enero. 
proporcionada por el XV Censo Nacional de Población y IV de Vivienda realizado en 1982 que permitió, entre otros aspectos, brindar un marco de referencia global para las etapas siguientes.

1.1.2. Segunda etapa: Censo de Reducciones Indigenas Seleccionadas, pertenecientes a los distritos de Labranza, Molco, Maquehue y Metrenco, cercanos a la ciudad de Temuco. Fueron censados un total de 2850 hogares, correspondientes a 13560 personas, aunque finalmente se consideraron 12952 personas y 2714 hogares luego de revisar algunos casos que no constitufan reducciones. Los resultados del total censado fueron publicados en un conjunto de tabulaciones básicas. ${ }^{2}$

1.1.3. Tercera etapa: investigación epidemiológica y antropológica, con el fin de conocer los factores biologicos, culturales y demográficos determinantes de las condiciones de salud y mortalidad materno infantil, por medio de una metodología de casos y controles.

\section{El área de estudio: 1a IX Región}

La Región de La Araucanía o IX Región se sitúa al sur de Chile (mapa 3). Su población estimada en 1988 asciende a alrededor de 770000 habitantes, con una densidad del orden de 24 habitantes por kilometro cuadrado. Casi un 42 por ciento de la población de esta región reside en áreas rurales, lo que representa uno de los mayores porcentajes en el país. Temuco es la capital y ciudad principal de la región, con cerca de 160000 habitantes, según el Censo Nacional de Población de 1982.

Como lo sugiere su denominación, La Araucania concentra el grueso de la población mapuche de Chile. E1 Censo Nacional de 1982 evidenció que cerca de 300000 personas residian en reducciones indigenas, lo que representó el 20 por ciento de la población regional y el 46 por ciento de la población rural.

2 Universidad de La Frontera (UFRO); Instituto Nacional de Estadisticas (INE); Fundación Instituto Indigena (FII); Programa de Apoyo y Extensión en Salud Materno Infantil (PAESMI) y Centro Latinoamericano de Demografia (CELADE) (1989), Censo Experimental de Reducciones Indigenas Seleccionadas Cautin - Chile 1988. Tabulaciones básicas. Imprenta INE, Santiago, diciembre. 
En la IX Región la agricultura es el sector básico de su economia, siendo el que genera mayor empleo, seguido por los servicios y el comercio. La actividad agricola es predominantemente del tipo extensivo, donde destaca el cultivo de cereales.

E1 Producto Geográfico Bruto representó en 1984 un 3 por ciento del Producto Geográfico Bruto del pals, en tanto que el producto per cápita se advertía como el más bajo del pais (alrededor de $\$ 15000$ ), lo que equivale a casi un 100 por ciento de inferioridad con respecto al promedio nacional. ${ }^{3}$ De esto se sugiere que en la IX Región existen condiciones de pobreza que afectan a una importante proporción de su población.

\section{Análisis de resultados del Censo de 1988}

La presente publicación de análisis de resultados del Censo de Reducciones Indigenas Seleccionadas pone a disposición un conjunto de antecedentes que permite el conocimiento de las condiciones de vida de una población indigena campesina, desde un punto de vista interdisciplinario y con el objetivo global de sistematizar aspectos claves para el planteamiento de politicas.

Como objetivo más especifico, se considera de particular importancia el tratar de dar respuesta a numerosas interrogantes sobre las actuales condiciones de vida de una población mapuche campesina asentada en su territorio original que, a contar de la segunda mitad del siglo XIX, fue radicada en territorios definidos como "reducciones indigenas".

En general, los estudios sobre el pueblo mapuche tienen una larga tradición, razón por la cual en esta ocasión se ha recurrido frecuentemente a los resultados de algunos de ellos, como apoyo en la explicación y descripción de los problemas detectados. Sin embargo, algunas particularidades de este estudio son, por un lado, que se ha podido considerar un número de casos hasta ahora poco frecuente, lo que significa una base solida en la elaboración de conclusiones $y$, por otro lado, se han incorporado aspectos escasamente explorados. 1988. INE, Santiago. 
E1 análisis de resultados está estructurado en cinco capitulos, cuyos ineamientos se describen en la forma que sigue:

I. Caracterfsticas demográficas: el tema de los aspectos demográficos entre los mapuches llena un vacio existente desde este punto de vista y ofrece resultados bastante interesantes. Se analizan los componentes demográficos (fecundidad, mortalidad y migración), junto con el crecimiento y estructura por sexo y edad de la población. La metodologla empleada consiste principalmente en la aplicación de técnicas indirectas de estimación demográfica. El propósito de este capitulo es entregar ordenes de magnitud de los indicadores demográficos y un conocimiento básico de la dinámica de la población.

II. Mortalidad y atención de salud materno infantil: el campo de la salud es, sin duda, un aspecto de primordial importancia en la realidad de cualquier población campesina, en especial si se trata de un grupo indfgena en que se supone la presencia de algunas particularidades en la actitud de la población frente a la enfermedad y la muerte. El capitulo analiza el comportamiento diferencial de la mortalidad infantil según variables socioculturales, asi como presenta ordenes de magnitud de la mortalidad materna. Con relación a la atención de salud, se examinan la atención en el parto y la atención recibida por el último hijo nacido vivo antes de morir, tratando de conocer el tipo de atención de salud al que se orienta la población y las variables que intervienen en dicha orientación. E1 propósito de este capitulo es entregar una aproximación al estado de salud de la población.

III. Caracteristicas educacionales: el análisis de las caracteristicas educacionales reviste singular relevancia, en atención a la problemática que esto representa en toda población rural. Sobre la base de la información proporcionada por el Censo de 1988, se examinan el analfabetismo y la situación de escolaridad de la población, asociándolos con la lengua hablada en el hogar, la edad y el sexo de las personas. E1 propósito de este capitulo es describir la situación educativa de la población estudiada, identificando los principales problemas, los grupos mayormente afectados y los factores relacionados con estas situaciones.

IV. Caracterfsticas económicas: atendiendo a las condiciones de pobreza generalizada que caracterizan al pueblo mapuche asentado en reducciones, los aspectos económicos son tratados en forma especial. La información 
que se analiza se refiere a dos aspectos básicos, a saber: el grado de participación de la población en la actividad económica y las características ocupacionales de la población económicamente activa. Se consideran como variables el sexo y la edad de las personas, asi como otras más especificas, siendo destacable que se ha experimentado en la medición del grado de participación de la población en la actividad económica de un modo que permita captar la actividad entre la población joven y entre las mujeres en una economia de subsistencia. Este capitulo tiene como propósito contribuir al conocimiento de las modalidades de organización e inserción productiva de la población que reside en las reducciones seleccionadas.

V. Vivienda, hogar y familia: el análisis de las caracteristicas ambientales y socioculturales de la población mapuche representa, por si solo, un aspecto de crucial significación en la comprensión de las modalidades de vida asumidas en la actualidad como consecuencia del largo proceso de contacto entre la cultura tradicional y la cultura occidental. La información que se analiza en este capitulo guarda relación con las caracteristicas de la vivienda, de los hogares y de las familias, describiendo aspectos de las condiciones materiales de vida, as 1 como algunos aspectos relativos a la cultura (lengua hablada en el hogar y grado de apego a1 modo de vida tradicional). E1 proposito fundamental es contribuir al conocimiento de las condiciones materiales de vida y de algunas caracteristicas culturales de la población. 

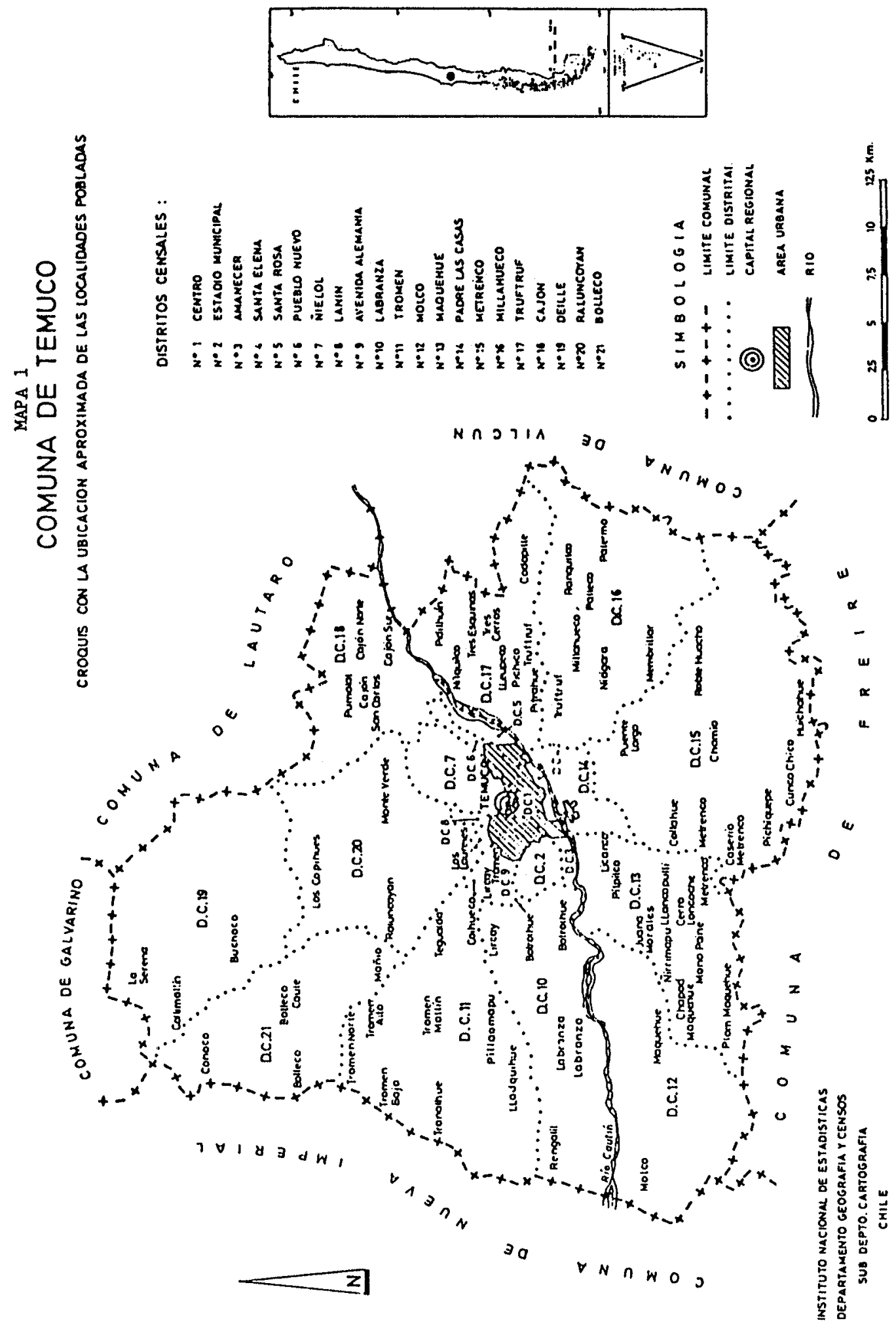


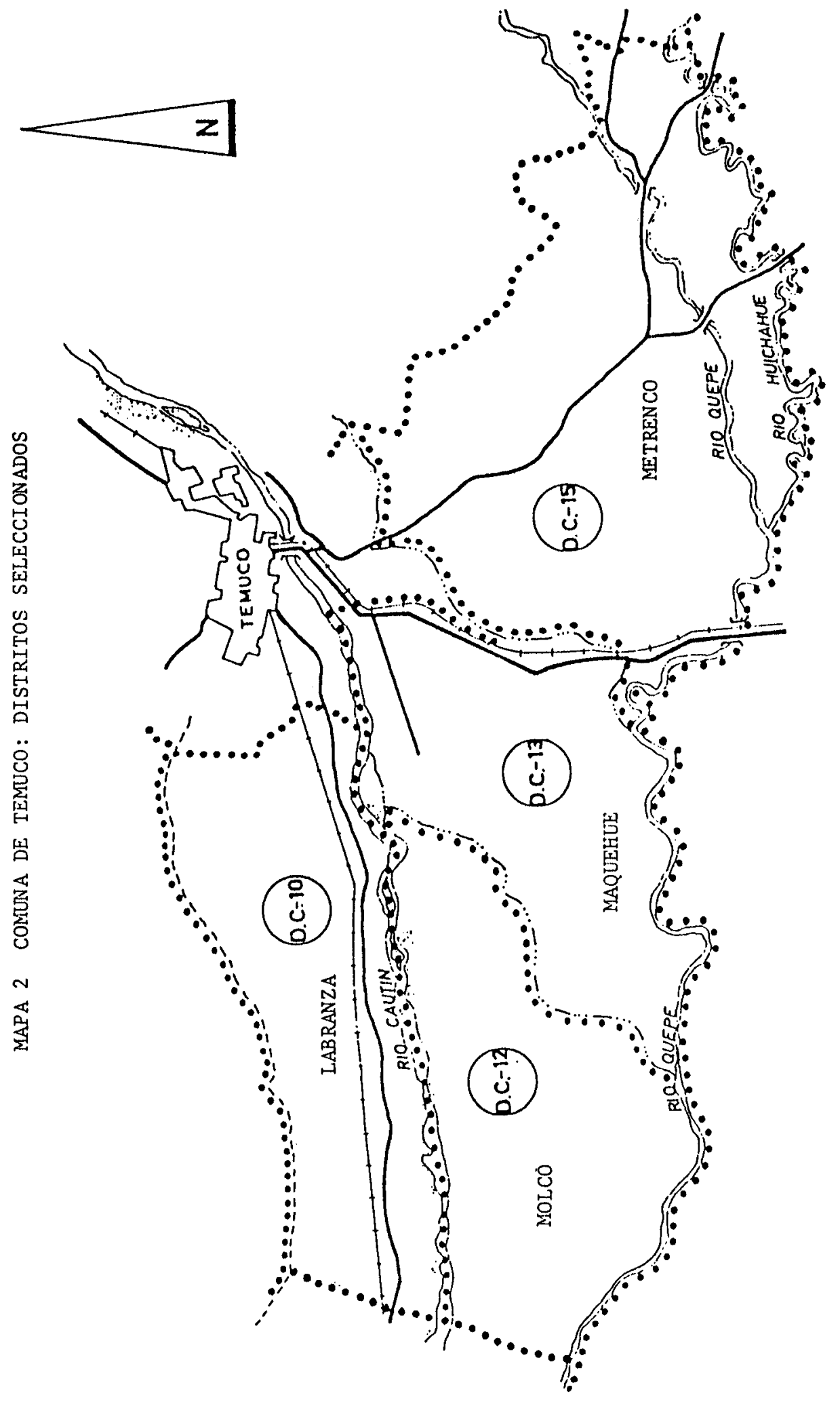

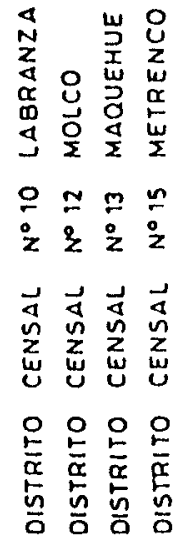




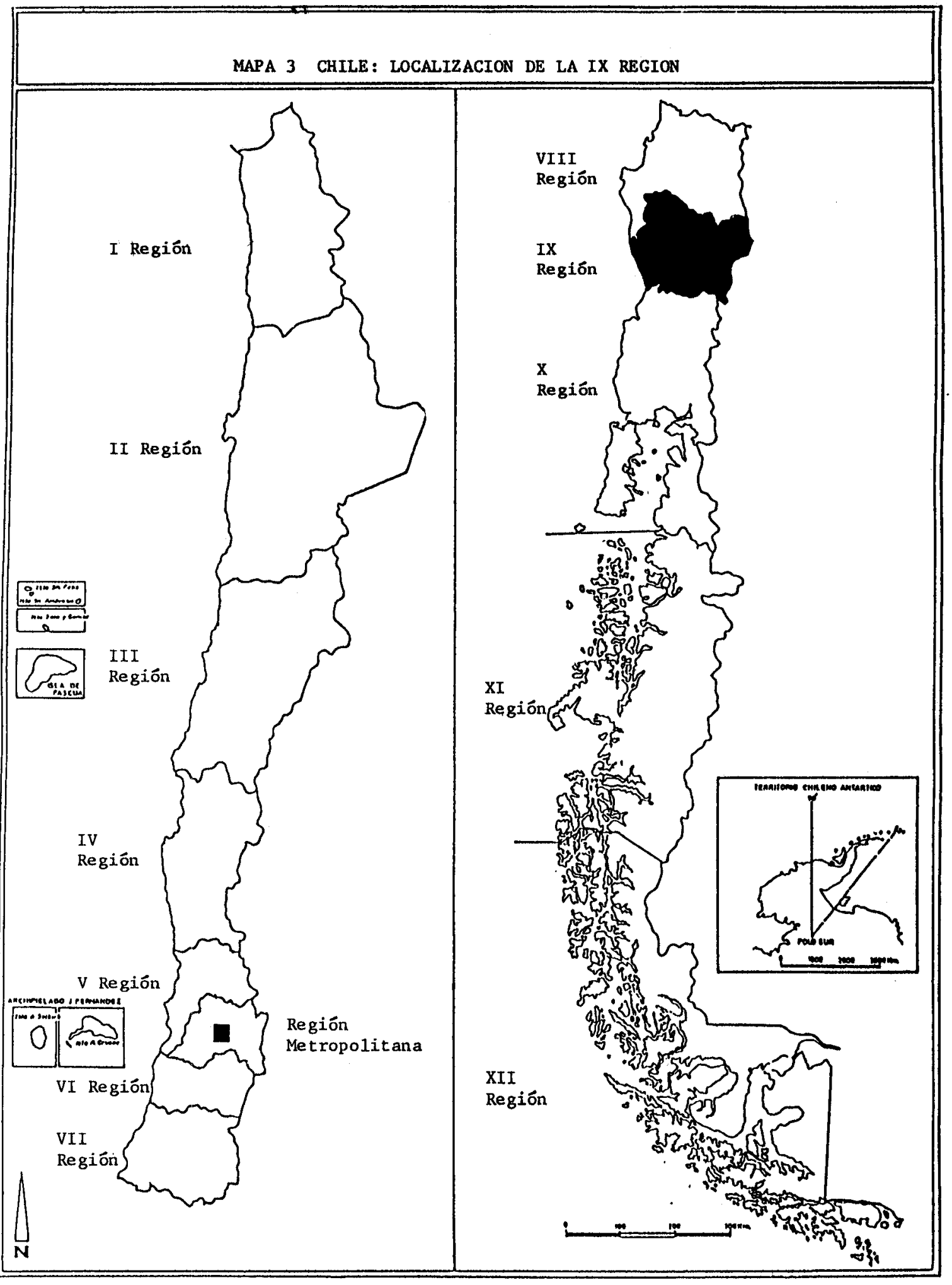




\title{
I. CARACTERISTICAS DEMOGRAFICAS
}

\author{
Jorge Rodriguez* \\ Jorge Martinez** \\ Juan Chackiel
}

\section{Introducción}

Este capitulo trata sobre las caracteristicas demográficas de la población censada en 1988 en las reducciones indigenas de los distritos de Labranza, Molco, Maquehue y Metrenco, ubicados en la Comuna de Temuco, IX Región. A través de cinco secciones se describen, en primer lugar, aspectos generales de la población, presentando luego el análisis de la fecundidad, la mortalidad y la migración. Finalmente, se aborda el crecimiento y la estructura por sexo y edad de la población de las reducciones estudiadas, junto a unas conclusiones que surgirán de los aspectos más relevantes.

La estructura de este capitulo considera el crecimiento y composición de la población por sexo y edad en último lugar, debido a que éste es consecuencia de las tendencias que han tenido la fecundidad, la mortalidad y las migraciones.

Los datos recolectados en el Censo de 1988 permiten la aplicación de métodos indirectos de estimación de indicadores de la fecundidad y la mortalidad. Con respecto a la migración, el análisis del tamaño y composición de la población estudiada permitirá dar algunos indicios sobre su significación.

Universidad de La Frontera, Temuco.

* Centro Latinoamericano de Demografia.

*** Centro Latinoamericano de Demografia. 
A lo largo del capitulo se realizarán frecuentes comparaciones entre los resultados correspondientes a las reducciones censadas en 1988 en los cuatro distritos señalados y aquellos derivados del Censo Nacional de 1982 . Sin embargo, en algunas ocasiones se procederá a comparar dichos resultados con los del total de reducciones indigenas de la IX Región, censadas en 1982. En cualquier caso, se ha buscado configurar un esquema que permita comprender la dinámica demográfica de estas poblaciones, teniendo presente que las conclusiones a las que se derive no son necesariamente válidas para otras poblaciones que habitan en reducciones indigenas de la IX Región.

En sintesis, la información que se ha obtenido permitirá tener ordenes de magnitud de los indicadores demográficos y un conocimiento básico de la dinámica de la población de los cuatro distritos señalados, aspectos que a nivel global se conocen escasamente, cuya necesidad de abordar constituye un propósito fundamental de este trabajo.

\section{Aspectos generales de la población}

La población mapuche de Chile se estima actualmente en un número de alrededor de 500000 personas, concentradas en cerca de un 80 por ciento en la IX Región del pais. El resto de esta población residiria en las regiones VIII y $\mathrm{X}, \mathrm{y}$ en los principales centros urbanos nacionales, particularmente en Santiago y Concepción (Leiva, 1985; Oyarce, Romaggi y Vidal, 1989). Considerando una estimación levemente inferior hacia 1982, la población mapuche habria representado alrededor de un 4 por ciento del total de la población censada en ese entonces en el Censo Nacional (INE, 1987a).

En el cuadro 1 se puede observar que la población mapuche que habita en reducciones indigenas en la IX Región, representaba alrededor de un 20 por ciento del total regional y un 46 por ciento de la población rural en 1982, según los antecedentes del Censo Nacional de 1982. 
CUADRO 1

IX REGION: POBLACION RURAL, TOTAL Y DE REDUCCIONES INDIGENAS POR AREA. CENSO NACIONAL DE 1982

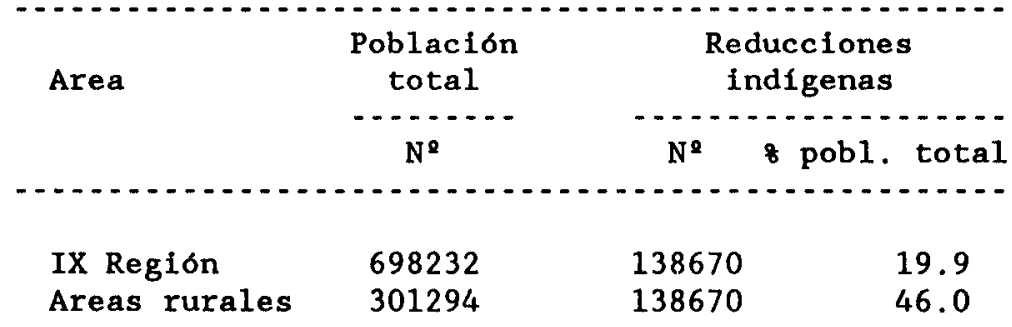

Fuente: Oyarce, Romaggi y Vidal (1989).

Dado el hecho de la concentración de la población mapuche en la IX Región, es necesario señalar algunas caracteristicas de la población de esta región, antecedentes que, como se verá, permitirán introducir en el contexto general de la población estudiada a partir del Censo de Reducciones Indigenas Seleccionadas de 1988 .

La IX Región tenia en 1988 una población total estimada de 768308 habitantes, 10 que representa un 6 por ciento del total nacional (INE, 1987c), con una superficie de 31858 kilómetros cuadrados (INE, 1988a). Su densidad de población ascenderia a 24 habitantes por kilómetro cuadrado. La tasa anual de crecimiento total de la población de la IX Región alcanzó a 13 por mil en el periodo intercensal 1970-1982, la segunda más baja del pais, después de la experimentada por la X Región (Martinez, 1990). Entre 1980-1990 se estima que la IX Región creció a un ritmo anual de cerca de 14 por mil, lo que la situaria en la cuarta tasa más baja del pais (INE, 1987c).

Como se puede observar, la migración extrarregional parece tener una gran importancia en esta región. En efecto; en el pasado cercano, elevadas tasas negativas de migración neta han caracterizado a la IX Región, las que le han valido un fuerte impacto desfavorable sobre su dinámica demográfica (INE, 1987c; Martínez, 1990). Sistemáticamente, tanto entre 1965-1970 como entre 1977-1982, la población femenina ha sido protagonista principal en el balance negativo de los movimientos migratorios (Martinez, 1990). 
Diferentes estudios muestran que la Región de La Araucania es la que mantiene uno de los mayores deterioros en los niveles de salud (Instituto de Economia, 1982), lo cual ha significado que sea definida como una de las principales zonas de extrema pobreza del pais. Los indicadores de mortalidad registrados en ella son los más altos del pals, manteniendo un retraso de cínco años al compararlo con el nivel nacional (Mermoud y Rodríguez, 1986).

Estos indicadores tan desventajosos para la población, se vinculan al hecho de que la IX Región tiene una alta proporción de población que reside en zonas rurales (41.5 por ciento en 1988; según INE, 1989a), una de las más elevadas del pafs, y en donde es esperable que los indicadores mencionados sean más deteriorados. Esto adquiere relevancia si se admite que en el pais las diferencias intrarregionales en los niveles de vida de regiones con importante presencia de población rural son marcadas, e incluso pueden llegar a serlo más aun que las diferencias entre regiones.

Debido a que la población que vive en reducciones indigenas es parte importante de la población rural de la región, se podria esperar que ella posea indicadores sociales y demográficos relativamente más deteriorados que el resto de la población regional y que los promedios nacionales.

Los cuatro distritos censados en 1988 están ubicados en áreas rurales del centro de la IX Región, especificamente en las cercanfas de la ciudad de Temuco. Con relación al Censo Nacional de 1982 representaban alrededor del 13 por ciento de la población de las reducciones indigenas del área centro, y cerca del 10 por ciento de los efectivos de todas las reducciones indigenas de la IX Región. En el Censo de 1988 la población quedó distribuida en los distritos de la manera como lo muestra el cuadro 2, en que resalta el tamaño de la población de Metrenco, que acumula un 40 ciento del total de la población censada."

La población censada ascendí a 13560 personas. Mediante una revisión del material obtenido y a través de visitas a terreno, se detectó que menos de un 5 por ciento del total no residia en reducciones indigenas, con lo que la cifra de entrevistados se redujo a 12952 personas. 
CUADRO 2

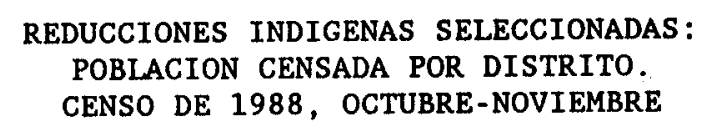

$\begin{array}{lcc} & \begin{array}{c}\text { Población censada } \\ \text { Distritos }\end{array} & \\ & & \\ & & \\ \text { Labranza } & 1732 & 13.4 \\ \text { Molco } & 2715 & 21.0 \\ \text { Maquehue } & 3306 & 25.5 \\ \text { Metrenco } & 5199 & 40.1 \\ & & \\ \text { Total } & 12952 & 100.0 \\ & & \\ & & \end{array}$

Fuente: Tabulados especiales Censo de 1988 .

Como se sabe, el tamaño, la estructura etaria, la composición por sexo, la distribución espacial y el crecimiento de una población en un momento dado, están determinados por la evolución histórica de los niveles y tendenclas de los componentes del cambio demográfico, esto es, la fecundidad, la mortalidad y la migración. Estos aspectos se presentan en las secciones que siguen.

\section{Fecundidad}

La fecundidad está asociada a la procreación humana, en términos del número efectivo de hijos con relación a las mujeres que están en edades reproductivas.

El análisis de la fecundidad, desde el punto de vista demográfico, intenta medir en qué grado y cómo se van produciendo los nacimientos. Su importancia radica en el hecho de que éstos van conformando, entre otros, el crecimiento y la estructura de la población. Además, el número de hijos que tienen las mujeres guarda relación con aspectos tales como la salud de las mujeres y los niños, y con aspectos sociales ligados a la configuración de las familias.

La medición del nivel de la fecundidad, por lo general, se hace a través de la Tasa Global de Fecundidad (TGF), que se define como el número medio de hijos que tendria una cohorte hipotética de mujeres, que durante su periodo 
fértil tuvieran sus hijos de acuerdo a las tasas de fecundidad por edad observadas en la población, suponiendo que entre el nacimiento y el término de su perlodo fértil no ha ocurrido ninguna muerte. Su cálculo se obtiene mediante la suma de las tasas fecundidad por edad, las cuales se obtienen del cociente entre el total de hijos nacidos vivos de las mujeres del grupo quinquenal ( $x$, $x+4)$ y el total de mujeres de ese mismo grupo quinquenal de edad $(x, x+4)$. Dado que se trata de tasas quinquenales, la suma obtenida debe multiplicarse por cinco para obtener la TGF. El análisis de la fecundidad incorpora también otras medidas, como lo son la paridez media y las tasas de reproducción, las que se definirán más adelante.

Es importante señalar que los niveles de la fecundidad en el pais han experimentado un fuerte descenso desde los años 60, influyendo decisivamente en la calda de la tasa de crecimiento natural. En esos años, la TGF nacional fue ligeramente superior a 5 hijos por mujer, en cambio, en la primera mitad de la década del 80, ésta era algo menor de 3 hijos por mujer (INE-CELADE-ACDI, 1989).

La transición (descenso) de la fecundidad se asocia con una redistribución de las tasas por edades, lo que lleva a una participación creciente de las mujeres jóvenes, entre 20 y 29 años de edad. Asi por ejemplo, las mujeres de estos grupos de edades representaban un 48 por ciento de 1 a fecundidad en el pais hacia 1962, en tanto que hacia 1985 su participación alcanzaba a 56 por ciento (INE-CELADE-ACDI, 1989). La disminución de la fecundidad tiene como efecto una reducción del tamaño medio de la familia y afecta también la estructura por edad de la población, desacelerando el crecimiento de los grupos etarios más jovenes $y$, en el largo plazo, contribuyendo decisivamente a un envejecimiento de la población.

Los descensos no han sido homogéneos social y espacialmente, ya que las mujeres de menor educación y de estratos sociocupacionales bajos presentan aun una TGF considerablemente más elevada. Del mismo modo, aunque menos marcadas, prevalecen diferencias entre los niveles de las zonas rurales y urbanas, lo que determina ciertas desigualdades intrarregionales que suelen ser más importantes que aquellas discrepancias entre regiones.

La transición de la fecundidad está definida por los cambios que se generan en el comportamiento reproductivo de la población. Al imponerse un tamaño deseado de familia menor, la disponibilidad de métodos anticonceptivos modernos juega un papel esencial en el descenso de la fecundidad y ayuda a consolidar el nuevo tamaño ideal de familia. 
Sin entrar en detalles, existe una serie de factores que se asocian con los cambios que ha sufrido la fecundidad en el contexto chileno. Entre éstos, tal vez el más importante es el que se refiere al fuerte proceso de urbanización que ha vivido la sociedad chilena con sus consiguientes efectos de transformaciones materiales y culturales.

Hacia 1982 la IX Región posela una TGF del orden de 3.8 hijos por mujer. De acuerdo con este nivel y según las consideraciones anteriores, puede plantearse que es posible que en regiones como La Araucania, donde el grado de urbanización presenta un amplio rango de expansión $\mathrm{y}$, en especial en las áreas cercanas a los centros urbanos, continúen a futuro los descensos en los niveles de fecundidad.

En el Censo de Reducciones Indigenas de 1988, que en este trabajo se analiza, la medición de la fecundidad se obtuvo a partir de la siguiente información solicitada a cada mujer de $15 \mathrm{y}$ más años de edad:

- la edad en años cumplidos

- el número total de hijos tenidos vivos

- el número de hijos nacidos vivos el último año

La recolección de estos datos permite la aplicación de técnicas indirectas de estimación de la fecundidad, que son adecuadas para poblaciones de estas caracteristicas. ${ }^{2}$ Se presentan en las próximas secciones las estimaciones de paridez media, TGF y tasas de reproducción, junto con una descripción de las diferencias socioculturales de la fecundidad según la educación de la madre y la lengua hablada con más frecuencia en el hogar.

\subsection{Paridez media o fecundidad retrospectiva}

La paridez media representa una medida retrospectiva de la fecundidad, interpretándose como el número medio de hijos de las mujeres sobrevivientes de una cohorte, desde el inicio de su vida reproductiva hasta la edad que tienen al momento de ser entrevistadas. Es una medida retrospectiva del nivel de la fecundidad, porque abarca el comportamiento de las generaciones.

2 Los antecedentes provenientes de registros de estadísticas vitales no consignan datos tales como si la mujer vive en reducciones indigenas, por ejemplo, lo que los hace inapropiados para este estudio. 
La paridez media se calcula como el cociente entre el total de hijos nacidos vivos declarados por las mujeres y la población femenina, por cada grupo quinquenal de edad (15-19, 20-24, 25-29, 30-34, 35-39,40-44, 45-49, 50-54). En las edades posteriores se supone que el valor se estabiliza, debido a que las mujeres han llegado al término de su vida reproductiva, y a que en el pasado la fecundidad ha sido relativamente constante. El número medio de hijos se puede considerar como una buena estimación de la fecundidad total de una generación, es decir, de aquellas mujeres sobrevivientes que han terminado su periodo fértil, sólo si la magnitud de los érrores en la declaración tanto de la edad de las mujeres como de la información de los hijos nacidos vivos, es despreciable.

Para el cálculo de la paridez media de las reducciones censadas en 1988 se utilizó como denominador el total de mujeres de cada grupo quinquenal de edad, ya que el porcentaje de mujeres sin declaración del número de hijos no es relevante. Este alcanza a 0.3 por ciento, siendo en el grupo menor de 20 años de edad donde se concentra el mayor, porcentaje de no respuesta.

En el cuadro 3 y gráfico 1 se muestra el comportamiento de la paridez media de las reducciones Indigenas a partir del Censo Nacional de 1982 y del Censo de 1988. Se observan resultados que indican una paridez mayor en las mujeres de las reducciones del Censo Nacional de 1982, tanto en el total de reduccciones indigenas de la IX Región, como en las mismas reducciones que posteriormente fueron censadas en 1988 (reducciones seleccionadas).

En las distribuciones mencionadas el número promedio de hijos por mujer se estabiliza cerca de los 5.9 hijos, aunque desciende levemente en las mujeres de las reducciones del Censo de 1988. La disminución de la paridez media en las mujeres menores de 35 años de edad del Censo de 1988 podria hacer pensar que existiria un cambio de conducta reproductiva en las mujeres más jóvenes con respecto a generaciones anteriores, por lo que este indicador podrfa continuar descendiendo en el mediano plazo en dichas poblaciones.

Las irregularidades que presentan las mujeres mayores de 40 años de edad en su declaración de los hijos nacidos vivos plantean la conveniencia de investigar más profundamente este hecho. 
CUADRO 3

REDUCCIONES INDIGENAS: PARIDEZ MEDIA POR GRUPOS QUINQUENALES DE EDAD. CENSOS DE 1982 Y 1988

(número medio de hijos por mujer)

\begin{tabular}{|c|c|c|c|}
\hline $\begin{array}{l}\text { Grupos } \\
\text { de }\end{array}$ & & - - - - - & $\begin{array}{r}1988 \\
-\end{array}$ \\
\hline edad & $\begin{array}{l}\text { Total reducc. } \\
\text { IX Región (1) }\end{array}$ & $\begin{array}{l}\text { Reducciones } \\
\text { seleccionadas (2) }\end{array}$ & $\begin{array}{r}\text { Reduccion } \\
\text { seleccionad }\end{array}$ \\
\hline $15-19$ & 0.18 & 0.23 & 0.1 \\
\hline $20-24$ & 1.03 & 1.02 & 0.8 \\
\hline $25-29$ & 2.06 & 1.87 & 1.70 \\
\hline $30-34$ & 3.31 & 3.12 & 2.72 \\
\hline $35-39$ & 4.14 & 3.63 & 3.81 \\
\hline $40-44$ & 5.24 & 4.73 & 4.02 \\
\hline $45-49$ & 5.74 & 5.30 & 4.64 \\
\hline $50-54$ & 5.86 & 5.87 & 5.7 \\
\hline
\end{tabular}

Fuente: (1) Oyarce, Romaggi y Vidal (1989).

(2) Anexo 3-D.

(3) Anexo 1 y tabulados especiales Censo de 1988.

\subsection{Fecundidad actual (TGF)}

La disponibilidad de información sobre la fecundidad acumulada a lo largo del periodo fértil de las mujeres o fecundidad retrospectiva (número total de hijos nacidos vivos), y sobre la fecundidad reciente (nacimientos ocurridos en el último año), permite aplicar la metodologia propuesta por Brass, denominada Método $\mathrm{P} / \mathrm{F}$, para el cálculo de los indicadores de fecundidad más conocidos, que son las tasas especificas de fecundidad por edad y la tasa global de fecundidad (TGF).

E1 procedimiento supone que la información acerca del número de hijos nacidos vivos en el último año tiene ciertas probabilidades de error que son independientes de la edad. Estos problemas pueden generar niveles de la fecundidad subestimados o sobreestimados. En otras palabras, se supone que el patrón por edad de la fecundidad actual observada es correcto y que los niveles, en cambio, están distorsionados. 
Gráfico 1

REDUCCIONES INDIGENAS: PARIDEZ MEDIA POR GRUPOS QUINQUENALES DE EDAD. CENSOS DE 1982 Y 1988

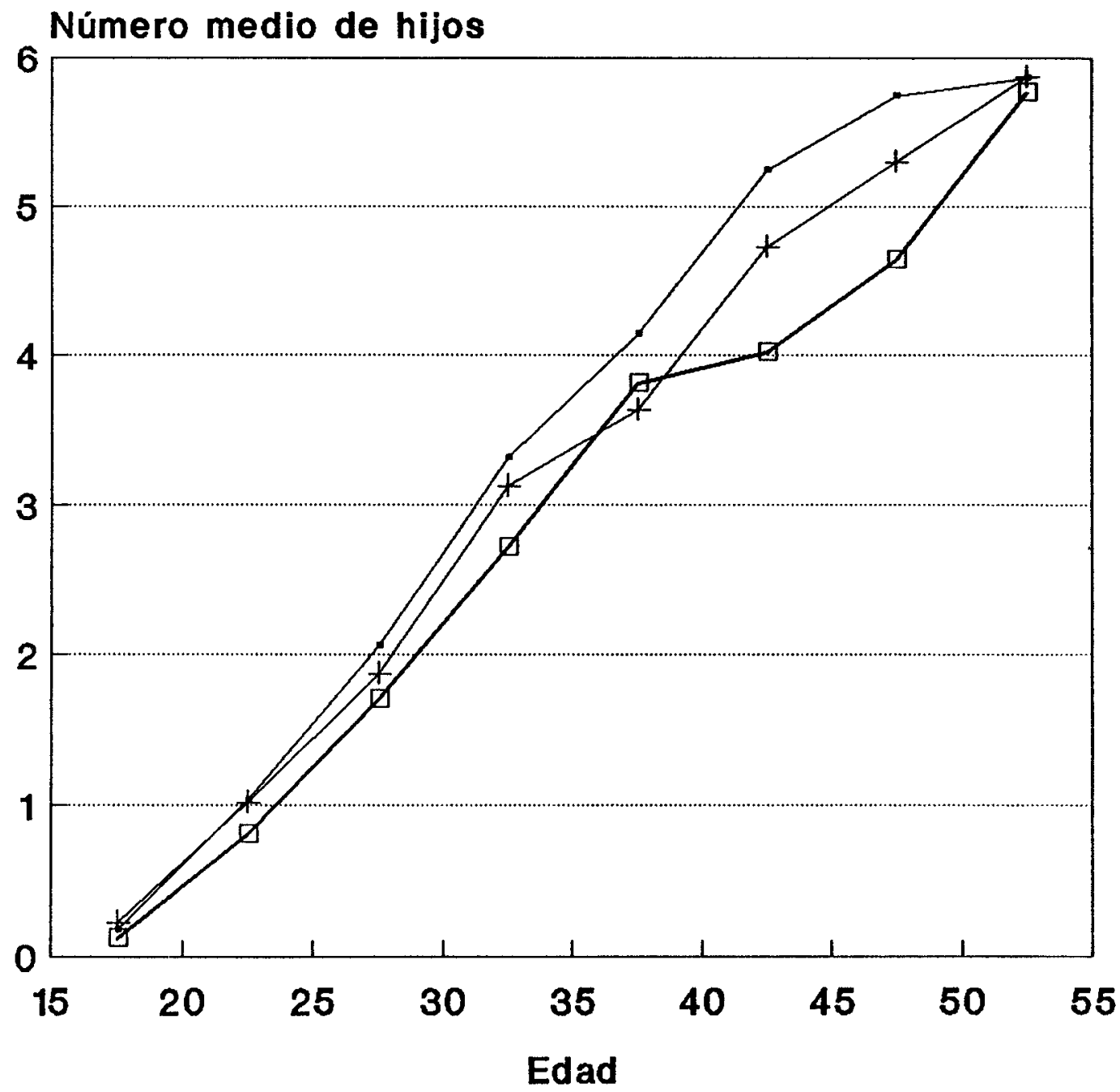

- Total red.Ind. 82

+ Red.selec. 82

— Red.selec. 88

Fuente: Cuadro 3 
Considerando que la información del último año tendria como dato confiable la distribución por edades de la fecundidad, y que la paridez media seria correcta en edades jóvenes, el procedimiento de Brass combina ambas cualidades para lograr un factor de corrección de las tasas observadas para el año anterior a la fecha del censo. El ajuste asi definido sólo será válido en la medida que los patrones de reproducción de las mujeres jovenes no hayan sufrido cambios importantes.

Según el Censo de Reducciones Indigenas Seleccionadas la TGF estimada para 1988 es de 3.9 hijos por mujer. En la IX Región la tasa alcanzaria a 3.1 hijos por mujer para el mismo periodo aproximado (cuadro 4).

\section{CUADRO 4}

IX REGION Y REDUCCIONES INDIGENAS SELECCIONADAS:

TASAS DE FECUNDIDAD POR GRUPOS QUINQUENALES DE EDAD Y TASA GLOBAL

DE FECUNDIDAD (TGF). PERIODO 1980-1990

(tasas especificas por mil mujeres)

\begin{tabular}{lrrrr} 
Grupos & \multicolumn{1}{c}{ IX Región } & Reducciones selecc. \\
de & $1980-85$ & $1987-88$ & 1982 & 1988 \\
edad & 198 & & \\
\hline $15-19$ & 83.4 & 71.3 & 91.3 & 56.9 \\
$20-24$ & 202.0 & 167.9 & 207.3 & 202.6 \\
$25-29$ & 197.5 & 156.9 & 188.8 & 199.0 \\
$30-34$ & 143.2 & 124.9 & 168.3 & 172.8 \\
$35-39$ & 87.1 & 75.6 & 116.8 & 111.0 \\
$40-44$ & 34.5 & 24.7 & 63.9 & 34.9 \\
$45-49$ & 5.9 & 5.6 & 12.6 & 6.1 \\
TGF & 3.8 & 3.1 & 4.3 & 3.9
\end{tabular}

Fuente: Anexos 2-A y 2-B.

Los niveles de fecundidad observados en las reducciones indigenas seleccionadas, en ambos censos, son bastante altos en el contexto nacional, aunque no lo son a nivel internacional, si se comparan con los niveles de otras comunidades o grupos indígenas de otros países (Oyarce, Romaggi y Vidal, 1989).

Detalles del procedimiento de cálculo se pueden encontrar en Naciones Unidas (1986) y la aplicación a este caso en el anexo 1. 
Sin embargo, durante el decenio de los 80 se observaría una disminución de la TGF en las reducciones indigenas, pasando de 4.3 en 1982 al valor ahora encontrado de 3.9 hijos por mujer.

En los cuadros 4 y 5 se presentan las estimaciones de las tasas de fecundidad por grupos quinquenales de edad para la IX Región entre 1980-1985 y entre 1987-1988 (este último dato obtenido de registros corregidos), y para las reducciones indigenas en 1982 y en 1988. La representación gráfica (gráfico 2) permite apreciar que los resultados correspondientes a las reducciones indigenas de los cuatro distritos muestran una curva de "cúspide temprana" en 1982, con altas tasas de fecundidad en las mujeres menores de 25 años de edad, mientras que según el Censo de 1988, la estructura de la fecundidad presenta una tendencia al patrón de "cúspide dilatada". Por su parte, los datos correspondientes a la IX Región indicarian una disminución de la fecundidad.

\section{CUADRO 5}

IX REGION Y REDUCCIONES INDIGENAS SELECCIONADAS : DISTRIBUCION RELATIVA DE LAS TASAS DE FECUNDIDAD POR GRUPOS QUINQUENALES DE EDAD. PERIODO 1980-1990

\begin{tabular}{|c|c|c|c|c|}
\hline \multirow{2}{*}{$\begin{array}{l}\text { Grupos } \\
\text { de } \\
\text { edad }\end{array}$} & \multicolumn{2}{|c|}{ IX Región } & \multicolumn{2}{|c|}{ Reducciones selecc. } \\
\hline & $1980-85$ & $1987-88$ & 1982 & 1988 \\
\hline $15-19$ & 11.1 & 11.4 & 10.8 & 7.3 \\
\hline $20-24$ & 26.8 & 26.8 & 24.4 & 25.9 \\
\hline $25-29$ & 26.2 & 25.0 & 22.2 & 25.4 \\
\hline $30-34$ & 19.0 & 19.9 & 19.8 & 22.1 \\
\hline $35-39$ & 11.6 & 12.1 & 13.8 & 14.2 \\
\hline $40-44$ & 4.6 & 3.9 & 7.5 & 4.5 \\
\hline $45-49$ & 0.8 & 0.9 & 1.5 & 0.8 \\
\hline Total & 100.0 & 100.0 & 100.0 & 100.0 \\
\hline
\end{tabular}

Fuente: Anexos 2-A y 2-B. 
Gráfico 2

IX REGION Y REDUCCIONES INDIGENAS SELECCIONADAS:

TASAS DE FECUNDIDAD POR GRUPOS QUINQUENALES DE EDAD. PERIODO 1980-1990

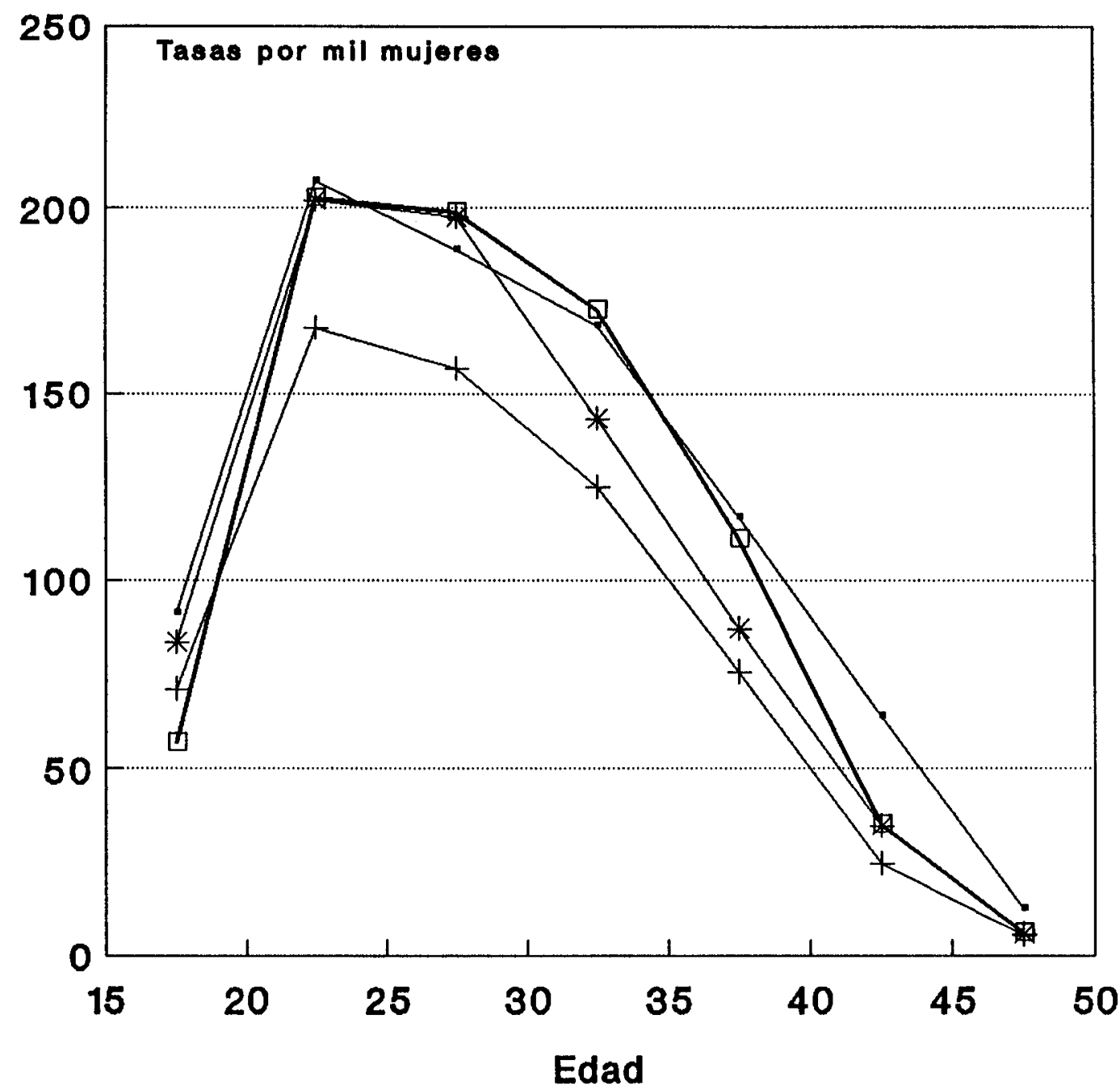

- Red.Ind. 82

七 Red.Ind. 88

* IX Reg. 80-86

+ IX Reg. 87-88

Fuente: Cuadro 4 
Admitiendo que se trata de ordenes de magnitud, las reducciones estudiadas denotarian una tendencia al descenso en sus niveles de fecundidad, 10 que plantea la existencia de probables cambios en los patrones reproductivos de la población. E110 motivaria indagar en los factores que acompañarian esta transición, en su interrelación tanto a nivel socioeconónico (nivel de instrucción, participación económica), como en aquellos niveles extraeconomicos que pueden operar con cierto grado de independencia de los primeros (difusión de pautas y valores relativos al comportamiento de baja fecundidad).

\subsection{Tasas de reproducción}

Otros indicadores importantes de la fecundidad son las tasas de reproducción (bruta y neta). Ellas entregan intexpretaciones distintas, aunque la Tasa Bruta de Reproducción es una derivación de la Tasa Global de Fecundidad.

La Tasa Bruta de Reproducción ( $R^{\prime}$ ) se interpreta como el número medio de hijas que tendrla una mujer de una cohorte hipotética, si las mujeres tuviesen el mismo patrón de fecundidad de la población en estudio $y$, además, bajo el supuesto que no estaria expuesta al riesgo de morir desde el nacimiento hasta el término de su periodo fértil.

La tasa bruta de reproducción se obtendra como el producto entre la TGF y el valor 0.4878 . Este coeficiente se obtiene suponiendo que la relación de masculinidad al nacer es de 100 nacimientos femeninos por cada 205 nacimientos totales. E1 cuadro 6 muestra que la población de las reducciones indigenas en 1988 mantiene un valor levemente superior (1.90) a la cifra regional (1.76), con una tendencia a la baja con relación a lo observado en las mismas reducciones en el año 1982. En Chile la tasa sería de 1.30 alrededor de 1987 (CELADE, 1987).

El valor obtenido señalaría que existe una alta fecundidad en la población de las reducciones indigenas, con una capacidad de reemplazo bastante significativa, suponiendo que se cumplen los requisitos hipotéticos antes mencionados para el uso de este indicador (mortalidad nula).

Una forma más explícita de definir las condiciones de reemplazo que tiene una generación, es a través de la Tasa Neta de Reproducción (R), la cual se diferencia de la anterior en que se considera el riesgo y efecto de la mortalidad observada en las mujeres de la población en estudio. Es decir, es una estimación que incluye solo a las mujeres sobrevivientes que están expuestas a las posibilidades de tener hijas. 
IX REGION Y REDUCCIONES INDIGENAS SELECCIONADAS:

TASAS BRUTA Y NETA DE REPRODUCCION. CENSOS DE 1982 Y 1988

\begin{tabular}{lllll} 
Area & \multicolumn{2}{c}{ Tasas de Reproduccínn } \\
& \multicolumn{1}{c}{ Bruta } & \multicolumn{1}{c}{ Neta } \\
\hline IX Región (1) & 1982 & 1988 & 1982 & 1988 \\
Reducciones indigenas $(2)$ & 2.10 & 1.90 & $1.89 \mathrm{a}$ & 1.72
\end{tabular}

Fuente: (1) Anexos 2-A y 2-B e INE (1987c).

(2) Anexos 2-A, 2-B y 8-A.

a: La estimación corresponde a todas las reducciones de la región, según Oyarce, Romaggi y Vidal (1989).

La tasa neta de reproducción debe ser evaluada en términos de $s i$ sus valores son menores de 1 , igual a 1 o mayores que 1 , ya que una población aseguraria su reemplazo cuando este indicador es igual a la unidad. En caso de ser inferior a 1, la población tenderfa a estar en proceso de disminución $y$, obviamente, en caso de ser superior a la unidad, la población estaria en un proceso de expansión.

En el cuadro 6 se aprecia que para el año 1982 las reducciones indfgenas de toda la IX Región tenian un valor de 1.89 , cifra que representa una alta resolución para reemplazar la población. Para las reducciones seleccionadas en el año 1988, este indicador se ha estimado en un valor de 1.72. En Chile, 1a tasa neta de reproducción estimada para 1987 era de 1.30 hijas por mujer (CELADE, 1987).

De los antecedentes anteriores, puede afirmarse que la población que reside en las reducciones indigenas seleccionadas tiene una alta capacidad de reemplazo, probablemente mantenida en los últimos años, hecho que indica que si en la realidad su población disminuye o crece muy lentamente, ello debería atribuirse a una importante emigración. 


\subsection{Diferencias socioculturales de la fecundidad}

E1 comportamiento de la fecundidad, como muchos fenómenos de la población, suele tener diferencias según algunas caracteristicas socioculturales. Por ejemplo, es importante conocer si existen diferencias en la fecundidad (paridez media) de la población de las reducciones indigenas seleccionadas, según la educación de la madre y la lengua más frecuentemente hablada en el hogar, ya que se sabe que menores niveles de educación de la madre y mayor grado de tradicionalismo suelen asociarse con altos niveles relativos de fecundidad, dando cuenta de una cierta heterogeneidad con que se caracteriza el comportamiento reproductivo al interior de una población.

Para este efecto, la información se ha obtenido a partir de las siguientes preguntas formuladas en el Censo de 1988:

- "¿Cuál es el último curso que terminó en la educación primaria, básica, secundaria, media o universitaria?"

- "¿Qué lengua se habla más frecuentemente en este hogar?"

La primera pregunta respondería acerca del nivel de instrucción de 1 a madre, siendo también un indicador aproximado de estrato socioeconómico y de inserción en la estructura social. La segunda pregunta respondería al idioma que se habla en el hogar, como una aproximación al apego o distanciamiento de los valores culturales tradicionales de la población.

\subsubsection{Fecundidad y educación de la madre}

La distribución de las mujeres entre 15-54 años de edad según categorfas de educación, muestra que un 33 por ciento tiene entre 0 y 3 años de estudio aprobados; un 38 por ciento posee entre 4 y 6 años; y un 29 por ciento registra 7 y más años de estudio aprobados."

Estas categorias han sido seleccionadas atendiendo a la distribución del número de casos $\mathrm{y}$, además, al hecho de que las personas que cuentan con entre 1 y 3 años de estudio aprobados son consideradas analfabetas funcionales. Por 10 tanto, la categoria 0 y 3 años de estudio aprobados representa al total de analfabetas (para mayores antecedentes, ver Capitulo Caracteristicas Educacionales). 
Al analizar el comportamiento que tiene la fecundidad con la educación de las madres, al margen de las irregularidades, se descubre que al comparar las curvas de paridez para cada una de las tres categorías del nivel educacional, el número promedio de hijos por mujer (paridez media) presenta una relación inversa con los años de estudio de la madre (gráfico 3). En general, se observa que a mayor educación relativa de ésta, menor número medio de hijos por mujer, relación que confirma la conocida asociación inversa que tiene la fecundidad con la educación de la madre. Esta situación se detecta también entre las mujeres de las mismas reducciones que fueron censadas en 1982, según los antecedentes de1 anexo 3-D.

Conviene destacar que en el Censo de 1988, las mujeres de instrucción más elevada presentan las mayores irregularidades a partir de 10 s 40 años de edad, hecho contrario a lo generalmente observado, incluso opuesto al resultado registrado en las mujeres de las reducciones de los mismos distritos en 1982 . En lineas discontinuas, en el gráfico 3 se sugiere una corrección de todas las irregularidades, en el supuesto de la existencia de posibles errores en la declaración de la información.

La paridez media de las mujeres de 50-54 años de edad alcanza a los 6.1 hijos en las mujeres con entre 0 y 3 años de estudio aprobados (analfabetas). Por su parte, el valor alcanza a 4.8 hijos por mujer en las madres con entre 4 y 6 años de estudio, y el grupo con educación igual o superior a 7 años de estudio aprobados registra una paridez media de 4.0 hijos. Estas diferencias, en grados variable's, corroboran lo planteado en otros trabajos referidos a otras poblaciones (por ejemplo; Toro, 1981 y 1982) y, como se menciono, se aprecian igualmente entre las mujeres de las mismas reducciones censadas en 1982, denotando probables diferencias en el comportamiento reproductivo según los años de instrucción de la madre.

En términos generales, se puede postular que estas situaciones podrian estar reflejando que las madres que logran tener más educación se asocian a un estrato social más afectado por la modernización. Por lo tanto, serian las mujeres más instruidas -en términos relativos-quienes inician el descenso de la fecundidad. 


\section{Gráfico 3}

REDUCCIONES INDIGENAS SELECCIONADAS: PARIDEZ MEDIA POR GRUPOS QUINQUENALES DE EDAD SEGUN EDUCACION DE LA MADRE. CENSO DE 1988

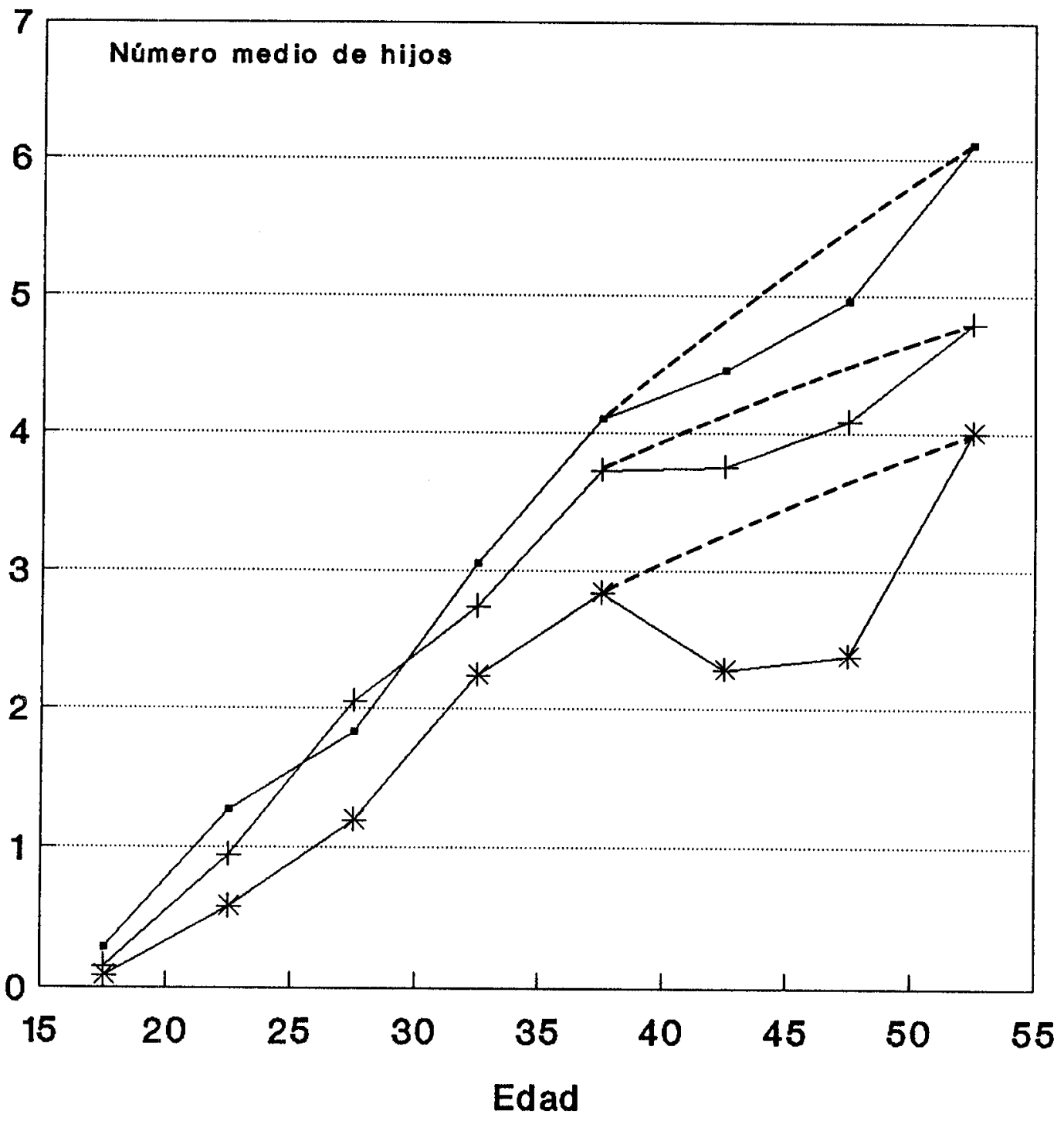

$\rightarrow$ Educa. 0-3 + Educa. 4-6 * Educa. 7 y más

Fuente: Anexos 3-A-B-C 
Esta hipotesis general, por supuesto, requiere ser contrastada empiricamente, para conocer con certeza el comportamiento real de los factores intervinientes, en especial si se trata de una población de bajos niveles de escolaridad. No puede dejar de mencionarse al respecto que las coyunturas politico-económicas, asi como las politicas públicas (por ejemplo, en el campo de la educación, la salud o la vivienda), y la disponibilidad de programas de planificación familiar, pueden acelerar o retrasar las tendencias del comportamiento reproductivo de la población.

\subsubsection{Fecundidad y lengua hablada en el hogar}

La lengua más frecuentemente hablada en el hogar puede considerarse como un indicador del grado de apego o distanciamiento a los valores culturales tradicionales de la población femenina del grupo étnico mapuche. El uso de la lengua mapuche es considerado como uno de los criterios básicos de diferenciación cultural actual del mapuche (Leiva, 1985). En términos simplificados, se puede asimilar el grupo de habla mapuche (mapudungun) a la cultura más tradicional y el grupo de habla castellano a los valores y normas menos tradicionales (o más afectados por la modernización), situando en una posición intermedia a los que hablan ambos idiomas."

La distribución de las mujeres de 15-54 años de edad fértil según la lengua hablada más frecuentemente en el hogar muestra que un 8 por ciento corresponde a lengua mapuche; un 49 por ciento corresponde a las personas bilingües; en tanto el 44 por ciento corresponde al grupo que habla castellano.

Los resultados obtenidos 1laman la atención, puesto que, además de las irregularidades en las curvas, como se aprecia en el gráfico 4, la mayor paridez en las mujeres de 50-54 años de edad corresponde al grupo que habla castellano con más frecuencia ( 6.4 hijos), que serfa el grupo de comportamiento menos tradicional. Por su parte, la categoria de mujeres correspondientes al grupo de lengua mapuche hablada con más frecuencia, presenta valores, en general, más bajos (con una cifra de 4.1 hijos en las mujeres de 50-54 años de edad).

Sobre la naturaleza de estos supuestos puede consultarse el Capítulo Caracteristicas Educacionales y el Capitulo Vivienda, Hogar y Familia. 
Gráfico 4

REDUCCIONES INDIGENAS SELECCIONADAS: PARIDEZ MEDIA POR GRUPOS QUINQUENALES DE EDAD SEGUN LENGUA HABLADA EN EL HOGAR. CENSO DE 1988

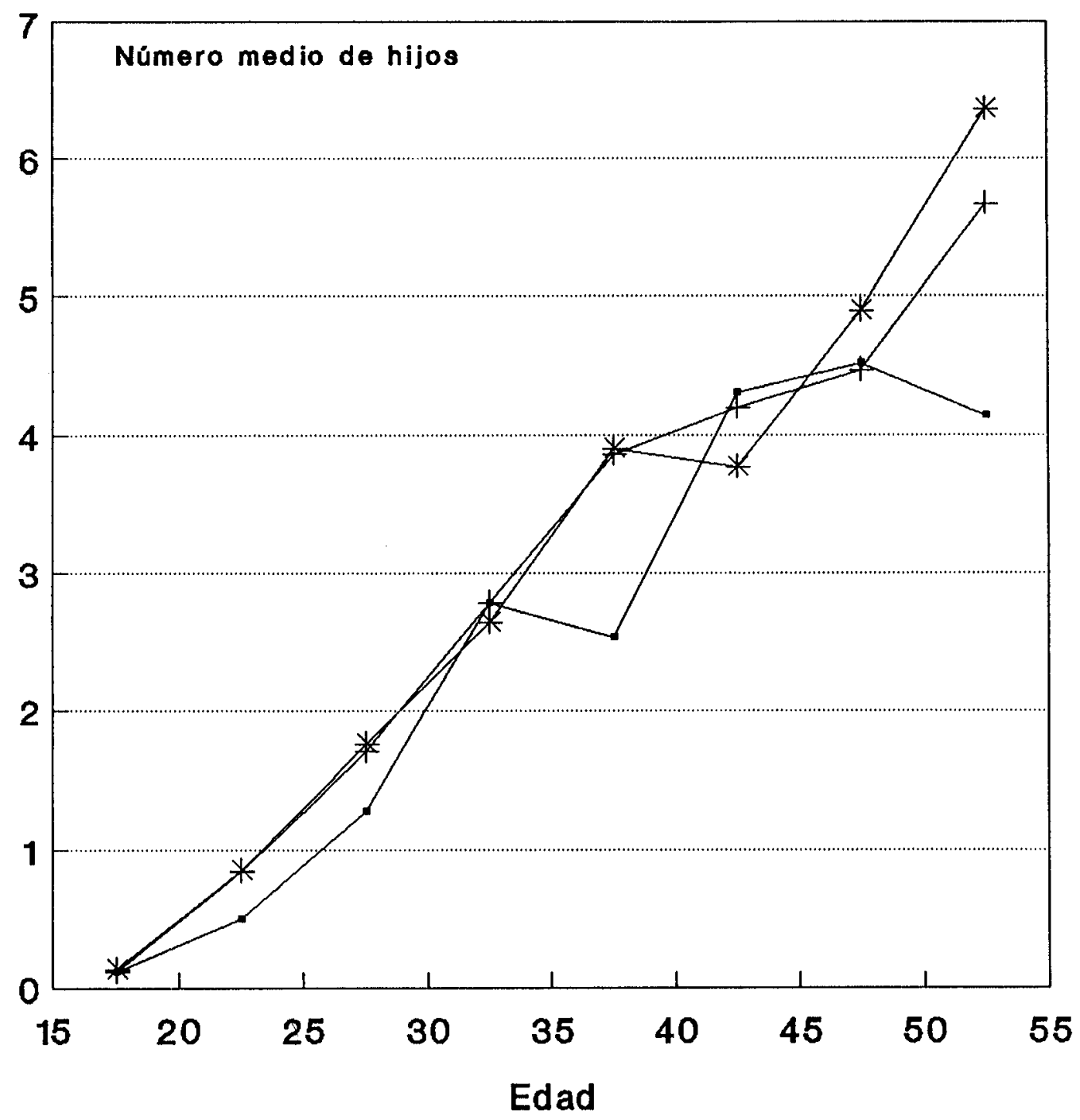

- Mapuche $\quad$ Mapu.-caste. $\quad$ * Castellano

Fuente: Anexos 4-A-B-C 
Es interesante observar que la menor fecundidad de las mujeres que mantienen el uso frecuente del mapudungun determina que sus hogares sean de menor tamaño que el resto, lo que plantea una contradicción con las caracteristicas que se esperarla encontrar en el tamaño de los hogares con mayor apego a la cultura tradicional. ' Tal fenómeno podria estar asociado con el hecho que las familias con menor descendencia presentan un contacto más reducido con la cultura urbana, debido a la menor influencia de la escuela expresada en los hijos $y$, por ello, mantendrian el mapudungun como la lengua más hablada. De todas maneras, la información presentada podría también estar afectada por exrores debido al reducido número de casos, a problemas en su declaración, o a una combinación de estos factores.

De modo comparativo, se aprecia una similitud perfecta en la paridez media hasta los 40 años de edad considerando solo dos categorias (mapuche-bilingüe y castellano), como lo muestra el gráfico 5 .

De los antecedentes anteriores, puede reconocerse que los datos provenientes de1 Censo de 1988 reportan diferencias importantes en 1a fecundidad según la lengua que más frecuentemente se habla en el hogar de las madres sólo cuando se considera la paridez media de las mujeres de 50-54 años de edad. Al respecto, hay que considerar que esta es una comparación al interior de una población con predominio de un grupo étnico. Un contraste étnico tal vez mostraria que la variable "lengua hablada en el hogar" conduce a generar diferencias a lo largo de las edades de las mujeres, como ha ocurrido en estudios de otros paises. Finalmente, un aspecto que requiere profundizarse guarda relación con la menor paridez observada entre las mujeres que mantienen el uso frecuente de la lengua mapuche, debido a la originalidad de su comportamiento.

1 El tamaño promedio de los hogares donde se mantiene el uso frecuente de 1a lengua mapuche es de 4 personas. Los hogares donde se hablan los dos idiomas con similar frecuencia alcanzan un promedio de 5 personas, en tanto los del grupo que habla castellano más frecuentemente registran un valor de 4.7 personas (ver Capitulo Vivienda, Hogar y Familia). 


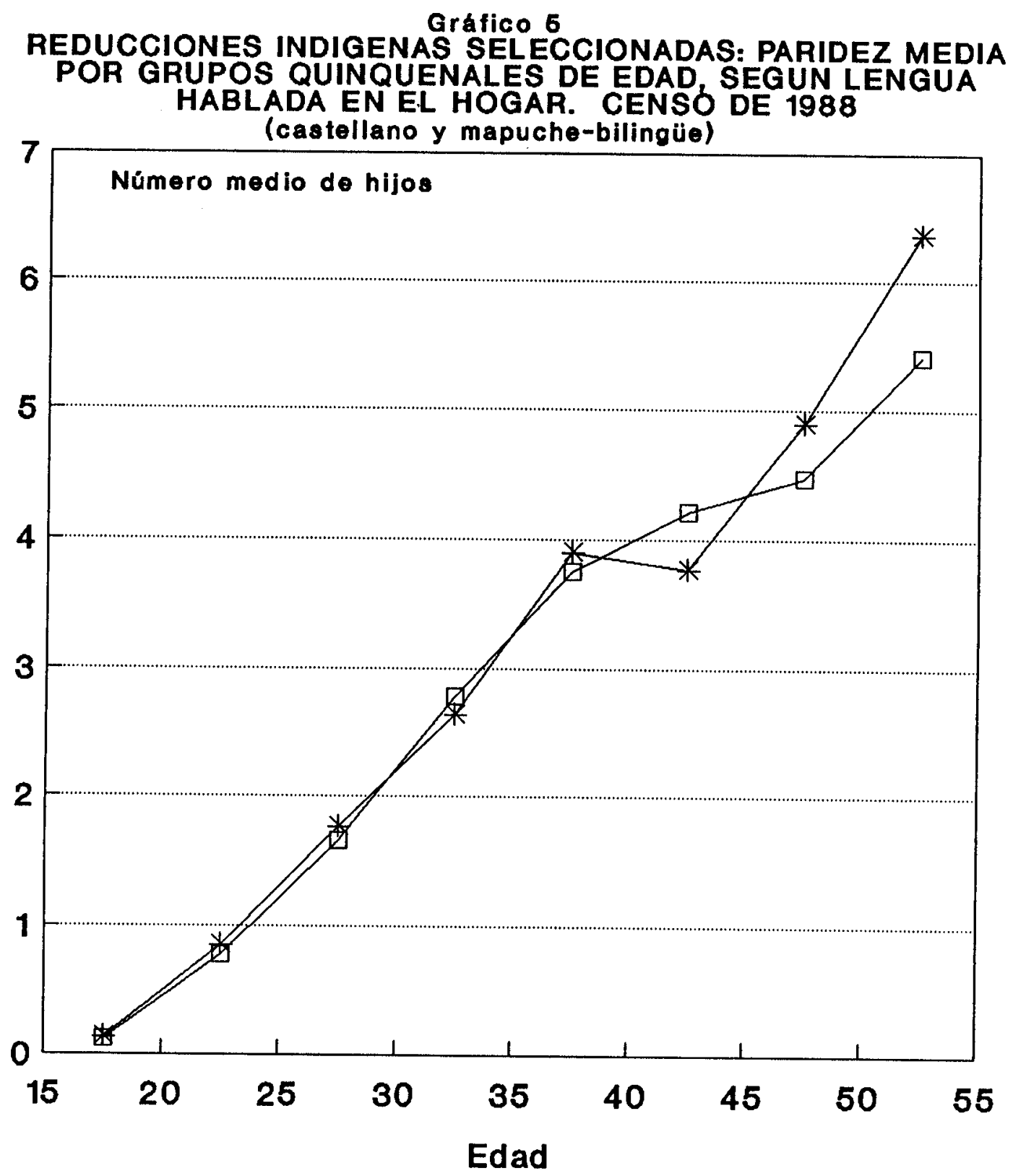

* Castellano $\square$ Mapu.+mapu.-caste.

Fuente: Anexos 4-A-B-C 


\section{Mortalidad}

Los niveles de mortalidad suelen dar cuenta de las condiciones sanitarias que envuelven a una población. El riesgo de morir es diferencial según factores biológicos como la edad y el sexo, pero lo es también desde el punto de vista de la estructura socioeconómica y espacial, determinando as 1 una desigualdad ante la muerte. Esta se presenta tanto al interfor de una sociedad, como entre paises, especialmente entre paises desarrollados y en desarrollo.

Del mismo modo, la evolución de la mortalidad se comporta en forma disimil según las variables mencionadas, lo que a niveles locales se relaciona directamente con el acceso de la población a la atención de salud."

En las próximas secciones se analizará la esperanza de vida y la mortalidad infantil estimadas para la población de las reducciones indigenas seleccionadas, describiendo oportunamente la naturaleza de cada indicador y estableciendo algunas comparaciones con estimaciones correspondientes a los datos de las mismas reducciones que fueron censadas en 1982 y otras áreas.

\subsection{Mortalidad y esperanza de vida}

Por lo general, la mortalidad suele expresarse a través de medidas que dan cuenta de la situación promedio de la población. Asi por ejemplo, la Tasa Bruta de Mortalidad indica la frecuencia con que se producen los fallecimientos dentro de una población en un perfodo dado. La frecuencia de muertes dependerá siempre de la estructura de edad, por lo que es una medida que no expresa los niveles reales de mortalidad. Debido a este factor, se tiene que paises desarrollados 1legan a poseer mayores tasas de mortalidad que paises en desarrollo: 1a explicación estriba en el hecho de que los primeros presentan una estructura de edad con fuerte participación de población en edad avanzada. Asi, la tasa bruta de mortalidad impide apreciar el mayor nivel de expectativas de vida que han alcanzado esos paises.

- Al respecto, puede consultarse el Capitulo Mortalidad y Atención de Salud Materno-Infantil. 
No obstante sus limitaciones como indicador del nivel de mortalidad, la tasa bruta de mortalidad permite estimar, junto a la tasa bruta de natalidad, la tasa de crecimiento natural o vegetativo de la población en un periodo dado.'

Un indicador que resume adecuadamente el nivel de mortalidad alcanzado por una población es la esperanza de vida, que se define como el número promedio de años que le resta por vivir a las personas de edad $x$. Dentro de ésta, la esperanza de vida al nacer es un indicador frecuentemente utilizado para realizar comparaciones entre diferentes periodos o contextos espaciales. Ella se define como el promedio de años que correspondería vivir a los recién nacidos expuestos a morir según las condiciones de mortalidad prevalecientes en un período dado.

Las preguntas formuladas a las mujeres en edad fértil sobre el número de hijos nacidos vivos e hijos sobrevivientes, as 1 como la pregunta sobre orfandad materna, permiten realizar estimaciones indirectas de la mortalidad en las reducciones indigenas bajo estudio. De este modo, se ha obtenido un orden de magnitud de la esperanza de vida al nacer de cerca de 59 años para el perfodo aproximado de 1975-1980, y de cerca de 63 años para alrededor de 1988.10

En el cuadro 7 se presenta la evolución de la esperanza de vida al nacer en el pais y en la IX Región, asi como las estimaciones para las reducciones indigenas seleccionadas.

Este aspecto se analizará en la sección sobre crecimiento y composición de la población por sexo y edad.

Para este efecto, se construyeron tablas de mortalidad por sexo para cerca de 1978 (1975-1980) y para alrededor de 1988, considerando las estimaciones de mortalidad en la niñez y mortalidad adulta (según la sobrevivencia de las madres), correspondientes a la población de las reducciones. La tabla de 1978 se basa en los niveles 19 (hasta los 15 años de edad) y 15 (adulta) de la familia "este" de tablas modelo de Coale y Demeny. La tabla de 1988 se basa en los niveles 20 y 18 , respectivamente, de la familia "oeste" de tablas modelo de Coale y Demeny (anexos 8-A y 8-B). 
PAIS, IX REGION Y REDUCCIONES INDIGENAS SELECCIONADAS:

ESPERANZA DE VIDA AL NACER TOTAL Y SEGUN SEXO. 1960-1990 (en años)

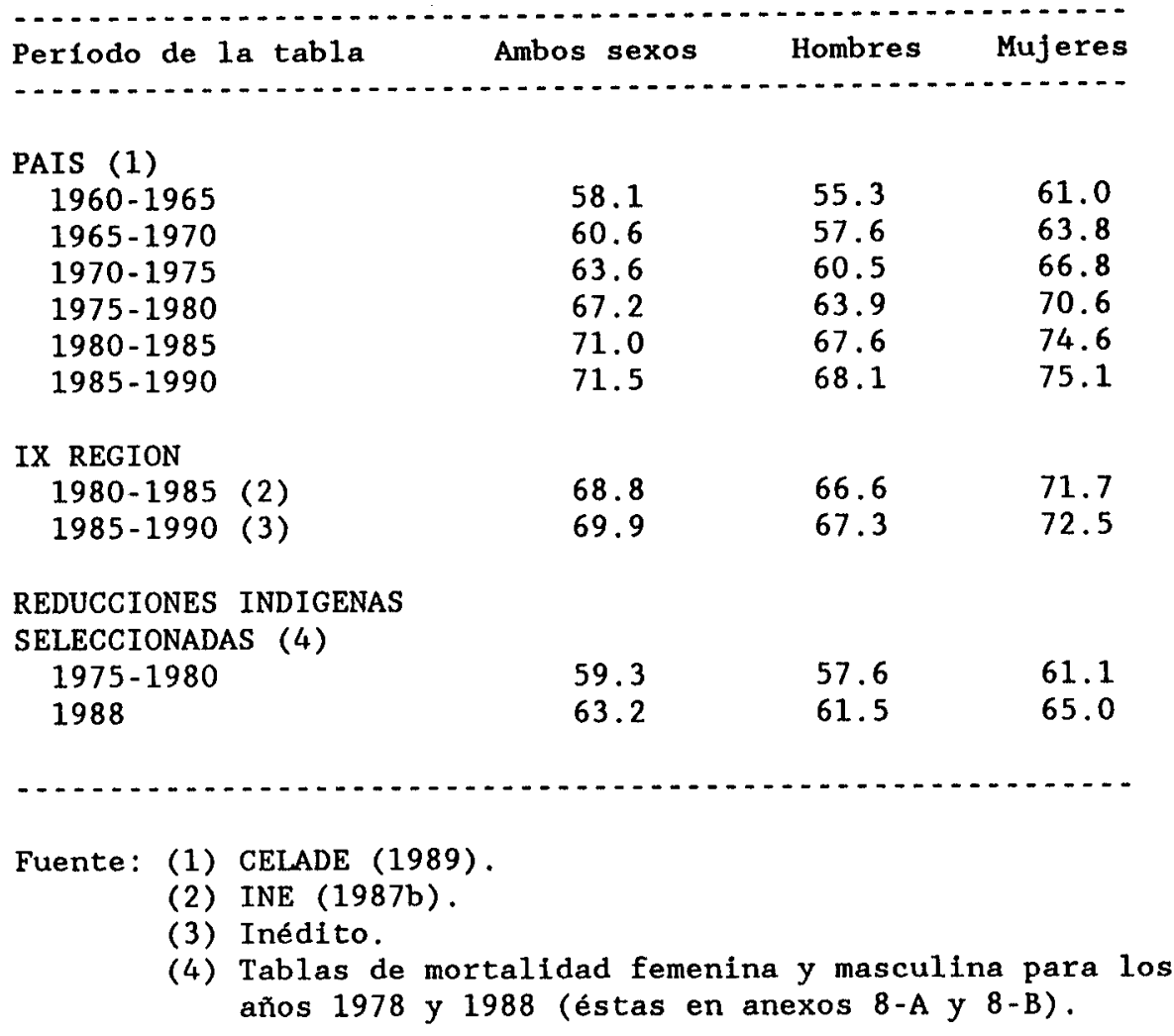

Lo importante es que existe, y pareciera mantenerse, una diferencia de ocho años de edad entre la esperanza de vida al nacer promedio del pals y la estimada para la población de las reducciones indigenas seleccionadas. Esto significaria un período de unos diez años de diferencia, al ritmo actual de aumento de la esperanza de vida al nacer del pais. Tal situación señalaria las diferencias que existen a nivel no sólo nacional, sino también intrarregional, en las condiciones de mortalidad de una población, siendo el caso de las reducciones indigenas ubicadas en los cuatro distritos de la Comuna de Temuco, en la IX Región. 


\subsection{Mortalidad infantil}

La mortalidad infantil o del primer año de vida es un importante indicador del nivel de salud de una población, ya que es en esta etapa de la vida donde existen las mayores posibilidades de eliminar o disminuir el rlesgo de muerte. Por consiguiente, su descenso suele contribuir decisivamente a los aumentos en la esperanza de vida al nacer.

El indicador correspondiente es la Tasa de Mortalidad Infantil (TMI), que se define como la relación entre el número de muertes de los menores de un año de vida y los nacimientos ocurridos en un periodo de referencia.

Los paises en desarrollo suelen presentar altas tasas de mortalidad infantil y bajas tasas brutas de mortalidad, lo que constituye el reverso de la situación de los paises desarrollados. No obstante, factores como la introducción de técniças de salud de bajo costo, han ayudado a que muchos paises en desarrollo alcancen marcados descensos en la TMI, aunque la brecha con los paises desarrollados pareciera no continuar disminuyendo una vez logrados ciertos niveles relativamente muy elevados en comparación con estos últimos.

Chile, junto a Cuba y Costa Rica, registran las tasas de mortalidad infantil más bajas de América Latina, con valores inferiores a 20 por mil nacidos vivos. Sin embargo, y como se verá, al interior del país existen diferencias del nivel de mortalidad infantil, las que se registran principalmente entre áreas urbanas y rurales, dando cuenta de diferenciales sociales que se alcanzan al interior de la población chilena.

La medición de la mortalidad infantil a partir de la información recolectada en el Censo de 1988, se realizó a través de los métodos indirectos de estimación de la mortalidad infantil y juvenil propuestos por Brass $y$ actualizados por Trusse11, combinándolos con las familias de las tablas de vida modelo de Coale y Demeny (Naciones Unidas, 1986). " De esta forma, se pudo obtener una estimación del nivel y la tendencia de la mortalidad en los primeros años de vida, lo que requiere como información básica el número de mujeres, el número

11

E1 fuerte descenso experimentado por la mortalidad infantil en Chile a contar de los años 80 , ha llevado a un cambio en la estructura de la mortalidad por edades, la que ha tendido a asimilarse con la familia "oeste" de tablas modelo de Coale y Demeny. 
de hijos nacidos vivos y el número de hijos actualmente vivos (información desagregada por grupos quinquenales de edad de las mujeres entre 15 y 49 años).

Con dicha información se aplicó el método mencionado, obteniéndose en primer término, la proporción de hijos muertos por grupos quinquenales de edad de la madre. Dicho coclente es, en principio, un Indicador de la mortalidad infantil y juvenil, a pesar que no es una medida que se utilice con frecuencia.

En total, la proporción de hijos muertos en la población de las reducciones de los cuatro distritos censados en 1988 muestra un valor inferior con respecto a la cifra que corresponde a las mismas reducciones según el Censo Nacional de 1982 (cuadro 8 y gráfico 6). Sin embargo, la tendencia por grupos de edad es irregular, lo que podria explicarse por la existencia de algunos problemas en la declaración del número de hijos nacidos e hijos sobrevivientes y en la edad de la madre.

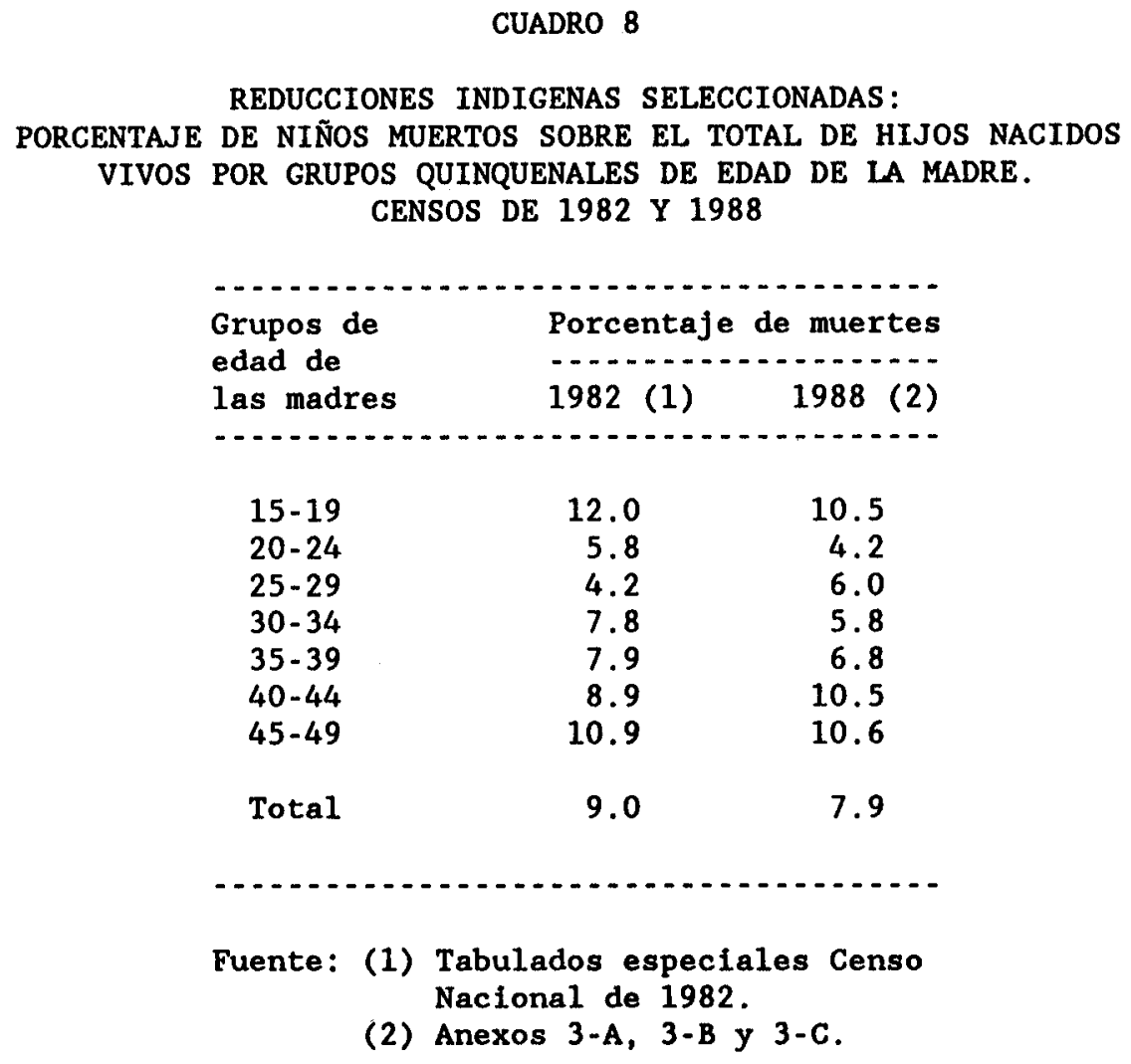




\section{Gráfico 6}

REDUCCIONES INDIGENAS SELECCIONADAS: PORCENTAJE DE NINOS MUERTOS SOBRE NACIDOS VIVOS, POR GRUPOS QUINQUENALES DE EDAD DE LA MADRE. CENSOS 1982 Y 1988

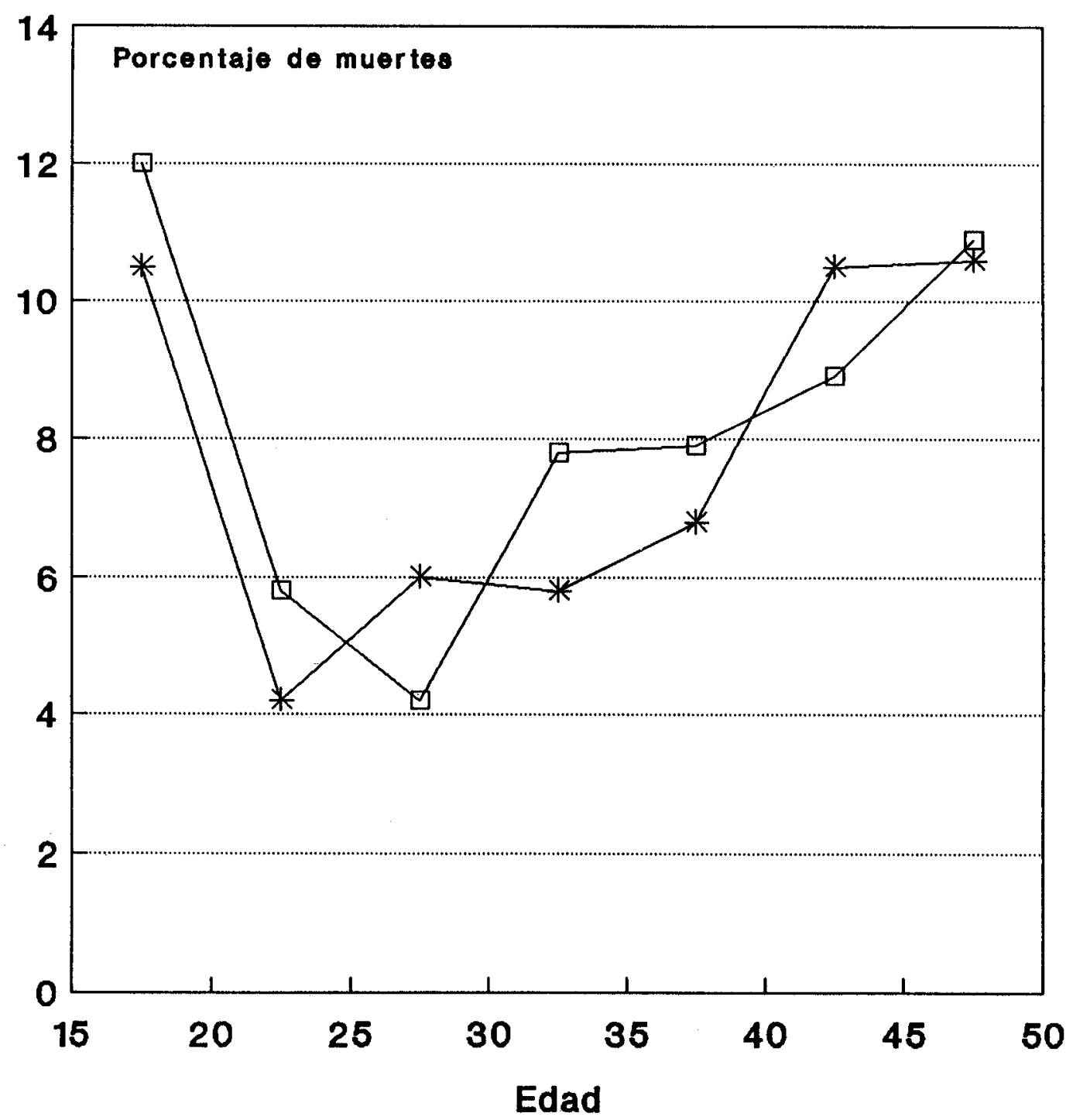

๑- Red.ind. $82 \quad$ * Red.ind. 88

Fuente: Cuadro 8 
Por su parte, el nivel de la tasa de mortalidad infantil, que se obtiene como un promedio de los grupos de edades 20-34 años, da como resultado un valor de 45.4 muertes por mil nacidos vivos para alrededor de 1985 (cuadro 9)."2

\section{CUADRO 9}

\section{PAIS, IX REGION Y REDUCCIONES INDIGENAS SELECCIONADAS: \\ TASAS DE MORTALIDAD INFANTIL. 1978-1.988 \\ (por mil nacidos vivos)}

\begin{tabular}{|c|c|c|c|}
\hline Año & $\begin{array}{l}\text { Pais } \\
\text { (1) }\end{array}$ & IX Región & $\begin{array}{l}\text { Reducciones } \\
\text { indígenas (2) }\end{array}$ \\
\hline 1978 & 40 & 72 & 59 \\
\hline 1979 & 38 & 66 & - \\
\hline 1985 & 20 & 32 & 45 \\
\hline 1988 & $18 \mathrm{a}$ & 27 & - \\
\hline
\end{tabular}

Fuente: (1) INE (1984 y 1988).

(2) Tabulados especiales Censo Nacional de 1982 y anexo 5 .

a: Inédito.

Aun cuando se trata de un orden de magnitud, las reducciones estudiadas según el Censo de 1988 se ubican en posiciones más desventajosas que la región y el pais (1985). Sin embargo, teniendo un alto nivel de mortalidad infantil con relación al pais, en el contexto de América Latina el nivel obtenido para las reducciones es bajo, puesto que los paises de esta región, en buen número, poseen valores superiores e incluso muy superiores.

12 Es importante resaltar que para esta estimación, se considera como aquella información más confiable la que proviene de las mujeres de dichas edades, puesto que las mujeres de edades más avanzadas tienden a omitir a los hijos que han emigrado, se han casado o han fallecido, y las mujeres más jóvenes tienden a no declarar los hijos nacidos vivos, ya que por ejemplo, existe en ellas un gran porcentaje de madres solteras. 
Por otro lado, el gráfico 7 muestra que al comparar la TMI de las reducciones indigenas del Censo de 1988 con la de las mismas reducciones que fueron censadas en 1982, se observa una tendencia al descenso del indicador a 1o largo de todo el perfodo estudiado (1966-1987). Por lo que se conoce del nivel de mortalidad infantil en Chile en la década del 60 , debe suponerse que las estimaciones que aquí se presentan para esos años en las reducciones seleccionadas, subestiman el verdadero nivel, ya sea por problemas en la declaración del número de hijos muertos o por limitaciones relacionadas con la metodologia (modelo de mortalidad utilizado).

En cualquier caso, la tendencia a la disminución de la mortalidad infantil podria guardar alguna relación con el aumento de los niveles de escolaridad de la población, pese a que éstos siguen siendo bajos en las reducciones estudiadas. ${ }^{13}$

En sintesis, no obstante las tendencias señaladas, prevalecen diferencias en los niveles de mortalidad infantil, asi como en la esperanza de vida al nacer, con respecto a los valores del pais y la IX Región. Tales discrepancias apoyarian la hipotesis de la existencia de una sobremortalidad que afectaria a la población de las reducciones indigenas. Si las magnitudes estimadas son cercanas a la realidad, se estaria en presencia de una situación de postergación al que se verian enfrentados algunos grupos sociales en el mejoramiento de sus condiciones de vida, especialmente en las relativas a la salud. Esta desigualdad se aprecia nitidamente al contrastar la tasa de mortalidad infantil de las reducciones con la tasa de las poblaciones del área oriente de Santiago (sectores de altos ingresos), en que comunas como Las Condes y Vitacura registraban un nivel inferior a 10 por mil en 1985 (INE, 1988b), es decir, casi cinco veces menor al valor estimado en las reducciones indigenas seleccionadas. Por 1o tanto, es posible plantear que existiria en Chile un nivel de mortalidad infantil que es discriminatorio según el grupo social al que pertenece la población.

E1 22 por ciento de las mujeres de 15 años y más son analfabetas absolutas y el 24 por ciento son analfabetas funclonales, cifras que disminuyen en las mujeres menores de 30 anos de edad (ver Capitulo Caracteristicas Educacionales). 
Gráfico 7

REDUCCIONES INDIGENAS SELECCIONADAS:

TASAS DE MORTALIDAD INFANTIL. CENSOS DE 1982 Y 1988

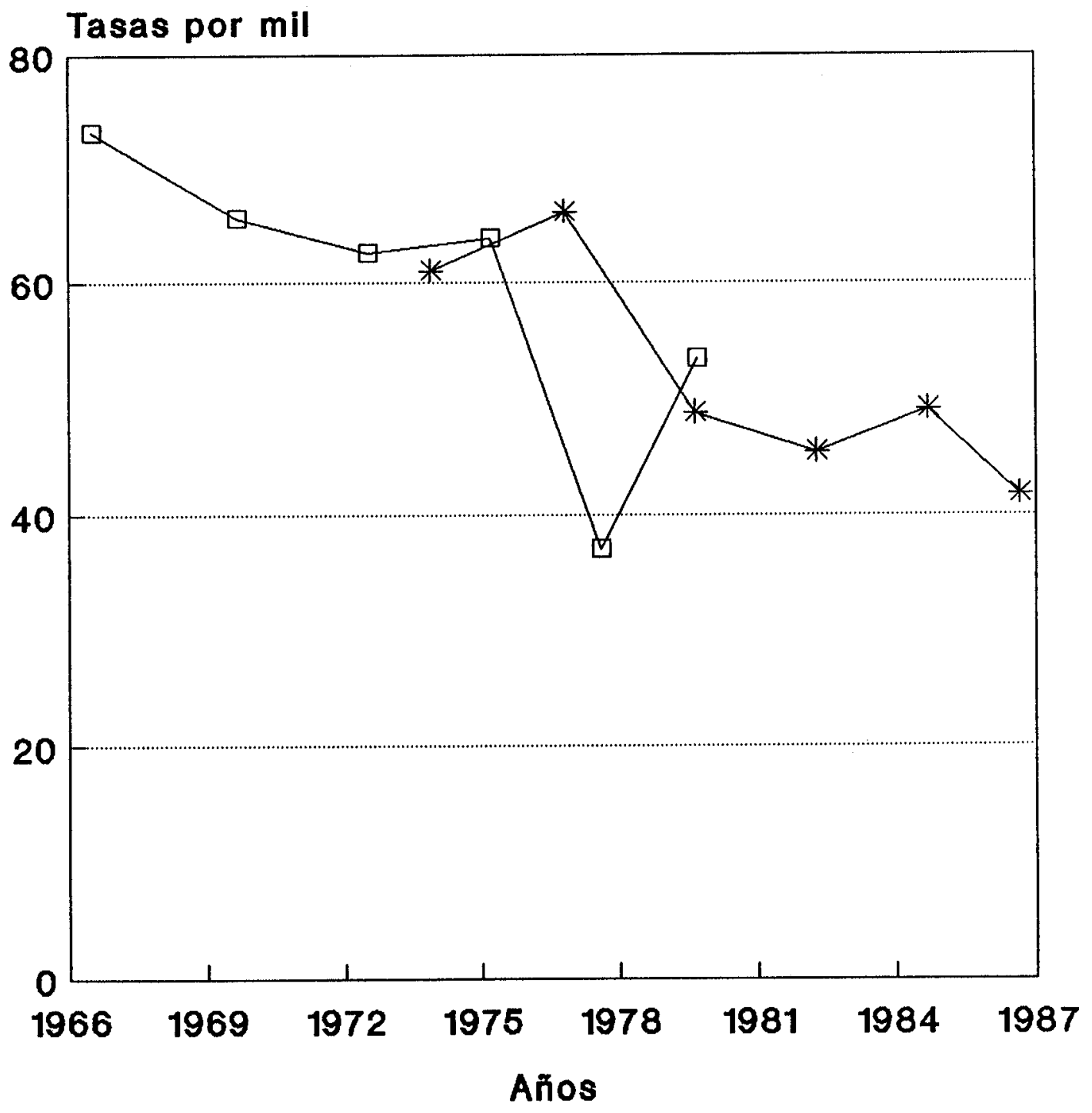

$\square$ Red.ind. $82 \quad$ * Red.ind. 88

Fuente:Anexo 6 y Tabs. esp. Censo 1982 


\section{Migracion}

Los movimientos que realiza la población al interior de un pais con el objeto de trasladar su residencia habitual representan el componente migratorio de la dinámica demográfica. Los volúmenes de estos desplazamientos normalmente pueden medirse a través de preguntas especfficas incluidas en censos y encuestas, - bien por medio de registros de migración. Estos antecedentes permiten, además, describir los flujos y caracteristicas de la población migrante, y estimar directamente el balance (migración neta) entre la inmigración (entrada de personas) y la emigración (salida de personas) en un periodo.

Aunque en el Censo de 1988 no fueron recopilados datos que permitan una medición de los movimientos de inmigración y emigración de la población de las reducciones (estos últimos, debido a la dificultad de medirlos con preguntas hechas en el lugar de origen y cuyos métodos están en estado experimental), resulta extremadamente importante presentar un panorama de la magnitud del balance que se establece entre dichos movimientos. Ello es as 1 por varias razones.

En primer lugar, se sabe que en áreas pequeñas la migración puede constituir el principal componente de la dinámica demográfica, y en el caso de los mapuches, son numerosos los estudios que plantean la presencia de un comportamiento migratorio caracteristico en este grupo étnico, 1o que ha 11 evado a afirmar que la migración entre los mapuches constituye una realidad conocida desde, por lo menos, la mitad del presente siglo, situación que estaria asociada con las condiciones de pobreza y de subsistencia (Bengoa, 1983).14

En segundo lugar, sobre la base de los antecedentes aportados por Oyarce, Romaggi y Vidal (1989), y de los volúmenes de población de las reducciones seleccionadas en dos momentos (1982 y 1988), se advierte que, efectivamente, 1a migración tendria una gran relevancia a través de la emigración.

Dada la dificultad de lograr estimaciones de los movimientos de población $y$, en particular, de la dirección de los flujos, asi como del carácter temporal - permanente de la migración, se puede conocer en forma aproximada la predominancla de la emigración en las reducciones en un periodo dado, según la magnitud de la migración neta. Esta es estimada por medio de la comparación entre los totales de población en 1982 y 1988, y sobre la base del análisis del

Al respecto, puede consultarse el Capitulo Caracteristicas Económicas. 
crecimiento natural que corresponderia a la población en el periodo 1982-1988. Por otra parte, el panorama de la significación de la migración se puede complementar a través de la comparación de la estructura etaria de la población censada en 1988 con la estructura de edad de una población teórica que tiene la particularidad de exhibir el comportamiento de la fecundidad $y$ mortalidad observada en las reducciones, y no esté sujeta a movimientos migratorios.

Es preciso señalar antes de exponer los resultados, que cuando la migración posee un volumen significativo, no sólo puede llegar a afectar directamente el crecimiento demográfico, a través del balance -positivo o negativo- que se produce en los intercambios de población entre áreas geográficas. Su efecto sobre la dinámica demográfica puede expresarse, además, en forma indirecta, cuando se establece una fuerte migración de mujeres en edades de alta fecundidad, situación que puede afectar el número de nacimientos en un área determinada y con ello, el crecimiento natural de la población.

Estas consideraciones cobran interés si se tiene en cuenta que en paises como Chile, la migración es selectiva según el sexo y la edad de las personas, y que en las áreas rurales está dada principalmente por movimientos de salida de población (emigración) hacia las áreas urbanas. Es asi que se conoce que los emigrantes de áreas rurales se concentran entre las mujeres adultas jóvenes, afectando el tamaño y la estructura de edad de la población de las zonas de origen, en especial si se trata de áreas de pequeños montos de población.

En 1982 se detectó que la emigración en todas las reducciones de la IX Región tendria una gran importancia en ese entonces, según el comportamiento observado en la estructura etaria de la población (Oyarce, Romaggi y Vidal, 1989). Los autores descubrieron que el patrón de predominio de mujeres jóvenes adultas emigrantes pareciera confirmarse, con la particularidad que éstas emigrarian a edades más tempranas que los hombres, incluso desde antes de los 20 años de edad y, probablemente, algunas de ellas con sus hijos pequeños. Estos hallazgos no hacen más que apoyar las hipótesis que se han planteado sobre la migración entre los mapuches, y que sostienen que ella habria comenzado a desencadenarse vigorosamente a principios de la década del 50 , ante la presión sobre la tierra en un territorio limitado; la pauperización creciente de la población; la falta de oportunidades de trabajo (y de remuneraciones, especialmente para las mujeres); factores que se unirian a la oferta de trabajo en áreas agrícolas de empleo temporal y en los centros urbanos, producto de la urbanización e industrialización (Babarovic et al., 1987; Zambrano, 1989). De este modo, con intensidades variables, la emigración (permanente o temporal) adquirió el carácter de estrategia de sobrevivencia familiar. 
Cabe destacar que en el caso de las reducciones seleccionadas, la cercania a Temuco, principal centro urbano de la IX Región y quinta ciudad del país, debiera incidir decisivamente en la mayor intensidad de la migración con respecto al resto de reducciones indigenas de la región.

\subsection{Importancia de la migración derivada de la comparación entre la población en 1982 y 1988}

Considerando la población de las mismas reducciones censadas en el Censo Nacional de 1982 y en el Censo de 1988, es posible determinar la significación de la migración entre 1982-1988, descubriéndose en primer lugar una fuerte pérdida de población que se habría experimentado en el periodo.

E1 análisis puede realizarse confrontando la población censada en 1982 con la población censada en 1988, obteniendo de este modo 2159 personas menos en este último año. Dado que las reducciones indigenas presentaban en 1982 una tasa positiva de crecimiento natural (aproximadamente 15 por mil anual), la diferencia entre la población de ambos censos muestra la existencia de una emigración importante, aunque no se descarta que parte de esta diferencia pueda deberse a una falta de comparabilidad en 1 a cobertura de ambos censos.

Como se aprecia en el cuadro 10, a lo largo del perlodo 1982-1988, las reducciones pertenecientes a los cuatro distritos estudiados habrian perdido unas 3500 personas a través de la migración neta. Para este cálculo se comparó la población censada en 1988 con la población esperada en esa misma fecha, obtenida a partir de la tasa de crecimiento natural de 15 por mil aplicada a la población censada en 1982 . $^{\text {s }}$

E1 balance migratorio del perlodo corresponde a una emigración neta de personas. La magnitud de la emigración por si sola deberia ser un poco mayor, si se conociera la inmigración del periodo, puesto que la cifra estimada de cerca de 3500 personas resulta del balance entre ambos movimientos. Cabe destacar que este valor es alto para la población estudiada en el periodo considerado, pero es dificil que se mantenga en esos niveles por un tiempo prolongado, pues en ese caso la población residente en las reducciones seleccionadas se extinguiria con rapidez.

15

En el anexo 6 se detalla el procedimiento seguido en este sencillo ejercicio. 
CUADRO 10

REDUCCTONES INDIGENAS SELECCIONADAS: ANTECEDENTES DE POBLACION $Y$ MIGRACION NETA ESTIMADA POR SEXO. 1982-1988

$\begin{array}{lcccc}\text { Sexo } & \begin{array}{c}\text { Población } \\ \text { censada } \\ 1982\end{array} & \begin{array}{c}\text { Población } \\ \text { censada } \\ 1988\end{array} & \begin{array}{c}\text { Población } \\ \text { esperada } \\ 1988\end{array} & \begin{array}{c}\text { Migración } \\ \text { neta }\end{array} \\ & & & & \\ & & & & \\ & & & & \\ \text { Hombres } & 7775 & 6763 & 8502 & 1739 \\ \text { Mujeres } & 7336 & 6189 & 8021 & 1832 \\ \text { Ambos sexos } & 15111 & 12952 & 16523 & 3571\end{array}$

Fuente: Anexo 6.

(1): Emigración neta 1982-1988.

Finalmente, en el cuadro 10 se aprecia que el 51 por ciento de la migración neta corresponde a mujeres. Como se puede advertir, el patrón de emigración femenina se confirmaria, aunque falta conocer si ello acontece o no entre las adultas jovenes.

\subsection{Importancia de la migración derivada del anális is de la estructura de edad y sexo de la población}

Otra forma de apreciar la significación de los movimientos migratorios de la población de las reducciones seleccionadas, se expresa a partir del análisis de la estructura de edad y sexo. Por medio de la comparación entre la estructura etaria de la población censada en 1988 y una estructura teórica de una "población estable", que posee 1a fecundidad y mortalidad implicita en la población de las reducciones, y que tiene, además, la caracteristica de no registrar migración, se pueden detectar los indicios de la migración en las reducciones entre los sexos y los distintos grupos de edad. ${ }^{16}$

Las diferencias entre ambas estructuras estarian asociadas principalmente con los cambios en la fecundidad (especialmente en los grupos de menor edad) y con la migración de población, pues la mortalidad juega un papel secundario. En el cuadro 11 y gráfico 8 se presentan los resultados de este ejercicio,

16

La "población estable" posee fecundidad y mortalidad constantes en el tiempo. 
apreciándose que el descenso de la fecundidad provoca una menor importancia relativa de los menores de 15 años de edad en la población de las reducciones. Se aprecia también una sobrerepresentación de los mayores de 64 años de edad en las mismas. En el gráfico 8 se advierte que son 10 menores de 10 años de edad quienes contribuyen a la menor representación del grupo 0-14 años.

Sin embargo, lo que interesa en este análisis es observar las discrepancias que asoman entre la población femenina de edades entre 15-64 años, puesto que estarian relacionadas con la emigración femenina. En total, las mujeres de este grupo presentan un menor porcentaje en la población de las reducciones (cuadro 11), cuyo comportamiento desagregado se visualiza en el gráfico 8 . En éste, se detecta que son las mujeres correspondientes a los grupos de edades entre 20-49 años quienes tendrian una menor participación relativa en las reducciones.

Este antecedente ayudaria a sustentar la hipótesis que existe una emigración de gran magnitud entre la población de las reducciones estudiadas, y que ella es selectiva, ya que se concentraria entre las mujeres adultas jóvenes.

CUADRO 11

ESTRUCTURA RELATIVA DE LA POBLACION DE REDUCCIONES INDIGENAS SELECCIONADAS Y DE UNA POBLACION ESTABLE POR GRUPOS DE EDAD, SEGUN SEXO

\begin{tabular}{|c|c|c|c|c|}
\hline \multirow[t]{2}{*}{$\begin{array}{l}\text { Grupos } \\
\text { de } \\
\text { edad }\end{array}$} & \multicolumn{2}{|c|}{$\begin{array}{c}\text { Reducciones } \\
\text { indigenas } 1988 \\
\text { (1) }\end{array}$} & \multicolumn{2}{|c|}{$\begin{array}{c}\text { Población } \\
\text { estable } \\
\text { (2) }\end{array}$} \\
\hline & Hombres & Mujeres & Hombres & Mujeres \\
\hline $\begin{array}{l}0-14 \\
15-64 \\
65 \text { y más }\end{array}$ & $\begin{array}{r}33.9 \\
59.2 \\
6.9\end{array}$ & $\begin{array}{r}34.7 \\
57.1 \\
8.2\end{array}$ & $\begin{array}{r}36.3 \\
58.7 \\
5.0\end{array}$ & $\begin{array}{r}35.5 \\
58.6 \\
5.9\end{array}$ \\
\hline Total & 100.0 & 100.0 & 100.0 & 100.0 \\
\hline
\end{tabular}

Fuente: (1) Anexo 7 .

(2) Coale y Demeny (1983). Población estable de nivel 19 familia oeste, según tasa bruta de reproducción de 2.0 . 
Gráfico 8

POBLACION ESTABLE Y DE REDUCCIONES INDIGENAS SELECCIONADAS. CENSO DE 1988

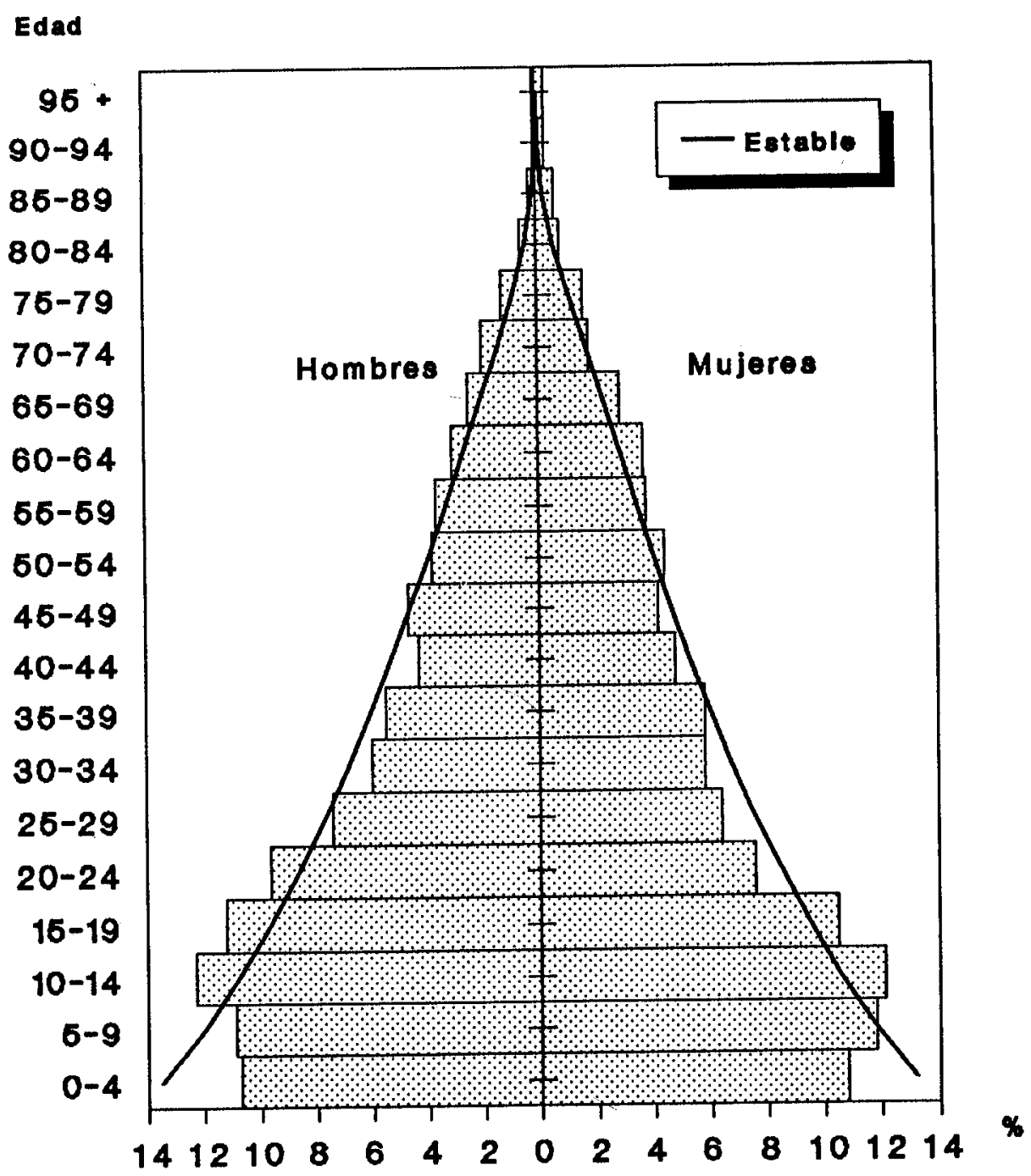

Fuente: Anexo 7 y Coale y Demeny (1983) 
Los indicios de una emigración significativa aparecen también al estudiar las caracteristicas de la población según el sexo y la edad. Al respecto, la observación de los indices de masculinidad (relación entre población masculina y población femenina), confirma la presencia de la emigración selectiva, pues se tienen indices que alcanzan cifras elevadas en edades activas, denotando un fuerte desequilibrio entre la población de ambos sexos. Estos y otros antecedentes serán examinados en las secciones que siguen, pero debe destacarse finalmente que estos hallazgos debieran investigarse en sus factores explicativos, particularmente en 10 que guarda relación con las consecuencias de la Ley 2568 dictada en 1979, conocida como "División de las Tierras Mapuches". Hasta mediados de la década del 80 , se habian dividido legalmente 1a mayoria de las reducciones, hasta entonces indivisas, de la IX Región, en el marco de una polftica de uniformización étnica y cultural (Babarovic et al., 1987).

\section{Crecimiento y composición de la población por edad y sexo}

La evolución de los componentes demográficos, analizados en las secciones anteriores, determina las diversas caracteristicas que asume la población. Entre éstas, se procederá a describir en primer lugar, el crecimiento demográfico. Posteriormente se analizará en detalle la estructura de edad y sexo de la población de las reducciones seleccionadas, como resultado de las tendencias de la fecundidad, la mortalidad y la migración.

\subsection{Crecimiento de la población}

E1 balance que se establece entre la natalidad y la mortalidad determina el ritmo de crecimiento natural de la población en un período dado. A su vez, el ritmo de crecimiento total corresponde a la diferencia entre el crecimiento natural y el balance migratorio. De esta forma, la dinámica de la población obedece a la evolución de los componentes demograficos: fecundidad, mortalidad y migración. 
De los datos del Censo de 1988, la tasa de crecimiento natural se estimó en 13 por mil (12.67), ${ }^{17}$ valor algo inferior al obtenido de los datos del Censo Nacional de 1982 para todas las reducciones indigenas de 1a IX Región (15.23 por mil; Oyarce, Romaggi y Vidal, 1989). La tasa de natalidad estimada de los datos del Censo de 1988 fue de 25 por mil (24.98), en tanto la tasa bruta de mortalidad estimada fue de 12 por mil (12.31).

Para tener una idea, en la IX Región el ritmo de crecimiento natural se ha estimado en un valor promedio anual de 21 por mil en el periodo 1980-1990, uno de los más altos entre todas las regiones del país (INE, 1987c). ${ }^{18}$ Esto significa que el ritmo de crecimiento natural de las reducciones estudiadas sería bastante menor que el de la región.

El bajo nivel de crecimiento natural de la población de las reducciones seleccionadas encuentra su explicación en la elevada mortalidad que se registraría en ellas, en el hecho de que la fecundidad está en descenso $y$, especialmente, en el efecto indirecto de la migración sobre la dinámica demografica. E1 efecto de la emigración sobre el crecimiento natural de la población proviene de la particular estructura de edad de las mujeres, a través

17 La metodología que se utilizó para calcular la tasa de crecimiento natural fue la siguiente:

a) Tasa de crecimiento natural: se obtuvo como la diferencia entre las tasas de natalidad y mortalidad.

b) Tasa bruta de mortalidad: se calculó dividiendo el total de defunciones estimadas, por la población total del Censo de 1988. Las defunciones se estimaron multiplicando las tasas centrales de mortalidad de las tablas de mortalidad por sexo de las reducciones (1988), por la población según grupos quinquenales de edad.

c) Tasa de natalidad: se calculó dividiendo el total de nacimientos estimados, por la población total del Censo de 1988. Los nacimientos fueron estimados a partir de la multiplicación de las tasas de fecundidad según grupos quinquenales de edad, por las mujeres en edad fértil del Censo de 1988 en los grupos respectivos.

En este período la Región de La Araucanía tuvo una tasa de natalidad estimada del orden de 28 por mil y una tasa bruta de mortalidad de cerca de 8 por mil (INE, 1987b). 
de la fuerte emigración de muchas de ellas que están en edades de alta fecundidad, determinando asi un menor número de nacimientos que el que cabría esperar de acuerdo a los niveles observados de fecundidad."

Si se considera el crecimiento total -incluyendo la migración neta- las reducciones de los cuatro distritos habrian experimentado una tasa anual negativa del orden de 25 por mil ( -23 por mil entre los hombres y -28 por mil entre las mujeres), lo que significa un decrecimiento significativo, producto de la fuerte emigración. ${ }^{20}$ Como se señalara al inicio de este capitulo, la IX Región creció con una tasa anual cercana a 14 por mil entre 1980-1990, teniendo en cuenta que a comienzos de dicho periodo contaba con balances negativos en sus intercambios de población con el resto de regiones del país.

En resumen, se puede concluir que la población de las reducciones indigenas seleccionadas habria experimentado un crecimiento negativo muy fuerte en el perfodo 1982-1988, que de persistir a este ritmo, reducirla su tamaño a la mitad en 25 años. No se descarta que parte de la significativa diferencia entre los volúmenes de población de ambos censos pueda deberse a una falta de comparabilidad real en la cobertura de éstos.

\subsection{Estructura de edad de la población}

La importancia del conocimiento de la estructura (o distribución relativa) por edad de la población, radica en el hecho de que ella determina la oferta de mano de obra y las necesidades de empleo, educación, salud y demás servicios esenciales. A su vez, el crecimiento de la población está asociado con la distribución por edades de ésta, debido a que el comportamiento de los componentes demográficos varia según la edad de las personas.

La población de reducciones indigenas correspondientes a los cuatro distritos estudiados según el Censo de 1988, presenta una estructura de edad joven, caracteristica de una fecundidad aun alta, puesto que más de un tercio

19 Para tener una aproximación al efecto indirecto de la migración sobre la dinámica demográfica de las reducciones seleccionadas, se calculo la tasa de natalidad que tendrian éstas si tuvieran la estructura relativa de las mujeres en edad fértil que presentaba el pals en 1982. Aplicando dicha estructura al total de mujeres respectivas de las reducciones, se obtiene una tasa de natalidad que se eleva desde 25 a 31 por mil. Estos resultados corresponden a tabulados especiales. en 1982) ; en donde $t=6$ años. 
de la población es menor de 15 años de edad, esto es, un 34 por ciento (cuadro 12). En las mismas reducciones según el Censo Nacional de 1982, los menores de 15 años de edad representaban un 39 por ciento (cuadro 13). La importante representación de la población joven se aprecia en los gráficos 9 y $10 .^{21}$

E1 porcentaje inferior de personas menores de 15 años en 1988 con respecto a 1982, y la menor participación relativa de las personas de edades entre 0-4 años con respecto a la de los grupos 5-9 y 10-14, seria reflejo del descenso de la fecundidad $y$, tal vez, de una emigración de niños funto a sus padres.

CUADRO 12

REDUCCIONES INDIGENAS SELECCIONADAS: ESTRUCTURA DE LA POBLACION POR GRUPOS QUINQUENALES DE EDAD, SEGUN SEXO. CENSO DE 1988

\begin{tabular}{|c|c|c|c|c|c|c|}
\hline \multirow{3}{*}{$\begin{array}{l}\text { Grupos } \\
\text { de } \\
\text { edad }\end{array}$} & \multicolumn{6}{|c|}{$P \circ b 1 a c i o n$} \\
\hline & \multicolumn{4}{|c|}{ Ambos sexos $\quad$ Hombres } & \multicolumn{2}{|c|}{ Mujeres } \\
\hline & $\mathrm{N}^{2}$ & 8 & $\mathrm{~N}^{2}$ & 8 & $\mathrm{~N}^{\mathrm{e}}$ & 8 \\
\hline $0-4$ & 1389 & 10.7 & 721 & 10.7 & 668 & 10.8 \\
\hline $5-9$ & 1468 & 11.3 & 736 & 10.9 & 732 & 11.8 \\
\hline $10-14$ & 1581 & 12.2 & 834 & 12.3 & 747 & 12.1 \\
\hline $15-19$ & 1405 & 10.9 & 756 & 11.2 & 649 & 10.5 \\
\hline $20-24$ & 1123 & 8.7 & 652 & 9.6 & 471 & 7.6 \\
\hline $25-29$ & 897 & 6.9 & 502 & 7.4 & 395 & 6.4 \\
\hline $30-34$ & 767 & 5.9 & 406 & 6.0 & 361 & 5.8 \\
\hline $35-39$ & 730 & 5.6 & 370 & 5.5 & 360 & 5.8 \\
\hline $40-44$ & 584 & 4.5 & 289 & 4.3 & 295 & 4.8 \\
\hline $45-49$ & 577 & 4.5 & 316 & 4.7 & 261 & 4.2 \\
\hline $50-54$ & 533 & 4.1 & 258 & 3.8 & 275 & 4.4 \\
\hline 55.59 & 485 & 3.7 & 248 & 3.7 & 237 & 3.8 \\
\hline $60-64$ & 435 & 3.4 & 206 & 3.1 & 229 & 3.7 \\
\hline 65 y más & 978 & 7.5 & 469 & 6.9 & 509 & 8.2 \\
\hline Total & 12952 & 100.0 & 6763 & 100.0 & 6189 & 100.0 \\
\hline
\end{tabular}

Fuente: Anexo 7.

21 E1 promedio de edad de 1a población de las reducciones alcanza a 28.41 años (29.01 entre las mujeres y 27.86 entre los hombres). En 1982 habria alcanzado a un valor de 27.55 años (27.88 entre las mujeres y 27.23 entre los hombres). Como antecedente comparativo, la edad promedio de 1a población del pais, según el Censo Nacional de 1982, era de 28 años, en tanto la de la IX Región en 1988 sería de 27 años. 
CUADRO 13

REDUCCIONES INDIGENAS SELECCIONADAS: ESTRUCTURA DE LA POBLACION POR GRUPOS QUINQUENALES DE EDAD, SEGUN SEXO. CENSO NACIONAL DE 1982

\begin{tabular}{|c|c|c|c|c|c|c|}
\hline \multirow[t]{2}{*}{ edad } & \multirow{2}{*}{$\begin{array}{l}\text { Ambos } \\
\mathrm{N}^{\circ}\end{array}$} & \multirow{2}{*}{$\begin{array}{c}\text { sexos } \\
8\end{array}$} & \multicolumn{2}{|c|}{ Hombres } & \multicolumn{2}{|c|}{ Mujeres } \\
\hline & & & $\mathrm{N}^{2}$ & 8 & $\mathrm{~N}^{2}$ & 8 \\
\hline $0-4$ & 1792 & 11.9 & 915 & 11.8 & 877 & 12.0 \\
\hline $5-9$ & 2031 & 13.4 & 1035 & 13.3 & 996 & 13.6 \\
\hline $10-14$ & 2066 & 13.7 & 1049 & 13.5 & 1017 & 13.9 \\
\hline $15-19$ & 1640 & 10.9 & 897 & 11.5 & 743 & 10.1 \\
\hline $20-24$ & 1147 & 7.6 & 643 & 8.3 & 504 & 6.9 \\
\hline $25-29$ & 858 & 5.7 & 437 & 5.6 & 421 & 5.7 \\
\hline $30-34$ & 825 & 5.5 & 434 & 5.6 & 391 & 5.3 \\
\hline $35-39$ & 749 & 5.0 & 357 & 4.6 & 392 & 5.3 \\
\hline $40-44$ & 757 & 5.0 & 379 & 4.9 & 378 & 5.2 \\
\hline $45-49$ & 612 & 4.1 & 301 & 3.9 & 311 & 4.2 \\
\hline $50-54$ & 649 & 4.3 & 359 & 4.6 & 290 & 4.0 \\
\hline $55-59$ & 537 & 3.6 & 248 & 3.2 & 289 & 3.9 \\
\hline $60-64$ & 397 & 2.6 & 206 & 2.7 & 191 & 2.6 \\
\hline 65 y más & 1.051 & 7.0 & 515 & 6.6 & 536 & 7.3 \\
\hline Total & 15111 & 100.0 & 7775 & 100.0 & 7336 & 100.0 \\
\hline
\end{tabular}

Fuente: Tabulados especiales Censo Nacional de 1982.

Por otra parte, también es relevante el porcentaje de personas mayores de 64 años de edad, que alcanzaba a un 7 por ciento en 1982 (cuadro 13) y representó casi un 8 por ciento en 1988 (cuadro 12). Dado que se analiza la distribución relativa de la población por tramos de edades, esto se debería a la falta de personas entre 15-64 años de edad por efecto de la emigración.

La evolución de los grupos con edades entre 15-64 años muestra un aumento en su participación relativa entre 1982 y 1988 , pasando desde un 54 a un 58 por ciento. Esta evolución se debería, básicamente, a la disminución de la participación de los menores de 15 años de edad y a la existencia de una alta fecundidad en el pasado. 
Gratico $\theta$

POBLACION DE REDUCCIONES INDIGENAS

SELECGIONADAS. CENSO DE 1982

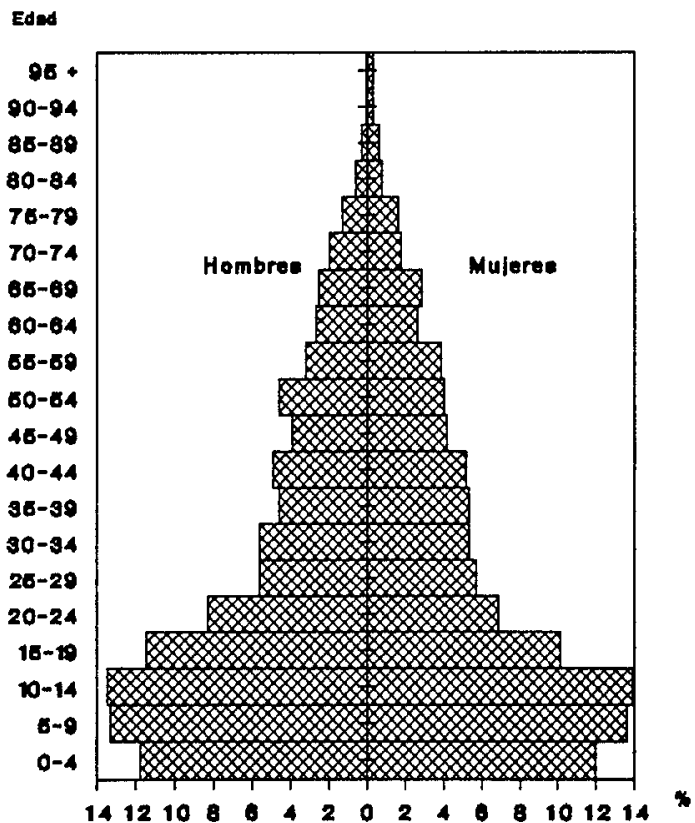

Fuenter Tabe, eep. Ceneo 1802
Grafico 10

POBLACION DE REDUCCIONES INDIGENAS

SELECCIONADAS. CENSO DE 1988

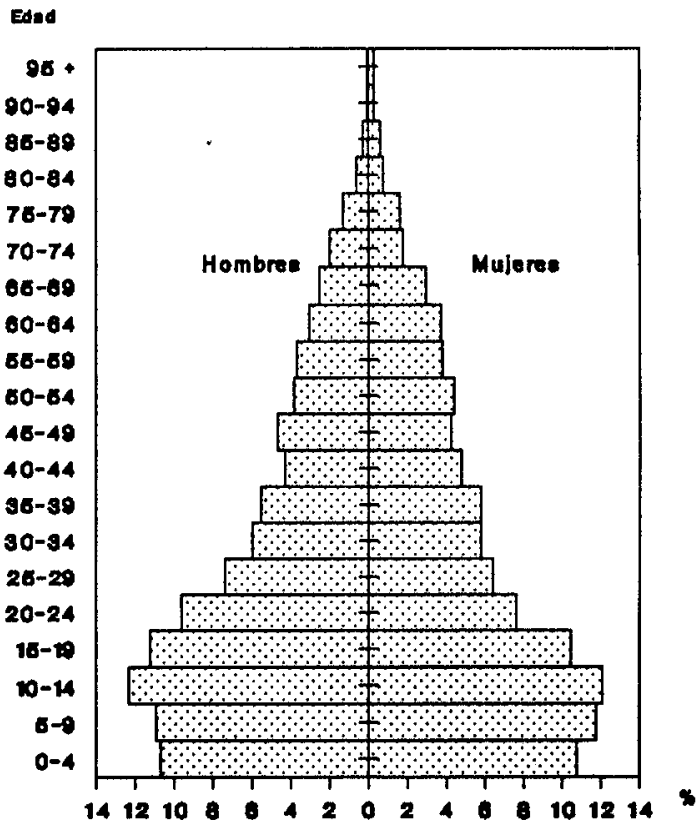

Fuanter Anaxo $T$ 
Cabe destacar que la IX Región presentaba en 1988 una participación relativa de población joven del orden del 34 por clento y una representación de 7 por ciento de su población mayor de 64 años de edad. La población con edades entre 15-64 años alcanzaba al 59 por ciento (INE, 1987c).

Al relacionar la población de los grupos en edades inactivas (menores de 15 años y mayores de 64 años de edad) con los efectivos en edades activas (resto de la población), se obtiene un indicador cuya evolución por sexo es, en gran medida, consecuencia de la migración y por lo tanto, contribuye a establecer indiclos sobre las tendenclas de ésta en las reducciones selecclonadas. Este indicador es la relación de dependencia.

La relación de dependencia encontrada en la población de las reducciones estudiadas en 1988 es de 719 por mil, lo que significa que por cada mil personas en edad activa habrian 719 en edad inactiva ("dependientes"). Al considerar la relación de dependencia por sexo, las mujeres muestran un indice de 752 mujeres dependientes por cada mil en edad activa. El valor para los hombres, en cambio, alcanza a 689 hombres en edad inactiva por cada mil en edad activa.

Al comparar la relación de dependencia de las reducciones indigenas en 1988 con la relación correspondiente a las reducciones de los mismos distritos en el Censo Nacional de 1982, se advierte que ella ha disminuido desde 849 a 719 por mil. El descenso se debe fundamentalmente a la calda porcentual en los menores de 15 años de edad y al aumento relativo entre la población en edad activa (15-64 años). Esto parece relacionarse, como se ha mencionado, con el descenso de la fecundidad, ya que desde el momento que ila población joven no aumenta en términos relativos, ello obedece esencialmente a la disminución en el. número de nacimientos; as 1 también, el aumento de la participación de los grupos con edades entre 15-64 años se debe a la existencia de una alta fecundidad en el pasado.

En 1988 la IX Región presentaba una relación de dependencia de 692 por mil, con un valor de 682 dependientes por mil entre los hombres y 702 dependientes por mil entre las mujeres (INE, 1987c).

La relación de dependencia as 1 definida es una medida demográfica de mucho interés socioeconómico, pero no expresa la efectiva dependencia, ya que se conoce que la población que desarrolla una actividad económica no coincide exactamente con la que corresponde a los grupos de edades entre 15-64 años. 
De acuerdo con los antecedentes anteriores, las discrepancias de la relación de dependencia entre hombres y mujeres se explicarian por la migración selectiva en las reducciones. Es asi que se verifica que la mayor emigración femenina se refleja en un menor número relativo de personas en edad activa, 1o que acontecla también entre la población de las mismas reducciones en 1982 (en esta fecha la relación de dependencia para las mujeres era de 876 por mil, en tanto para los hombres era de 825 por mil).

En sintesis, la estructura de edad de la población de las reducciones indigenas seleccionadas muestra el efecto de una fecundidad alta pero en descenso, reflejándose en la fuerte participación de población joven y en un aumento relativo en los restantes grupos etarios, donde es llamativa la sobrerepresentación de la población mayor de 64 años de edad, producto de una emigración importante en las edades activas, especialmente entre el sexo femenino.

\subsection{Composición de la población por sexo}

La composición de la población por sexo afecta directamente el número de nacimientos y defunciones que se registran, asi como el número de uniones o matrimonios.

E1 Indice o relación de masculinidad permite conocer la composición de la población por sexo. Este indice suele asumir un valor de 105 hombres por cada 100 mujeres al nacimiento, relación que tiende a reducirse gradualmente con el aumento de la edad, a causa de la natural sobremortalidad masculina. Las desviaciones a este patrón obedecen ya sea a una mortalidad particular o, principalmente, a una migración significativa, lo cual se expresa en el indice para la población total y para los distintos grupos de edad.

Como se muestra en el cuadro $14,10 s$ indices de masculinidad señalan un predominio masculino significativo, que habria aumentado entre 1982 y 1988 . Conviene consignar que esta es una situación caracteristica de las poblaciones rurales o de zonas con una importante participación de éstas.

A nivel global existen 109 hombres por cada 100 mujeres en las reducciones estudiadas, cifra mayor a la registrada en estas reducciones en 1982 (106 por cien), y bastante superior a la que exhibiria la IX Región en 1988 (102 por cien; INE, 1987c). 
CUADRO 14

REDUCCIONES INDIGENAS SELECCIONADAS :

INDICES DE MASCULINIDAD POR GRUPOS QUINQUENALES DE EDAD.

CENSOS DE 1982 Y 1988

$\begin{array}{lrr}\begin{array}{l}\text { Grupos de } \\ \text { edad }\end{array} & \begin{array}{c}\text { Censo } 1982 \\ (1)\end{array} & \begin{array}{c}\text { Censo } \\ (2)\end{array} \\ 0-4 & 104.33 & 198.93 \\ 5-9 & 103.92 & 100.55 \\ 10-14 & 103.15 & 111.65 \\ 15-19 & 120.73 & 116.49 \\ 20-24 & 127.58 & 138.43 \\ 25-29 & 103.80 & 127.09 \\ 30-34 & 111.00 & 112.47 \\ 35-39 & 91.07 & 102.78 \\ 40-44 & 100.27 & 97.97 \\ 45-49 & 96.79 & 121.07 \\ 50-54 & 123.79 & 93.82 \\ 55-59 & 85.81 & 104.64 \\ 60-64 & 107.85 & 89.96 \\ 65 \text { y más } & 96.08 & 92.14 \\ & & \\ \text { Total } & 105.98 & \\ & & \\ \ldots . . . \ldots 9.27\end{array}$

Fuente: (1) Cuadro 13

(2) Cuadro 12

Como se aprecia, los valores más altos corresponden a los grupos etarios 20-24 (138 por cien) y 25-29 (127 por cien). En el Censo Nacional de 1982, las reducciones de los mismos distritos registraban el indice más elevado en el grupo 20-24 años (128 por cien).

Contrastando la estructura del indice en ambos censos, como se observa en el gráfico 11, el predominio femenino se da sólo en cuatro grupos quinquenales. Este aparece desde los 35 años de edad en el Censo Nacional de 1982 y a partir de los 40 años de edad en el Censo de 1988.

En sintesis, la composición por sexo de la población, medida a través del Indice o relación de masculinidad, expresa un predominio masculino que ha ido en aumento entre 1982-1988, mostrando la gravitación que alcanzarla la emigración de la población femenina, principalmente entre los 15-39 años de edad. 
Gráfico 11

REDUCCIONES INDIGENAS SELECCIONADAS: INDICES DE MASCULINIDAD POR GRUPOS QUINQUENALES DE EDAD. CENSOS DE 1982 Y 1988
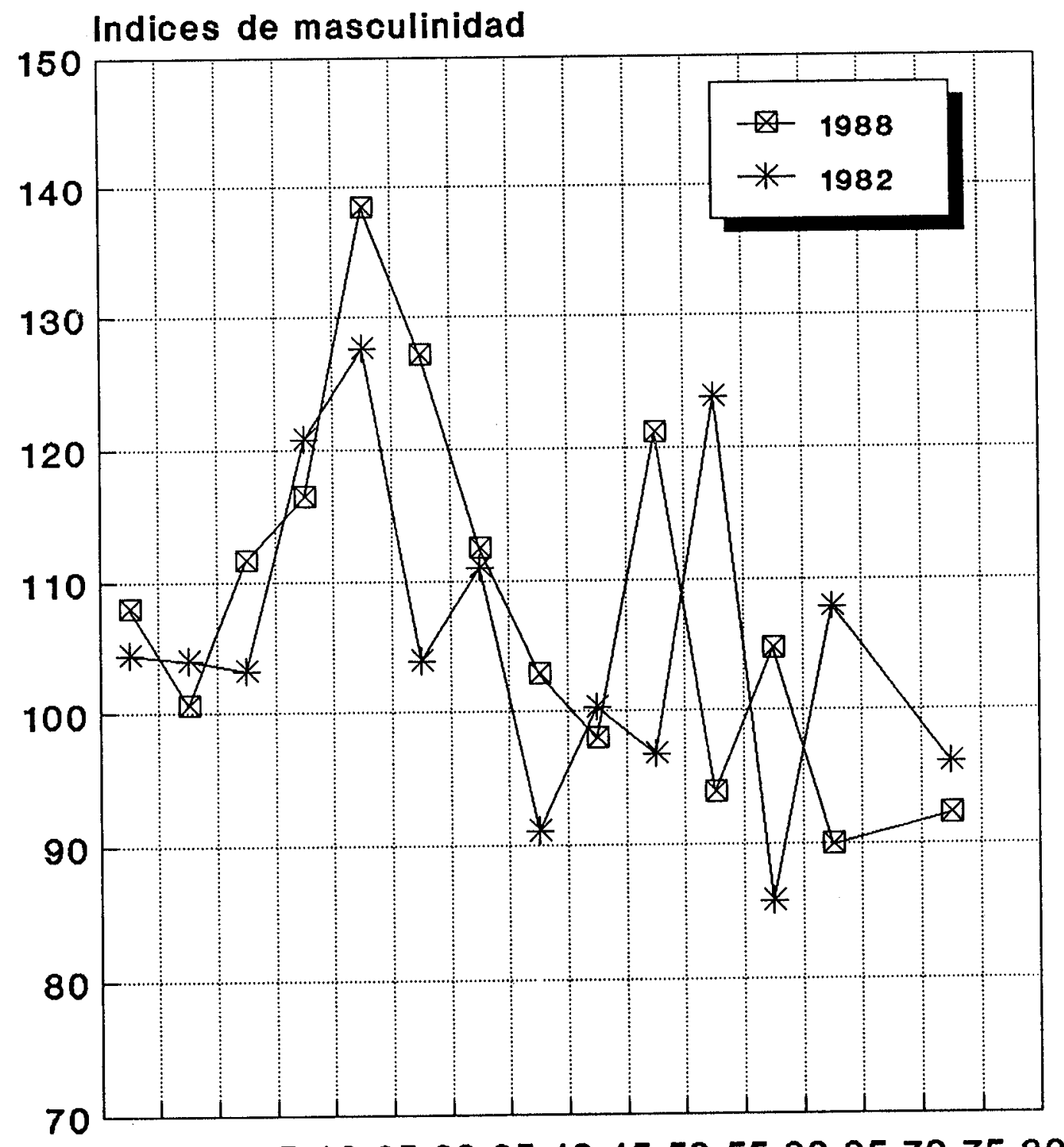

$0 \quad 5101520253035404550556065707580$

Edad

Fuente: Cuadro 14 


\section{Conclustones}

La población de los distritos de Labranza, Molco, Maquehue y Metrenco, que constituia cerca del 10 por clento de la población de las reducciones indigenas de la IX Región en 1982, presenta una dinámica demográfica en transición, caracterizada por una fecundidad y una mortalidad en descenso, junto con una migración de gran significación.

Admitiendo que los datos analizados configuran órdenes de magnitud sobre las variables demográficas, planteándose oportunamente las limitaciones de aquéllos $y$ de los procedimientos utilizados, debe destacarse que se han descubierto interesantes hallazgos de aspectos de los que no se tenia información, a través de los cuales se ha podido introducir al conocimiento del comportamiento reproductivo, las condiciones de mortalidad, los patrones migratorios, la dinámica y la composición de la población de las reducciones seleccionadas.

En primer lugar, se ha logrado estimar el comportamiento de la fecundidad como componente demográfico que expresa la conducta procreativa de una población. La medición de la fecundidad Indica que su nivel es alto en el contexto nacional, aunque se apreciarla una tendencia decreciente. Las mujeres de la población estudiada tendrian actualmente, en promedio, casi 4 hijos al término de su vida fértil, cifra cuyo descenso en los últimos años expresaria la existencia de probables cambios en el comportamiento reproductivo de la población. Tales cambios podrian guardar relación con, entre otros, el aumento de la escolaridad de la población femenina; su tendencia diversificada en la participación en actividades económicas; y la cercanía a Temuco, que permitirfa la difusión de pautas culturales sobre nuevos tamanos ideales de familia, tipicos de los centros urbanos.

Hay que destacar que los antecedentes examinados según variables de orden sociocultural, indicarian que la población de las reducciones indigenas seleccionadas presenta en su interior una cierta diferencia en el comportamiento de la fecundidad. Al respecto, cabe mencionar que se han observado diferencias esperadas según los años de estudio aprobados por la madre, y que con relación a la lengua hablada con más frecuencia en el hogar, las mujeres que mantienen el uso frecuente del mapudungun registrarian una fecundidad algo menor que el resto de las mujeres, 10 que se corresponde con un menor tamaño de sus hogares. Llama la atención este hallazgo, puesto que el mayor apego a los valores culturales tradicionales, dado por el uso frecuente del idioma materno en el 
hogar, parece contradecirse con el comportamiento de la fecundidad, situación que motivaria investigarse. Una posible hipotesis para explicar la contradicción guarda relación con el hecho de que la menor descendencla favoreceria un mantenimiento de la lengua mapuche, debido al contacto más reducido que ejercerfa la escuela como agente de introducción del castellano en estos hogares.

Puede concluirse con respecto a la fecundidad que, aunque estaria en descenso, su nivel expresaria todavia una alta capacidad de reemplazo de la población. La importancia central del comportamiento descendente de este componente demográfico y de sus discrepanclas observadas al interior de la población, obligan a investigar los factores asociados con su evolución.

En segundo lugar, se han podido obtener estimaciones del nivel de la mortalidad, como componente demográfico que influye sobre la dinámica de la población y que permite aproximarse a sus condiciones de salud. Los Indicadores respectivos señalan que, a pesar que se observaria una tendencia general en su mejoramiento, existiría una situación deteriorada con relación a la que se presenta en el contexto nacional. En efecto, la población de las reducciones seleccionadas viviria en promedio unos 63 años de vida, cifra que corresponde al valor que se estimaba para la población del pais en la segunda mitad de la década del 70. Del mismo modo, la mortalidad infantil indica que alrededor de 45 por cada mil nacidos vivos moririan antes de cumplir el primer año de vida (1985), cifra que es aproximadamente el doble de la que presenta el pais y casi cinco veces más alta que la que de algunas comunas del área oriente de Santiago.

En sintesis, las condiciones de mortalidad de la población de las reducciones indigenas seleccionadas son desfavorables con relación a las que existen en el pais en su conjunto, lo que sugiere que en éste existe una desigualdad ante la muerte según el grupo social.

En tercer lugar, la información que se ha manejado ha permitido detectar que la migración sería el componente demográfico de mayor gravitación sobre la dinámica de la población. Esto acontecerfa a través de la fuerte emigración, de orden selectivo, dada principalmente por mujeres en edades activas. Los indicios de este fenómeno son diversos, pero destaca la predominancia de la población masculina en casi todas las edades, fundamentalmente entre los grupos en edades activas. El efecto de la migración se expresaria no sólo en forma directa, por medio de la disminución de la población que se detecta en los últimos años, sino además, en forma indirecta, a través de la reducción del número de nacimientos que se produciria debido a la falta de mujeres en edades de mayor fecundidad. 
En sintesis, de persistir la fuerte emigración que se apreciaria en los últimos años, la población se reduciria en forma importante, anulando el comportamiento natural creciente producto de $1 a$ aun alta fecundidad. La importancia de este hallazgo, además, radica en el hecho de que se han podido confirmar, con alguna base, las numerosas hipótesis que en distintos momentos se han planteado sobre la migración como patrón de comportamiento social entre los mapuches.

Las tendencias descritas en cuanto a las variables demográficas determinan el crecimiento y la composición de la población por edad y sexo. Con respecto al crecimiento natural, se observa que, a pesar de la alta fecundidad, la combinación del efecto de una elevada mortalidad y la consecuencia indirecta de la emigración de mujeres en edades reproductivas, conducen a una tasa de crecimiento natural relativamente baja (13 por mil). Por su parte, el crecimiento total en los últimos años habria sido negativo, producto de la alta emigración de personas.

Asi también, como consecuencia de las tendencias de los componentes demográficos, especialmente de la alta fecundidad y la fuerte emigración, la composición de la población por grupos de edad muestra que poco más de un tercio es menor de 15 años de edad (igual a la IX Región), lo que la caracteriza como una población joven. Es destacable, además, la representación.de las personas mayores de 64 años de edad, con cast un 8 por ciento (mayor a la región), lo que es producto de una importante emigración de personas en edades activas.

Como efecto de la migración, la composición por sexo expresa un predominio masculino que es típico de zonas rurales, el que estaria en aumento en los últimos años.

Si se tiene en cuenta que la importante participación de ninos y ancianos en la estuctura etaria determina un alto indice de dependencia, se puede concluir que las necesidades de educación y salud que demanda esta población conformarian un objeto distintivo de preocupación inmediata.

Finalmente, uno de los aspectos posiblemente más destacables que han surgido del análisis de las caracteristicas demograficas, guarda relación con la importante emigración de personas desde las reducciones, en la medida que puede contribuir a la disminución sensible de la población, cuyos factores determinantes $y$ consecuencias debieran explorarse en el contexto historico, social y económico en que se inscribe la realidad de la población mapuche. 


\section{Bibliografla}

Babarovic, Ivo; Campaña, Pilar; Diaz, Cecilia y Durán, Esteban (1987), Campesinado mapuche y procesos socio-económicos regionales. Grupo de Investigaciones Agrarias, Santiago, AHC, Serie Docs. de Trabajo N2 34, agosto.

Bengoa, José (1983), El campesinado chileno después de la Reforma Agraria. Ediciones Sur, Santiago.

Centro Latinoamericano de Demografia (CELADE) (1987), América Latina; fecundidad 1950-2025. Santiago, Boletín Demográfico, Año XXI, $N^{2} 41$, enero.

Centro Latinoamericano de Demografia (CELADE) (1989), América Latina, Tablas de mortalidad. Santiago, Boletín Demográfico, Año XXII, N²4, julio.

Coale, Ansley J. y Demeny, Paul (1983), Regional model life tables and stable populations. Academic Press, New York, Second edition.

Instituto Nacional de Estadisticas (INE) (1984), Compendio estadistico 1984. INE, Santiago, mayo.

Instituto Nacional de Estadisticas (INE) (1987a), Total pais. Población XV Censo Nacional de Población y IV de Vivienda - Chile 1982. INE, Santiago, Tomo I, mayo.

Instituto Nacional de Estadisticas (INE) (1987b), Chile. Tablas abreviadas de mortalidad por sexo. Total pais y regiones 1980-1985. INE, Santiago, Fasciculo F/CHI. 2, agosto.

Instituto Nacional de Estadisticas (INE) (1987c), Chile, Proyecciones de población por sexo y edad, Regiones 1980-2000. INE, Santiago, Fasciculo F/CHI. 3, noviembre.

Instituto Nacional de Estadisticas (INE) (1988a), Compendio estadistico 1988. INE, Santiago.

Instituto Nacional de Estadisticas (INE) (1988b), Anuario de demografia 1985. INE, Santiago, marzo.

Instituto Nacional de Estadisticas (INE) (1989a), Chile, Proyecciones y estimaciones de población por sexo y edad. Total pais y regiones: 19802000 Urbano-Rural. INE, Santiago, Fasciculo F/CHI. 6, marzo.

Instituto Nacional de Estadisticas (INE) (1989b), Anuario de demografia 1987. INE, Santiago, abril.

Instituto Nacional de Estadisticas (INE) (1990), Anuario de demografia 1988. INE, Santiago, junio. 
Instituto Nacional de Estadisticas (INE); Centro Latinoamericano de Demografia (CELADE); Agencia Canadiense para el Desarrollo Internacional (ACDI) (1989), La transición de la fecundidad en Chile. Un anális is por grupos socioeconómicos y áreas geográficas 1950-1985. INE, Santiago, Fasciculo F/CHI. 7, marzo.

Leiva, Arturo (1985), Transformaciones en la situación social de la población mapuche. CEPAL, Santiago, División de Desarrollo Social, noviembre.

Martinez P., Jorge (1990), Patrones mlgratorios interregionales en Chile: análisis de casos seleccionados. CELADE, Santiago, (en prensa).

Mermoud, J. y Rodriguez, J. (1986), "Estudio comparativo de la evolución de las tasas de mortalidad. Chile-IX Región, perfodo 1960-1983". En Revista Médica del Sur, Vol. $11 \mathrm{~N}^{2} 2$, septiembre, pp. 67-69.

Naciones Unidas (1986), Manual $X$. Técnicas indirectas de estimación demográfica. Naciones Unidas, Nueva York, Depto. Asuntos Económicos y Sociales Internacionales, Estudios de Población $\mathrm{N}^{2} 81$.

Oyarce, Ana M.; Romaggi, Marisabel y Vidal, Aldo (1989), Cómo viven los mapuches. Análisis del Censo de Población de Chile de 1982. PAESMI, Santiago, Serie Docs. de Trabajo $\mathrm{N}^{2} 01$, enero.

Toro, Luis F. (1981), Chile; diferenciales de fecundidad y mortalidad por estrato social. CELADE, Santiago, Trabajo de Investigación Primer Año de Maestria, diciembre.

Toro, Luis F. (1982), Chile: diferenciales de fecundidad por estrato social y por contexto regional. CELADE, Santiago, Trabajo Final de Investigación, Maestria, diciembre.

Zambrano N., Mireya (1989), "Experiencias educativas en Chile". En D'Emilio, A. L. (comp.), Mujer indigena y educación en América Latina, UNESCO-OREALC, Santiago, junio, pp. 339-369. 


\section{Anexos}


ANEXO 1

REDUCCIONES INDIGENAS SELECCIONADAS:

ESTIMACIONES DE LA FECUNDIDAD A TRAVES DEL METODO P/F DE BRASS. CENSO DE 1988

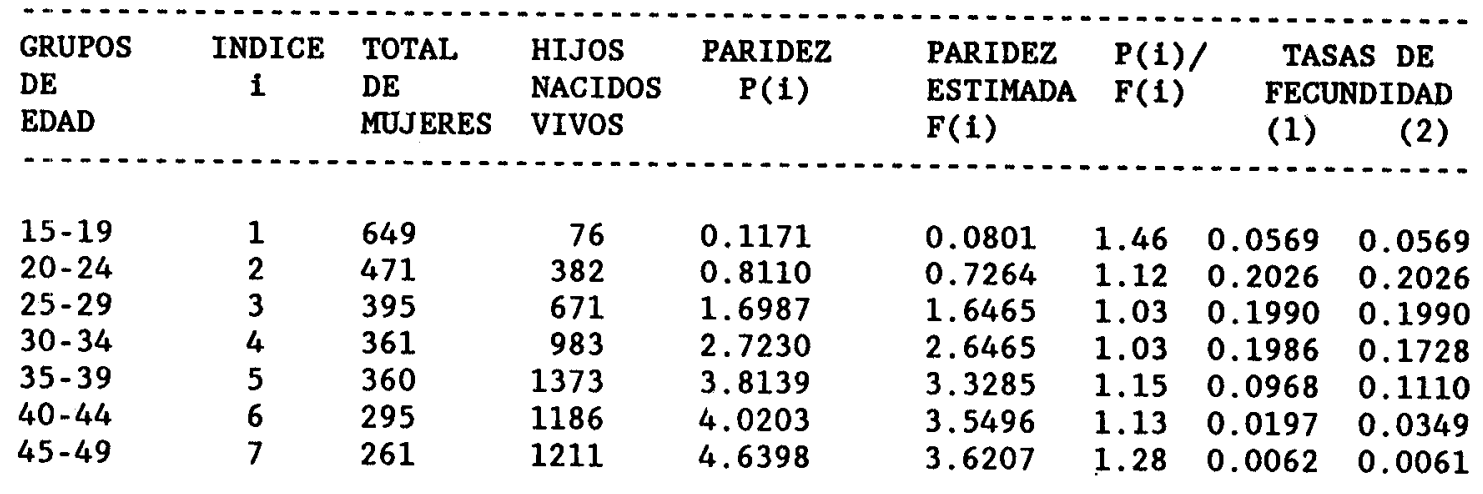

Fuente: Tabulados especiales Censo de 1988.

(1): Corregidas con (P2/F2 + P3/F3)/2 y con desplazamiento de medio año.

(2): Suavizadas con ajuste gráfico. 
ANEXO 2-A

REDUCCIONES INDIGENAS SELECCIONADAS Y IX REGION:

TASAS DE FECUNDIDAD Y ESTRUCTURA RELATIVA POR GRUPOS QUINQUENALES DE EDAD DE LAS MUJERES. 1982

\begin{tabular}{|c|c|c|c|c|}
\hline $\begin{array}{l}\text { GRUPOS DE } \\
\text { EDAD }\end{array}$ & \multicolumn{2}{|c|}{ REDUCCIONES INDIGENAS ( 1 ) } & \multicolumn{2}{|c|}{ IX REGION (2) } \\
\hline $15-19$ & 0.0913 & 10.75 & 0.0834 & 11.07 \\
\hline $20-24$ & 0.2073 & 24.42 & 0.2020 & 26.80 \\
\hline $25-29$ & 0.1888 & 22.24 & 0.1975 & 26.21 \\
\hline $30-34$ & 0.1683 & 19.82 & 0.1432 & 19.00 \\
\hline $35-39$ & 0.1168 & 13.76 & 0.0871 & 11.56 \\
\hline $40-44$ & 0.0639 & 7.53 & 0.0345 & 4.58 \\
\hline $45-49$ & 0.0126 & 1.48 & 0.0059 & 0.78 \\
\hline
\end{tabular}

Tasa Global

de Fecundidad

(TGF)

4.3100 .00

$3.8 \quad 100.00$

Fuente: (1) Tabulados especiales Censo Nacional de 1982. Tasas corregidas por el método $\mathrm{P} / \mathrm{F}$, utilizando la estructura de la fecundidad del total de reducciones de la IX Región.

(2) Estimación de INE (1987c) para el quinquenio 1980-1985. 
ANEXO 2-B

REDUCCIONES INDIGENAS SELECCIONADAS Y IX REGION:

TASAS DE FECUNDIDAD Y ESTRUCTURA RELATIVA POR GRUPOS QUINQUENALES DE EDAD DE LAS MUJERES. 1988

\begin{tabular}{|c|c|c|c|c|}
\hline GRUPOS DE & REDUCCIONES & S INDIGENAS (1) & IX REGI & (2) \\
\hline EDAD & TASA & 8 & TASA & 8 \\
\hline $15-19$ & 0.0569 & 7.26 & 0.0713 & 11.37 \\
\hline $20-24$ & 0.2026 & 25.86 & 0.1679 & 26.78 \\
\hline $25-29$ & 0.1990 & 25.41 & 0.1569 & 25.03 \\
\hline $30-34$ & 0.1728 & 22.06 & 0.1249 & 19.92 \\
\hline $35-39$ & 0.1110 & 14.17 & 0.0756 & 12.06 \\
\hline $40-44$ & 0.0349 & 4.46 & 0.0247 & 3.94 \\
\hline $45-49$ & 0.0061 & 0.78 & 0.0056 & 0.89 \\
\hline
\end{tabular}

Tasa Global

de Fecundidad (TGF)

Fuente: (1) Anexo 1 .

(2) Estimación realizada a partir del promedio de nacidos vivos entre 1987-1988 (INE, 1989b y 1990), corregidos con 25 por ciento de inscripciones tardías. Población femenina de INE (1987c). 
ANEXO 3-A

REDUCCIONES INDIGENAS SELECCIONADAS: INFORMACION BASICA DE MORTALIDAD Y PARIDEZ MEDIA POR GRUPOS QUINQUENALES DE EDAD, SEGUN EDUCACION DE 0-3 AÑOS DE ESTUDIO APROBADOS DE LA MADRE. CENSO DE 1988

$\begin{array}{lccccc}\begin{array}{l}\text { GRUPOS DE } \\ \text { EDAD }\end{array} & \begin{array}{c}\text { TOTAL } \\ \text { MUJERES }\end{array} & \begin{array}{c}\text { MUJERES CON } \\ \text { DECLARACION }\end{array} & \begin{array}{c}\text { HIJOS NACIDOS VIVOS } \\ \text { TOTAL }\end{array} \\ \text { MUERTOS } & \begin{array}{c}\text { PARIDEZ } \\ \text { MEDIA }\end{array} \\ 15-19 & 36 & 36 & 10 & 3 & 0.28 \\ 20-24 & 65 & 65 & 82 & 6 & 1.26 \\ 25-29 & 78 & 78 & 142 & 6 & 1.82 \\ 30-34 & 107 & 107 & 326 & 17 & 3.05 \\ 35-39 & 173 & 173 & 709 & 52 & 4.10 \\ 40-44 & 167 & 167 & 743 & 76 & 4.45 \\ 45-49 & 176 & 176 & 873 & 96 & 4.96 \\ 50-54 & 210 & 210 & 1280 & 176 & 6.10 \\ 55-59 & 183 & 182 & 1110 & 209 & 6.07 \\ 60 \text { y más } & 642 & 642 & 3869 & 996 & 6.03 \\ \text { Ignorado } & 6 & 6 & 33 & 7 & \\ & & & & & \end{array}$

Fuente: Tabulados especiales Censo de 1988. 
ANEXO 3-B

REDUCCIONES INDIGENAS SELECCIONADAS: INFORMACION BASICA DE MORTALIDAD Y PARIDEZ MEDIA POR GRUPOS QUINQUENALES DE EDAD, SEGUN EDUCACION

DE 4-6 AÑOS DE ESTUDIO APROBADOS DE LA MADRE. CENSO DE 1988

\begin{tabular}{|c|c|c|c|c|c|}
\hline $\begin{array}{l}\text { GRUPOS DE } \\
\text { EDAD }\end{array}$ & $\begin{array}{c}\text { TOTAL } \\
\text { MUJERES }\end{array}$ & $\begin{array}{l}\text { MUJERES CON } \\
\text { DECLARACION }\end{array}$ & $\begin{array}{c}\text { HIJOS NA } \\
\text { TOTAL }\end{array}$ & $\begin{array}{l}\text { IDOS VIVOS } \\
\text { MUERTOS }\end{array}$ & $\begin{array}{l}\text { PARIDEZ } \\
\text { MEDIA }\end{array}$ \\
\hline $15-19$ & 232 & 231 & 34 & 0 & 0.15 \\
\hline $20-24$ & 177 & 177 & 166 & 6 & 0.94 \\
\hline $25-29$ & 177 & 177 & 362 & 26 & 2.05 \\
\hline $30-34$ & 175 & 175 & 480 & 28 & 2.74 \\
\hline $35-39$ & 155 & 155 & 576 & 35 & 3.72 \\
\hline $40-44$ & 102 & 102 & 382 & 44 & 3.75 \\
\hline $45-49$ & 75 & 75 & 306 & 30 & 4.08 \\
\hline $50-54$ & 61 & 61 & 292 & 39 & 4.79 \\
\hline $55-59$ & 52 & 52 & 252 & 40 & 4.85 \\
\hline 60 y más & 83 & 82 & 446 & 97 & 5.37 \\
\hline TOTAL & 1289 & 1287 & 3296 & 345 & \\
\hline
\end{tabular}

Fuente: Tabulados especiales Censo de 1988. 
ANEXO 3-C

REDUCCIONES INDIGENAS SELECCIONADAS: INFORMACION BASICA DE MORTALIDAD Y PARIDEZ MEDIA POR GRUPOS QUINQUENALES DE EDAD, SEGUN EDUCACION DE 7 Y MAS AÑOS DE ESTUDIO APROBADOS DE LA MADRE. CENSO DE 1988

\begin{tabular}{|c|c|c|c|c|c|}
\hline $\begin{array}{l}\text { GRUPOS DE } \\
\text { EDAD }\end{array}$ & $\begin{array}{c}\text { TOTAL } \\
\text { MUJERES }\end{array}$ & $\begin{array}{l}\text { MUJERES CON } \\
\text { DECLARACION }\end{array}$ & $\begin{array}{c}\text { HIJOS NA } \\
\text { TOTAL }\end{array}$ & $\begin{array}{l}\text { CIDOS VIVOS } \\
\text { MUERTOS }\end{array}$ & $\begin{array}{l}\text { PARIDEZ } \\
\text { MEDIA }\end{array}$ \\
\hline $15-19$ & 381 & 379 & 32 & 5 & 0.08 \\
\hline $20-24$ & 227 & 227 & 130 & 4 & 0.57 \\
\hline $25-29$ & 138 & 137 & 163 & 8 & 1.18 \\
\hline $30-34$ & 79 & 79 & 177 & 12 & 2.24 \\
\hline $35-39$ & 31 & 31 & 88 & 6 & 2.84 \\
\hline $40-44$ & 25 & 25 & 57 & 4 & 2.28 \\
\hline $45-49$ & 8 & 8 & 19 & 1 & 2.38 \\
\hline $50-54$ & 4 & 4 & 16 & 2 & 4.00 \\
\hline $55-59$ & 2 & 2 & 13 & 4 & 6.50 \\
\hline 60 y más & 7 & 7 & 44 & 5 & 6.29 \\
\hline TOTAL & 902 & 899 & 739 & 51 & \\
\hline
\end{tabular}

Fuente: Tabulados especiales Censo de 1988. 
ANEXO 3-D

REDUCCIONES INDIGENAS SELECCIONADAS: PARIDEZ MEDIA DE POBLACION FEMENINA POR GRUPOS QUINQUENALES DE EDAD, SEGUN TOTAL DE MUJERES Y AÑOS DE ESTUDIO APROBADOS . CENSO NACIONAL DE 1982 *

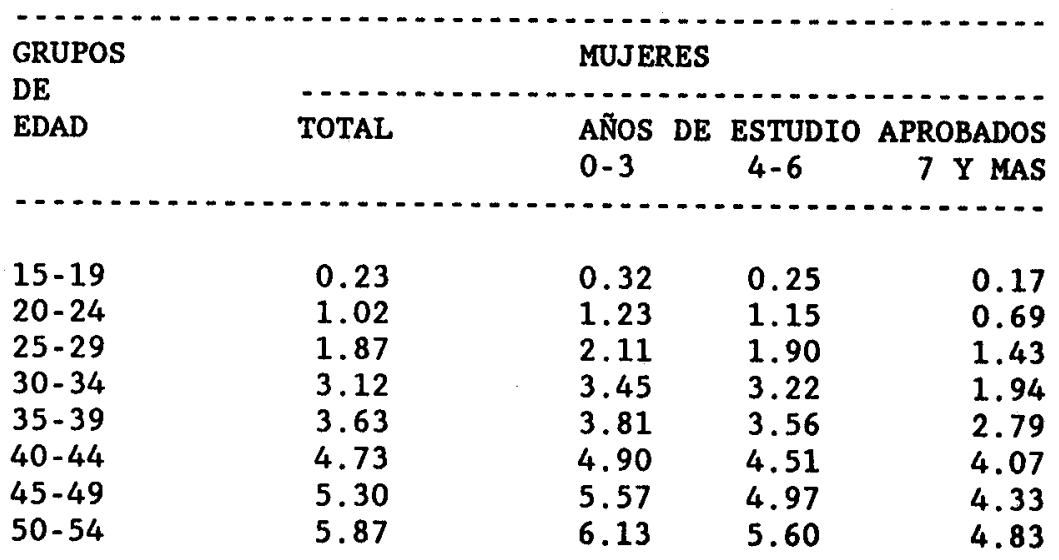

Fuente: Tabulados especiales Censo Nacional de 1982.

*: Mujeres con declaración de hijos nacidos vivos y sobrevivientes. 
ANEXO 4-A

REDUCCIONES INDIGENAS SELECCIONADAS: INFORMACION BASICA DE MORTALIDAD Y PARIDEZ MEDIA POR GRUPOS QUINQUENALES DE EDAD, SEGUN LENGUA MAPUCHE HABLADA CON MAS FRECUENCIA EN EL HOGAR DE LA MADRE. CENSO DE 1988

\begin{tabular}{|c|c|c|c|c|c|}
\hline $\begin{array}{l}\text { GRUPOS DE } \\
\text { EDAD }\end{array}$ & $\begin{array}{l}\text { TOTAL } \\
\text { MUJERES }\end{array}$ & $\begin{array}{l}\text { MUJERES CON } \\
\text { DECLARACION }\end{array}$ & $\begin{array}{c}\text { HIJOS N } \\
\text { TOTAL }\end{array}$ & $\begin{array}{l}\text { IDOS VIVOS } \\
\text { MUERTOS }\end{array}$ & $\begin{array}{l}\text { PARIDEZ } \\
\text { MEDIA }\end{array}$ \\
\hline $15-19$ & 53 & 53 & 6 & 0 & 0.11 \\
\hline $20-24$ & 46 & 46 & 23 & 1 & 0.50 \\
\hline $25-29$ & 32 & 32 & 41 & 4 & 1.28 \\
\hline $30-34$ & 23 & 23 & 64 & 2 & 2.78 \\
\hline $35-39$ & 17 & 17 & 43 & 3 & 2.53 \\
\hline $40-44$ & 13 & 13 & 56 & 10 & 4.31 \\
\hline $45-49$ & 23 & 23 & 104 & 19 & 4.52 \\
\hline $50-54$ & 29 & 29 & 120 & 12 & 4.14 \\
\hline $55-59$ & 32 & 32 & 147 & 28 & 4.59 \\
\hline 60 y más & 138 & 138 & 747 & 195 & 5.41 \\
\hline ignorado & 2 & 2 & 9 & 1 & \\
\hline COTAL & 408 & 408 & 1360 & 275 & \\
\hline
\end{tabular}

Fuente: Tabulados especiales Censo de 1988. 
ANEXO 4-B

REDUCCIONES INDIGENAS SELECCIONADAS: INFORMACION BASICA DE MORTALIDAD Y PARIDEZ MEDIA POR GRUPOS QUINQUENALES DE EDAD, SEGUN LENGUA MAPUCHE $Y$ CASTELIANO HABLADA CON MAS FRECUENCIA EN EL HOGAR DE LA MADRE. CENSO DE 1988

$\begin{array}{lccrrr}\begin{array}{l}\text { GRUPOS DE } \\ \text { EDAD }\end{array} & \begin{array}{c}\text { TOTAL } \\ \text { MUJERES }\end{array} & \begin{array}{c}\text { MUJERES CON } \\ \text { DECLARACION }\end{array} & \begin{array}{c}\text { HIJOS NACIDOS VIVOS } \\ \text { TOTAL }\end{array} \text { MUERTOS } & \begin{array}{c}\text { PARIDEZ } \\ \text { MEDIA }\end{array} \\ 15-19 & 321 & 319 & 35 & 7 & 0.11 \\ 20-24 & 197 & 197 & 165 & 8 & 0.84 \\ 25-29 & 171 & 170 & 293 & 19 & 1.71 \\ 30-34 & 187 & 187 & 520 & 34 & 2.78 \\ 35-39 & 187 & 187 & 722 & 44 & 3.86 \\ 40-44 & 155 & 155 & 651 & 62 & 4.20 \\ 45-49 & 133 & 133 & 594 & 53 & 4.47 \\ 50-54 & 140 & 140 & 794 & 115 & 5.67 \\ 55-59 & 116 & 116 & 669 & 126 & 5.77 \\ 60 \text { y más } & 385 & 384 & 2293 & 606 & 6.00 \\ \text { ignorado } & 3 & 3 & 14 & 3 & \\ & & & & & \end{array}$

Fuente: Tabulados especiales Censo de 1988. 


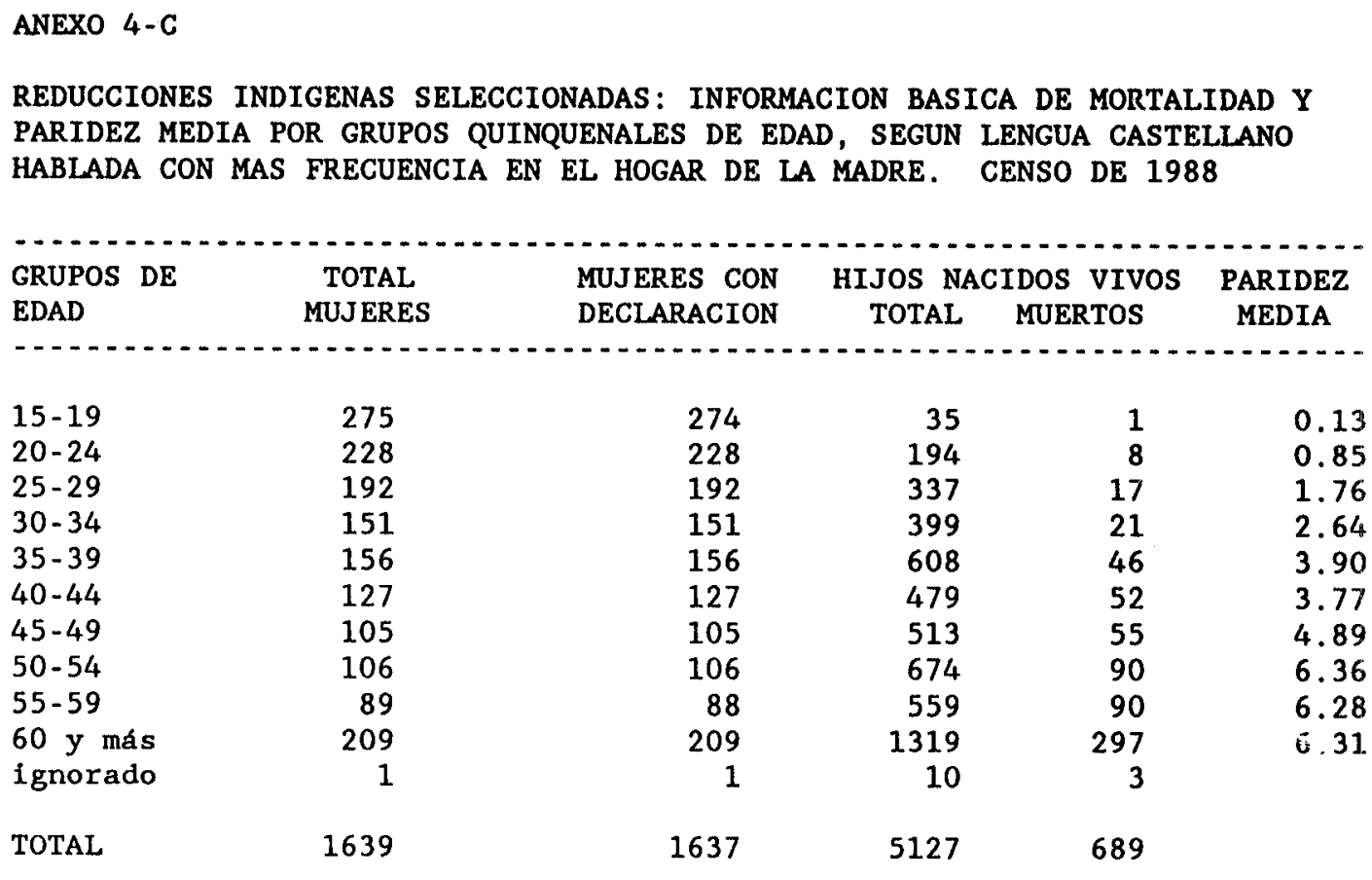

Fuente: Tabulados especiales Censo de 1988. 
ANEXO 5

REDUCCIONES INDIGENAS SELECCIONADAS: ESTIMACIONES DE MORTALIDAD INFANTIL Y JUVENIL, MODELO OESTE DE COALE Y DEMENY. CENSO DE 1988

\begin{tabular}{|c|c|c|c|c|c|c|c|}
\hline I & $D(I)$ & $\mathrm{x}$ & $Q(X)$ & N. C\&D & FECHA & $Q(1)$ & $Q(2)$ \\
\hline 1 & 0.10526 & 1 & 0.11753 & 13.84 & 1987.95 & 0.11753 & 0.14552 \\
\hline 2 & 0.04450 & 2 & 0.04685 & 20.44 & 1986.65 & 0.04182 & 0.0468 \\
\hline 3 & 0.05961 & 3 & 0.05930 & 19.73 & 1984.66 & 0.04906 & 0.05586 \\
\hline 4 & 0.05799 & 5 & 0.05809 & 20.08 & 1982.27 & 0.04542 & 0.05125 \\
\hline 5 & 0.06773 & 10 & 0.06898 & 19.76 & 1979.63 & 0.04878 & 0.05549 \\
\hline 6 & 0.10455 & 15 & 0.10516 & 18.11 & 1976.82 & 0.06617 & 0.07790 \\
\hline 7 & 0.10487 & 20 & 0.10468 & 18.59 & 1973.87 & 0.06096 & 0.07116 \\
\hline
\end{tabular}

Fuente: Tabulados especiales Censo de 1988.

P1/P2 $=0.1444 \quad$ P2/P3 $=0.4774$

I: Grupos quinquenales de edad de la madre (15-19 a 45-49 años)

$D(I)$ : $\quad$ Proporción de hijos muertos sobre nacidos vivos

$X$ : $\quad$ Edad exacta desde el nacimiento hasta $X$

$\mathrm{Q}(\mathrm{X})$ : $\quad$ Probabilidad de muerte desde el nacimiento hasta la edad exacta $\mathrm{X}$

N.C\&D: Nivel de mortalidad de tabla modelo de Coale y Demeny

$Q(1) \mathrm{y}$

$Q(2):$

Probabilidad de muerte desde el nacimiento hasta la edad exacta 1 año (mortalidad infantil) y 2 años 
ANEXO 6

REDUCCIONES INDIGENAS SELECCIONADAS:

ANTECEDENTES DE POBLACION Y MIGRACION NETA POR SEXO. 1982-1988

$\begin{array}{cccccc} & \text { POBLACION } & \text { POBLACION } & \text { POBLACION } & \text { MIGRACION } & \text { TASA DE } \\ \text { SEXO } & \text { CENSADA } & \text { CENSADA } & \text { ESPERADA } & \text { NETA } & \text { CRECIM. } \\ & 1982 & 1988 & 1988 & 1982-1988 & \text { NATURAL }\end{array}$
(1)
(2)
(3)
(4)
(5)

$\begin{array}{llllll}\text { HOMBRES } & 7775 & 6763 & 8502 & 1739 & 15.0 \\ \text { MUJERES } & 7336 & 6189 & 8021 & 1832 & 15.0\end{array}$

AMBOS

SEXOS

15111

12952

16523

3561

15.0

Fuente: (1) Tabulados especiales Censo Nacional de 1982.

(2) Anexo 7.

(3) Columna (1)* $(1+0.015)^{6}$.

(4) Columna (3) - columna (2).

(5) Por mil, según tasa de crecimiento natural de todas las reducciones en 1982 y el valor estimado en 1988 para las reducciones seleccionadas ( 13 por mil). 
ANEXO 7

REDUCCIONES INDIGENAS SELECCIONADAS:

POBLACION POR GRUPOS QUINQUENALES DE EDAD, SEGUN SEXO.

CENSO DE 1988

\begin{tabular}{|c|c|c|c|c|c|c|}
\hline \multirow{4}{*}{$\begin{array}{l}\text { GRUPOS } \\
\text { DE } \\
\text { EDAD }\end{array}$} & \multicolumn{6}{|c|}{ 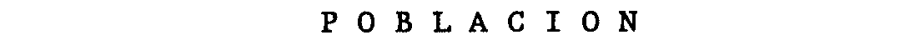 } \\
\hline & $\ldots$ & - & & & $\cdots$ & 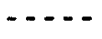 \\
\hline & \multicolumn{2}{|c|}{ AMBOS SEXOS } & \multicolumn{2}{|c|}{ HOMBRES } & \multicolumn{2}{|c|}{ MUJERES } \\
\hline & $\mathrm{N}^{2}$ & 8 & $\mathrm{~N}^{2}$ & 8 & $\mathrm{~N}^{2}$ & 8 \\
\hline $0-4$ & 1389 & 10.7 & 721 & 10.7 & 668 & 10.8 \\
\hline $5-9$ & 1468 & 11.3 & 736 & 10.9 & 732 & 11.8 \\
\hline $10-14$ & 1581 & 12.2 & 834 & 12.3 & 747 & 12.1 \\
\hline $15-19$ & 1405 & 10.9 & 756 & 11.2 & 649 & 10.5 \\
\hline $20-24$ & 1123 & 8.7 & 652 & 9.6 & 471 & 7.6 \\
\hline $25-29$ & 897 & 6.9 & 502 & 7.4 & 395 & 6.4 \\
\hline $30-34$ & 767 & 5.9 & 406 & 6.0 & 361 & 5.8 \\
\hline $35-39$ & 730 & 5.6 & 370 & 5.5 & 360 & 5.8 \\
\hline $40-44$ & 584 & 4.5 & 289 & 4.3 & 295 & 4.8 \\
\hline $45-49$ & 577 & 4.5 & 316 & 4.7 & 261 & 4.2 \\
\hline $50-54$ & 533 & 4.1 & 258 & 3.8 & 275 & 4.4 \\
\hline $55-59$ & 485 & 3.7 & 248 & 3.7 & 237 & 3.8 \\
\hline $60-64$ & 435 & 3.4 & 206 & 3.1 & 229 & 3.7 \\
\hline $65-69$ & 351 & 2.7 & 170 & 2.5 & 181 & 2.9 \\
\hline $70-74$ & 244 & 1.9 & 135 & 2.0 & 109 & 1.8 \\
\hline $75-79$ & 185 & 1.4 & 89 & 1.3 & 96 & 1.6 \\
\hline $80-84$ & 90 & 0.7 & 40 & 0.6 & 50 & 0.8 \\
\hline $85-89$ & 57 & 0.4 & 22 & 0.3 & 35 & 0.6 \\
\hline $90-94$ & 29 & 0.2 & 8 & 0.1 & 21 & 0.3 \\
\hline 95 y más & 22 & 0.2 & 5 & 0.1 & 17 & 0.3 \\
\hline Total & 12952 & 100.0 & 6763 & 100.0 & 6189 & 100.0 \\
\hline
\end{tabular}

Fuente: Tabulados especiales Censo de 1988. 
ANEXO 8-A

REDUCCIONES INDIGENAS SELECCIONADAS: TABLA ABREVIADA DE MORTALIDAD FEMENINA 1988

\begin{tabular}{|c|c|c|c|c|c|c|c|c|c|}
\hline EDAD & $\mathbf{n}$ & $\mathrm{m}(\mathrm{x}, \mathrm{n})$ & $q(x, n)$ & $1(x)$ & $d(x, n)$ & $L(x, n)$ & $T(x)$ & $e(x)$ & $P(x, x+n)$ \\
\hline & & & & & & & & $P(b):$ & \\
\hline 0 & 1 & 0.042 .11 & 0.04069 & 100000 & 4069 & 96631 & 6503996 & & 0. \\
\hline 1 & 4 & 0.0 & 0.0 & 95931 & 1238 & 380 & & 66 & \\
\hline 5 & 5 & 0.00102 & 0.00507 & 94693 & 480 & 472262 & 9 & 63 & 0 \\
\hline 10 & 5 & 0.00080 & 0.00397 & 94212 & 374 & 470127 & 5554 & 6 & \\
\hline 15 & 5 & 0.00208 & 0.01036 & 93838 & 972 & 466762 & 5084399 & 8 & 2 \\
\hline 20 & 5 & 0.00278 & 0.01382 & 92866 & 1283 & 461123 & 4617637 & 12 & 6 \\
\hline 25 & 5 & 0.00324 & 0.01608 & 91583 & 1473 & 454233 & 4156515 & 39 & 7 \\
\hline 30 & 5 & 0.00375 & 0.01860 & 90110 & 1676 & 446361 & 3702282 & 41 & 5 \\
\hline 35 & 5 & 0.0 & 0.0 & 88434 & 1940 & 437320 & 3255921 & 36.82 & 576 \\
\hline 40 & 5 & 0.0 & 0.0 & 86494 & 2301 & 426718 & 2818601 & 32.59 & 964 \\
\hline 45 & 5 & 0.0 & 0. & 841 & 28 & 4137 & 2391884 & 28.41 & 0.95909 \\
\hline 50 & 5 & 0. & 0.0 & 813 & 388 & 3968 & 1978 & 24.33 & 266 \\
\hline 55 & 5 & 0 . & 0. & 774 & 521 & 374 & 1581283 & 20.42 & 595 \\
\hline 60 & 5 & 0 . & & 722 & 7364 & 3426 & 1207201 & 16.72 & 0.87301 \\
\hline 65 & 5 & 0 . & 0.1 & 64846 & 10041 & 2991 & 864561 & 13.33 & 0.80586 \\
\hline 70 & 5 & 0 . & 0.2 & 548 & 13188 & 241056 & 565432 & 10.32 & 0.70699 \\
\hline 75 & 5 & 0.0 & 0.3 & 41617 & 15065 & 170423 & 324377 & 7.79 & 0.57872 \\
\hline 80 & 5 & 0.1 & 0.5 & 26552 & 13654 & 98627 & 153953 & 5.80 & 0.42860 \\
\hline 85 & 5 & 0.2 & 0.6 & 12898 & 888 & 42272 & 55326 & 4.29 & 0.27300 \\
\hline 90 & 5 & 0.2 & 0.8 & 4010 & 3405 & 11540 & 13054 & 3.26 & \\
\hline 95 & w & 0.40000 & 1.00000 & 606 & 606 & 1514 & 1514 & 2.50 & \\
\hline & & & & & & & & 10 & .11000 \\
\hline
\end{tabular}

$f(0)=0.1721 ; f(1-4)=1.4579$ (factores de separacion)

$\mathrm{n}$ : Intervalo de edad

$\mathrm{m}(\mathrm{x}, \mathrm{n}): \quad$ Tasa central de mortalidad

$q(x, n): \quad$ Probabilidad de morir de una persona de edad exacta $x$ en los $n$ años siguientes

1(x): $\quad$ Número de personas que alcanza la edad exacta $x$

$\mathrm{d}(\mathrm{x}, \mathrm{n})$ : Número de muertes entre los componentes del grupo $1(\mathrm{x})$ antes de llegar a la edad exacta $x+n$

$L(x, n): \quad$ Tiempo vivido entre las edades exactas $x y+n$

$\mathrm{T}(\mathrm{x})$ : $\quad$ Tiempo vivido entre edad exacta $\mathrm{x} y$ w (edad en la cual no quedan sobrevivientes)

$e(x)$ : Esperanza de vida o promedio de años que resta por vivir a los componentes del grupo 1(x)

$P(x, x+n):$ Relación de supervivencia entre edad exacta $x$ y $x+n-1$ 
ANEXO 8-B

REDUCCIONES INDIGENAS SELECCIONADAS: TABLA ABREVIADA DE MORTALIDAD MASCULINA 1988

\begin{tabular}{|c|c|c|c|c|c|c|c|c|c|}
\hline EDAD & $\mathrm{n}$ & $m(x, n)$ & $q(x, n)$ & $1(x)$ & $d(x, n)$ & $L(x, n)$ & $T(x)$ & $e(x)$ & $P(x, x+n)$ \\
\hline & & & & & & & & $P(\mathrm{~b}):$ & \\
\hline 0 & 1 & 0.05464 & 0.05233 & 100000 & 5233 & 95777 & 6150863 & 51 & 1721 \\
\hline 1 & 4 & 0.00376 & 0.01491 & 94767 & 1413 & 375529 & 6055086 & 63.89 & \\
\hline 5 & 5 & 0.00128 & 0.00639 & 93354 & 597 & 465279 & 5679557 & 60.84 & 0.99432 \\
\hline 10 & 5 & 0.00100 & 0.00497 & 92757 & 461 & 462635 & 5214278 & 56.21 & 0.99325 \\
\hline 15 & 5 & 0.00171 & 0.00853 & 92296 & 787 & 459514 & 4751643 & 51.48 & 0.98726 \\
\hline 20 & 5 & 0.00343 & 0.01699 & 91509 & 1555 & 453659 & 4292129 & 46.90 & 0.98249 \\
\hline 25 & 5 & 0.00364 & 0.01803 & 89954 & 1622 & 445718 & 3838469 & 42.67 & 0.98075 \\
\hline 30 & 5 & 0.00414 & 0.02049 & 88333 & 1810 & 437138 & 3392752 & 38.41 & 0.97723 \\
\hline 35 & 5 & 0.0 & 0.02510 & 86523 & 2172 & 427184 & 2955614 & 34.16 & 0.97098 \\
\hline 40 & 5 & 0.0 & 0.0 & 84351 & 2788 & 414785 & 2528430 & 29.98 & 0.96092 \\
\hline 45 & 5 & 0.0 & 532 & 81563 & 3696 & 398575 & 2113645 & 25.91 & 4517 \\
\hline 50 & 5 & 0.0 & 480 & 77867 & 5046 & 376719 & 1715070 & 22.03 & 0.92143 \\
\hline 55 & 5 & 0.01957 & 0.09329 & 72821 & 6793 & 347121 & 1338351 & 18.38 & 0.88603 \\
\hline 60 & 5 & 0.02936 & 0.13678 & 66027 & 9031 & 307559 & 991230 & 15.01 & 478 \\
\hline 65 & 5 & 0.04399 & 0.19817 & 56996 & 11295 & 256744 & 683671 & 12.00 & 0.76169 \\
\hline 70 & 5 & 0.06739 & 0.28836 & 45701 & 13178 & 195560 & 426927 & 9.34 & 5994 \\
\hline 75 & 5 & 0.10400 & 0.41270 & 32523 & 13422 & 129059 & 231367 & 7.11 & 3182 \\
\hline 80 & 5 & 0.15658 & 0.56265 & 19101 & 10747 & 68636 & 102308 & 5.36 & 687 \\
\hline 85 & 5 & 0.22921 & 0.72856 & 8354 & 6086 & 26553 & 33672 & 4.03 & 0.24081 \\
\hline 90 & 5 & 0.30925 & 0.87205 & 2268 & 1977 & 6394 & 7119 & 3.14 & \\
\hline 95 & w & 0.40000 & 1.00000 & 290 & 290 & 725 & 725 & 2.50 & \\
\hline & & & & & & & \multicolumn{2}{|c|}{$P(90, w):$} & 0.10188 \\
\hline
\end{tabular}

$f(0)=0.1929 ; f(1-4)=1.4953$ (factores de separación)

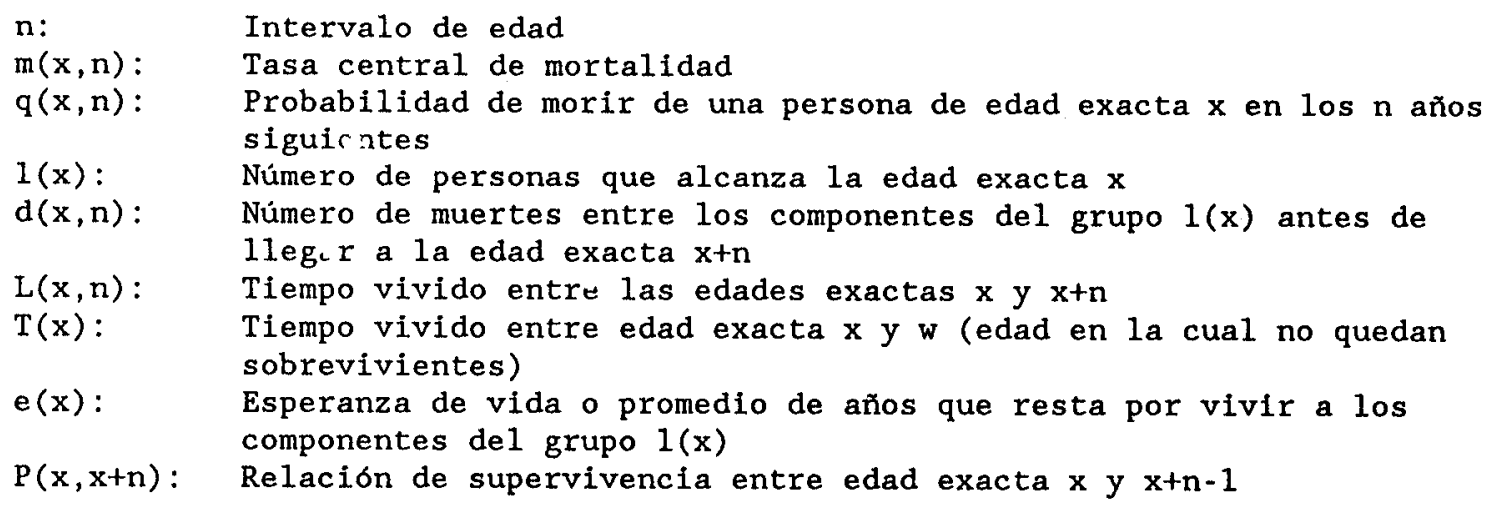




\title{
II. MORTALIDAD Y ATENCION DE SALUD MATERNO INFANTIL.
}

\author{
Susana Schkolnik" \\ Ana M. Oyarce*
}

\section{Introducción}

En este capitulo se tratarán los temas relacionados con mortalidad y atención de salud materno-infantil en la población de las reducciones indigenas censadas en 1988, pertenecientes a los distritos de Labranza, Molco, Maquehue y Metrenco de la Provincia de Cautin, IX Región.

Se presenta un análisis de la mortalidad infantil y materna, variables que pueden considerarse como indicadores del estado de salud de una población. Las estimaciones correspondientes se obtuvieron mediante la aplicación de métodos indirectos, a partir de información retrospectiva basada en preguntas formuladas en el Censo de Reducciones Indigenas Seleccionadas de 1988. Si bien en el Capitulo Caracteristicas Demográficas se han presentado las estimaciones de mortalidad infantil para el total de la población, asi como sus tendencias en el tiempo, aqui se ha tratado de identificar al interior de la población aquellos grupos que pudieran caracterizarse como de mayor vulnerabilidad ante la muerte. Se examinarán, en consecuencia, algunos diferenciales socioculturales de esta variable, tales como la educación de la madre y la lengua hablada más frecuentemente en el hogar, ésta última como indicador de apego a diferentes ámbitos culturales. Sobre mortalidad materna, por su parte, se presentarán las estimaciones obtenidas y se examinará su impacto en la población bajo estudio.

Centro Latinoamericano de Demografia.

- Programa de Apoyo y Extensión en Salud Materno Infantil y Universidad de La Frontera, Temuco. 
En cuanto a la atención de salud, se buscó investigar, con un carácter exploratorio, cuál era el tipo de atención al que esta población se orientaba predominantemente, asi como algunas caracteristicas de las usuarias, teniendo en cuenta la coexistencia de diferentes sistemas médicos en el medio estudiado. Para ésto, el análisis se baso en información acerca de la atención profesional en el parto y del tipo de atención recibida por el último hijo nacido vivo de las mujeres entrevistadas, en los casos en que éste hubiera fallecido. Esta información se analizó también con relación a la edad y la educación de las madres, asi como con respecto a la lengua hablada más frecuentemente en el hogar.

\section{Mortalidad infantil}

Los niveles de mortalidad infantil en una zona determinada son producto de un complejo conjunto de condiciones sociales, culturales, económicas, ambientales, etc. En consecuencia, encontrar diferencias entre los sectores sociales, las áreas geográficas o los grupos étnico-culturales dentro de un pais es muy común, especialmente en los países subdesarrollados, donde los recursos no son distribuidos en forma equitativa entre sus habitantes.

Parece obvio, pero no puede dejar de mencionarse, que la pobreza es el principal factor al que puede hacerse responsable de la mayoria de las defunciones tanto maternas como infantiles. Esto significa, en la mayor parte de los casos, falta de recursos económicos, una salud precaria, falta de educación, desconocimiento de las acciones a seguir y, finalmente, acceso insuficiente a la atención médica. Hay también factores de riesgo que se ven acentuados por esta situación: nacimientos muy seguidos, fecundidad en los extremos del período reproductivo (menos de 20 y más de 35 años de edad) y un número muy elevado de hijos. En el caso de los niños, un bajo peso al nacer, como consecuencia de lo anterior, limita sus posibilidades de supervivencia.

También hay que mencionar que no es sólo la muerte, sino que también hay un número significativo de mujeres y niños que, por estas mismas complicaciones, sufre otros daños permanentes a la salud, aunque su incidencia es muy dificil de estimar debido a que las estadisticas de morbilidad, son, por 10 general, incompletas.

La estimación de los niveles y tendencias de la mortalidad infantil, a partir de la información obtenida en el Censo de 1988, se obtuvo mediante la aplicación de un método indirecto de estimación propuesto por Brass y actualizado 
por Trusse11.' Esta metodologia ha permitido observar que la tasa de mortalidad infantil alrededor del año 1985 era de aproximadamente 45 por mil nacidos vivos en estas reducciones, siendo más elevada que la de la IX Región en su conjunto (32 por mil) y más del doble que la del total del pais (20 por mil) en la misma fecha. ${ }^{2}$

En diversos estudios se ha mostrado la asociación existente entre la mortalidad infantil y algunas variables socioeconómicas (como por ejemplo, la educación de la madre y el nivel socioeconómico del hogar), asi como con indicadores de las condiciones materiales de vida (vivienda, saneamiento ambiental, etc.). A nivel nacional, donde pueden distinguirse diferentes estratos socioeconómicos, como en los casos de Bolivia, Paraguay y paises de América Central, estas asociaciones han sido evidentes (CELADE-UNICEF, 1985; CELADE, 1986; CELADE-UNICEF-OPS, 1989).

En el caso de las reducciones indigenas estudiadas, sin embargo, se ha observado que, en general, la población es bastante homogénea tanto en algunas de sus caracteristicas personales como en las condiciones materiales de vida, y ésto ha hecho dificil la identificación de los diferenciales mencionados. En cuanto a las condiciones de vida, por ejemplo, la situación es bastante similar en el conjunto de los hogares: el 80 por ciento de la población activa se ocupa en actividades agropecuarias, predominando los trabajadores por cuenta propia y familiares no remunerados, tipicos de las economías de subsistencia; en general, la población posee una baja escolaridad, ya que la mayoria de las mujeres de mayor instrucción alcanzan como máximo la enseñanza básica completa; e1 agua que se consume en los hogares proviene casi en un 90 por ciento de los casos directamente de "pozo", ya sea cubierto o desprotegido, en tanto que el 90 por ciento de los hogares dispone de "cajón sobre pozo negro" como sistema de servicio sanitario. Demográficas. 
Esta homogeneidad, sumada al pequeño número de casos de mujeres en edad fértil en algunos grupos, impide la identificación de diferencias significativas cuando se intenta observar el comportamiento de la mortalidad infantil para diferentes categorias de estas variables.' A este respecto hay que hacer notar que, por ejemplo, los grupos que se supone presentan mayor riesgo de muerte infantil, como el de las mujeres analfabetas absolutas (ningún año de estudio), sólo representan un 8 por ciento del total de mujeres en edades fértiles. En el otro extremo, las mujeres con 7 y más años de estudio, también son poco frecuentes en este medio.

No obstante 10 anterior, se presentan las tasas de mortalidad infantil calculadas según las dos variables que han dado mayores diferencias en la estimación, nivel de instrucción de la madre y lengua hablada más frecuentemente en el hogar. Con ello se buscará poner de manifiesto que, aun dentro de una situación en que las condiciones de vida del grupo parecen muy parejas, es posible detectar grupos más vulnerables que otros. Cabe señalar, además, que las diferencias detectadas, aunque pequeñas, muestran la dirección esperada.

E1 cuadro 1 contiene las estimaciones obtenidas en el Censo de 1988, además de las correspondientes a las mismas reducciones censadas en el Censo Nacional de 1982. Ambas estimaciones corresponden a la variable "años de estudio aprobados por la madre". Las estimaciones que se hicieron sobre la base del Censo Nacional de 1982 corresponden a un periodo anterior y, en este sentido, no sólo permiten apreciar la coherencia de las estimaciones entre ambos censos, sino también dar una idea del descenso de la mortalidad infantil a través del tiempo.

En primer lugar, se observa en el Censo de 1988 que las diferencias entre las estimaciones de los grupos de nivel de instrucción no son muy marcadas. Más aun, se puede decir que las estimaciones obtenidas definen sólo dos grupos: el de 0-6 años de instrucción, por un lado, y el de 7 y más, por otro (gráfico 1). Si bien es esperable que las mujeres de mayor educación ( 7 y más años de estudio) registren más bajos niveles relativos de mortalidad infantil que las mujeres de menor educación, no lo es tanto la falta de una diferencia significativa entre los otros grupos, 1o que podria indicar una subestimación de este indicador entre las mujeres que poseen entre 0 y 3 años de estudio.

Hay que recordar que el método aplicado, basado en la proporción de hijos nacidos vivos e hijos sobrevivientes, requiere, además, que la información básica se desagregue por grupos de edad de las mujeres. 
REDUCCIONES INDIGENAS SELECCIONADAS:

TASAS DE MORTALIDAD INFANTIL (TMI) POR AÑOS DE ESTUDIO DE LA MADRE. CENSOS DE 1982 Y 1988

(por mil nacidos vivos)

\begin{tabular}{lcccc}
\hline Años de & Censo de $1982(1)$ & Censo de 1988 (2) \\
estudio & Año & TMI & Año & TMI \\
aprobados & & & & \\
\hline & 1977 & 47 & 1983 & 44 \\
$0-3$ & 1977 & 55 & 1985 & 46 \\
$4-6$ & 1978 & 49 & 1985 & 41 \\
7 y más & & & &
\end{tabular}

Fuente: (1) Promedio de estimaciones de los grupos de edad 20-34 años; tabulados especiales Censo Nacional de 1982 .

(2) Promedio de estimaciones de los grupos de edad 20-34 años; anexos 2-A, 2-B y 2-C.

En el caso de las estimaciones derivadas del Censo Nacional de 1982, 11ama aun más notablemente la atención que los indicadores correspondientes a las mujeres con menor educación ( 0 a 3 años de estudio) muestran valores menores a los del grupo intermedio ( 4 a 6 años de estudio), 1o que podria ir en apoyo del supuesto de una subestimación del nivel de mortalidad infantil entre las primeras.

En sintesis, las diferencias de mortalidad infantil entre los grupos considerados son bastante más reducidas que las que se esperaban, según el conocimiento que se tiene de la relación entre estas variables. Teniendo en cuenta que los valores obtenidos en el Censo de 1988 oscilan entre 46 y 41 por mil, esta situación podría interpretarse como que la ausencia de una asociación destacable entre el nivel de mortalidad infantil y la educación de la madre se debe a que, como se mencionó anteriormente, las condiciones de vida de estas mujeres son muy semejantes $y$, en particular, con relación a aquellos aspectos que influyen en el ámbito de la salud. No obstante, la experiencia en el trabajo de campo en las zonas rurales también ha puesto de manifiesto, en algunos casos, que la declaración del número de hijos tenidos e hijos sobrevivientes es más deficiente entre las mujeres con menor instrucción, lo que puede afectar 1a validez de las estimaciones respectivas. 


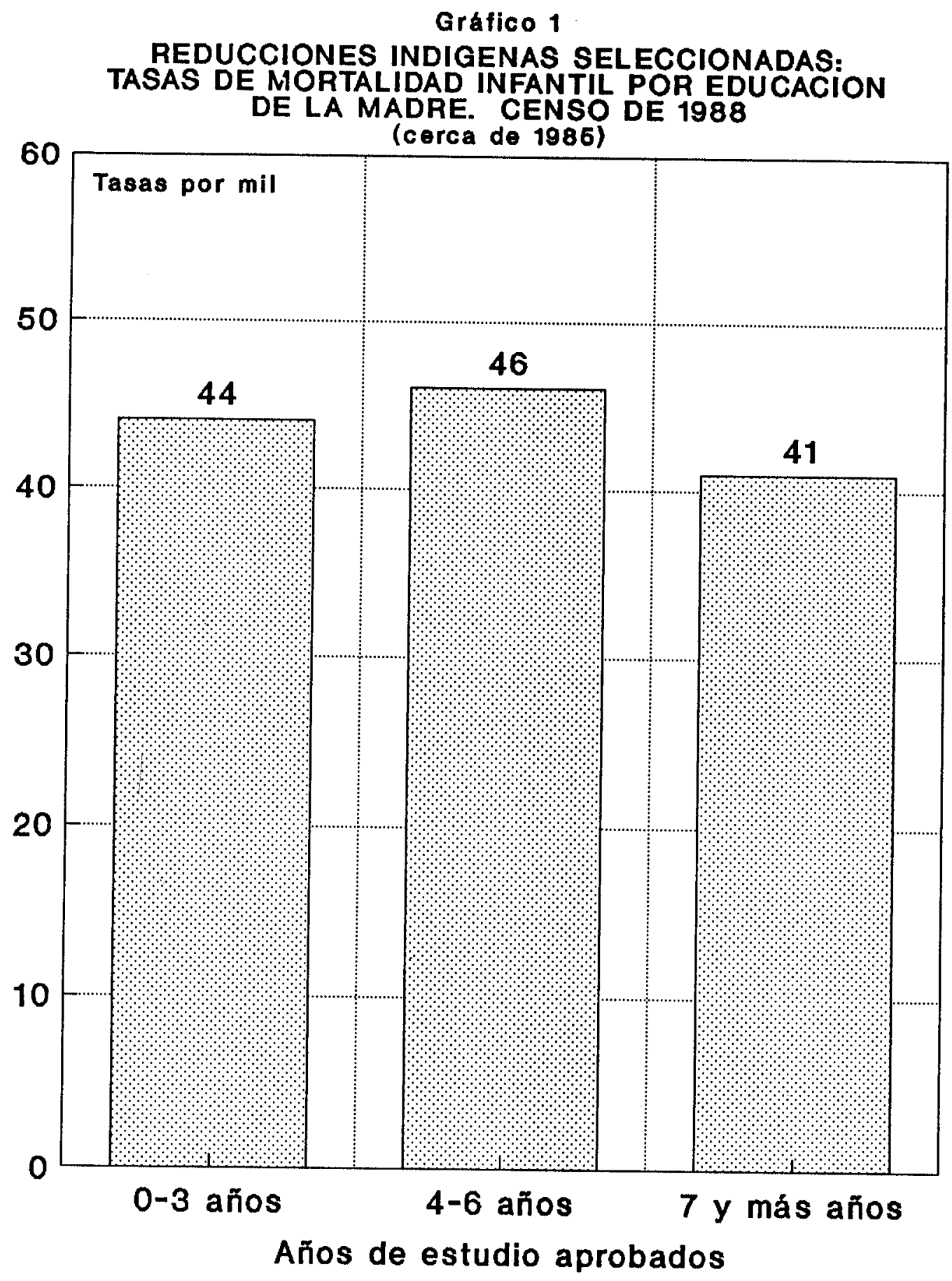

Fuente: Cuadro 1 
En cuanto a su evolución en el tiempo, la comparación de los indicadores con los del Censo Nacional de 1982 muestra un descenso de la mortalidad infantil en todas las categorias, entre aproximadamente 1977 y 1985 . Sin embargo, de acuerdo con las estimaciones obtenidas, el grupo de menor instrucción seria el que menos se habria beneficiado con el cambio.

Finalmente, en el cuadro 2 y gráfico 2 se puede advertir que la asociación entre el nivel de mortalidad infantil con la lengua hablada más frecuentemente en el hogar muestra mayores contrastes que con la educación de la madre. Esta información está disponible sólo para el Censo de 1988, ya que no es un tema que se investiga en los censos nacionales, de manera que no es posible establecer comparaciones como en el caso de la educación de las madres entre ambos censos.

\section{CUADRO 2}

REDUCCIONES INDIGENAS SELECCIONADAS :

TASAS DE MORTALIDAD INFANTIL (TMI) POR LENGUA HABLADA MAS

FRECUENTEMENTE EN EL HOGAR DE LA MADRE.

CENSO DE 1988 *

(por mil nacidos vivos)

$\begin{array}{lcc}\text { Lengua hablada } & \text { Año } & \text { TMI } \\ \text { en e1 hogar } & & \\ \text { - Mapuche } & 1985 & 53 \\ \text { - Mapuche y } & & \\ \text { Castellano } & 1985 & 49 \\ \text { - Castellano } & 1985 & 41 \\ & & \end{array}$

Fuente: Anexos 3-A, 3-B y 3-C.

*: Promedio de estimaciones de los grupos de edad 20-34 años.

En los hogares de las mujeres donde se habla'con más frecuencia el mapudungun se observa un mayor nivel de mortalidad infantil que en los otros hogares, especialmente con respecto a aquellos en los que se habla predominantemente el castellano. Esta asociación de la mortalidad infantil con el contexto cultural del hogar en que el hecho tiene lugar, se manifiesta con mayor intensidad que en el caso de la educación de la madre, ya que los valores fluctúan entre 53 por mil, en los hogares donde se habla más frecuentemente mapuche, y 41 por mil, en los que la lengua de mayor uso es el castellano. 
Gráfico 2

REDUCCIONES INDIGENAS SELECCIONADAS: TASAS DE MORTALIDAD INFANTIL POR LENGUA HABLADA CON MAS FRECUENCIA EN EL HOGAR DE LA MADRE. CENSO DE 1988

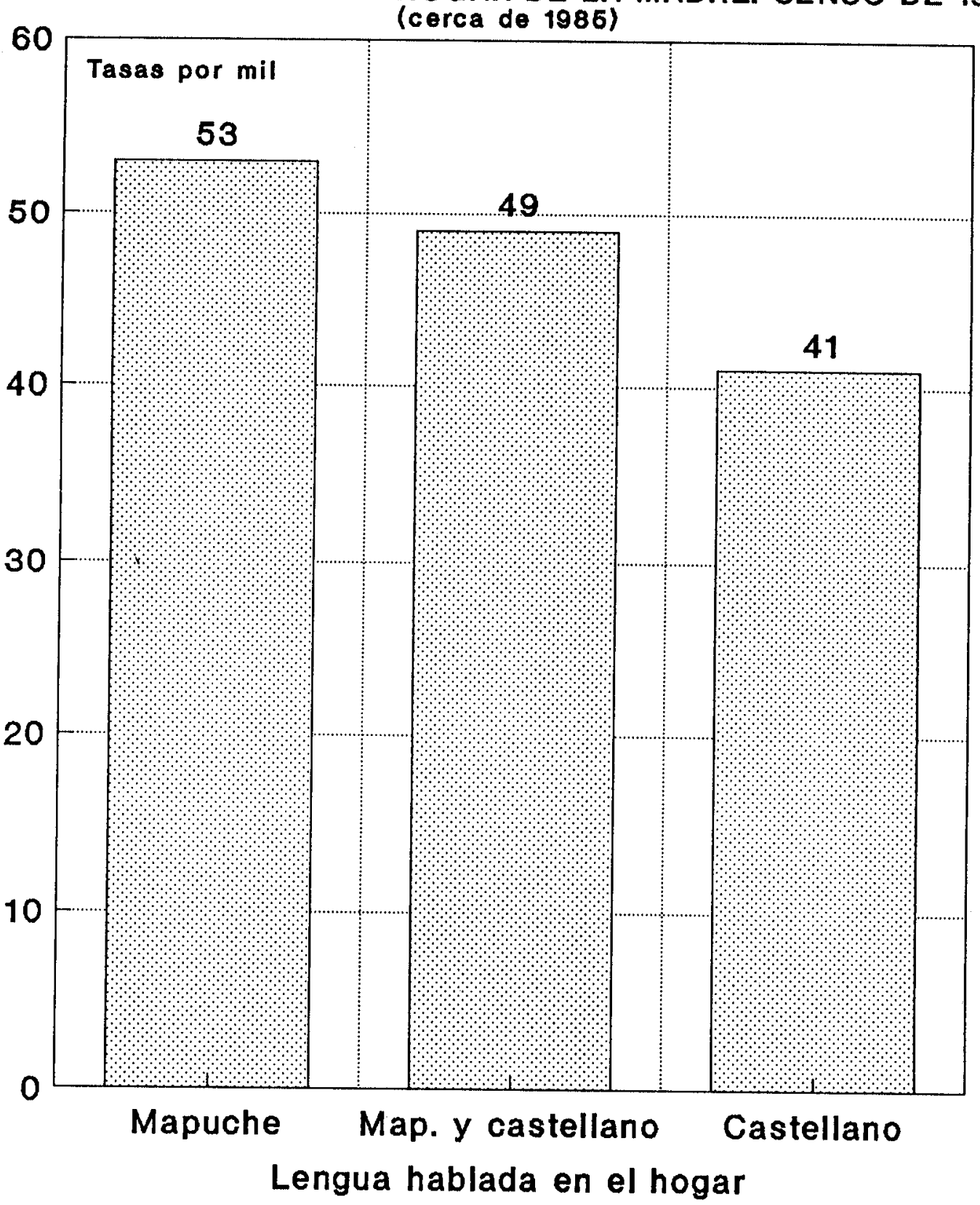

Fuente: Cuadro 2 
Estos resultados estarian mostrando que los hogares más apegados a $1 a$ tradición son los que tienen una mayor propensión al riesgo de muerte en el caso de los menores de un año de edad. En consecuencia, sería necesario determinar si las discrepancias en los niveles de mortalidad infantil son realmente atribuibles a factores directamente asociados con las creencias y costumbres del grupo, que pueden influir, por ejemplo, en la forma de enfrentar las enfermedades y en el acceso a los servicios de salud, o bien se deben a diferencias en los niveles de vida de las familias.

\section{Mortalidad materna}

Hasta hace poco tiempo no se habia prestado suficiente atención a este problema debido a que, en parte, los datos provenientes de las estadisticas vitales a menudo subestiman su verdadera magnitud. Estudios de casos realizados en algunos países en desarrollo han demostrado, sin embargo, que los niveles de mortalidad materna se encuentran muy por encima de los informados, 10 que permite apreciar la magnitud del subregistro y destacar las dimensiones del problema (OPS-OMS, 1986). Se cree que en América Latina, además del subregistro de defunciones en general, una de las principales razones del subregistro de muertes maternas es la ilegalidad del aborto, 1o que induce a ocultar las defunciones que se derivan de las condiciones inadecuadas en que se realiza este tipo de intervenciones.

No obstante el subregistro, del que no están exentos los paises desarrollados, se advierte que las diferencias en los niveles de mortalidad materna son grandes: Las mujeres en áreas muy subdesarrolladas tienen un riesgo de morir por causas maternas que puede llegar a ser varios cientos de veces mayor que el riesgo a que están expuestas las que viven en zonas desarrolladas. La gravedad de esta situación es que las muertes maternas, aunque en términos relativos no son numerosas, son evitables prácticamente en su totalidad.

Para conocer el nivel de la mortalidad femenina por causas maternas, por lo general se utiliza la tasa de mortalidad materna, indice que relaciona el número de muertes por causas asociadas al embarazo, parto o puerperio con las mujeres expuestas a dicho riesgo, es decir, con el número total de embarazos. Como este denominador es muy dificil de obtener, se usa una aproximación al mismo, que consiste en el número de nacimientos vivos en un año determinado. Relacionando asi el número de muertes maternas con el número de nacimientos vivos se obtiene un cociente al que convencionalmente se ha dado el nombre de tasa de mortalidad materna y que se deriva de las estadisticas vitales. 
Debido, sin embargo, a los problemas que en general se presentan en los paises subdesarrollados para obtener la información adecuada y completa para estimar esta tasa, recientemente Graham y Brass (1988) han desarrollado un procedimiento indirecto, denominado Método de la Sobrevivencia de Hermanas, que permite derivar indicadores de mortalidad materna de las proporciones de hermanas que llegaron a la edad de exposición al riesgo de muerte materna y que fallecieron durante el emharazo, parto o puerperio. Con este procedimiento se pueden calcular tasas de mortalidad materna comparables con las que proceden de las estadisticas vitales. Cabe mencionar que la estimación resultante tiene una ubicación en el tiempo que corresponde aproximadamente a unos diez o doce años antes de la fecha en que se realizó la encuesta o censo.

Con el propósito de obtener esta Información en el caso de los cuatro distritos seleccionados de la Provincia de Cautín, se incorporaron al cuestionario las preguntas que se requieren para recoger la información necesaria para la aplicación del método y se realizaron los cálculos correspondientes (Wong et al., 1990).

En el caso de Chile, las estadisticas vitales indican que la tasa de mortalidad materna del total del pais era de 260 muertes por cien mil nacidos vivos en 1965 y que ésta habria descendido a 122 en 1975 y a 50 en 1985 . En cuanto a la Provincia de Cautin, ' la información correspondiente al perfodo 1982 1984 indica que la tasa era, para esa fecha, de 74 muertes maternas por cien mil nacidos vivos. No obstante que Chile puede ubicarse entre los palses de América Latina que tienen menos de un 15 por ciento de omisión de las defunciones totales, incluyendo tanto el subregistro estimado como el grupo de causas mal definidas (Chackiel, 1987), cabe esperar que exista subregistro de muertes maternas, ya que ésto ha sido observado en otros casos similares. En efecto, en estudios realizados para paises con estadisticas relativamente confiables se ha encontrado un fuerte subregistro de estas muertes.

Como resultado de la aplicación del método de la sobrevivencia de hermanas, se ha estimado que la tasa de mortalidad materna en las reducciones indigenas seleccionadas es de 414 muertes por cien mil nacidos vivos, lo que implica que la probabilidad que tendria cada mujer de morir por una causa materna a lo largo de su periodo reproductivo es de 1 por cada 53 mujeres alrededor del año 1975 (Wong et al., 1990). Esta tasa es de un orden de magnitud similar a la que se

La provincia es la unidad administrativa más pequeña para la cual se dispone de esta información a partir de 1982 . 
obtiene para Bolivia, que es de 373 muertes maternas por cien mil nacidos vivos para el período 1982-1988 (Rutenberg et al., 1990).

Cabe mencionar que la aplicación de esta metodologia tiene un carácter experimental, dado que no se ha realizado todavia un número suficiente de aplicaciones. No obstante, las estimaciones que se obtienen son consistentes, por lo general, con otras estimaciones de mortalidad obtenidas a partir de los mismos datos $y$, en algunos casos, con estimaciones alternativas (Graham, Brass y Snow, 1989). El estudio de Bolivia (Rutenberg et al., 1990) Incluso sugiere que, para algunos periodos pasados, las estimaciones provenientes de 1a aplicación del método indirecto podrian estar subestimando el verdadero nivel de la mortalidad materna.

Como se puede apreciar, la estimación que resulta de la aplicación del método indirecto es casi tres veces y media más elevada en las reducciones estudiadas que la que corresponde al total del pais en 1975 y hubiera duplicado en esa misma fecha a la tasa de la Provincia de Cautin, si el descenso de ésta hubiera sido similar al del total del país.

Se puede afirmar que las diferencias entre las estimaciones para la provincia y las reducciones son significativas, y podrian estar señalando tanto que hay omisiones de muertes maternas en los registros de estadisticas vitales, como que la condición de salud de las mujeres de las reducciones seleccionadas, con relación a su rol materno, se encuentra muy desfavorecida si se la compara con la condición que predominaria en la Provincia de Cautín y, más aun, en el pais.

Se ha visto, sin embargo, que esta estimación corresponde aproximadamente al año 1975. Para tener un indicador más actualizado, se pueden hacer algunas suposiciones sobre la base de otros datos obtenidos en el Censo de 1988. Por ejemplo, se ha observado que la mortalidad infantil en estas reducciones habria bajado su nivel desde 64 a 45 por mil entre alrededor de 1975 y 1985 , es decir, habria existido una reducción del 30 por ciento en el nivel de la tasa. Esto, obviamente, contrasta con lo que ha ocurrido en el pais y también en la Provincia de Cautin, ya que en estos dos casos el descenso ha sido más pronunciado, de 56 y 61 por ciento, respectivamente.

Dados estos resultados, una hipotesis razonable seria la de suponer que la mortalidad materna también ha descendido en el periodo a un ritmo similar al de la tasa de mortalidad infantil de las reducciones. Esto significa que se encontraria, alrededor de 1985, una tasa de mortalidad materna de 290 por cien 
mil nacidos vivos para las reducciones indigenas seleccionadas la que, ciertamente, contrasta con la del total del país, que es de sólo 44 por cien mil nacidos vivos, según las estadisticas vitales.

En cuanto al impacto real de este resultado para la población afectada, éste se puede resumir diciendo que, dado el nivel estimado de la fecundidad actual en estas reducciones indigenas, la cifra a la que se ha llegado Indica que cada año puede ocurrir, en promedio, una muerte materna. Si se compara este resultado con el del total del pais, se puede concluir que si la tasa de mortalidad materna en las reducciones fuera la misma que la del pais, o sea, 44 muertes maternas por cada cien mil nacidos vivos, no se tendria una muerte por año sino sólo una cada siete $u$ ocho años, diferencia que puede considerarse altamente significativa.

\section{Atención de salud}

Los niveles de mortalidad infantil y materna, calculados a partir de la información recolectada en el Censo de 1988 y comparados con los del promedio del pals, constituyen una indicación elocuente de que las condiciones en que se encuentra la población de los distritos estudiados en cuanto a su situación de salud son deficitarias.

Si bien en toda muerte, materna o infantil, hay factores o causas biológicas involucradas, el hecho de que la mayor parte de ellas puede ser evitada demuestra que la mortalidad depende en gran medida de factores socioeconómicos, entre los cuales debe incluirse el acceso a la atención médica, que también es diferencial para los distintos grupos sociales.

E1 panorama de la atención de salud en las zonas rurales con población indigena no es simple, sin embargo, dado que habitualmente coexisten diversos modelos o sistemas médicos (Oyarce, 1989). En el caso de las reducciones indigenas de la IX Región se presentan, por un lado, las prácticas médicas tradicionales que están plenamente vigentes, sean llevadas a cabo por el o la machi," la yerbatera o la propia dueña de casa (Grebe, 1975). Por otro lado, está el conocimiento popular campesino no mapuche con el que la población puede haberse relacionado. De hecho, la presencia de la partera puede ser explicada

Persona que ha recibido el don o capacidad de adivinar, diagnosticar y vencer el mal que causa una enfermedad en una ceremonia conocida como "machitún". Esta persona es reconocida socialmente con este poder a través de una larga preparación y consagración (Oyarce, 1988 y 1989). 
como producto de la intensificación del contacto entre los mapuches y el resto del campesinado no indfgena (Oyarce, 1989). Y, como una tercera vertiente, está la medicina occidental, que también se expandió en la zona, tanto debido al crecimiento de la ciudad de Temuco y su influencia sobre la población aledaña, como al importantisimo papel jugado por las misiones religiosas que, como en el caso del Hospital de Maquehue, en el distrito del mismo nombre, han constituido vias de introducción de estas prácticas médicas.

Si bien coexisten estas diferentes aproximaciones al fenómeno de la salud y la enfermedad, tanto desde el punto de vista de la etiologia, como del diagnóstico y la terapéutica, no parece existir una verdadera integración de las diferentes prácticas. Cabe pensar, más bien, que las personas recurren a uno $u$ otro agente de salud según los recursos disponibles, su grado de apego a la tradición cultural, el tipo de enfermedad y, posiblemente, su percepción del éxito o fracaso de los diferentes sistemas en el tratamiento de las enfermedades que han aquejado a los miembros del grupo familiar. Es sabido también que, para una misma persona, se puede recurrir a más de un agente de salud, en los diferentes estadios de la enfermedad.

Con el objeto de lograr una aproximación al conocimiento del uso que en este caso la población hace de los diferentes sistemas de atención médica, se han incluido en el Censo de 1988, en forma experimental, dos preguntas asociadas con el nacimiento del último hijo nacido vivo, formuladas a cada mujer mayor de 14 años de edad.

La primera pregunta se refiere directamente al tipo de atención que las mujeres recibieron en su último parto ("¿Quién 1 a atendió en el parto de su último hijo?"), mientras que en la segunda se trata de identificar, a partir del fallecimiento del último hijo, a quién se recúrió para tratar la enfermedad - las circunstancias que puedan haberlo provocado ("¿quén le hizo tratamiento a su último hijo antes de morir?").

Como puede verse, ambas preguntas se refieren a la elección que la mujer, pareja o familia hace, en cuanto a la atención, de salud, en estas dos circunstancias tan importantes referidas a la vida reproductiva y a la salud de los hijos. Se buscó conocer, a través de esta información, en qué medida la elección puede variar según la edad de la mujer, su nivel de instrucción y la lengua que se habla más frecuentemente en el hogar, variable esta última que podría indicar diferentes grados de apego al estilo de vida tradicional. 


\subsection{Atención en el parto}

En cuanto a la atención en el parto, se obtuvieron respuestas de 2771 mujeres, aquellas que tuvieron al menos un hijo nacido vivo. El cuadro 3 y gráfico 3 muestran que de cada 100 partos correspondientes al último hijo, 69 fueron atendidos dentro del sistema occidental por médico o matrona; 23 dentro del sistema tradicional, ya sea por curandera o machi ${ }^{6}$ o por parteras empiricas; una infima parte fue atendida por un auxiliar rural quien, por clerto, no está especialmente capacitado para ello; y 7 habrian sido atendidos o "ayudados" por otra persona, presumiblemente sin capacitación, sea ésta tradicional o moderna.

\section{CUADRO 3}

REDUCCIONES INDIGENAS SELECCIONADAS :

DISTRIBUCION RELATIVA DE LAS MADRES DE 15 AÑOS Y MAS DE EDAD POR GRUPOS DE EDAD, SEGUN TIPO DE ATENCION EN EL ULTIMO PARTO. CENSO DE 1988

$\begin{array}{lccccr}\begin{array}{l}\text { Grupos } \\ \text { de }\end{array} & \begin{array}{c}\text { Tipo de atención en el último parto } \\ \text { edad }\end{array} & \begin{array}{c}\text { Médico } \\ \text { o } \\ \text { matrona }\end{array} & \begin{array}{c}\text { Curandera, otro } \\ \text { partera } \\ \text { o machi }\end{array} & \begin{array}{c}\text { Aux. } \\ \text { rural }\end{array} & \text { Total } \\ & 94 & 1 & 4 & 1 & 100 \\ 15-24 & 93 & 3 & 4 & - & 100 \\ 25-34 & 89 & 6 & 5 & - & 100 \\ 35-44 & 69 & 21 & 9 & - & 100 \\ 45-54 & 32 & 57 & 10 & 1 & 100 \\ 55 \text { y más } & & & & & \\ & 69 & 23 & 7 & 1 & 100 \\ \text { Total } & (1915) & (636) & (186) & (16) & (2753)\end{array}$

Fuente: Tabulados especiales Censo de 1988.

En este último caso, el haber sido atendido por otra persona, tal vez un familiar con alguna experiencia o la persona que circunstancialmente se encontraba con ella, podria incluso considerarse como más "tradicional", ya que este tipo de parto parece haber sido frecuente en el siglo pasado. Según informan los primeros cronistas españoles que tomaron contacto con los mapuches,

En este caso la machi no actúa en su calidad de chaman sino por su experiencia en la atención de salud. 


\section{Gráfico 3 \\ REDUCCIONES INDIGENAS SELECCIONADAS: \\ DISTRIBUCION RELATIVA DE LAS MADRES DE 15 ANNOS YMAS DE EDAD POR TIPO DE ATENCION EN EL ULTIMO PARTO. CENSO DE 1988}

Médico o matrona $69 \%$

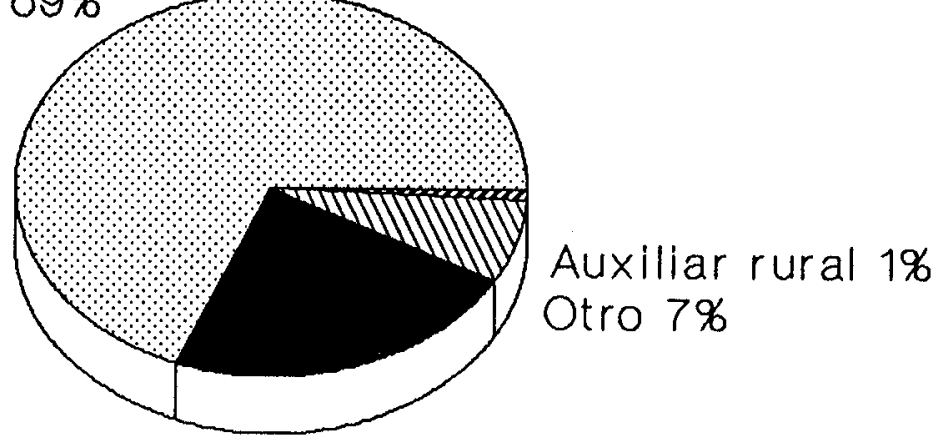

Curand,partera,machl 23\%

Fuente: Cuadro 3 
no existfa una persona especializada en la atención del parto, sino que la mujer daba a luz lejos de su hogar y de su núcleo familiar acompañada y asistida por una pariente con experiencia de haber dado a luz a un hijo (Guevara, 1898; Gusinde, 1917).

Cabe señalar que, por tratarse de población que vive en reducciones indigenas, llama la atención el alto porcentaje de cobertura profesional en el parto, aunque es menor que el estimado para la región en su conjunto. En efecto, los cuatro distritos tendrian un 69 por ciento frente a un 94 por ciento de cobertura de la IX Regíón en el mismo año (1988). Sin embargo, por tratarse de población indigena, supuestamente afectada en mayor o menor grado por costumbres tradicionales, la cobertura parece relativamente alta y pudiera explicarse por la proximidad de los hospitales de Temuco y Maquehue, asi como por la mayor posibilidad de acceso a los mismos para la población estudiada que el que pueden tener otras comunidades más alejadas de los centros de salud. Estos resultados, en todo caso, no permiten sacar conclusiones acerca de la calidad de la atención recibida ni de su oportunidad, lo que será tema de estudio para una próxima etapa de esta investigación.

Por su parte, el comportamiento de las mujeres en cuanto a la elección del tipo de atención en el parto varía según los diferentes grupos de edades, lo que indicaria la presencia de una asociación importante entre ambas variables. Se puede observar en el cuadro 3 que entre el 89 y el 94 por ciento de las mujeres más jóvenes, entre 15 y 44 años de edad, ha declarado haber sido atendida por médico o matrona, mientras que el 57 por ciento de las de mayor edad ha optado por la atención tradicional (curandera, partera o machi) y el 10 por ciento ha sido "ayudada" por otra persona. En particular, cabe destacar que la proporción de mujeres que se atiende con médico o matrona desciende abruptamente a partir de los 55 años. Entre las mujeres de 45 años y más de edad también la categoria "otro" tiene mayor peso, indicando posiblemente la ayuda de un familiar en el momento del parto. De acuerdo con estos datos, en las reducciones censadas ha habido un cambio en el tiempo con relación al aumento en el uso de los recursos médicos más modernos, que son más solicitados por las mujeres más jóvenes.

La asociación señalada está indicando claramente un cambio generacional influido, seguramente, por el hecho de que las mujeres de más edad son las que han tenido su último parto en un pasado más lejano, cuando la medicina moderna tenia un área de influencia menos amplia que en la actualidad. 
Los resultados son consistentes con estudios realizados en otras comunidades de la IX Región que han mostrado que los partos atendidos en el hospital son percibidos por las mujeres más jovenes como menos peligrosos para 1a madre y el recién nacido. En el caso de las mujeres que han tenido previamente hijos en la casa, el parto en el hospital no se considera como algo estrictamente necesario, además del hecho de que no han contado con alguien que las reemplace en sus obligaciones habituales (Oyarce, 1989).

También se observa una asociación importante entre la selección de un sistema de atención de salud y la educación que han alcanzado las mujeres. En el cuadro 4 se puede observar que a medida que aumentan los años de estudio aprobados por las mujeres aumenta también su acceso a la medicina occidental, siendo éste ya bastante elevado (más del 70 por ciento) cuando se tiene de 1 a 3 años de estudio. Entre las mujeres de mayor educación el acceso a la medicina moderna es todavia más alto (95 por ciento).

\section{CUADRO 4}

REDUCCIONES INDIGENAS SELECCIONADAS:

DISTRIBUCION RELATIVA DE LAS MADRES DE 15 AÑOS Y MAS DE EDAD

POR AÑOS DE ESTUDIO APROBADOS, SEGUN TIPO DE ATENCION EN EL ULTIMO PARTO. CENSO DE 1988

\begin{tabular}{|c|c|c|c|c|c|}
\hline $\begin{array}{l}\text { Años } \\
\text { de } \\
\text { estudio } \\
\text { aprobados }\end{array}$ & $\begin{array}{c}\text { Tipo de } \\
\text { Médico } \\
\text { o } \\
\text { matrona }\end{array}$ & $\begin{array}{c}\text { tención en } \\
\text { Curandera, } \\
\text { partera } \\
\text { o machi }\end{array}$ & el últ & $\begin{array}{r}\text { parto } \\
\text { Aux. } \\
\text { rural }\end{array}$ & Total \\
\hline Ninguno & 40 & 49 & 10 & 1 & 100 \\
\hline 1 a 3 & 72 & 21 & 6 & 1 & 100 \\
\hline 4 a 6 & 84 & 10 & 6 & - & 100 \\
\hline 7 y más & 95 & 2 & 3 & - & 100 \\
\hline tal & $\begin{array}{r}69 \\
(1915)\end{array}$ & $\begin{array}{r}23 \\
(636)\end{array}$ & $\begin{array}{r}7 \\
(186)^{7}\end{array}$ & $\begin{array}{r}1 \\
(16)\end{array}$ & $\begin{array}{r}100 \\
(2753)\end{array}$ \\
\hline
\end{tabular}

Fuente: Tabulados especiales Censo de 1988.

Las mujeres analfabetas absolutas, aquellas que han manifestado no haber aprobado ningún año de estudio, están mayoritariamente (49 por ciento) dentro de la medicina tradicional, aunque una proporción no desdeñable (40 por ciento), 
se habría atendido por médico o matrona en su último parto. Es evidente, sin embargo, que en esta situación también está implicita la asociación de la educación con la edad, ya que las mujeres de mayor edad son las que muestran mayores niveles de analfabetismo.

Cuando se trata de ver si existe asociación entre la lengua hablada más frecuentemente en el hogar, como indicador de apego a la cultura, y el tipo de atención en el parto, la situación, en rasgos generales, es similar a la anterior, pero la diferencia entre los grupos de mujeres es menos contrastante que en el caso de la edad o de la educación, como puede observarse en el cuadro 5 .

\section{CUADRO 5}

REDUCCIONES INDIGENAS SELECCIONADAS:

DISTRIBUCION RELATIVA DE LAS MADRES DE 15 AÑOS Y MAS DE EDAD POR LENGUA HABLADA MAS FRECUENTEMENTE EN EL HOGAR Y GRUPOS DE EDAD, SEGUN TIPO DE ATENCION EN EL ULTIMO PARTO. CENSO DE 1988

\begin{tabular}{|c|c|c|c|c|c|}
\hline $\begin{array}{l}\text { Lengua } \\
\text { hablada en } \\
\text { el hogar } \\
\text { y grupos } \\
\text { de edad }\end{array}$ & $\begin{array}{l}\text { Tipo de } \\
\text { Médico } \\
\text { o } \\
\text { matrona }\end{array}$ & $\begin{array}{c}\text { tención en } \\
\text { Curandera, } \\
\text { partera } \\
\text { o machi }\end{array}$ & $\begin{array}{c}\text { el últ } \\
\text { Otro }\end{array}$ & $\begin{array}{r}\text { parto } \\
\text { Aux. } \\
\text { rural }\end{array}$ & Total \\
\hline Mapuche & 48 & 42 & 9 & 1. & 100 \\
\hline $15-44$ & 96 & 1 & 3 & - & 100 \\
\hline 45 y más & 28 & 59 & 12 & 1 & 100 \\
\hline Map.y cast. & 65 & 26 & 8 & 1 & 100 \\
\hline $15-44$ & 89 & 5 & 5 & 1 & 100 \\
\hline 45 y más & 41 & 48 & 10 & 1 & 100 \\
\hline Castellano & 80 & 15 & 5 & $\begin{array}{l}- \\
-\end{array}$ & 100 \\
\hline $15-44$ & 94 & 3 & 3 & - & 100 \\
\hline 45 y más & 59 & 32 & 8 & 1 & 100 \\
\hline Total & $\begin{array}{r}69 \\
(1915)\end{array}$ & $\begin{array}{r}23 \\
(636)\end{array}$ & $\begin{array}{r}7 \\
(186)^{7}\end{array}$ & $(16)^{1}$ & $\begin{array}{r}100 \\
(2753)\end{array}$ \\
\hline
\end{tabular}

Fuente: Tabulados especiales Censo de 1988.

Al respecto, puede consultarse el Capitulo Caracteristicas Educacionales. 
En este caso se ve que una alta proporción de mujeres en los tres grupos de lengua hablada ha buscado la atención de médico o matrona, aunque ciertamente, la proporción disminuye al aumentar el apego a la cultura o tradicionalismo de la familia. Parece importante destacar que casi la mitad de las mujeres que viven en hogares donde la lengua hablada más frecuente es el mapudungun, también ha recibido atención de médico o matrona en el parto.

E1 hecho de que los diferenciales de atención en el parto sean de menor intensidad que los encontrados anteriormente indujo a analizar la información con mayor detalle. En efecto, el cuadro 5 muestra que la situación no es homogénea cuando se observan diferentes grupos de edades dentro de cada grupo de lengua hablada.

De acuerdo con la edad, el comportamiento de las mujeres más jóvenes, en cuanto a la elección del tipo de atención en el parto, es muy similar entre todas ellas, independientemente del grado de apego a la cultura tradicional de la familia en su conjunto. En el caso de las mujeres de mayor edad, en cambio, se observa una mayor influencia de los factores culturales, ya que la atención por algún agente de salud tradicional se eleva al aumentar su adhesión a las costumbres mapuches. De hecho, entre las familias donde se habla más frecuentemente el castellano, supuestamente familias más influidas por las costumbres occidentales, se observa que no sólo las más jóvenes, sino también las mujeres mayores, presentan un relativamente alto porcentaje de atención médica en el parto (más del doble que las mujeres de la misma edad en el grupo de lengua mapuche).

E1 grupo que muestra, sin embargo, la mayor diferenciación interna según la edad, es el de aquellas familias donde se habla más frecuentemente la lengua autóctona. En consecuencia, el relativamente elevado porcentaje de atención por médico o matrona, considerando que se trataria de las familias más tradicionales (48 por ciento), estaria muy influido por el comportamiento de las mujeres más jóvenes ${ }^{8}$ quienes, como se vio, no obstante pertenecer a este tipo de familia, se han atendido mayoritariamente en el sistema médico occidental ( 96 por ciento).

E1 nivel es bastante parejo dentro del grupo, aunque para las mujeres de 15-34 años de edad el porcentaje se eleva a 98 por ciento, mientras que para las de 35-44 años baja a 91 por ciento. 


\subsection{Atención al último hifo antes de morir}

A las mujeres que respondieron que su ủltimo hijo nacido vivo se encuentra actualmente muerto se les preguntó sobre el tipo de atención (o tratamiento) que este hijo recibiera antes de morir. Cabe señalar que en este caso se trata de una muestra muy pequeña, pues sólo 130 mujeres se encuentran en esta situación. De éstas, además, cerca del 50 por ciento tiene más de 55 años de edad, 10 que indica que el hecho al que se hace referencia ocurrió en un pasado relativamente lejano.

Como se observa en el cuadro 6 y gráfico 4, sólo el 54 por ciento de las mujeres encuestadas ha contestado que, previo al episodio que lo condujera a la muerte, su hijo fue atendido por médico o enfermera. Por su parte, un 11 por ciento de las madres recurrió a la medicina tradicional haciendo atender a sus hijos por yerbatero o machi.

\section{CUADRO 6}

REDUCCIONES INDIGENAS SELECCIONADAS:

DISTRIBUCION RELATIVA DE LAS MADRES DE 15 AÑOS Y MAS DE EDAD POR GRUPOS DE EDAD, SEGUN TIPO DE ATENCION AL ULTIMO HIJO ANTES DE MORIR. CENSO DE 1988

\begin{tabular}{lcccr} 
Grupos & \multicolumn{1}{c}{ Tipo de atención al último hijo } & \\
de & $\begin{array}{l}\text { Médico o } \\
\text { edad }\end{array}$ & $\begin{array}{c}\text { Yerbatero } \\
\text { enfermera }\end{array}$ & Nadie & Total \\
\hline $15-49$ & 78 & 18 & 22 & 100 \\
50 y más & 39 & 11 & 43 & 100 \\
Total & 54 & $(14)$ & 35 & 100 \\
& $(71)$ & & $(45)$ & $(130)$
\end{tabular}

Fuente: Tabulados especiales Censo de 1988.

Llama la atención un relativamente muy elevado porcentaje de casos - 35 por ciento- en que la madre declara que el hijo no ha sido atendido ni por agentes de la medicina moderna ni de la medicina tradicional. 


\section{Gráfico 4 REDUCCIONES INDIGENAS SELECCIONADAS: DISTRIBUCION RELATIVA DE LAS MADRES DE 15 ANOS Y MAS DE EDAD POR TIPO DE ATENCION AL ULTIMO HIJO ĀNTES DE MORIR. CENSO DE 1988}

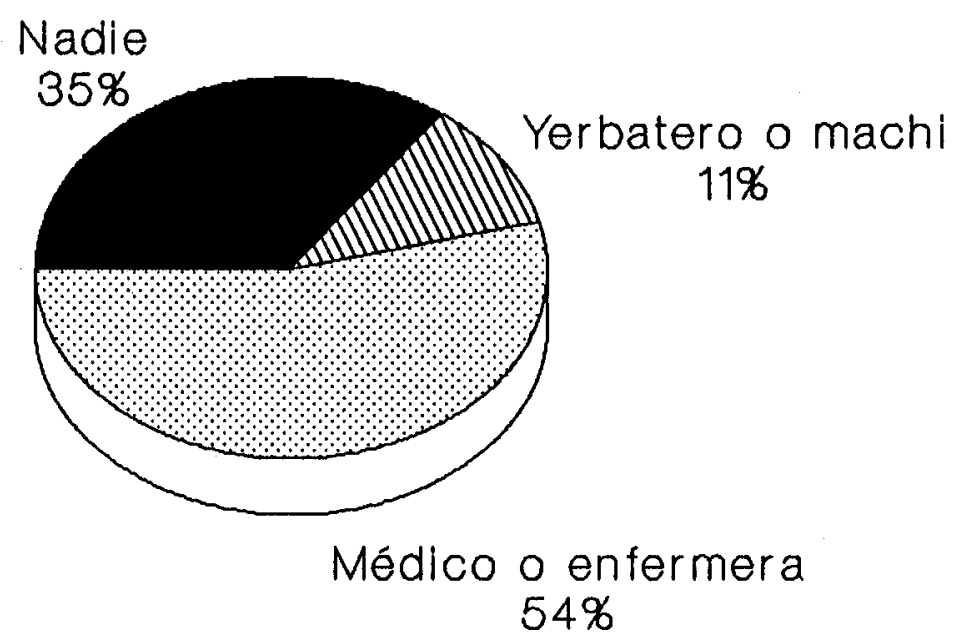

Fuente: Cuadro 6 
En cuanto a las edades se observa que, al menos en esta muestra, el acceso a la medicina moderna es mayor cuando las madres son más jóvenes y que sólo las mujeres de 50 años y más de edad han declarado haber acudido al yerbatero o machi para tratamiento. Como es evidente que el acontecimiento que se investiga, en el caso de las mujeres de mayor edad, ha tenido lugar en un pasado más lejano que en el de las más jóvenes, parte de la diferencia también puede atribuirse a cambios en el entorno social y cultural, asi como a una menor difusión de los conocimientos médicos modernos en el pasado, en el ámbito de las comunidades.

Finalmente, aunque más elevado entre las mujeres de mayor edad, en ambos grupos de edades el porcentaje de niños que no ha recibido una atención de salud especializada parece ser bastante alto. Esto requiere una investigación más profunda, pero pueden hacerse algunas conjeturas.

Una de ellas se relaciona con el hecho de que muy posiblemente los niños, a1 comenzar una enfermedad, son atendidos en el hogar por su madre $u$ otro pariente, administrándoseles medicinas caseras basadas generalmente en el conocimiento tradicional. Sólo cuando se percibe que la enfermedad se agrava, si hay tiempo para ello y recursos económicos, la familia consulta al médico, yerbatero o machi.

En segundo lugar, se sabe que en esta población, en los últimos cinco años, un alto porcentaje de muertes infantiles corresponde al periodo neonatal $\mathrm{y}$, dentro de éste, a las primeras horas o días después del nacimiento.' Si ésta fuera también una situación más general, y no sólo de los últimos cinco años, se comprenderia que es diffcil la atención del niño o niña, en particular cuando el parto es domiciliario o bien cuando la madre se ha retirado muy recientemente del hospital.

En cuanto a las caracteristicas educativas de las madres, el cuadro 7 indica que, como en el caso de la atención en el parto, hay un mayor acceso a la medicina moderna cuando la madre ha tenido más años de estudio; que las mujeres sin educación formal, seguramente las de mayor edad, son las que más recurren a los agentes tradicionales; y que se mantiene un alto porcentaje de casos que no ha recibido tratamiento especializado antes de morir, incluso entre las mujeres que han cursado hasta 6 años de estudio.

Dentro del mismo proyecto se ha realizado un cotejo entre las defunciones de los menores de un año declaradas en el Censo de 1988 correspondientes a los últimos cínco años, y las estadisticas vitales y fichas médicas, encontrándose aproximadamente un 60 por ciento de muertes neonatales. 
REDUCCIONES INDIGENAS SELECCIONADAS:

DISTRIBUCION RELATIVA DE LAS MADRES DE 15 AÑOS Y MAS DE EDAD

POR AÑOS DE ESTUDIO APROBADOS, SEGUN TIPO DE ATENCION AL ULTIMO HIJO ANTES DE MORIR. CENSO DE 1988

\begin{tabular}{|c|c|c|c|c|}
\hline $\begin{array}{l}\text { Años } \\
\text { de } \\
\text { estudio } \\
\text { aprobados }\end{array}$ & $\begin{array}{l}\text { Tipo de } \\
\text { Médico o } \\
\text { Enfermera }\end{array}$ & $\begin{array}{c}\text { Yón al últ } \\
\text { Yerbatero } \\
\text { o machi }\end{array}$ & $\begin{array}{l}\text { hijo } \\
\text { Nadie }\end{array}$ & Total \\
\hline Ninguno & 39 & 21 & 40 & 100 \\
\hline 1 a 3 & 68 & - & 32 & 100 \\
\hline 4 a 6 & 61 & 6 & 33 & 100 \\
\hline 7 y más & 100 & - & - & 100 \\
\hline otal & $\begin{array}{r}55 \\
(71)\end{array}$ & $\begin{array}{c}11 \\
(14)\end{array}$ & $\begin{array}{r}35 \\
(45)\end{array}$ & $\begin{array}{r}100 \\
(130)\end{array}$ \\
\hline
\end{tabular}

Fuente: Tabulados especiales Censo de 1988.

Con respecto a la influencia de la cultura evidenciada a través de 1a lengua vernácula hablada en el hogar, en el cuadro 8 se observa que también, como en el caso anterior, hay diferenclas. En efecto, se observa una mayor recurrencia a la atención médica cuando la mujer pertenece a una familia donde se habla más frecuentemente el castellano.

En este caso, sin embargo, llama aun más la atención el alto porcentaje de madres que declaró que sus hijos no hablan recibido tratamiento antes de morir entre las mujeres cuyas familias mantienen el uso frecuente de la lengua mapuche (62 por ciento). Aun cuando se puede suponer que en muchos de estos casos los niños son tratados con remedios caseros, seguramente recetados y administrados por su madre, ésto requiere ser estudiado en mayor profundidad, tanto para un mejor conocimiento de la situación de salud como para identificar los factores determinantes o condicionantes de la mortalidad infantil de esta población. 
CUADRO 8

REDUCCIONES INDIGENAS SELECCIONADAS:

DISTRIBUCION RELATIVA DE LAS MADRES DE 15 AÑOS Y MAS DE EDAD POR LENGUA HABLADA MAS FRECUENTEMENTE EN EL HOGAR, SEGUN TIPO DE ATENCION AL ULTIMO HIJO ANTES DE MORIR. CENSO DE 1988

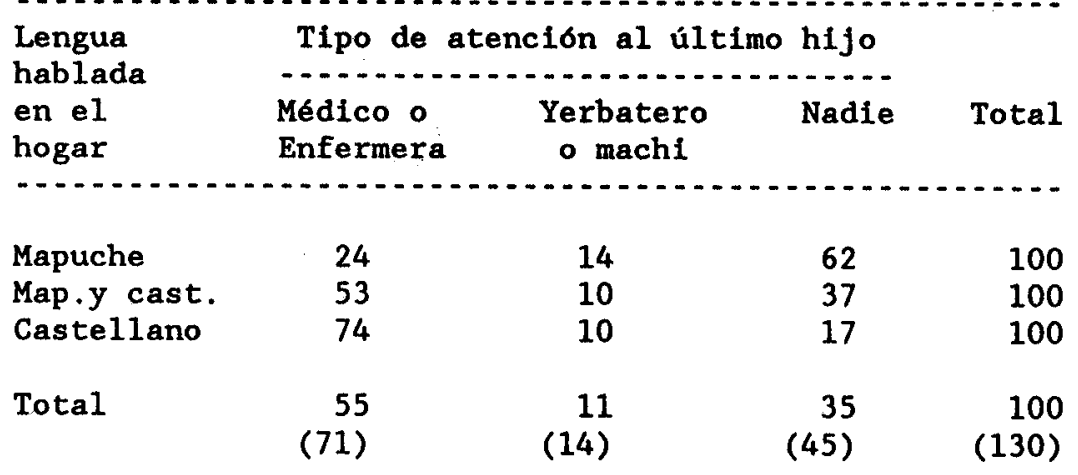

Fuente: Tabulados especiales Censo de 1988.

Como es evidente, estos datos, aunque limitados, presentan nuevos interrogantes tanto sobre el comportamiento de las personas y sobre sus conductas concretas con relación a la salud, como sobre la efectividad de estas acciones y de sus consecuencias para la sobrevivencia de los miembros de la familia, en especial aquellos que se encuentran en edades de mayor riesgo. 


\section{Conclusiones}

En este capitulo se han examinado aquellos aspectos de la población de las reducciones indigenas que se relacionan con la mortalidad y la salud maternoinfantil, destacándose los siguientes resultados.

El nivel de mortalidad Infantil en las reducciones seleccionadas es de 45 por mil, es decir, más del doble que el que corresponde al total del pals para el año 1985. Al interior de la población estudiada no se han encontrado diferencias muy importantes en el comportamiento de esta variable debido, posiblemente, a que se trata de una población relativamente homogénea en cuanto a sus condiciones de vida.

No obstante 10 anterior, se pueden destacar algunas diferencias en la mortalidad infantil según la educación de la madre y la lengua hablada más frecuentemente en el hogar. En el primer caso, se observó que las mujeres con 7 y más años de estudio registran niveles algo menores ( 41 por mil) que las analfabetas o las que tienen hasta 6 años de estudio (44-46 por mil). En e1 segundo, se detectó que en los hogares donde se habla más frecuentemente la lengua mapuche la mortalidad infantil es superior ( 53 por mil) que en los hogares donde predomina el castellano ( 41 por $\mathrm{mIl}$ ). Esto permite concluir que, aun en un medio relativamente homogéneo, los niños que nacen en famillas de madres más educadas o en hogares aparentemente menos orientados hacia los valores $y$ comportamientos tradicionalmente aceptados, tienen mayores probabilidades de sobrevivencia durante el primer año de vida. Quedan por conocer, sin embargo, las causas a que este hecho puede atribuirse y en qué medida éstas se relacionan con las condiciones materiales de vida, con determinantes de carácter social o cultural, con las limitaciones o deficiencias en. la atención de salud, o bien con alguna combinación de estos factores.

Con respecto a la mortalidad materna en las reducciones, cabe señalar que ésta también es mayor que la correspondiente al promedio del pais. Una proyección de las estimaciones realizadas indica que, hacia 1985, la tasa de mortalidad materna para las reducciones podría ubicarsé alrededor de 290 muertes maternas por cada cien mil nacidos vivos, lo que contrasta fuertemente con la cifra que se obtiene de las estadisticas vitales para el total del pais, que es de sólo 44 muertes por cien mil nacidos vivos. El nivel encontrado para la tasa de mortalidad materna implica que, en el ámbito de la población estudiada ocurriria, en promedio, una muerte materna cada año. 
En cuanto a la atención de salud -moderna o tradicional- se ha observado que, en conjunto, en las reducciones estudiadas aproximadamente un 70 por ciento de las mujeres entrevistadas afirmó haber tenido atención profesional en su último parto y un 23 por ciento declaro haber recurrido a algún agente de salud tradicional. E1 resto respondió que fue ayudada por alguna otra persona no especializada.

E1 tipo de atención en el parto también varia según algunas características de las usuarias: la atención profesional es mayor cuando las mujeres son más jóvenes, más educadas o viven en hogares donde se habla más frecuentemente el castellano. Dado que la asociación más fuerte se presenta con la edad de las mujeres, ésto sugiere que ha habido un cambio generacional en el uso de los recursos médicos más modernos.

Con relación a la atención de salud recibida por los hijos antes de morir, se observó que también el acceso a la medicina moderna es mayor cuando las madres son más jóvenes, han tenido más años de estudio y tienen menos apego a las tradiciones culturales, medido por el mayor uso del castellano como lengua más frecuente en el hogar. Sin embargo, llama la atención que en los hogares donde se mantiene el, uso frecuente del mapudungun, un alto porcentaje de las madres declaró que sus hijos no habrían recibido atención especializada -sea tradicional o moderna- antes de morir. Posiblemente, éstos sean casos de muertes neonatales precoces o bien podrian estar indicando un uso bastante extendido de la medicina casera.

Considerando en conjunto los resultados obtenidos, se puede formular la hipotesis de que, sin duda, por su cercania con el centro urbano y el contacto con la sociedad chilena, por influencia de los programas de atención maternoinfantil y los beneficios a que tienen acceso a través de éstos, la población de las reducciones indigenas estudiadas posiblemente ha venido aumentando su acceso a la medicina occidental, aun cuando no necesariamente comparta las creencias y valores subyacentes, que son diferentes a los de su propia cultura. En particular, la atención profesional en el parto puede que sea uno de los cambios más importantes en las prácticas relacionadas con la salud.

Es posible, sin embargo, que la falta de medios económicos y las dificultades para llegar con facilidad a los hospitales o consultorios, en especial en la época de invierno, lleve a que, por el contrario, otro tipo de consultas por razones de salud no sean tan frecuentes, fomentándose asi el empleo de la medicina casera. Esta estrategia, aunque basada en el conocimiento 
tradicional, generalmente transmitido por generaciones, no siempre resulta ser eficiente, ya que enfermedades aparentemente comunes pueden dar lugar, al complicarse, a otras más graves o mortales. Si como lo indican las orientaciones de la atención primaria de salud (OPS-OMS, 1980), se deberia buscar fortalecer la participación comunitaria como una estrategia para reducir la morbimortalidad, se requerirá desarrollar programas de capacitación que a la vez que, estimulen las prácticas tradicionales positivas, incorporen también tecnologias modernas y avanzadas para adecuar las prácticas de autocuidado famillar a las reales necesidades de salud de sus miembros. 


\section{Bibliografia}

Centro Latinoamericano de Demografia (CELADE) (1986), Paraguay: 1a mortalidad infantil según varlables socioeconomicas y geográficas, 1955-1980. CELADE, Santiago, Serie A, N 172 .

Centro Latinoamericano de Demografla (CELADE); Fondo de las Naciones Unidas para la Infancia (UNICEF) (1985), La mortalidad infantil en Bolivia. CELADE, Santiago, Serie OI, $N^{2} 38$.

Centro Latinoamericano de Demografia (CELADE); Fondo de las Naciones Unidas para la Infancia (UNICEF); Organización Panamericana de la Salud (OPS) (1989), La mortalidad en la niñez en Centroamérica. Panamá y Belice, 1970-1985. San José, Costa Rica.

Chackiel, Juan (1987), "La investigación sobre causas de muerte en la América Latina". En Notas de Población, Año XV, N2 44, agosto, pp. 9-30.

Graham, Wendy y Brass, William (1988), Field performance of the sisterhood method for measuring maternal mortality. Documento presentado al Seminario "Recolección y procesamiento de datos demográficos en América Latina", IUSSP, Santiago, mayo 23-27.

Graham, Wendy; Brass, William y Snow (1989), "Estimating maternal mortality: the sisterhood method". En Studies in Family Planning, 20(3), pp. 125135 .

Grebe V., Maria E. (1975), "Taxonomia de enfermedades mapuches". En: Nueva Epoca, $\mathrm{N}^{2} 2, \mathrm{pp} .27-39$.

Guevara, Tomás (1898), Historia de la civilización de la Araucania. Imprenta Cervantes, Santiago, 3 volúmenes.

Gusinde, Martin (1917), "Medicina e higiene entre los antiguos araucanos". En Revista Chilena de Historia y Geografia, Vols. 22-23, N² 26-7, pp. 382$415,139-194$.

Organización Panamericana de la Salud (OPS); Organización Mundial de la Salud (OMS) (1980), Salud para todos en el año 2000, Estrateglas. OPS, Washington.

Organización Panamericana de la Salud (OPS); Organización Mundial de la Salud (OMS) (1986), Documento de referencia sobre estudio y prevención de $1 \mathrm{a}$ mortalidad materna. OPS-OMS, Washington.

Oyarce, Ana M. (1988), "La salud entre los mapuches". En Revista Experienclas, PAESMI, $\mathrm{N}^{2} 3$, pp. 1-44.

Oyarce P., Ana M. (1989), Conocimientos, creencias y prácticas en torno al ciclo vital en una comunidad mapuche de la IX Región de Chile. PAESMI, Santiago, Serie Docs. de Trabajo No. 2, maya. 
Rutenberg, N. ; Boerma, T.; Sullivan, J. y Croft, T. (1990), Direct and Indirect estimates of maternal mortality with data on the survivorship of sisters: results from the Bolivia DHS. Documento presentado a la Reunion Anual de Population Association of America, Toronto, Ontario, mayo 3-5.

Wong, Laura R.; Simons, Harmen; Graham, Wendy y Schkolnik, Susana (1990), Estimaciones de mortalidad materna a partir del método de sobrevivencia de hermanas: experiencias en América Latina. (Inédito). 
Anexos 
ANEXO 1

REDUCCIONES INDIGENAS SELECCIONADAS: ESTIMACIONES DE MORTALIDAD INFANTIL Y JUVENIL, MODELO OESTE DE COALE Y DEMENY. CENSO DE 1988

$\begin{array}{llllllll}I & \mathrm{D}(\mathrm{I}) & \mathrm{X} & \mathrm{Q}(\mathrm{X}) & \mathrm{N} . \mathrm{C} \& \mathrm{D} & \mathrm{FECHA} & \mathrm{Q}(1) & \mathrm{Q}(2) \\ 1 & 0.10526 & 1 & 0.11753 & 13.84 & 1987.95 & 0.11753 & 0.14552 \\ 2 & 0.04450 & 2 & 0.04685 & 20.44 & 1986.65 & 0.04182 & 0.04685 \\ 3 & 0.05961 & 3 & 0.05930 & 19.73 & 1984.66 & 0.04906 & 0.05586 \\ 4 & 0.05799 & 5 & 0.05809 & 20.08 & 1982.27 & 0.04542 & 0.05125 \\ 5 & 0.06773 & 10 & 0.06898 & 19.76 & 1979.63 & 0.04878 & 0.05549 \\ 6 & 0.10455 & 15 & 0.10516 & 18.11 & 1976.82 & 0.06617 & 0.07790 \\ 7 & 0.10487 & 20 & 0.10468 & 18.59 & 1973.87 & 0.06096 & 0.07116\end{array}$

Fuente: Tabulados especiales Censo de 1988. P1/P2=0.1444 P2/P3-0.4774

I: Grupos quinquenales de edad de la madre (15-19 a $45-49$ años)

$D(I): \quad \quad \quad \quad$ Proporción de hijos muertos sobre nacidos vivos

$\mathrm{X}$ : $\quad$ Edad exacta desde el nacimiento hasta $\mathrm{X}$

$Q(X): \quad$ Probabilidad de muerte desde el nacimiento hasta la edad exacta $X$ N.C\&D: $\quad$ Nivel de mortalidad de tabla modelo de Coale y Demeny

$\mathrm{Q}(1) \mathrm{y}$

$Q(2):$

Probabilidad de muerte desde el nacimiento hasta la edad exacta 1 año (mortalidad infantil) y 2 años

\section{ANEXO 2-A}

REDUCCIONES INDIGENAS SELECCIONADAS: ESTIMACIONES DE MORTALIDAD INFANTIL Y JUVENIL SEGUN EDUCACION DE 0-3 AÑOS DE ESTUDIÓ APROBADOS DE LA MADRE, MODELO OESTE DE COALE Y DEMENY. CENSO DE 1988

$\begin{array}{lllllllll}\mathrm{I} & \mathrm{D}(\mathrm{I}) & \mathrm{X} & \mathrm{Q}(\mathrm{X}) & \mathrm{N} . \mathrm{C} \& \mathrm{D} & \mathrm{FECHA} & \mathrm{Q}(1) & \mathrm{Q}(2) \\ 1 & 0.30000 & 1 & 0.32294 & 3.21 & 1987.96 & 0.32294 & 0.39617 \\ 2 & 0.07317 & 2 & 0.06988 & 18.68 & 1986.16 & 0.05997 & 0.06988 \\ 3 & 0.04225 & 3 & 0.03843 & 21.29 & 1983.41 & 0.03333 & 0.03666 \\ 4 & 0.05215 & 5 & 0.04837 & 20.73 & 1980.21 & 0.03876 & 0.04311 \\ 5 & 0.07334 & 10 & 0.06937 & 19.74 & 1976.78 & 0.04900 & 0.05578 \\ 6 & 0.10229 & 15 & 0.09545 & 18.60 & 1973.47 & 0.06084 & 0.07101 \\ 7 & 0.10997 & 20 & 0.10192 & 18.72 & 1970.63 & 0.05955 & 0.06934\end{array}$

Fuente: Tabulados especiales Censo de 1988. Consultar anexo 1. P1/P2-0.2202 P2/P3-0.6930 
ANEXO 2-B

REDUCCIONES INDIGENAS SELECCIONADAS: ESTIMACIONES DE MORTALIDAD INFANTIL Y JUVENIL SEGUN EDUCACION DE 4-6 AÑOS DE ESTUDIO APROBADOS DE IA MADRE, MODELO OESTE DE COALE Y DEMENY. CENSO DE 1988

\begin{tabular}{|c|c|c|c|c|c|c|c|}
\hline I & $D(I)$ & $\mathrm{X}$ & $Q(X)$ & N. C\&D & FECHA & $Q(1)$ & $Q(2)$ \\
\hline 1 & - & & & & & & \\
\hline 2 & 0.03614 & 2 & 0.03800 & 21.17 & 1986.59 & 0.03449 & 0.03800 \\
\hline 3 & 0.07182 & 3 & 0.07207 & 18.86 & 1984.73 & 0.05809 & 0.06745 \\
\hline 4 & 0.05833 & 5 & 0.05907 & 20.02 & 1982.50 & 0.04610 & 0.05207 \\
\hline 5 & 0.06076 & 10 & 0.06262 & 20.13 & 1980.03 & 0.04498 & 0.05071 \\
\hline 6 & 0.11518 & 15 & 0.11730 & 17.51 & 1977.36 & 0.07285 & 0.08661 \\
\hline 7 & 0.09804 & 20 & 0.09906 & 18.86 & 1974.42 & 0.05810 & 0.06746 \\
\hline
\end{tabular}

Fuente: Tabulados especiales Censo de 1988. Consultar anexo 1. P1/P2-0.1563 P2/P3-0.4586

ANEXO 2-C

REDUCCIONES INDIGENAS SELECCIONADAS: ESTIMACIONES DE MORTALIDAD INFANTIL Y JUVENIL SEGUN EDUCACION DE 7 Y MAS AÑOS DE ESTUDIO APROBADOS DE LA MADRE, MODELO OESTE DE COALE Y DEMENY. CENSO DE 1988

\begin{tabular}{llllllll}
\hline $\mathrm{I}$ & $\mathrm{D}(\mathrm{I})$ & $\mathrm{X}$ & $\mathrm{Q}(\mathrm{X})$ & $\mathrm{N} . \mathrm{C} \& \mathrm{D}$ & $\mathrm{FECHA}$ & $\mathrm{Q}(1)$ & $\mathrm{Q}(2)$ \\
1 & 0.15625 & 1 & 0.17438 & 10.07 & 1987.95 & 0.17438 & 0.21883 \\
2 & 0.03077 & 2 & 0.03229 & 21.70 & 1986.63 & 0.02956 & 0.03229 \\
3 & 0.04908 & 3 & 0.04868 & 20.49 & 1984.62 & 0.04124 & 0.04614 \\
4 & 0.06780 & 5 & 0.06774 & 19.48 & 1982.20 & 0.05164 & 0.05916 \\
5 & 0.06818 & 10 & 0.06926 & 19.74 & 1979.53 & 0.04894 & 0.05570 \\
6 & 0.07018 & 15 & 0.07040 & 19.92 & 1976.70 & 0.04714 & 0.05339 \\
7 & 0.05263 & 20 & 0.05240 & 21.27 & 1973.75 & 0.03350 & 0.03685
\end{tabular}

Fuente: Tabulados especiales Censo de 1988. Consultar anexo 1. P1/P2-0.1467 P2/P3-0.4849 
ANEXO 2-D

REDUCCIONES INDIGENAS SELECCIONADAS: ESTIMACIONES DE MORTALIDAD INFANTIL Y JUVENIL SEGUN EDUCACION DE 0-6 AÑOS DE ESTUDIO APROBADOS DE LA MADRE, MODELO OESTE DE COALE Y DEMENY. CENSO DE 1988

$\begin{array}{llllllll}\mathrm{I} & \mathrm{D}(\mathrm{I}) & \mathrm{X} & \mathrm{Q}(\mathrm{X}) & \mathrm{N} . \mathrm{C} \& \mathrm{D} & \mathrm{FECHA} & \mathrm{Q}(1) & \mathrm{Q}(2) \\ & & & & & & & \\ 1 & 0.06818 & 1 & 0.07535 & 17.29 & 1987.95 & 0.07535 & 0.08988 \\ 2 & 0.04839 & 2 & 0.05000 & 20.18 & 1986.55 & 0.04441 & 0.05000 \\ 3 & 0.06349 & 3 & 0.06214 & 19.53 & 1984.42 & 0.05107 & 0.05843 \\ 4 & 0.05583 & 5 & 0.05516 & 20.28 & 1981.88 & 0.04342 & 0.04879 \\ 5 & 0.06770 & 10 & 0.06804 & 19.81 & 1979.09 & 0.04823 & 0.05479 \\ 6 & 0.10667 & 15 & 0.10586 & 18.07 & 1976.20 & 0.06656 & 0.07840 \\ 7 & 0.10687 & 20 & 0.10527 & 18.56 & 1973.27 & 0.06126 & 0.07155\end{array}$

Fuente: Tabulados especiales Censo de 1988. Consultar anexo 1. $\mathrm{P} 1 / \mathrm{P} 2=0.1602$ P2/P3-0.5185

ANEXO 3-A

REDUCCIONES INDIGENAS SELECCIONADAS: ESTIMACIONES DE MORTALIDAD INFANTIL Y JUVENIL SEGUN LENGUA MAPUCHE HABLADA CON MAS FRECUENCIA EN EL HOGAR, MODELO OESTE DE COALE Y DEMENY. CENSO DE 1988

\begin{tabular}{|c|c|c|c|c|c|c|c|}
\hline I & $D(I)$ & $\mathrm{X}$ & $Q(X)$ & N. $C \& D$ & FECHA & $Q(1)$ & $Q(2)$ \\
\hline 1 & - & & & & & & \\
\hline 2 & 0.04348 & 2 & 0.04485 & 20.60 & 1986.22 & 0.04019 & 0.04485 \\
\hline 3 & 0.09756 & 3 & 0.10111 & 17.02 & 1984.88 & 0.07844 & 0.09391 \\
\hline 4 & 0.03125 & 5 & 0.03307 & 21.92 & 1983.38 & 0.02757 & 0.02999 \\
\hline 5 & 0.06977 & 10 & 0.07552 & 19.39 & 1981.73 & 0.05259 & 0.06038 \\
\hline & 0.17857 & 15 & 0.19153 & 14.13 & 1979.67 & 0.11357 & 0.14026 \\
\hline & 0.18269 & 20 & 0.19421 & 14.66 & 1976.78 & 0.10683 & 0.13139 \\
\hline
\end{tabular}

Fuente: Tabulados especiales Censo de 1988. Consultar anexo 1. $\mathrm{P} 1 / \mathrm{P} 2=0.2264$

P2/P3=0.3902 
ANEXO 3-B

REDUCCIONES INDIGENAS SELECCIONADAS: ESTIMACIONES DE MORTALIDAD INFANTIL Y JUVENIL SEGUN LENGUA MAPUCHE Y CASTELLANO HABLADA CON MAS FRECUENCIA EN EL HOGAR, MODELO OESTE DE COALE Y DEMENY. CENSO DE 1988

$\begin{array}{llllllll}\mathrm{I} & \mathrm{D}(\mathrm{I}) & \mathrm{X} & \mathrm{Q}(\mathrm{X}) & \mathrm{N} . \mathrm{C} \& \mathrm{D} & \mathrm{FECHA} & \mathrm{Q}(1) & \mathrm{Q}(2) \\ & & & & & & & \\ 1 & 0.20000 & 1 & 0.23274 & 6.94 & 1988.05 & 0.23274 & 0.29045 \\ 2 & 0.04848 & 2 & 0.05127 & 20.08 & 1986.72 & 0.04544 & 0.05127 \\ 3 & 0.06485 & 3 & 0.06414 & 19.40 & 1984.64 & 0.05249 & 0.06025 \\ 4 & 0.06538 & 5 & 0.06497 & 19.65 & 1982.12 & 0.04987 & 0.05690 \\ 5 & 0.06094 & 10 & 0.06149 & 20.20 & 1979.32 & 0.04428 & 0.04985 \\ 6 & 0.09524 & 15 & 0.09485 & 18.63 & 1976.40 & 0.06051 & 0.07058 \\ 7 & 0.08923 & 20 & 0.08821 & 19.38 & 1973.44 & 0.05260 & 0.06040\end{array}$

Fuente: Tabulados especiales Censo de 1988. Consultar anexo 1. P1/P2=0.1302

$\mathrm{P} 2 / \mathrm{P} 3-0.4888$

ANEXO 3-C

REDUCCIONES INDIGENAS SELECCIONADAS: ESTIMACIONES DE MORTALIDAD INFANTIL Y JUVENIL SEGUN LENGUA CASTELLANO HABLADA CON MAS FRECUENCIA EN EL HOGAR, MODELO OESTE DE COALE Y DEMENY. CENSO DE 1988

$\begin{array}{llllllll}I & \text { D (I) } & \text { X } & \text { Q (X) } & \text { N.C\&D } & \text { FECHA } & \text { Q(1) } & \text { Q(2) } \\ 1 & 0.02857 & 1 & 0.03166 & 21.47 & 1987.94 & 0.03166 & 0.03472 \\ 2 & 0.04124 & 2 & 0.04322 & 20.73 & 1986.62 & 0.03885 & 0.04322 \\ 3 & 0.05045 & 3 & 0.05005 & 20.39 & 1984.61 & 0.04227 & 0.04739 \\ 4 & 0.05263 & 5 & 0.05263 & 20.45 & 1982.21 & 0.04168 & 0.04667 \\ 5 & 0.07566 & 10 & 0.07693 & 19.31 & 1979.55 & 0.05340 & 0.06142 \\ 6 & 0.10856 & 15 & 0.10902 & 17.92 & 1976.74 & 0.06829 & 0.08065 \\ 7 & 0.10721 & 20 & 0.10685 & 18.49 & 1973.80 & 0.06206 & 0.07259\end{array}$

Fuente: Tabulados especiales Censo de 1988. Consultar anexo 1. $\mathrm{P} 1 / \mathrm{P} 2=0.1496$ P2/P3 $=0.4848$ 


\section{ANEXO 3-D}

REDUCCIONES INDIGENAS SELECCIONADAS: ESTIMACIONES DE MORTALIDAD INFANTIL Y JUVENIL SEGUN LENGUA MAPUCHE Y MAPUCHE-CASTELLANO HABLADA CON MAS

FRECUENCIA EN EL HOGAR, MODELO OESTE DE COALE Y DEMENY. CENSO DE 1988

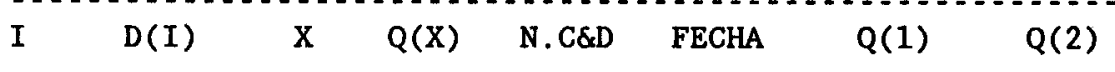

$\begin{array}{rrrrrrrr}1 & 0.17073 & 1 & 0.19092 & 9.11 & 1987.95 & 0.19092 & 0.23939 \\ 2 & 0.04787 & 2 & 0.05056 & 20.14 & 1986.67 & 0.04486 & 0.05056 \\ 3 & 0.06886 & 3 & 0.06870 & 19.08 & 1984.71 & 0.05572 & 0.06439 \\ 4 & 0.06164 & 5 & 0.06191 & 19.84 & 1982.34 & 0.04792 & 0.05439 \\ 5 & 0.06164 & 10 & 0.06272 & 20.12 & 1979.72 & 0.04505 & 0.05078 \\ 6 & 0.10184 & 15 & 0.10268 & 18.23 & 1976.93 & 0.06481 & 0.07613 \\ 7 & 0.10315 & 20 & 0.10321 & 18.66 & 1973.98 & 0.06021 & 0.07019\end{array}$

Fuente: Tabulados especiales Censo de 1988. Consultar anexo 1. P1/P2=0.1417 P2/P3=0.4702 


\title{
III. CARACTERISTICAS EDUCACIONALES
}

\author{
Gabriela Pérez"
}

\section{Introducción}

En este capitulo se analizan las caracteristicas educacionales de la población de reducciones indigenas de los distritos de Labranza, Molco, Maquehue y Metrenco, sobre la base de la información recopilada en el Censo de 1988, en conjunto con antecedentes que permitirán apoyar algunas observaciones generales sobre la educación en Chile y entre los mapuches.

E1 análisis se centrará en el nivel de analfabetismo y en la situación de escolaridad de la población. Sobre este último punto se examinará la asociación existente entre escolaridad y lengua hablada más frecuentemente en el hogar, como una forma de aproximación a la identificación de la relación entre la identidad cultural y el nivel de educación alcanzado. Se establecerán también algunas comparaciones con la escolaridad de ia población del pals y de distintas áreas de la IX Región, buscando luego describir la escolaridad de las personas registradas como jefes de hogar. Finalmente, se presentarán algunas conclusiones sobre los aspectos relevantes encontrados en el análisis de las caracteristicas educacionales de la población.

E1 propósito de este capitulo es describir la situación educativa de la población que reside en las reducciones indigenas estudiadas, según las variables mencionadas y en conjunto con la edad y el sexo de las personas. Se tratará de poner de manifiesto la necesidad de abordar el estudio de la realidad educacional de los mapuches, identificando los principales problemas, los grupos mayormente afectados y los factores asociados con astas situaciones.

Universidad de La Frontera, Temuco. 


\section{La educación en Chile}

La educación es el proceso mediante el cual se entrega el conocimiento y las habilidades motoras, intelectuales y sociales básicas que permiten a las personas tener acceso a nuevos conocimientos y desempeñarse adecuadamente en los campos laboral, cultural y social, aplicando ese conocimiento a su realidad concreta. El aprendizaje se obtiene a lo largo de la vida, siendo la familia, la comunidad (sistema informal) y la escuela (sistema formal) los principales agentes que influyen en la socialización (Borsotti, 1984; Sepúlveda, 1982).

Existe conciencia generalizada que la educación no es sólo un factor esencial en el proceso de desarrollo social y económico de los pueblos, sino también un derecho básico del hombre como ser social, y que el recibirla constituye un principio de equidad y justicia. Dada la importancia que la educación reviste para el desarrollo nacional y personal, suministrar al menos educación básica a toda la población se ha constituido en una de las metas de las politicas de los paises en desarrollo (CEPAL, 1977).

Dentro de los pafses latinoamericanos, Chile está considerado como uno de los que posee un alto nivel relativo de escolaridad. Ya entre los años $1964 \mathrm{y}$ 1973 los gobiernos habian logrado universalizar la enseñanza básica y masificar la enseñanza media (Tironi, 1988). Sin embargo, al igual que en el resto de los paises latinoamericanos, el desarrollo educacional es desequilibrado según la región, el grado de urbanización, el estrato social e incluso el grupo étnico. Se menciona que en la rafi de esta situación estaria el acceso desigual a los circuitos de satisfacción de las necesidades educaciónales, producto de la aplicación de polfticas educacionales orientadas al sector urbano que, además, suponen que en el pals existe una cierta homogeneidad social, cultural, geográfica y lingüistica. Tradicionalmente la educación en las áreas rurales ha sido desfavorecida y el descenso del analfabetismo, como indicador que resume el estado de la educación, ha sido más lento que en las áreas urbanas, hecho que se asocia con la condición de pobreza (Borsotti, 1984).

En Chile, las regiones VII y IX han presentado'los porcentajes más altos de analfabetismo. En el caso de la IX Región, se señalan como factores que acompanan a esta situación el alto indice de ruralidad (sobre 40 por ciento), la tardía incorporación de esta zona a la sociedad chilena (1883), y la presencia del pueblo mapuche, con una lengua y cultura diferentes, que representa casi un tercio de la población regional (Hernández, 1984; Rivera, 1988; Sepúlveda, 1982). 


\subsection{La educación entre los mapuches}

Los estudios realizados sobre el pueblo mapuche muestran una situación educacional bastante inferior con respecto a los promedios nacionales, al igual que en el resto de los paises de América Latina que tienen presencia indigena, aun cuando con relación a la mayoria de ellos la tasa de analfabetismo de la población mapuche es relativamente baja (Rivera, 1988; Varese y Rodriguez, 1983). Sin embargo, esta situación presenta grados variables de deterioro, dependiendo de la ubicación particular de los asentamientos (desarrollo del área, urbanización y accesibilidad).

Esta inferioridad relativa del pueblo mapuche debe ser entendida como producto del largo proceso de dominación ejercido por la sociedad chilena y la relación de subordinación que ha marcado el contacto entre estas dos culturas, que se manifiesta, por ejemplo, en la aplicación de un sistema centralizado de educación que no considera las diferencias culturales y sociales de la población que la recibe. Este es un aspecto de trascendental importancia para la comprensión de la situación educacional del pueblo mapuche. E1 conocimiento entregado por un sistema de enseñanza que no toma en cuenta las necesidades e intereses especificos de la población mapuche y que no relaciona los contenidos que imparte con el trabajo y modo de vida de ésta, puede carecer de valor práctico y sus contenidos olvidarse con facilidad.

También es importante tener en cuenta que la población mapuche accede a una educación en que las condiciones materiales de las escuelas rurales, as 1 como los recursos humanos con que ellas cuentan, no siempre son suficientes ni adecuados a la realidad que deben atender (Lavados y Hi11, 1986).

En el área estudiada el número de establecimientos educacionales es suficiente para que prácticamente toda la población tenga acceso a la enseñanza básica. No obstante, debe consignarse que de los cincuenta establecimientos rurales que existen en la actualidad, sólo el 32 por ciento ofrece séptimo y octavo año básico (de las trece escuelas municipales el 62 por ciento ofrece esos grados). Por otra parte, existen colegios con matriculas inferiores a 50 alumnos (más de la mitad de los particulares), 1 en muchos de los cuales el único profesor

Esta situación, junto con otros antecedentes, se puede apreciar en los datos que se presentan en el anexo 5. Debe destacarse que la información corresponde a 1988, indicando una realidad semejante entre el área estudiada y la Comuna de Temuco. 
atiende en una jornada y en la única sala; además, se observa una subutilización de colegios mejor implementados. La limitación de la educación hasta el sexto año básico en la mayoria de los establecimientos afecta directamente las posibilidades de participación en el sistema. La enseñanza media, en sus distintas modalidades es un fenómeno casi exclusivamente urbano en la IX Región, por lo que la población escolar rural prácticamente no tiene acceso a ella, a menos que cuente con locomoción, vías de acceso y recursos económicos para viajar diariamente a los centros urbanos cercanos, o para permanecer en ellos.

Como se ha mencionado, no obstante el progreso en el promedio nacional de escolaridad, se reconoce un deterioro de la calidad de la educación, que parece ser mayor en el área rural. Sus manifestaciones se han acentuado a partir de 1981, año en que el Estado cede la administración de la educación a las municipalidades y al sector privado. A juzgar por los resultados, la educación no estaria ejerciendo uno de sus roles básicos como es el de reducir las desigualdades sociales; al contrario, el sistema escolar parece estar acrecentando las diferencias (Tironi, 1988). Así por ejemplo, en 1985 se detectó que en la IX Región el 60 por ciento de la población escolar mapuche matriculada entre primero y cuarto año básico no sabia leer ni escribir (SERPLAC IX Región, 1986).

E1 idioma en que se imparte la enseñanza es un factor de gran importancia en el proceso educativo, afectando directamente el rendimiento escolar. Al respecto, Lavados y Hill (1986), afirman que existe un bajo rendimiento en zonas cuya lengua materna no es el español y que en esta región -donde hay una importante cantidad de niños en edad escolar que sólo hablan mapudungun al ingresar a la escuela- un número importante abandona los estudios porque no puede aprender a leer ni escribir con la rapidez necesaria para mantener el nivel que exige el plan de enseñanza. Los niños que sólo hablan la lengua nativa, en su gran mayoria, siguen repitiendo el primer grado y suelen abandonar antes del tercero.

Otro de los factores que es necesario considerar se relaciona con el sistema económico de subsistencia familiar, que obliga a que los niños sean incorporados precozmente a la fuerza de trabajo o los sustrae temporalmente del proceso educativo cuando el trabajo agricola lo requiere. Según informaciones proporcionadas por profesores de escuela de los distritos estudiados, 1a inasistencia escolar es más alta en los periodos de siembra y cosecha que durante el invierno. Un estudio sobre ausentismo del escolar mapuche en escuelas de reducciones de Chol Chol (Comuna de Nueva Imperial, Provincia de Cautin), Indica que la asistencia de primero y segundo grado es más alta en el mes de junio, y 
1a de tercero y cuarto a partir de mayo, al finalizar la época de cosecha y comercialización del trigo, porotos y papas. Los factores climáticos en los meses de invierno aparecen determinando la mejor asistencia a la escuela, pues en ese periodo no se realizan actividades productivas (Ibarbe, 1976).

La conjunción de todos estos factores contribuye decisivamente a la comprensión de las caracteristicas de la participación de la población mapuche en el proceso educacional, asi como ayuda a entender el bajo rendimiento escolar y el retiro prematuro que se observa con frecuencia entre los educandos. Por e11o, parece ser evidente que la educación deberia cambiar su orientación en las áreas rurales de alta concentración indigena, mejorar cuantitativa $y$ cualitativamente la oferta educacional, buscar la integración a la sociedad nacional respetando la identidad cultural de los mapuches, emplear metodologias apropiadas para enseñar a una población cuyo idioma materno no es el castellano, adecuar los programas de estudio a esa realidad y -quizás-modífícar el calendario escolar, de manera que las épocas de mayor trabajo en el campo no dificulten la asistencia a clases.

Resta señalar como una reflexión final, que los beneficios que se esperaba provocar al obtener una elevación paulatina de la escolaridad de la población en las áreas rurales $y$, en particular, en el campesinado mapuche, se han traducido más bien en una asimilación de los valores urbanos y un cambio en las expectativas, impulsando a la gente joven a emigrar (Bengoa y Valenzuela, 1984), sumándose al factor de expulsión que significa la escasa disponibilidad de tierra.

En las próximas secciones de este capitulo se abordarán las caracteristicas educacionales de la población censada en 1988 en las reducciones indigenas de cuatro distritos de la Comuna de Temuco. Es necesario hacer presente que no se tiene el propósito de generalizar conclusiones ni hipótesis, ya que éstas pueden no ser representativas de toda la población que vive en reducciones indigenas - del grupo étnico mapuche en su totalidad.

\section{Definición y medición de las caracteristicas educacionales}

La información que se analiza proviene de la siguiente pregunta formulada en el Censo de 1988 a cada uno de los integrantes del grupo familiar de 5 años y más de edad:

- "¿Cuál es el último curso que terminó en la educación primaria, básica, secundaria, media o universitaria?" 
E1 objetivo de esta pregunta fue obtener Indicadores del grado de instrucción de las personas, como una forma de medir su situación de escolaridad, en el contexto de la inserción de la población en la estructura social.

E1 análisis de los datos se orientó a determinar el perfil educativo de la población, medido por el número de cursos aprobados en la educación formal. Atendiendo a los bajos niveles educacionales de la población, las categorias de anos de estudio aprobados se centraron en la enseñanza básica, de la siguiente manera:

- 0 año de estudio: sin asistencia a un establecimiento educacional o sin aprobación del primer año. Esta categoría corresponde a los analfabetos absolutos.

- 1 a 3 años de estudio aprobados: corresponde al nivel inferior del primer grado (enseñanza primaria o básica). Esta categoria equivale a los analfabetos funcionales, ya que existe consenso sobre la necesidad de aprobar un mínimo de 4 años de estudio para lograr un grado de alfabetización socialmente útil (Rivera, 1988).

- 4 a 6 años de estudio aprobados: corresponde al nivel superior de la enseñanza primaria o al nivel medio de la básica.

- 7 a 8 años de estudio aprobados: corresponde al nivel inferior de la enseñanza secundaria o al nivel superior de la enseñanza básica.

- 9 años de estudio aprobados y más: equivale al nivel superior de enseñanza secundaria o a la enseñanza media, y a la enseñanza superior o universitaria.

Con fines comparativos, al considerar el "curso aprobado" se tomó como base para los cálculos a la población de 5 años y más de edad, aun cuando la edad mínima de ingreso a la educación básica es de 6 años cumplidos (teóricamente no deberia haber nínos con algún curso aprobado sino a partir de los 7 años de edad). Por otra parte, las categorias indicadas, consideradas en forma individual, no se corresponden exactamente con los niveles de enseñanza, por 1o

E1 sistema educacional antiguo distinguia dos niveles de educación: "primaria", con una duración de 6 años, y "secundaria", también de 6 años. A partir de 1967 el sistema educacional cambió, aumentando el nivel primario, ahora "básico", a 8 años y reduciendo el nivel secundario, ahora "medio", a 4 años. 
que el análisis se referirá a la situación de escolaridad según las categorias propuestas, asi como al promedio de años de estudio.

\section{La educación en las reducciones indigenas}

\subsection{Analfabetismo}

Se considera que el analfabetismo es uno de los principales factores asociados con la pobreza en los palses en desarrollo, siendo más elevado en las áreas rurales, en especial en los paises y regiones con importante presencia indigena (Borsotti, 1984; CEPAL, 1977; Hernández, 1984).

Con relación al analfabetismo absoluto en las reducciones censadas en 1988, el cuadro 1 muestra que la proporción de personas de 5 años y más de edad que no han aprobado ningún curso en el sistema de educación formal alcanza a un 19 por ciento. ${ }^{3}$ La situación descrita afecta en mayor medida a las mujeres, ya que de cada 10 personas analfabetas, 6 son mujeres.

\section{CUADRO 1}

REDUCCIONES INDIGENAS SELECCIONADAS: POBLACION DE 5 AÑOS Y MAS DE EDAD POR SEXO, SEGUN CURSOS APROBADOS EN LA EDUCACION FORMAL. CENSO DE 1988

\begin{tabular}{|c|c|c|c|c|c|c|c|}
\hline \multirow[t]{2}{*}{ Sexo } & \multicolumn{2}{|c|}{$\begin{array}{c}\text { Algún curso } \\
\text { aprobado }\end{array}$} & \multicolumn{2}{|c|}{$\begin{array}{c}\text { Ningún curso } \\
\text { aprobado }\end{array}$} & \multicolumn{2}{|c|}{ Ignorado } & \multirow{2}{*}{$\begin{array}{c}\text { Total } \\
\mathrm{N}^{2}\end{array}$} \\
\hline & $\mathrm{N}^{2}$ & 8 & $\mathrm{~N}^{2}$ & 8 & $\mathrm{~N}^{\mathrm{e}}$ & 8 & \\
\hline Hombres & 5164 & 85.5 & 861 & 14.3 & 17 & 0.3 & 6042 \\
\hline Mujeres & 4204 & 76.2 & 1307 & 23.7 & 10 & 0.2 & 5521 \\
\hline mbos sexos & 9368 & 81.0 & 2168 & 18.8 & 27 & 0.2 & 11563 \\
\hline
\end{tabular}

Fuente: Anexo 1-A.

La proporción disminuye, evidentemente, si se considera a la población de 15 años y más de edad. Sin embargo, ello ocurre principalmente en los hombres, donde la proporción desciende al 10 por ciento. Estas cifras, en todo caso, son bastante mayores a los promedios nacionales. Sobre esto se volverá al analizar la situación de escolaridad de la población. 
Al considerar la edad de los analfabetos absolutos o personas que no han aprobado siquiera un curso en la educación formal, se puede apreciar en el cuadro 2 que las mayores proporciones se encuentran entre las personas de más edad, donde la situación de la mujer es más dramática. Entre éstas, las proporciones son sistemáticamente más elevadas que las de los hombres a partir de $10 s 30$ años de edad.

En los grupos entre 10 y 34 años de edad el analfabetismo se reduce considerablemente y las diferencias entre ambos sexos son menos notorias, tendiéndose a la igualdad. Como se observa en el gráfico 1, las discrepancias incluso se invierten en los menores de 25 años de edad, 10 que podria obedecer al hecho de que ha habido una mayor incorporación de las mujeres al sistema educacional, cuestión que ocurriria por 10 menos desde la década del 60 , debido a cambios en la estructura social mapuche respecto al rol que le corresponde desempeñar a la mujer.

E1 mayor analfabetismo en las mujeres de más edad se observa también con frecuencia en las áreas rurales y, en particular, en las comunidades indigenas de otros palses de América Latina (Hernández, 1984).

E1 alto porcentaje de analfabetismo observado entre los niños menores de 10 años de edad obedece a que un número importante de ellos tiene menos de 7 años de edad.' A su vez, parte del analfabetismo de los niños que tienen entre 7 y 9 años de edad se debe al ingreso tardio de éstos a la escuela o a repitencia en el primer curso. ${ }^{3}$

- En 1929 se dicta en Chile la Ley de Instrucción Primaria Obligatoria para la población de 7 a 15 años, que posteriormente se modifica en 6 a 15 años de edad.

3 Según un estudio realizado en reducciones de Chol Chol (Comuna de Nueva Imperial, Provincia de Cautin), las edades de los niños de primer grado fluctuaban entre 7 y 13 años (Ibarbe, 1976). 
CUADRO 2

REDUCCIONES INDIGENAS SELECCIONADAS: POBLACION DE 5 AÑOS Y MAS DE EDAD SIN NINGUN CURSO APROBADO POR GRUPOS QUINQUENALES DE EDAD, SEGUN SEXO. CENSO DE 1988

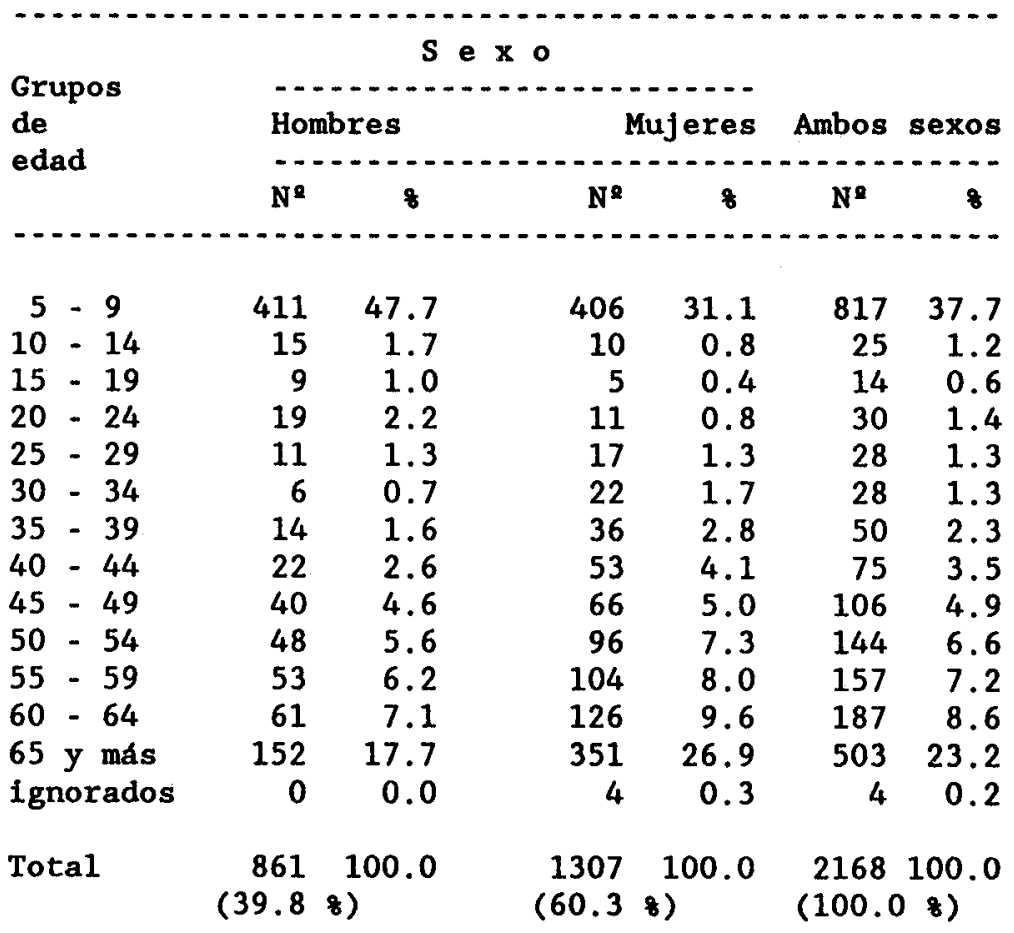

Fuente: Anexo 1-A.

A1 analizar las tasas especificas de analfabetismo, las cuales aparecen representadas en el cuadro 3, se advierte que en las edades más avanzadas el porcentaje de mujeres analfabetas es casi el doble del que presentan los varones; mientras para los varones mayores de 49 años de edad las tasas de analfabetismo casi no superan el 30 por ciento, para las mujeres de igual edad las tasas oscilan entre un 35 y un 70 por ciento. 
Gráfico 1

REDUCCIONES INDIGENAS SELECCIONADAS: TASAS ESPECIFICAS DE ANALFABETISMO ABSOLUTO POR GRUPOS QUINQUENALES DE LA POBLACION DE 10 ANOS Y MAS DE EDAD. CENSO DE 1988

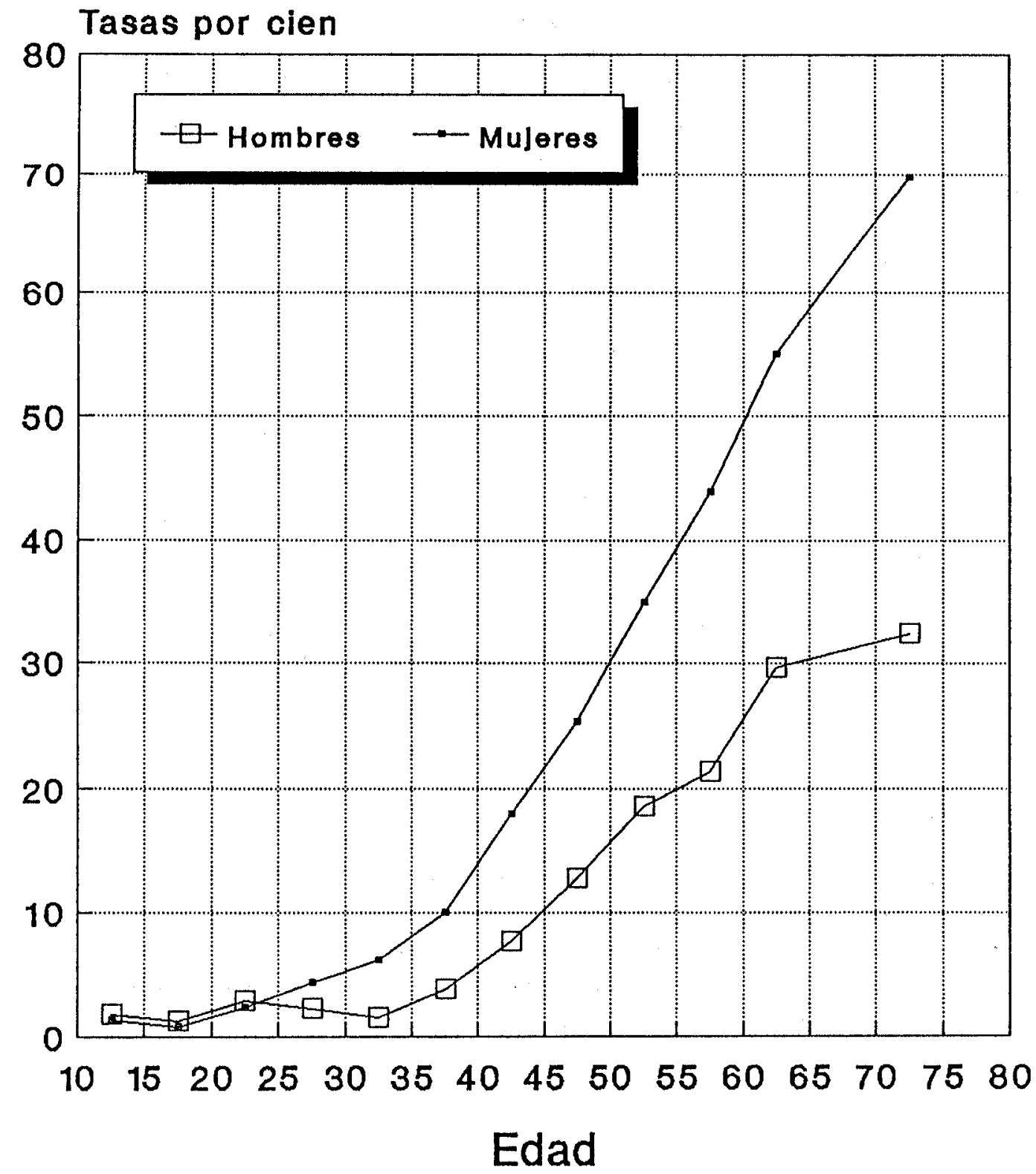

Fuente: Cuadro 3 
CUADRO 3

REDUCCIONES INDIGENAS SELECCIONADAS :

TASAS ESPECIFICAS DE ANALFABETISMO ABSOLUTO DE LA POBLACION

DE 6 AÑOS Y MAS DE EDAD POR GRUPOS DE EDAD, SEGUN SEXO. CENSO DE 1988

(por cien personas)

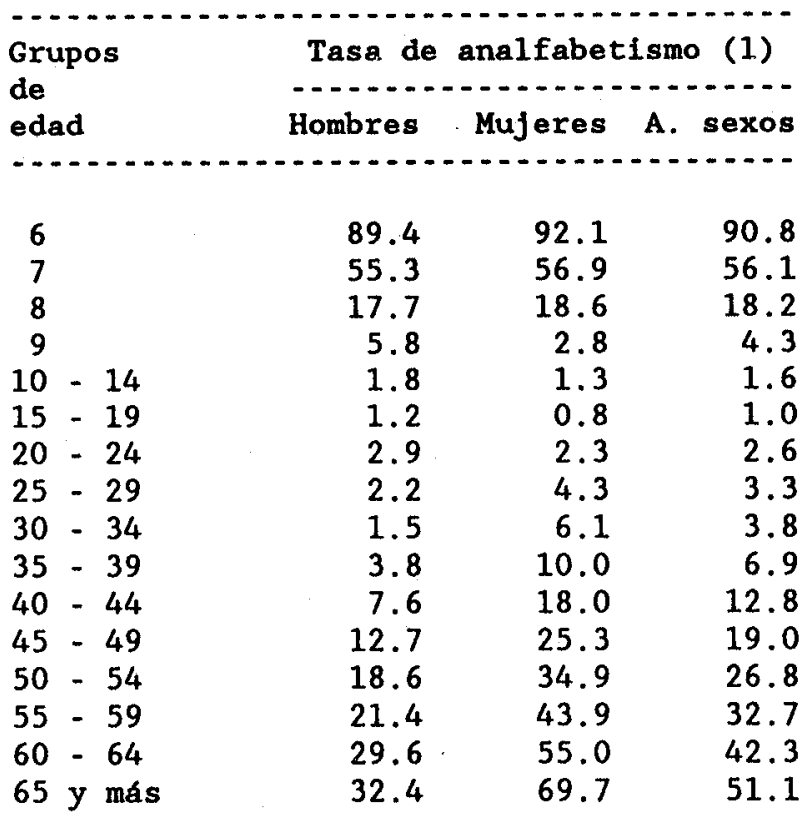

Fuente: Anexo 1-A.

(1): (Población sin ningún año de estudio aprobado/población total de1 grupo de edad) $* 100$.

La tendencia observada para el conjunto de la población se mantiene con leves variaciones al considerar los distritos por separado (cuadro 4): la mayor tasa de analfabetismo corresponde a Metrenco y la más baja a Maquehue. En todos los distritos el analfabetismo femenino es mayor que el de los varones $y$ hay diferencias importantes entre ambos sexos. 


\section{CUADRO 4}

REDUCCIONES INDIGENAS SELECCIONADAS: TASAS DE ANALFABETISMO ABSOLUTO DE LA POBLACION DE 5 AÑOS Y MAS DE EDAD POR DISTRITO, SEGUN SEXO.

CENSO DE 1988

(por cien personas)

\begin{tabular}{lccc} 
Distrito & \multicolumn{1}{c}{ Sexo } & & \\
& Hombres & Mujeres & $\begin{array}{c}\text { Ambos } \\
\text { sexos }\end{array}$ \\
Labranza & 14.8 & 22.3 & 18.5 \\
Molco & 14.5 & 22.6 & 18.2 \\
Maquehue & 11.4 & 22.4 & 16.7 \\
Metrenco & 15.7 & 25.5 & 20.4
\end{tabular}

Fuente: Anexos 1-B, 1-C, 1-D y 1-E.

E1 nivel de analfabetismo de la población censada en el año 1988 es alto con relación a los indicadores nacionales y regionales de 1982 (cuadro 5 y gráfico 2). Se puede apreciar que la tasa de analfabetismo para ambos sexos obtenida en este estudio duplica al valor de la tasa nacional (1982) y es algo stiperior a la tasa de analfabetismo de la IX Región (1982). Por su parte, el total de reducciones censadas en 1982 presentaban una tasa que era un 65 por ciento más elevada que la correspondiente a la IX Región.

Se observa que casi no hay diferencias entre el analfabetismo de hombres y mujeres en el pais; que éstas son de casi un 25 por ciento en la región, y que se mantienen cerca del 65 por ciento en las reducciones censadas en 1982 y 1988 (aunque en 1982 se incluyen todas las reducciones de la región).

En las mujeres estudiadas según el Censo de 1988 el analfabetismo sería considerablemente superior al observado en las mujeres del pals (1982) y también más elevado que el registrado en las mujeres de la región (1982). Como son grandes diferencias, es posible asociarlas con el hecho de que en las áreas urbanas existe una mayor oferta educacional y una mayor incorporación de las mujeres al mercado de trabajo, 1o que exige una mejor calificación. 
TASAS DE ANALFABETISMO ABSOLUTO DE LA POBLACION DE 5 AÑOS Y MAS DE EDAD POR AREA, SEGUN SEXO. CENSOS DE 1982 Y 1988

(por cien personas)

\begin{tabular}{|c|c|c|c|}
\hline \multirow[b]{2}{*}{ Area } & \multicolumn{2}{|c|}{ Sexo } & \multirow[b]{2}{*}{$\begin{array}{l}\text { Ambos } \\
\text { sexos }\end{array}$} \\
\hline & Hombres & Mujeres & \\
\hline Pais 1982 (1) & 9.6 & 10.0 & 9.8 \\
\hline IX Región 1982 (2) & 13.2 & 16.4 & 14.8 \\
\hline $\begin{array}{l}\text { Total reducciones } 1982 \text { (3) } \\
\text { Reducciones seleccionadas }\end{array}$ & 18.7 & 30.5 & 24.4 \\
\hline Censo de 1988 (4) & 14.3 & 23.7 & 18.8 \\
\hline
\end{tabular}

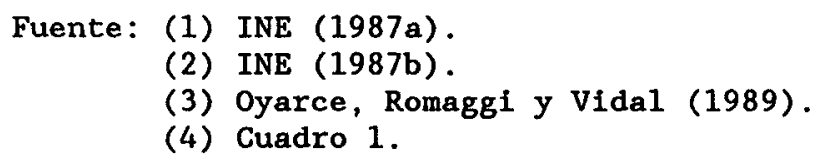

Finalmente, al existir una fuerte emigración entre las mujeres de las reducciones, se puede suponer que se estarian censando principalmente aquellas no migrantes, que son las de mayor edad y menor instrucción."

A1 comparar estos hallazgos con los resultados observados en la población de todas las reducciones de la IX Región en 1982, el analfabetismo en las reducciones seleccionadas es menor y las diferencias observadas entre hombres y mujeres son más reducidas. En esta comparación debe considerarse que en el Censo Nacional de 1982 se incluye un grupo de comunas muy heterogéneo, lo que implica que es posible encontrar un mayor grado de analfabetismo. Parte de las

Al respecto, es posible plantear como hipótesis más general que el nivel de analfabetismo de la población podría ser más bajo si se considerase a la población que reside algunos meses fuera de las reducciones, tales como estudiantes en establecimientos de Temuco. Esta hipótesis se sostiene en la probable existencia de un número importante de niños que estudian fuera de las reducciones, asi como en la fuerte emigración detectada en el área estudiada. 


\section{TASAS DE ANALFABETISMMO ${ }^{2}$ ABSOLUTO EN PAIS, IX REGION Y REDUCCIONES INDIGENAS. CENSOS DE 1982 Y 1988 (población de 5 años y más de edad)}

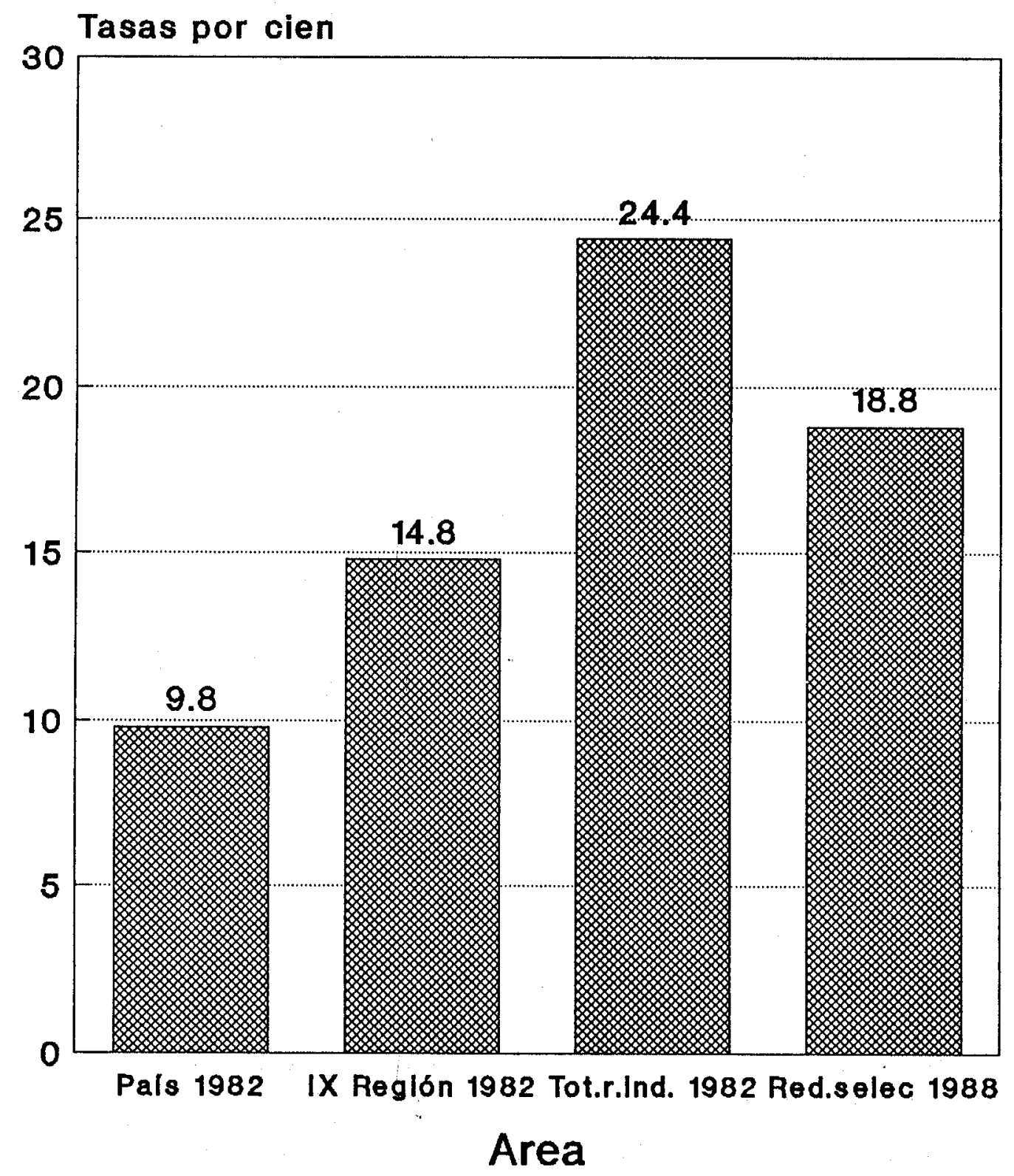

Fuente: Cuadro 6 
diferencias pueden obedecer al hecho de que en las áreas más alejadas ha sido más tardía la incorporación de la población a los procesos de cambio económico, social y de difusión tecnologica.'

De cualquier manera, es notorio que se ha producido un cambio en el ingreso al sistema educacional en las últimas décadas, especialmente en la mujer mapuche de las reducciones estudiadas. El proceso creciente de compenetración de los espacios urbanos y rurales habria provocado cambios culturales en el área rural, produciendo modificaciones en las pautas de conducta de la propia sociedad mapuche. La educación, además de ser valorada, sería utilizada como un mecanismo de ascenso social, siendo vista como una necesidad para poder desempeñarse con mayores ventajas en la sociedad nacional, en la medida que la dependencia con respecto a ésta es cada vez mayor, producto de la falta de oportunidades de trabajo y la baja rentabilidad de las actividades en el área rural.

\subsection{Situación de escolaridad}

A pesar de que el analfabetismo de la población de las reducciones indigenas seleccionadas muestra un nivel más bajo que el que correspondia al total de reducciones de la IX Región en 1982, reflejando una mayor participación en el sistema educativo de hombres y mujeres (especialmente en los grupos de población más joven), los niveles de escolaridad alcanzados son bastante bajos.

E1 cuadro 6 muestra que en la población estudiada predominan las personas que poseen entre 4 y 6 años de estudio aprobados (nivel medio de enseñanza básica; 33 por ciento), seguido por las personas que tienén entre 1 y 3 años de estudio aprobados (nivel inferior de enseñanza básica o analfabetos funcionales; 27 por ciento). Los analfabetos absolutos representan la tercera categoria (19 por ciento), la que sumada a los analfabetos funcionales totaliza el 45 por ciento de la población de 5 años y más de edad, proporción que se eleva al 50 por ciento entre las mujeres.

En general, tanto en términos absolutos como relativos, los hombres alcanzan una mayor presencia en las categorías más áltas de años de estudio aprobados, teniendo un promedio de escolaridad de 4.4 años, superior al de las

En la Comuna de Lumaco (Provincia de Malleco) el analfabetismo en la población de 15 años y más de edad alcanzaba en 1986 al 60 por ciento en la reducción Nahuelpán; 45 por ciento en la reducción Cayumán y 50 por ciento en la comunidad de Pilinmapu (Diaz, 1986). En las comunidades de Colpi, Temu Lemu y Nancahue (Comuna de Traiguén, Provincia de Malleco) el 35 por ciento de la población era analfabeta (Oyarce, 1988). 
mujeres, que alcanza a 3.8 años. De cualquier modo, tanto hombres como mujeres tienen, en promedio, educación básica o primaria incompleta.

\section{CUADRO 6}

REDUCCIONES INDIGENAS SELECCIONADAS: POBLACION DE 5 AÑ̃OS Y MAS DE EDAD POR AÑOS DE ESTUDIO APROBADOS, SEGUN SEXO. CENSO DE 1988

\begin{tabular}{|c|c|c|c|c|c|c|}
\hline \multirow{2}{*}{$\begin{array}{l}\text { Años de estudio } \\
\text { aprobados }\end{array}$} & \multicolumn{2}{|c|}{ Hombres } & \multicolumn{2}{|c|}{ Mujeres } & \multicolumn{2}{|c|}{ Ambos sexos } \\
\hline & $\mathrm{N}^{2}$ & 8 & $\mathrm{~N}^{2}$ & 8 & $\mathrm{~N}^{2}$ & 8 \\
\hline Ninguno & 861 & 14.3 & 1307 & 23.7 & 2168 & 18.7 \\
\hline 1 a 3 años & 1595 & 26.4 & 1469 & 26.6 & 3064 & 26.5 \\
\hline 4 a 6 años & 2131 & 35.3 & 1714 & 31.0 & 3845 & 33.3 \\
\hline 7 a 8 años & 1057 & 17.5 & 724 & 13.1 & 1781 & 15.4 \\
\hline 9 años y más & 381 & 6.3 & 297 & 5.4 & 678 & 5.9 \\
\hline Ignorados & 17 & 0.3 & 10 & 0.2 & 27 & 0.2 \\
\hline Total & 6042 & 100.0 & 5521 & 100.0 & 11563 & 100.0 \\
\hline Promedio (años) & 4. & & 3 & & 4 & \\
\hline
\end{tabular}

Fuente: Anexo 1-A.

Con relación a la escolaridad de la población del total de reducciones de 1a IX Región, que en 1982 presentaban un promedio de 3.2 años de estudio, la población censada en 1988 eleva éste a 4.1 años y la participación en educación básica casi se duplica.

El análisis de la situación de escolaridad en el grupo de población que teóricamente ha terminado el ciclo básico, es decir, los mayores de 14 años de edad, evita la distorsión producida por la inclusión de aquellas personas que por su edad no han entrado al sistema o que aun permanecen en él. Esta información se presenta en el cuadro 7. 
CUADRO 7

\section{REDUCCIONES INDIGENAS SELECCIONADAS: POBLACION DE 15 AÑOS Y MAS DE EDAD POR AÑOS DE ESTUDIO APROBADOS, SEGUN SEXO. CENSO DE 1988}

\begin{tabular}{|c|c|c|c|c|c|c|}
\hline \multirow{2}{*}{$\begin{array}{l}\text { Años de estudio } \\
\text { aprobados }\end{array}$} & \multicolumn{2}{|c|}{ Hombres } & \multicolumn{2}{|c|}{ Mujeres } & Ambos & sexos \\
\hline & $\mathrm{N}^{2}$ & 8 & Ne & 8 & Ne & 8 \\
\hline Ninguno & 435 & 9.7 & 891 & 22.0 & 1326 & 15.6 \\
\hline 1 a 3 años & 1000 & 22.4 & 952 & 23.6 & 1952 & 22.9 \\
\hline 4 a 6 años & 1665 & 37.2 & 1289 & 31.9 & 2954 & 34.7 \\
\hline 7 a 8 años & 975 & 21.8 & 605 & 15.0 & 1580 & 18.6 \\
\hline 9 años y más & 381 & 8.5 & 297 & 7.3 & 678 & 8.0 \\
\hline Ignorados & 16 & 0.4 & 8 & 0.2 & 24 & 0.3 \\
\hline Total & 4472 & 100.0 & 4042 & 100.0 & 8514 & 100.0 \\
\hline Promedio (años) & 5 . & & 4. & & 4. & \\
\hline
\end{tabular}

Fuente: Anexo 1-A.

De acuerdo con estos datos, sin embargo, no se aprecian modificaciones importantes; en la población predominan las personas que tienen entre 4 y 6 años de estudio aprobados ( 35 por ciento; gráfico 3 ). Las personas que alcanzan algún grado de enseñanza media o más representan el 8 por ciento y el porcentaje de analfabetos absolutos y funcionales se reduce, pero se acentuan las diferencias de los analfabetos absolutos entre hombres y mujeres.

Como se vio anteriormente al analizar el analfabetismo, el ingreso al sistema educacional ha aumentado en los grupos más jóvenes, coincidiendo con el aumento de la cobertura del sistema educacional, especialmente notorio desde 1960. Atendiendo a este hecho, se difererició a la población entre menores de 30 años (5-29) y población de 30 años y más de edad. E1 cuadro 8 muestra que, considerando la población de ambos sexos, existen notorias diferencias entre estos grupos de edad en todas las categorfas de educación, excepto en la que corresponde a 4 a 6 años de estudio, en que ambos grupos etarios presentan las más altas proporciones y sin que existan diferencias. 
Gráfico 3

REDUCCIONES INDIGENAS SELECCIONADAS:

DISTRIBUCION RELATIVA DE LA POBLACION DE

15 ANOS $Y$ MAS DE EDAD POR SEXO, SEGUN ANOS DE ESTUDIO APROBADOS. CENSO DE 1988
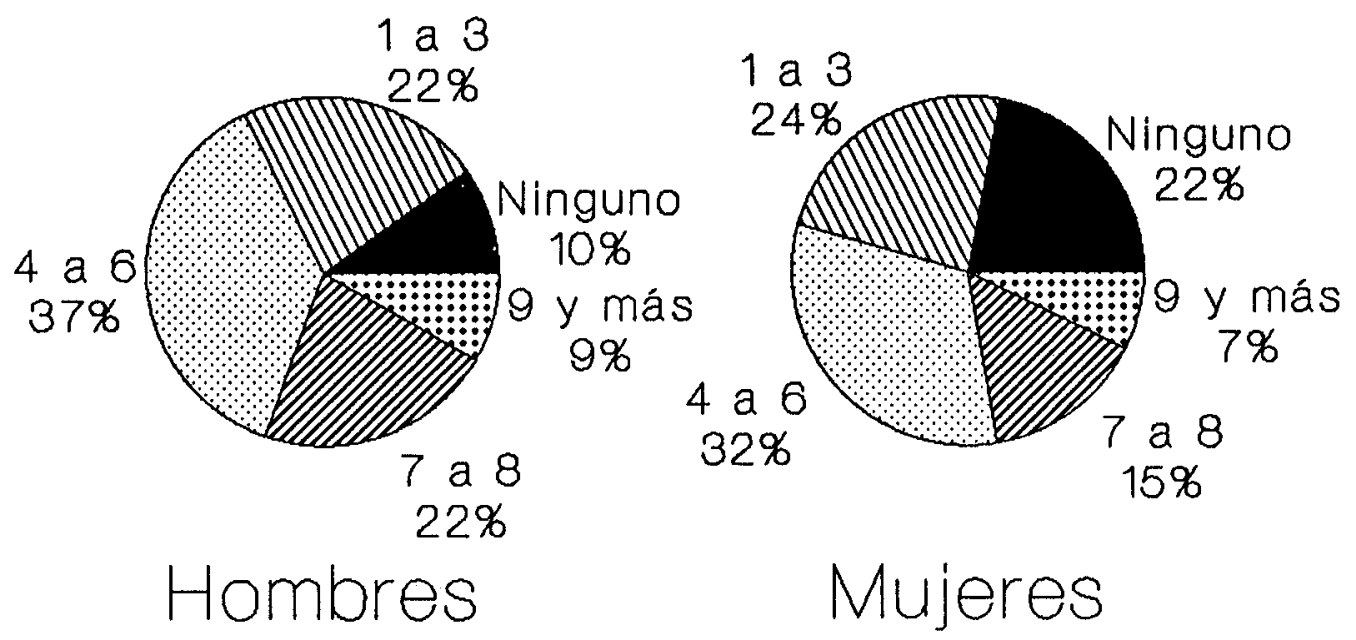

Fuente: Cuadro 7 
Los promedios más bajos de escolaridad se concentran en el grupo de 30 años y más de edad, con 3.2 años de estudio. En este grupo de edad el 57 por ciento de las personas se encuentra bajo el promedio.

\section{CUADRO 8}

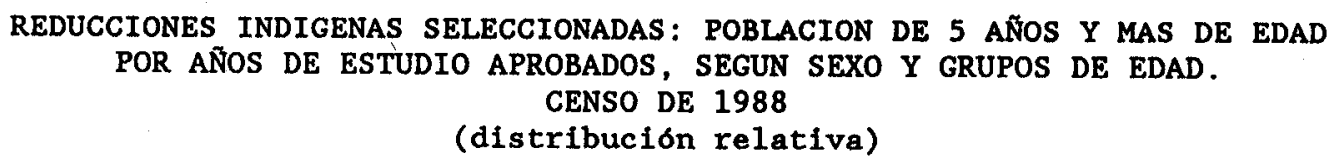

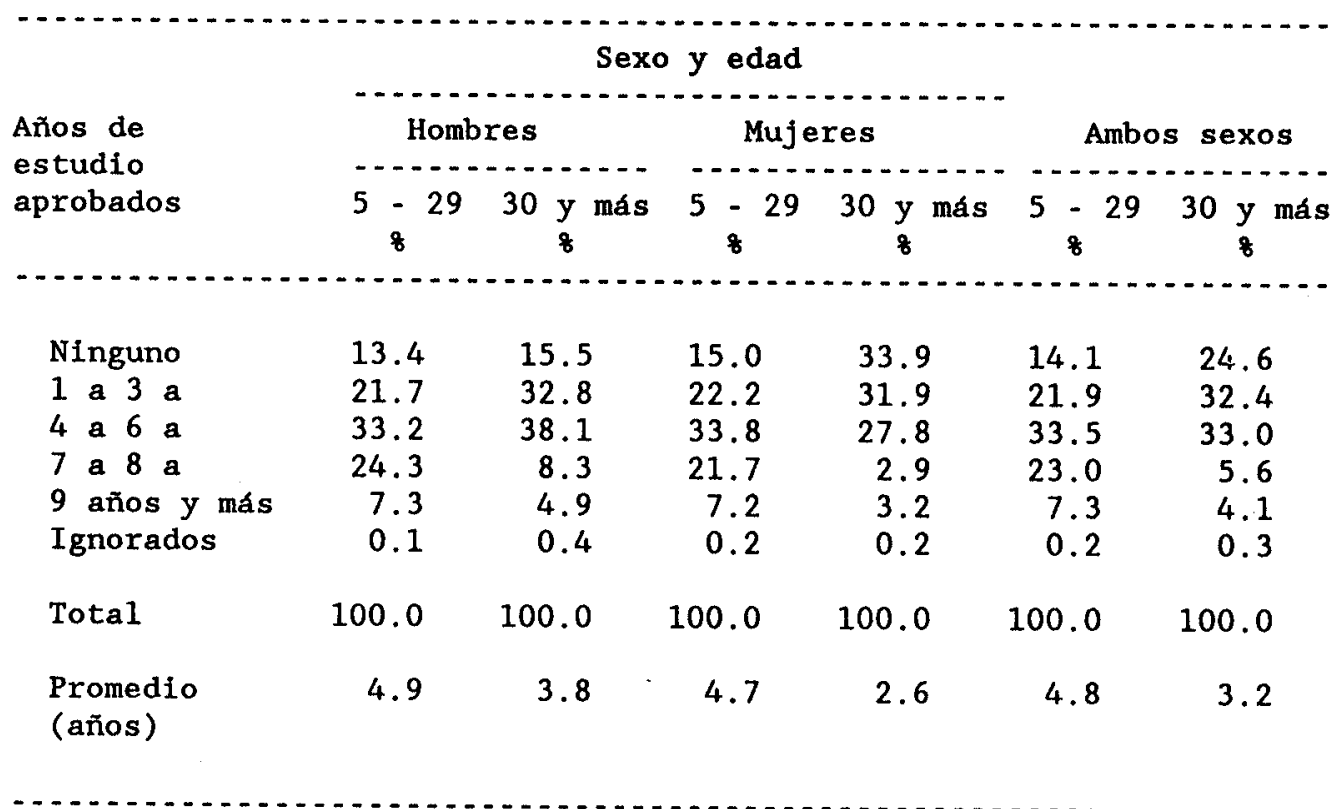

Fuente: Anexo 1-A.

E1 grupo de 5 a 29 años de edad presenta un promedio de 4.8 años de escolaridad y el 30 por ciento de la población se ubica por sobre él, siendo necesario enfatizar que en este grupo el proceso educacional no ha concluido, por lo que las diferencias observadas entre las personas jóvenes y las de mayor edad deberian acentuarse. Sin embargo, en este grupo el promedio de escolaridad está muy por debajo del promedio nacional para 1987, que corresponde a 8.1 años (Lavin y Larrain, 1989).

Al considerar el sexo de las personas, la distribución de los varones de ambos grupos de edad $y$ de las mujeres jóvenes sigue la misma tendencia, presentando los valores más altos la categoría de 4 a 6 años de estudio. En 
las mujeres de 30 años y más de edad, en cambio, las mayores frecuencias se encuentran en las analfabetas absolutas y funcionales.

Hay que destacar que las personas de 15 a 24 años de edad presentan e1 más alto promedio de escolaridad, con casi 7 años, tanto hombres como mujeres. Esto significa que en estos grupos el nivel educacional alcanzado corresponde al nivel superior de la educación básica.

Resumiendo, la población de las reducciones de Labranza, Molco, Maquehue y Metrenco posee una baja escolaridad, presentando una situación de mayor deterioro las personas de edad más avanzada, sobre todo en el caso de las mujeres; los grupos jóvenes tienen un mejor nivel, que es parejo para ambos sexos.

E1 aumento del número de establecimientos de enseñanza básica podría ser uno de los factores que explica el mayor nivel educacional de las generaciones más recientes, puesto que habria contribuido a incorporar al sistema educacional a la población de zonas más aisladas, asi como a incrementar la participación de las mujeres, aunque al respecto, Oyarce, Romaggi y Vidal (1989) mencionan que cerca de 1920 más de la mitad de la población masculina de las reducciones de la región habia ingresado al sistema escolar, mientras la participación femenina era muy baja. Esto sugiere que serian más bien los cambios relativos a la situación de la mujer en la sociedad mapuche los determinantes principales del mayor ingreso relativo de la población femenina al sistema educacional en las últimas décadas.

La situación educacional descrita para el total de la población se mantiene en sus lineamientos básicos al analizar por separado cada distrito (cuadro 9 y anexo 2). Tanto en el grupo de varones mayores de 29 años como en las mujeres de la misma edad, los niveles de escolaridad son similares en los cuatro distritos. Maquehue destaca como el distrito que presenta un mejor nivel educacional, con la menor tasa de analfabetismo y con los niveles más elevados de educación para los jóvenes; un factor que parece haber influido en ello es 1a presencia de la Misión Anglicana en este sector desde 1915, la que contribuye con servicios de salud y educación. En Metrenco, en cambio, la presencia de la población joven en las categorias superiores de años de estudio es inferior a la de los otros distritos. 
CUADRO 9

REDUCCIONES INDIGENAS SELECCIONADAS: PROMEDIO DE ESCOLARIDAD DE LA POBLACION DE 5 AÑOS Y MAS DE EDAD POR DISTRITO, SEGUN SEXO $Y$ GRUPOS DE EDAD. CENSO DE 1988 (años de estudio aprobados)

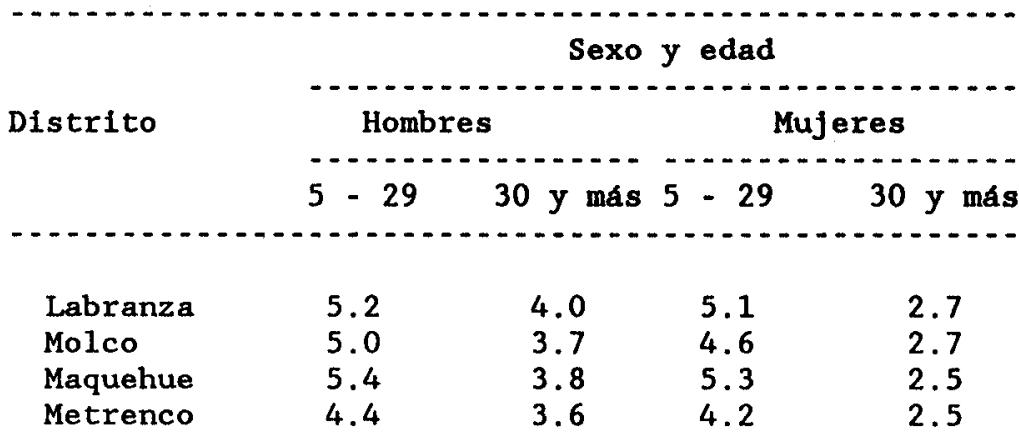

Fuente: Anexos 1-B, 1-C, 1-D y 1-E.

Sin embargo, los antecedentes disponibles no permiten explicar en su totalidad las discrepanclas anotadas. No parece haber una mayor concentración de establecimientos escolares en un área determinada ni diferencias en cuanto a antigüedad. Desde mediados del siglo pasado ha habido una fuerte influencia de distintos grupos religiosos en toda el área de las reducciones mapuches de la IX Región. Los Padres Capuchinos son los primeros en preocuparse de la educación del indigena fundando colegios, escuelas misionales; se instalan en Padre Las Casas después de 1883. La Iglesia Anglicana está en el sector de Maquehue desde 1915 y posteriormente se suman a esta labor la Iglesia Metodista $y$ otras instituciones religiosas. Todos estos grupos religiosos se han caracterizado por entregar una educación integral a un gran sector de la población mapuche, que contemplaba incluso el aprendizaje de un oficio (Bengoa, 1987; Bengoa y Valenzuela, 1984; Durán y Ramos, 1988).

Actualmente el 75 por ciento de los establecimientos de educación básica de la Comuna de Temuco se encuentra en el área rural, correspondiendo a una extensa red configurada por establecimientos municipalizados y del sector particular subvencionado, muchos de estos últimos a cargo de distintas iglesias. En general, la labor educativa de estos grupos ha sido muy importante en la incorporación de la población indigena a la sociedad nacional. 


\subsection{Educación y lengua hablada}

El bajo rendimiento educacional en aquellos paises o regiones en que coexisten diferentes grupos étnicos, ha llevado a prestar especial importancia a las diferencias lingüisticas y culturales que mantienen estos grupos (Hernández, 1984; Sepúlveda, 1982).

La mantención de la lengua materna como medio habitual de comunicación en un contexto de relaciones inter-étnicas desigual es considerado, junto con la concepción religiosa, como uno de los rasgos de mayor importancia en el sentimiento de pertenencia del mapuche a su grupo étnico y de su apego al modo de vida tradicional.

Al ser el lenguaje el elemento de comunicación de mayor importancia en el aprendizaje, las personas que por su socialización no tienen un dominio suficiente del idioma oficial, se encuentran en desventaja para adquirir los conocimientos entregados por un sistema educativo que ignora las diferencias culturales y lingüisticas que existen en la población."

En la IX Región, aproximadamente el 60 por ciento de la población del área rural es mapuche, según Oyarce (1988); en la Comuna de Temuco, el 87 por ciento de la matricula de las escuelas rurales corresponde a alumnos de esta etnia.' Parte importante del pueblo mapuche residente en el área rural mantiene el uso de su propio idioma, el mapudungun, el que utiliza en la socialización de sus miembros $y$ en todos los aspectos de su vida cultural (Sepúlveda, 1982).

Existe evidencia que el rendimiento escolar de la población mapuche es bajo (CEPAL, 1982; Sepúlveda,1982; SERPLAC IX Regíon, 1986). Estudios realizados por la Secretaria de Educación de la IX Región muestran indices altisimos de deserción escolar en esta área. Por otra parte, se señala que una de las causas de las dificultades en el aprendizaje entre los niños que al ingresar a la escuela no hablan español, deriva de su exposición a un sistema que utiliza un idioma que no es su lengua materna. Al no tener un manejo adecuado del idioma,

Sepúlveda (1982) señala que pese al gran número de escuelas en el área rural, sólo en muy pocas y desde hace breve tiempo se aplica un Programa de Educación Rural Mapuche que persigue adecuar la educación básica a las caracteristicas lingüisticas y culturales de los estudiantes.

Según antecedentes de la Secretaria Regional Ministerial de Educación de la IX Región. 
la comprensión de contenidos y conceptos se hace más dificil (Burrows et al., 1989; Hernández, 1984).

Los mapuches, al ser incorporados a la sociedad chilena, se han visto obligados a desempeñarse como hablantes bilingües, con distinto grado de competencia en el uso del castellano, por to que son bilingües en grado asimétrico. En estos grupos el manejo del castellano es especialmente dificil, pues el mapudungun no tiene un sistema de escritura y las estructuras idiomáticas de ambos lenguajes son diferentes, como apunta Sepúlveda (1982).

Dados estos antecedentes, interesa conocer la situación de escolaridad de la población que habla mapudungun, con relación a las personas que, viviendo en reducciones, tienen un mayor dominio del castellano. Para estos efectos, se diferenciaron las personas en cuyo hogar se habla frecuentemente mapudungun, de las provenientes de hogares en los que se habla preferentemente castellano, y de aquellas pertenecientes a hogares en que se usan ambas lenguas con similar frecuencia.

Es conveniente tener presente una restricción al relacionar la lengua hablada más frecuentemente en el hogar con la educación. La pregunta relativa a lengua hablada se obtuvo a nivel de hogar, en cambio, la información sobre educación se obtuvo para cada una de las personas. Se parte del supuesto que toda persona que vive en el hogar será socializada con el idioma que se habla más frecuentemente dentro de éste. Sin embargo, se sabe que el uso de la lengua se relaciona con la edad de la persona, por lo que en un mismo hogar puede haber personas que hablen con distinta frecuencia una $u$ otra lengua.

Los datos del cuadro 10 indican que, en general, el promedio de escolaridad es relativamente bajo en todos los grupos de lengua hablada. No obstante, es notorio que las personas mayores de 29 años de edad que viven en hogares en que se mantiene el uso frecuente del mapudungun presentan indicadores más deteriorados que las que hablan mapudungun-castellano y, especialmente, con relación a las personas que hablan castellano con más frecuencia. Al respecto, hay que tener presente que más de dos tercios de las personas que hablan mapudungun son analfabetas (absolutas y funcionales), en tanto que entre las personas bilingües y las que hablan castellano el analfabetismo se reduce a 48 y 39 por ciento, respectivamente. 
CUADRO 10

\section{REDUCCIONES INDIGENAS SELECCIONADAS: PROMEDIO DE ESCOLARIDAD DE LA POBLACION DE 5 AÑOS Y MAS DE EDAD POR LENGUA HABLADA MAS FRECUENTEMENTE EN EL HOGAR, SEGUN SEXO Y GRUPOS DE EDAD. CENSO DE 1988 \\ (años de estudio aprobados)}

\begin{tabular}{|c|c|c|c|c|}
\hline \multirow[t]{2}{*}{$\begin{array}{l}\text { Lengua } \\
\text { hablada }\end{array}$} & Hon & 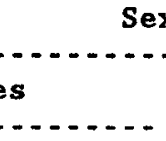 & 1 & res \\
\hline & $5-29$ & 30 y más & $5-29$ & 30 y más \\
\hline $\begin{array}{l}\text { - Mapudungun } \\
\text { - Mapudungun y } \\
\text { castellano } \\
\text { - Castellano }\end{array}$ & $\begin{array}{l}4.6 \\
5.1\end{array}$ & $\begin{array}{l}2.7 \\
3.6 \\
4.4\end{array}$ & $\begin{array}{l}4.3 \\
4.2 \\
5.2\end{array}$ & $\begin{array}{l}1.3 \\
2.3 \\
3.5\end{array}$ \\
\hline
\end{tabular}

Fuente: Anexo 3-A.

Al comparar los promedios de escolaridad de hombres y mujeres con relación a la lengua hablada, se aprecia que en términos globales, los hombres presentan una mejor situación, destacando que las diferencias según la lengua hablada son más notorias en el sexo femenino (gráfico 4).

El análisis de la influencia de la edad muestra que ésta discrimina entre los mayores de 29 años y los menores de 30 años. Entre los jóvenes, hombres y mujeres, las diferencias de escolaridad se atenúan o tienden a desaparecer, cualquiera sea el idioma que se practique.

Las personas mayores de 29 años de edad se concentran en la categoria sin educación y hasta 3 años de estudio, salvo aquellas que hablan castellano. Tres cuartas partes de la población que habla mapudungun es analfabeta; proporción que alcanza al 60 por ciento entre los que hablan ambas lenguas y desciende al 47 por ciento entre los que hablan castellano más frecuentemente. La proporción de población que tiene educación media es reducida en todos los grupos (ver anexo 3-A). 
Grafico 4

REDUCCIONES INDIGENAS SELECCIONADAS:

PROMEDIO DE ESCOLARIDAD DE LA POBLACION DE 5 ANOS Y MAS DE EDAD, SEGUN LENGUA HABLADA. CENSO DE 1988

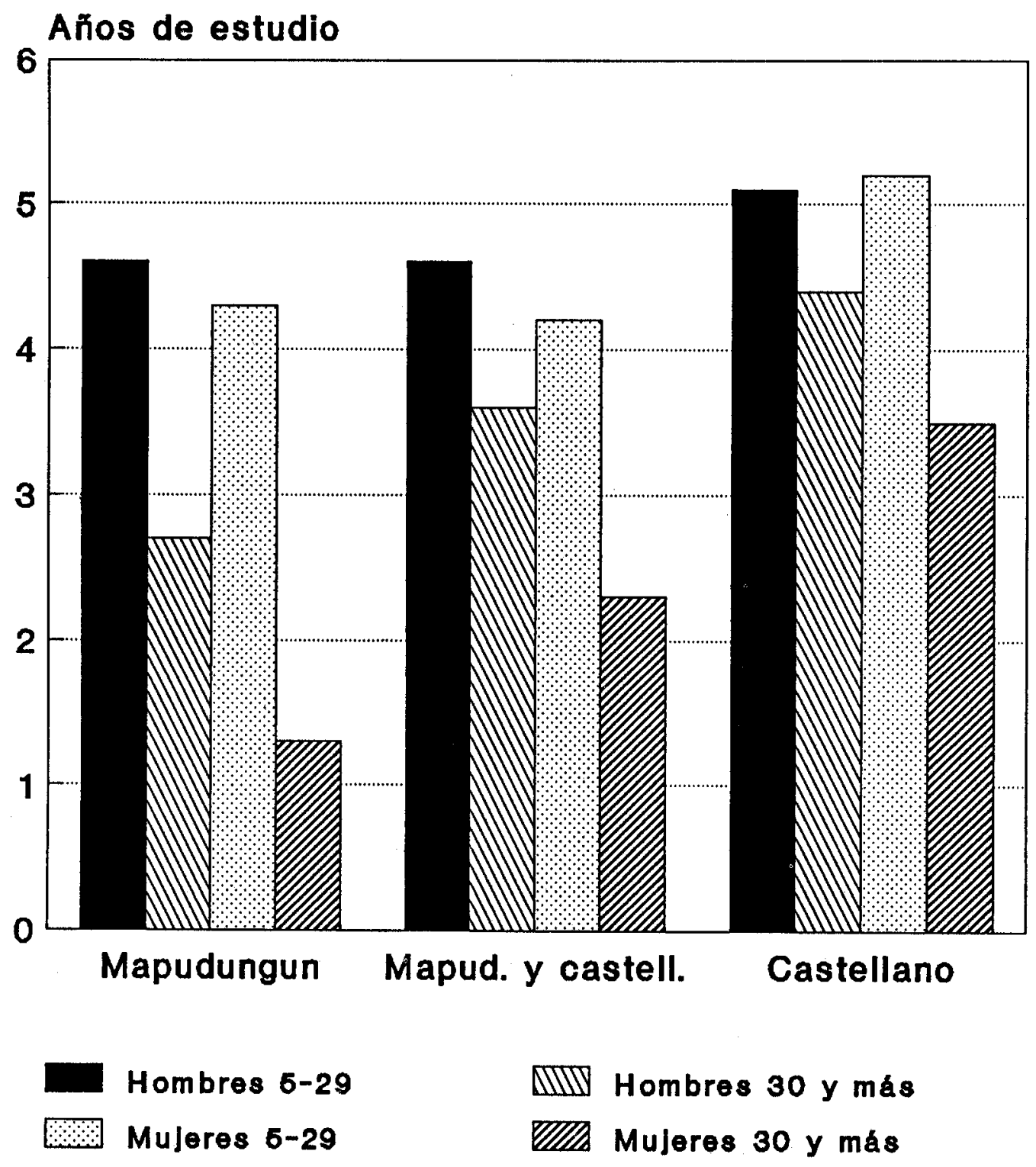

Fuente: Cuadro 10 
De la comparación del promedio de años de estudio entre los jóvenes y las personas de mayor edad en función de la lengua hablada, se observa que entre los que hablan mapudungun, el promedio de escolaridad de los jóvenes es considerablemente más elevado que el de las personas de mayor edad, especialmente entre las mujeres.

Entre las personas de mayor edad, se mantienen las diferencias de escolaridad por sexo en todos los grupos de lengua hablada, siendo más acentuadas entre los que hablan mapudungun (la escolaridad es el doble en los varones), superioridad masculina que disminuye al 56 por clento entre los bilingües y al 25 por ciento entre los que hablan castellano.

Resumiendo, la población que reside en las reducciones indigenas se muestra como un grupo de baja escolaridad. En general, las personas que hablan preferentemente mapudungun están en una situación más desmejorada que las que hablan castellano; esta situación se acentúa entre las personas de mayor edad y entre las mujeres, siendo la conjunción de ambas variables -edad y sexo- la que presenta peores indicadores. Una explicación para este fenómeno podria estar dada por la posición tradicional de predominio del hombre en sus relaciones con la sociedad nacional, mientras que el accionar de la mujer se realiza principalmente dentro de la comunidad mapuche. Sin embargo, esta situación parece haber ido cambiando con el tiempo, por la necesidad que ésta contribuya a Ia economia del hogar recurriendo al trabajo fuera de la comunidad (Bengoa y Valenzuela, 1984; Borsotti, 1984).

\subsection{La situación de escolaridad al interior de la IX Régión}

Para tener una idea de las diferencias intrarregionales con relación a la situación de escolaridad de la población, se comparan a continuación los niveles de educación de las reducciones seleccionadas correspondientes a cuatro distritos de la Comuna de Temuco, con los niveles detectados a partir del Censo Nacional de 1982 en las áreas urbanas y rurales de la IX Región y, dentro de estas últimas, los que corresponden a las parcelas (pequeñas propiedades con escasa - nula población mapuche) y al conjunto de las reducciones indigenas de la región.

Según la información proveniente del Censo Nacional de 1982, se aprecia que en las áreas urbanas de la IX Región la escolaridad de la población es mayor a la de las áreas rurales, debido al menor analfabetismo y a la elevada participación en la categoria 9 y más años de estudio, como se desprende de la 
Inspección del cuadro 11. E1 total de reducciones presentaba un mayor analfabetismo que las áreas rurales en su conjunto, hecho que se corresponde con el menor analfabetismo observado en las parcelas.

Las reducciones estudiadas en 1988 muestran una mejor situación de la escolaridad de su población con respecto a la totalidad de las reducciones en 1982. No obstante, salvo la mayor representación de la categoría 7 y 8 años de estudio aprobados, la distribución de la escolaridad de la población de las reducciones seleccionadas no se diferencia significativamente de la que correspondla a las áreas rurales y parcelas en 1982.

Estos antecedentes estarian indicando el atraso en el mejoramiento de $1 a$ escolaridad que caracterizaria a algunos grupos sociales en función de su ruralidad, de su pertenencia a estratos socioeconomicos bajos y por constituir una minorfa étnica.

CUADRO 11

IX REGION Y REDUCCIONES INDIGENAS: DISTRIBUCION RELATIVA DE LA POBLACION DE 5 AÑOS Y MAS DE EDAD POR AÑOS DE ESTUDIO APROBADOS. CENSOS DE 1982 Y 1988

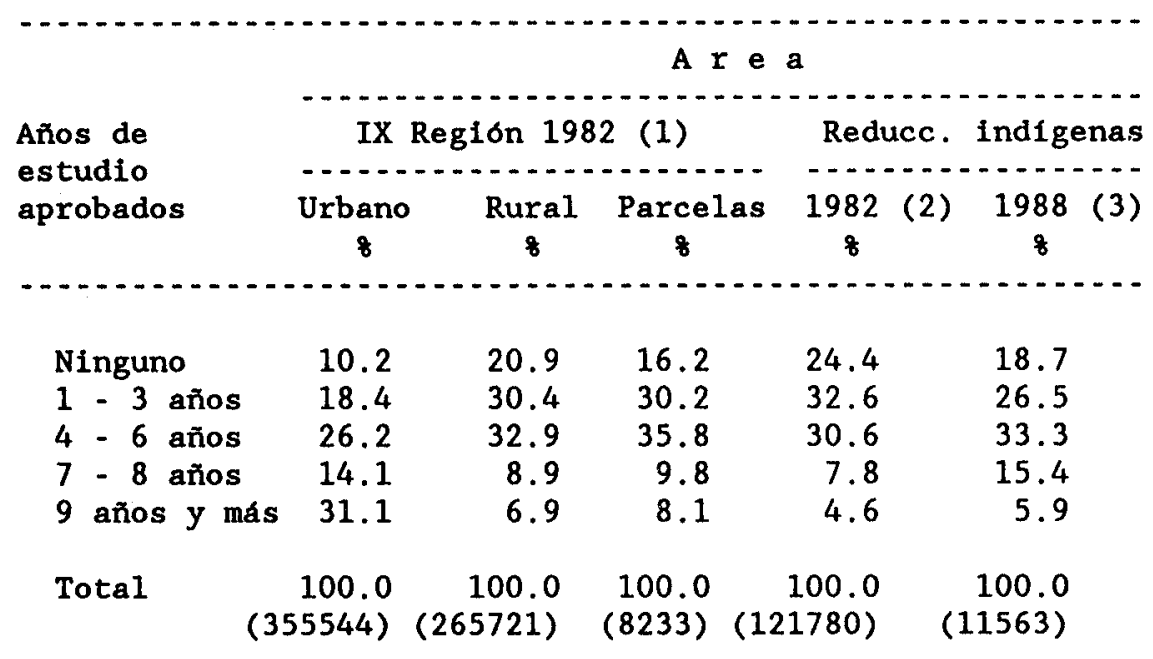

Fuente: (1) y (2) Oyarce, Romaggi y Vidal (1989). E1 año 1982 (3) Cuadro 6. corresponde al total de reducciones de la región. 


\subsection{La educacion del jefe de hogar}

Un aspecto interesante de estudiar es la educacion del jefe de hogar, ya que el nivel educacional alcanzado por los padres puede considerarse un indicador de la inserción económica y social de las familias, influyendo de esta forma en el rendimiento $y$-eventualmente- en el nivel escolar que puedan alcanzar sus hijos.

Las cifras del cuadro 12 muestran que la mayoria de los jefes de hogar tiene una baja escolaridad, presentando un analfabetismo de un 20 por ciento, cifra que se eleva a un 50 por ciento si se considera también a los analfabetos funcionales. Los niveles más bajos de escolaridad los presentan los jefes de hogar mayores de 49 años de edad, situación en la que se encuentra el 81 por ciento de ellos.

E1 comportamiento por sexo muestra que más de la mitad de las mujeres registradas como jefas de hogar es analfabeta absoluta y el analfabetismo total alcanza a 4 de cada 5 mujeres. Esto último plantea un problema de gran importancia, porque en el supuesto que la mujer jefa de hogar es la encargada principal de la socialización de los hijos, ello puede reflejarse negativamente en su rendimiento escolar, al no poder reforzarles en el hogar los contenidos educacionales entregados en la escuela. 
CUADRO 12

REDUCCIONES INDIGENAS SELECCIONADAS:

DISTRIBUCION RELATIVA DE LOS JEFES DE HOGAR POR GRUPOS DE EDAD

Y SEXO, SEGUN AÑOS DE ESTUDIO APROBADOS. CENSO DE 1988

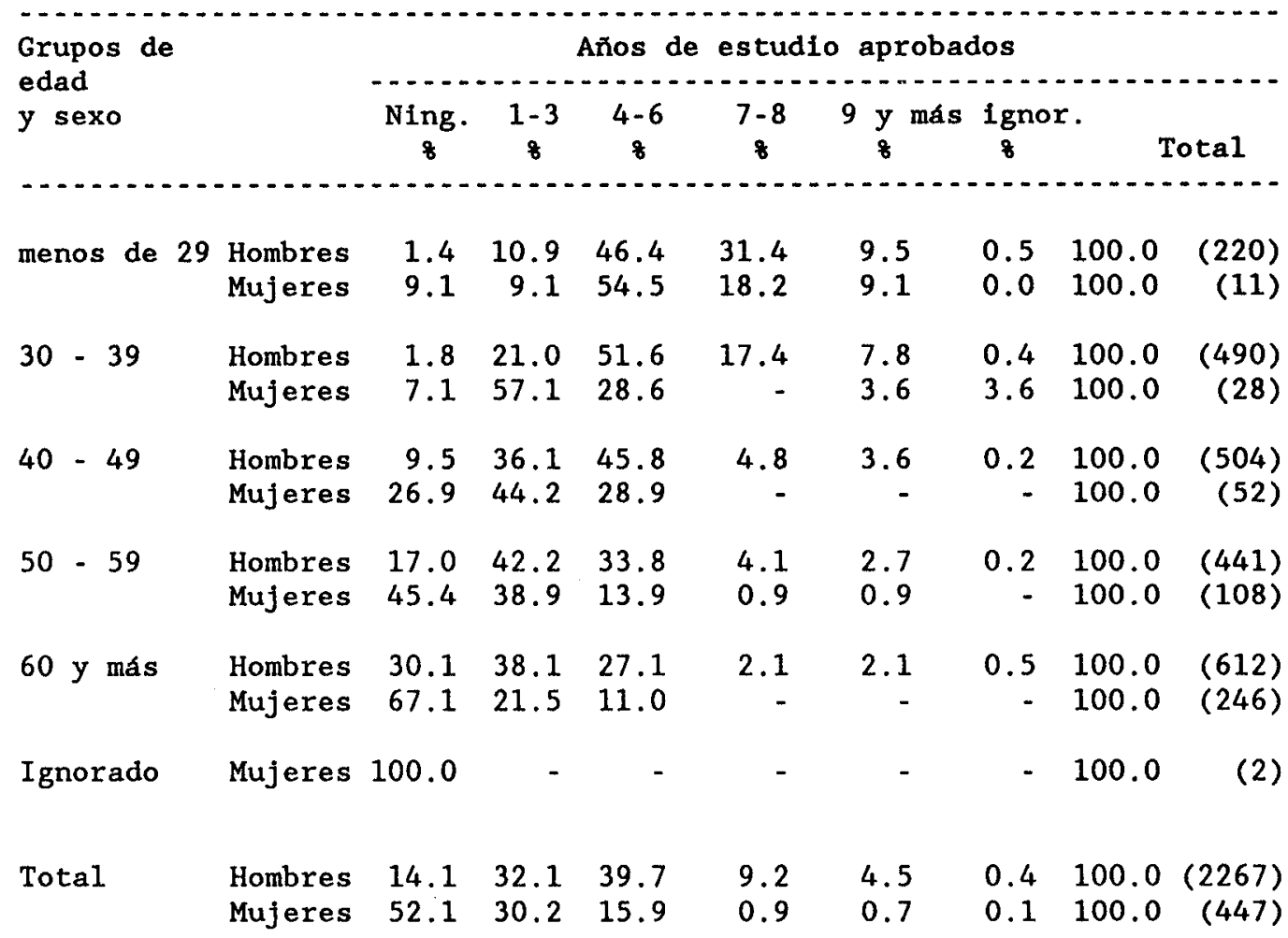

Fuente: Anexo 4 . 


\section{Conclusiones}

E1 análisis de la información obtenida a partir del Censo de 1988 muestra que el nivel educacional de la población de las reducciones indigenas de los distritos de Labranza, Molco, Maquehue y Metrenco, es'bastante bajo en el contexto nacional. Al distinguir el comportamiento según el sexo, se observa una notoria desigualdad entre hombres y mujeres, ya que éstas presentan indicadores, en promedio, bastante más desfavorables. Las diferencias, en todo caso, están determinadas por la variable edad: entre los jóvenes éstas no se registran, posiblemente por modificaciones en los patrones culturales en 10 concerniente al rol de la mujer.

El alto grado de analfabetismo de la población es tal vez el problema más importante que se ha logrado detectar desde el punto de vista de las caracteristicas educacionales, lo que ratifica los hallazgos del Censo Nacional de 1982 para el total de reducciones de la IX Región. En las reducciones estudiadas en el Censo de 1988 cerca de un 20 por ciento de la población de 5 años y más de edad; alrededor del 16 por ciento de la población de 15 años y más de edad; y casi un 25 por ciento de las personas de 30 años y más de edad, son analfabetos absolutos. Estas cifras se elevan a más del doble si se consideran también los analfabetos funcionales, es decir, aquellas personas que poseen menos de 4 años de estudio aprobados.

E1 analfabetismo absoluto es alto con relación al exhibido por el pais en su conjunto, aunque es menor al registrado en 1982 en el total de reducciones de la IX Región. Lo anterior no significa necesariamente que exista una tendencia al descenso del analfabetismo en la población estudiada, ya que es posible que ella mantenga diferencias con el resto de reducciones de la región $y$, por lo tanto, presentase un menor analfabetismo en 1982 .

E1 promedio de escolaridad de la población es de 4.1 años (3.8 entre las mujeres; 4.4 entre los hombres), cifra que alcanzaba a 3.2 en 1982 en la totalidad de las reducciones de la IX Región.

Al distinguir la situación de escolaridad según edad de las personas y lengua hablada con más frecuencia en el hogar, se observan diferencias significativas. En efecto, el analfabetismo es mayor entre las personas de más edad, lo que se acentúa entre la población femenina. Los mayores de 29 años de 
edad poseen un promedio de escolaridad de 3.2 años, en tanto las personas de 5 a 29 años de edad registran un promedio de 4.8 años de estudio aprobados, alcanzando a casi 7 años entre las personas de 15 a 24 años de edad.

La proporción más elevada de mujeres entre las personas mayores analfabetas y sus bajos indices de escolaridad parece confirmar una situación educacional que ha caracterizado a las áreas rurales habitadas por comunidades indigenas.

Según la lengua hablada con más frecuencia en el hogar, la población mayor de 29 años de edad que habla el mapudungun registra los más bajos indices, especialmente las mujeres (poco más de 1 año de estudio en promedio), tratándose de una población funcionalmente analfabeta. E1lo indicarla lo inadecuado que pueden ser los planes y programas educativos que no toman en cuenta la realidad social, cultural y lingüistica a quienes van dirigidos.

La existencia de un comportamiento similar en la escolaridad de hombres y mujeres menores de 30 años de edad indica que ha existido una tendencia hacia la mayor incorporación de la mujer al sistema educativo en las reducciones a partir de la década del 60. Esto se deberia, en parte, al aumento en la cobertura del sistema (enseñanza básica) y, especialmente, a cambios internos en la sociedad mapuche. Sin embargo, la ausencia de establecimientos de enseñanza media en el área han limitado las oportunidades educacionales para la población.

En sintesis, la población estudiada es un grupo de baja escolaridad y e1 análisis especffico de esta situación muestra que existe influencia de la edad y del sexo de las personas, así como de la lengua hablada con más frecuencia en el hogar, que se traduce en importantes desigualdades internas.

Se pueden señalar finalmente, dos hipótesis sobre las consecuencias de la situación descrita. Por un lado, la existencia de un bajo nivel educacional entre la población de mayor edad, principalmente entre las mujeres, podria repercutir desfavorablemente sobre el rendimiento escolar de los niños, al carecer de los conocimientos suficientes para facilitarles el aprendizaje. Por otra parte, habiéndose detectado indicios de una importante emigración femenina en edades adultas jóvenes, es posible suponer que el aumento de la participación femenina en el sistema escolar podría acompañarse de una mayor motivación para la emigración desde las reducciones, en búsqueda de un mejoramiento de sus condiciones de vida y de oportunidades laborales y educacionales. 


\section{Blbliografla}

Bengoa, José (1987), Historia del pueblo mapuche. Ediciones Sur, Santiago.

Bengoa, José y Valenzuela, Eduardo (1984), Economia mapuche, Pobreza y susbsistencia en la sociedad contemporánea. PAS, Santiago.

Borsotti, Carlos A. (1984), Sociedad rural educación y escuela en América Latina. Ed. Kapelusz, UNESCO-CEPAL-PNUD, Serie/Educación y Sociedad.

Comisión Económica para América Latina (CEPAL) (1977), Plan de Acción Regional para la Integración de la Mujer en el Desarrollo Economico y Social de América Latina (PAR). E/CEPAL/1042/Rev.1, noviembre.

Comisión Económica para América Latina (CEPAL) (1982), América Latina. Análisis de problemas sociales relativos a las mujeres de diversos sectores. R316, mayo.

Diaz, Cecilia (1986), Mapuches e italianos en Mallece. Grupo de Investigaciones Agrarias.

Durán, Teresa y Ramos, Ne1ly (1988), "Castellanización formal en La Araucania a través de la escuela". En Lenguas Modernas, Univ. de Chile, N ${ }^{2} 15$, pp. $131-154$.

Hernández, Isabel (1984), Conciencla étnica y educación de adultos indigenas en América Latina. CEAAL, Santiago, Apuntes 2, marzo.

Ibarbe S., Orlyn (1976), "Notas sobre la educación del mapuche en Cautin". En Simposio sobre la Educación Mapuche en Cautin, Pontificia Universidad Católica de Chile, Sede Regional Temuco.

Instituto Nacional de Estadisticas (INE) (1987a), Total pals. Población XV Censo Nacional de Población y IV de Vivienda. Chile 1982. INE, Santiago, Tomo II, mayo.

Instituto Nacional de Estadisticas (INE) (1987b), IX Región de La Araucania. Población XV Censo Nacional de Población y IV de Vivienda - Chile 1982. INE, Santiago, Tomo II, julio.

Lavados, Hugo y Hill, Eduardo (1986), El sistema educacional chileno. Elementos para un análisis global. CPU.

Lavin, Joaquin y Larrain Luis (1989), Chile, sociedad emergente. Ed. Zig-Zag, Santiago.

Oyarce, Ana M. (1988), "La salud entre los mapuches". En Revista Experiencias, PAESMI, $\mathrm{N}^{2} 3$, pp. 1-44. 
Oyarce, Ana M. ; Romaggi, Marisabel y Vịdal, Aldo (1989), Cómo viven los mapuches. Anális is del Censo de Población de Chile de 1982. PAESMI, Santiago, Serie Docs. de Trabajo $N^{2} 01$, enero.

Rivera P., Jorge (1988), Alfabetización. UNESCO/PREALC, Santiago.

Secretaria Regional de Planificación y Coordinación (SERPLAC) IX Región (1986), Directrices Regionales de Desarrollo. 1986.

Sepúlveda, Gastón (1982), Castellano para mapuches hablantes. Universidad Austral de Chile/Ministerio de Educación, Programa de Educación Rura1 Mapuche.

Tironi, Eugenio (1988), Los silencios de la revolución. Ed. La Puerta Abierta, Santiago.

Varese, Stefano y Rodriguez, Nemesio (1983), "Etnias indigenas y educación en América Latina: diagnóstico y perspectiva". En Educación. etnias y descolonización en América Latina. Una guia para la educación bilingúe intercultural, UNESCO, Vol 1.

Burrows G., Fernando; Carranza D., Gloria; Rojas V., Ricardo y Verges R., Jaime (eds.) (1989), Sembrando ideas: Reflexiones para la educación rural. Programa de Post-titulo en Educación Rural, Pontificia Universidad Católica de Chile, Sede Villarrica. 
Anexos 
ANEXO 1-A

REDUCCIONES INDIGENAS SELECCIONADAS: POBLACION DE 5 AÑOS Y MAS DE EDAD POR GRUPOS DE EDAD, SEGUN AÑOS DE ESTUDIO APROBADOS. CENSO DE 1988

HOMBRES TOTAL

\begin{tabular}{|c|c|c|c|c|c|c|c|}
\hline $\begin{array}{l}\text { Grupos } \\
\text { de edad }\end{array}$ & Ning. & $\begin{array}{r}\text { Años } \\
1-3\end{array}$ & $\begin{array}{l}\text { esti } \\
4-6\end{array}$ & $\begin{array}{c}\text { 10 apr } \\
7-8\end{array}$ & 9 y más & Ign. & Total \\
\hline 5 & 158 & 0 & 0 & 0 & 0 & 0 & 158 \\
\hline 6 & 144 & 16 & 0 & 0 & 0 & 1 & 161 \\
\hline 7 & 73 & 59 & 0 & 0 & 0 & 0 & 132 \\
\hline 8 & 29 & 135 & 0 & 0 & 0 & 0 & 164 \\
\hline 9 & 7 & 100 & 14 & 0 & 0 & 0 & 121 \\
\hline $10-14$ & 15 & 285 & 452 & 81 & 1 & 0 & 834 \\
\hline $15-19$ & 9 & 49 & 277 & 334 & 85 & 2 & 756 \\
\hline $20-24$ & 19 & 51 & 212 & 259 & 110 & 1 & 652 \\
\hline $25-29$ & 11 & 59 & 201 & 169 & 60 & 2 & 502 \\
\hline $30-34$ & 6 & 56 & 185 & 114 & 44 & 1 & 406 \\
\hline $35-39$ & 14 & 103 & 181 & 47 & 23 & 2 & 370 \\
\hline $40-44$ & 22 & 96 & 141 & 15 & 13 & 2 & 289 \\
\hline $45-49$ & 40 & 123 & 129 & 13 & 9 & 2 & 316 \\
\hline $50-54$ & 48 & 103 & 86 & 7 & 13 & 1 & 258 \\
\hline $55-59$ & 53 & 106 & 74 & 8 & 7 & 0 & 248 \\
\hline $60-64$ & 61 & 76 & 61 & 0 & 6 & 2 & 206 \\
\hline 65 y más & 152 & 178 & 118 & 9 & 11 & 1 & 469 \\
\hline Total & 861 & 1595 & 2131 & 1057 & 381 & 17 & 6042 \\
\hline
\end{tabular}


MUJERES TOTAL

\begin{tabular}{|c|c|c|c|c|c|c|c|}
\hline $\begin{array}{l}\text { Grupos } \\
\text { de edad }\end{array}$ & Ning. & $\begin{array}{r}\text { Años } \\
1-3\end{array}$ & le estu & $\begin{array}{l}\text { apr } \\
7-8\end{array}$ & $\begin{array}{l}\text { bados } \\
9 \text { y más }\end{array}$ & Ign. & Total \\
\hline 5 & 158 & 0 & 0 & 0 & 0 & 0 & 158 \\
\hline 6 & 139 & 12 & 0 & 0 & 0 & 0 & 151 \\
\hline 7 & 78 & 58 & 0 & 0 & 0 & 1 & 137 \\
\hline 8 & 27 & 118 & 0 & 0 & 0 & 0 & 145 \\
\hline 9 & 4 & 129 & 8 & 0 & 0 & 0 & 141 \\
\hline $10-14$ & 10 & 200 & 417 & 116 & 3 & 1 & 747 \\
\hline $15-19$ & 5 & 31 & 232 & 304 & 77 & 0 & 649 \\
\hline $20-24$ & 11 & 54 & 177 & 133 & 94 & 2 & 471 \\
\hline $25-29$ & 17 & 61 & 177 & 94 & 44 & 2 & 395 \\
\hline $30-34$ & 22 & 85 & 175 & 37 & 42 & 0 & 361 \\
\hline $35-39$ & 36 & 137 & 155 & 10 & 21 & 1 & 360 \\
\hline $40-44$ & 53 & 114 & 102 & 16 & 9 & 1 & 295 \\
\hline $45-49$ & 66 & 110 & 75 & 5 & 3 & 2 & 261 \\
\hline $50-54$ & 96 & 114 & 61 & 3 & 1 & 0 & 275 \\
\hline $55-59$ & 104 & 79 & 52 & 1 & 1 & 0 & 237 \\
\hline $60-64$ & 126 & 62 & 36 & 1 & 4 & 0 & 229 \\
\hline 65 y más & 355 & 105 & 47 & 1 & 1 & 0 & 509 \\
\hline Ignorado & 4 & 2 & 0 & 0 & 0 & 0 & 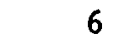 \\
\hline Total & 1307 & 1469 & 1714 & 724 & 297 & 10 & 552 \\
\hline
\end{tabular}

Fuente: Tabulados espectales Censo de 1988. 
ANEXO 1-B

DISTRITO LABRANZA: POBLACION DE 5 AÑOS Y MAS DE EDAD POR GRUPOS DE EDAD, SEGUN AÑOS DE ESTUDIO APROBADOS. CENSO DE 1988

\section{HOMBRES LABRANZA}

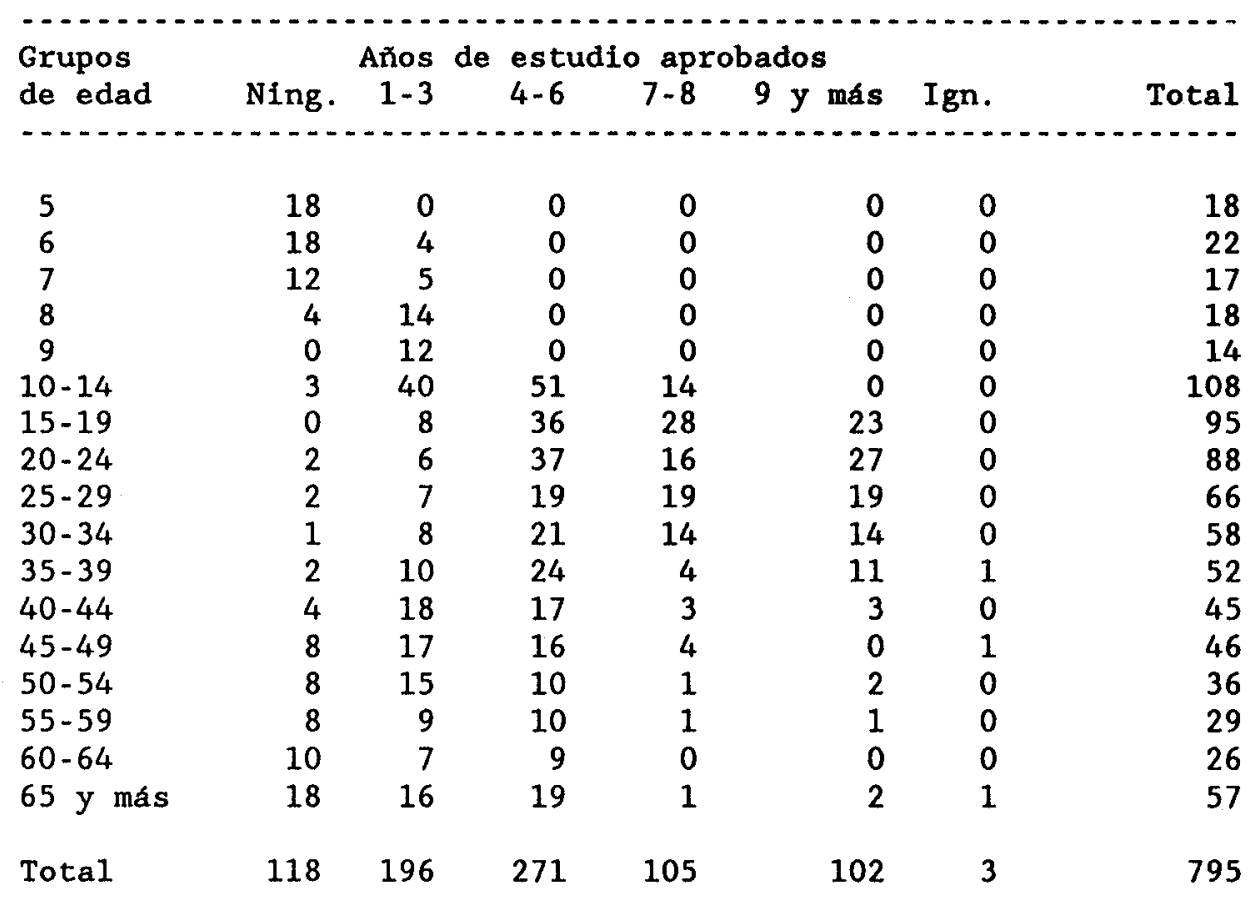


MUJERES LABRANZA

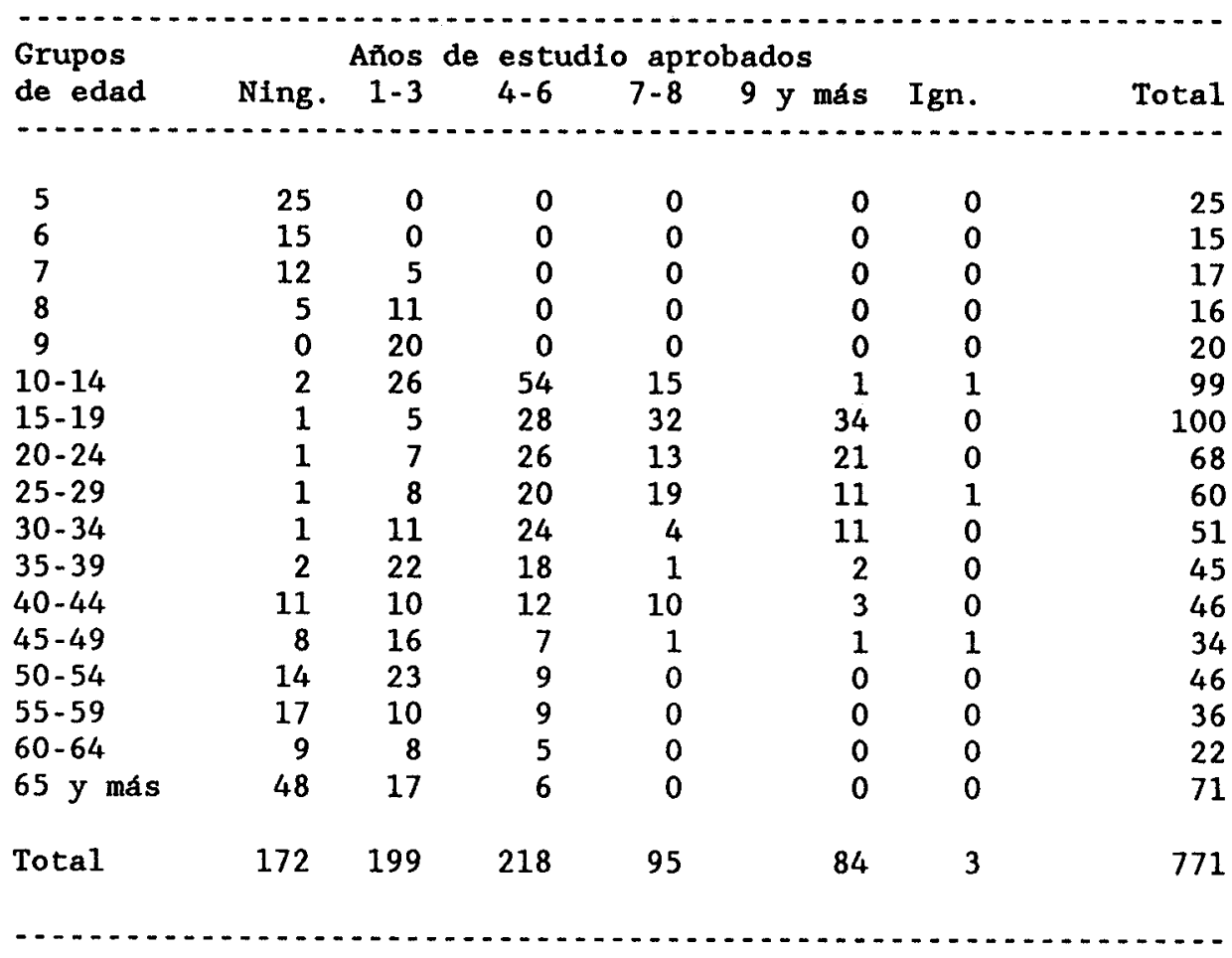

Fuente: Tabulados especiales Censo de 1988. 
ANEXO 1-C

DISTRITO MOLCO: POBLACION DE 5 AÑOS Y MAS DE EDAD POR GRUPOS DE EDAD, SEGUN AÑOS DE ESTUDIO APROBADOS. CENSO DE 1988

\section{HOMBRES MOLCO}

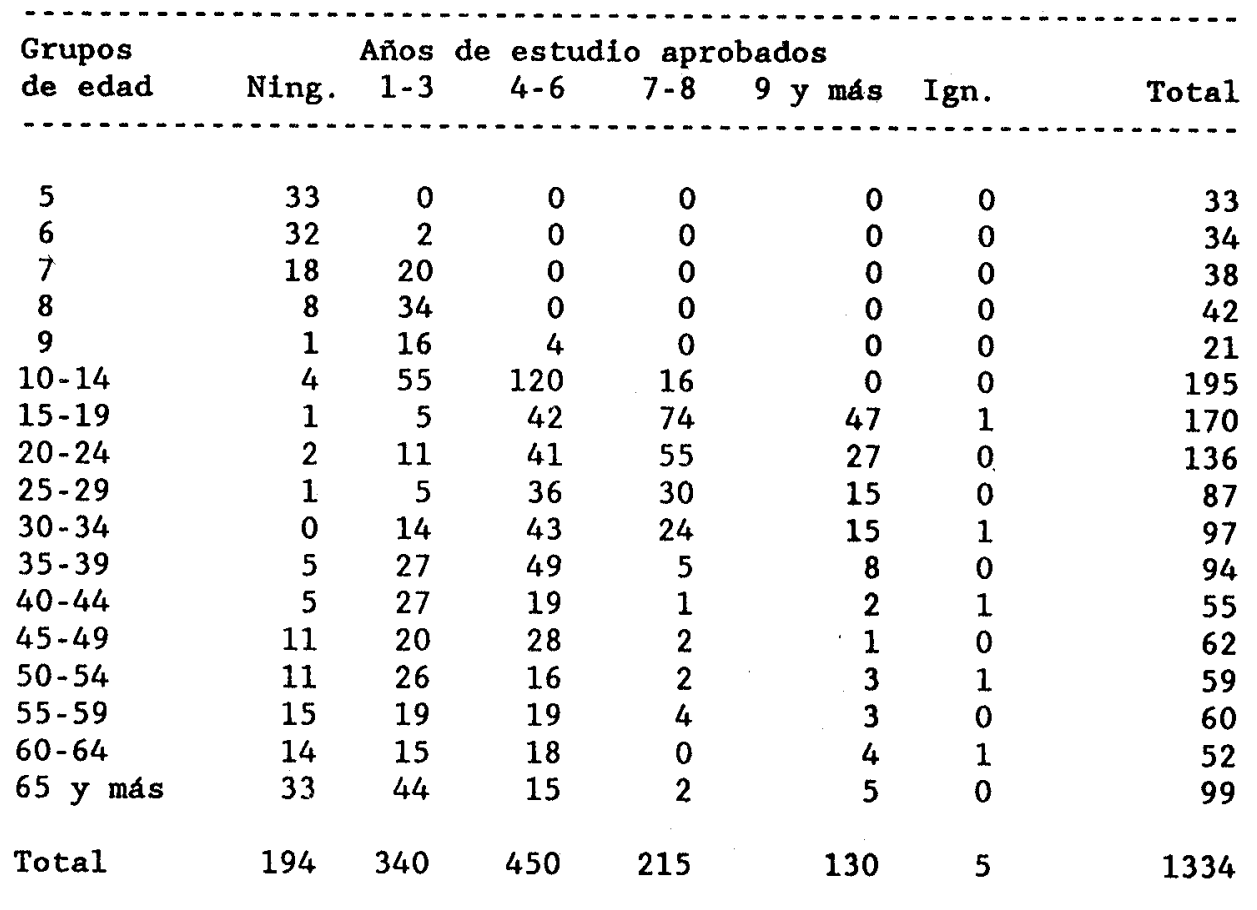


MUJERES MOLCO

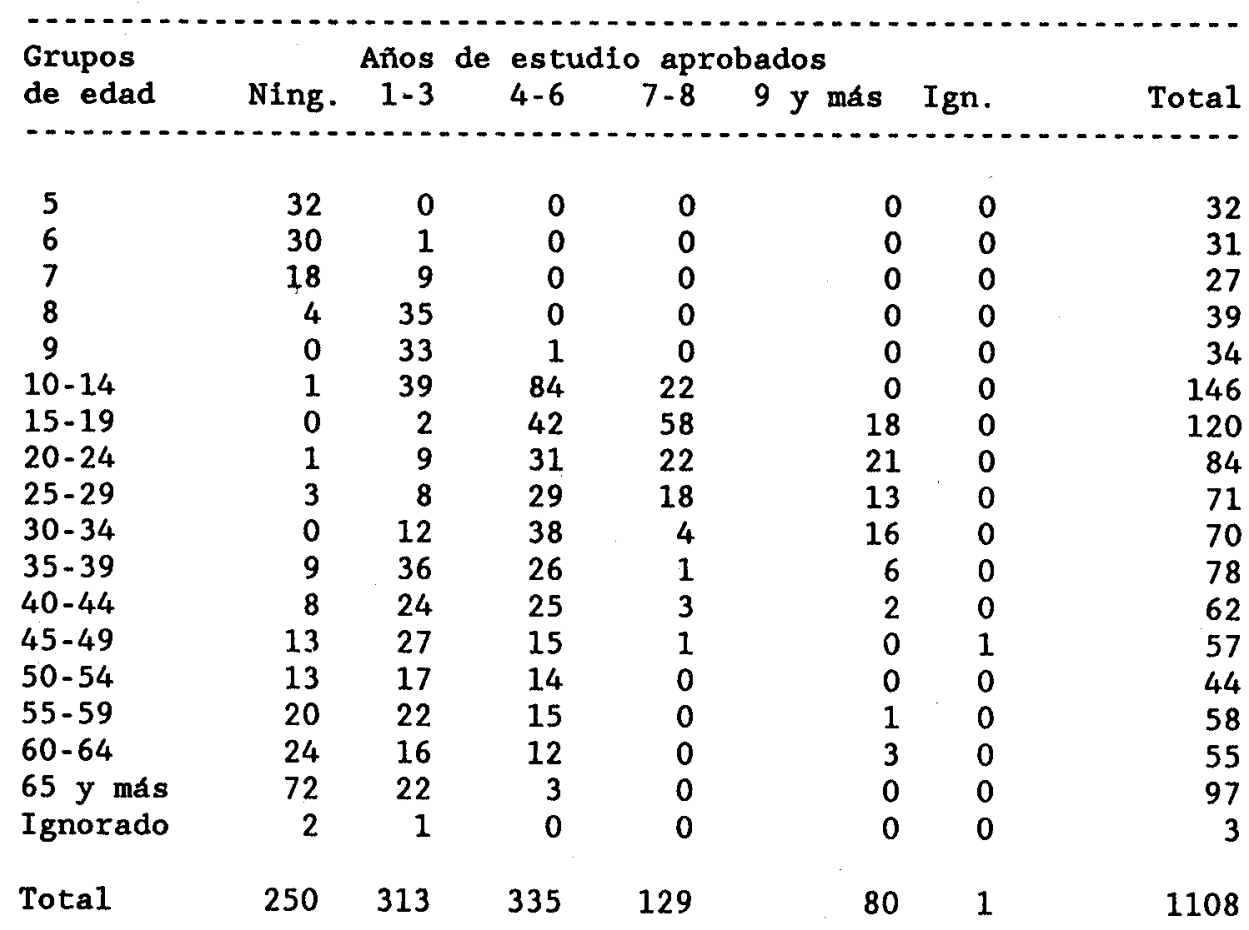

Fuente: Tabulados especiales Censo de 1988. 
ANEXO 1-D

DISTRITO MAQUEHUE: POBLACION DE 5 AÑOS Y MAS DE EDAD POR GRUPOS DE EDAD, SEGUN AÑOS DE ESTUDIO APROBADOS. CENSO DE 1988

HOMBRES MAQUEHUE

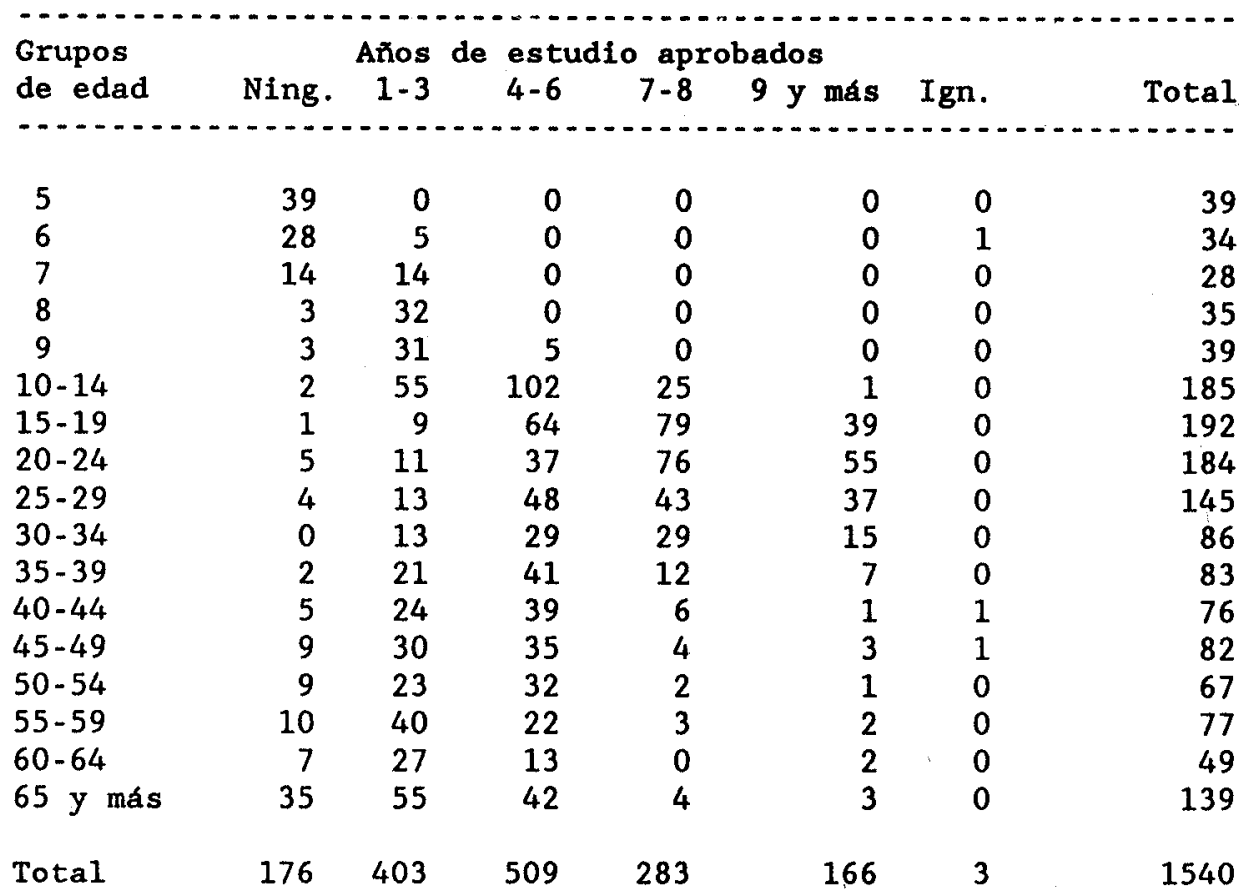




\section{MUJERES MAQUEHUE}

\begin{tabular}{|c|c|c|c|c|c|c|c|}
\hline $\begin{array}{l}\text { Grupos } \\
\text { de edad }\end{array}$ & Ning. & $\begin{array}{r}\text { Años } \\
1-3\end{array}$ & $\begin{array}{l}\text { estr } \\
4-6\end{array}$ & $\begin{array}{c}\text { apr } \\
7-8\end{array}$ & $\begin{array}{l}\text { bados } \\
9 \text { y más }\end{array}$ & Ign. & Total \\
\hline 5 & 38 & 0 & 0 & 0 & 0 & 0 & 38 \\
\hline 6 & 29 & 7 & 0 & 0 & 0 & 0 & 36 \\
\hline 7 & 14 & 18 & 0 & 0 & 0 & 1 & 33 \\
\hline 8 & 1 & 23 & 0 & 0 & 0 & 0 & 24 \\
\hline 9 & 2 & 30 & 5 & 0 & 0 & 0 & 37 \\
\hline $10-14$ & 3 & 38 & 112 & 39 & 1 & 0 & 193 \\
\hline $15-19$ & 1 & 5 & 42 & 93 & 41 & 0 & 182 \\
\hline $20-24$ & 0 & 14 & 36 & 39 & 39 & 1 & 129 \\
\hline $25-29$ & 2 & 13 & 47 & 16 & 23 & 1 & 102 \\
\hline $30-34$ & 3 & 23 & 35 & 7 & 14 & 0 & 82 \\
\hline $35-39$ & 8 & 31 & 36 & 4 & 5 & 0 & 84 \\
\hline $40-44$ & 12 & 26 & 26 & 1 & 2 & 1 & 68 \\
\hline $45-49$ & 17 & 27 & 20 & 1 & 1 & 0 & 66 \\
\hline $50-54$ & 27 & 26 & 15 & 0 & 1 & 0 & 69 \\
\hline $55-59$ & 31 & 26 & 17 & 1 & 0 & 0 & 75 \\
\hline $60-64$ & 34 & 15 & 10 & 1 & 0 & 0 & 60 \\
\hline 65 y más & 97 & 29 & 22 & 0 & 1 & 0 & 149 \\
\hline Ignorado & 2 & 1 & 0 & 0 & 0 & 0 & 3 \\
\hline Total & 321 & 352 & 423 & 202 & 128 & 4 & 1430 \\
\hline
\end{tabular}

Fuente: Tabulados especiales Censo de 1988. 


\section{ANEXO 1-E}

DISTRITO METRENCO: POBLACION DE 5 AÑOS Y MAS DE EDAD POR GRUPOS DE EDAD, SEGUN AÑOS DE ESTUDIO APROBADOS. CENSO DE 1988

\section{HOMBRES METRENCO}

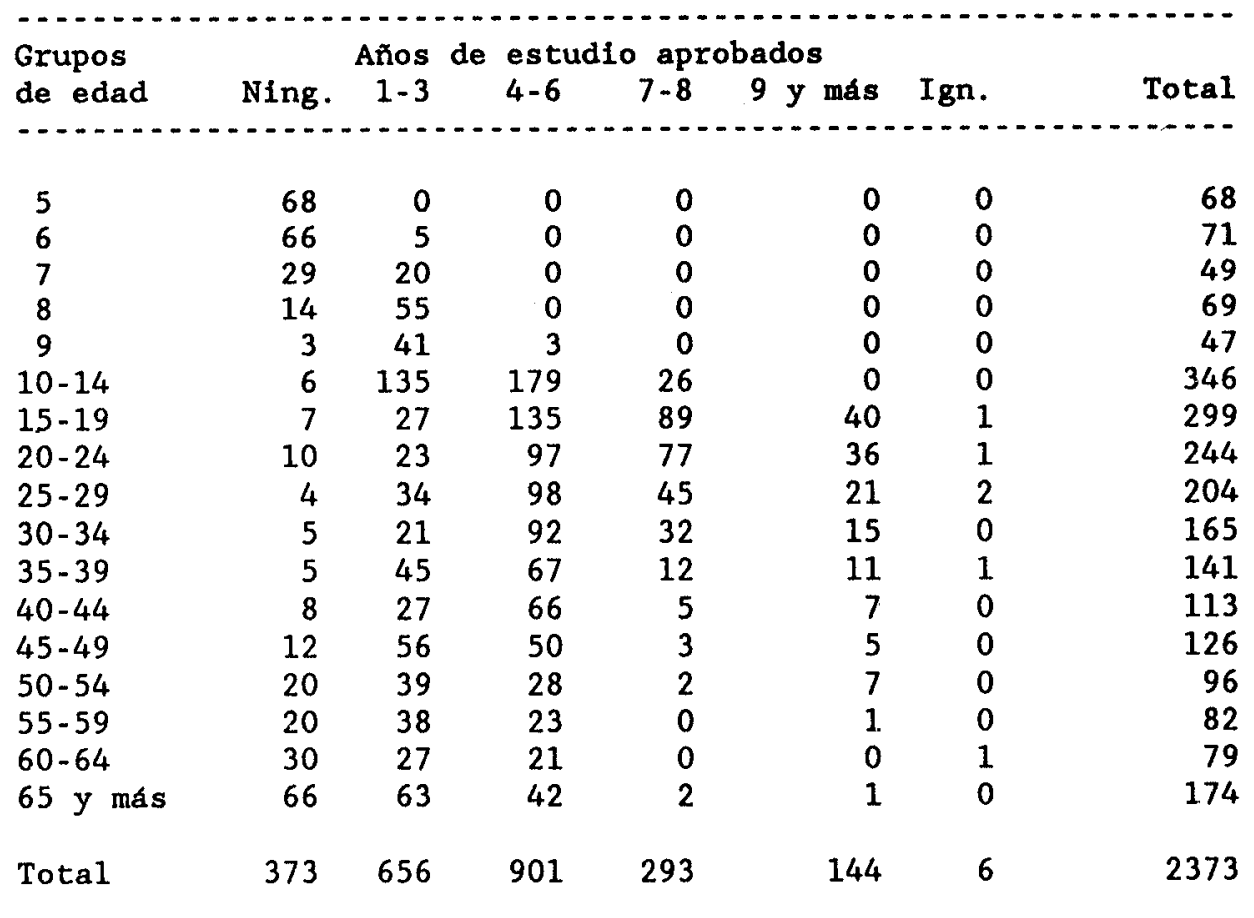




\section{MUJERES METRENCO}

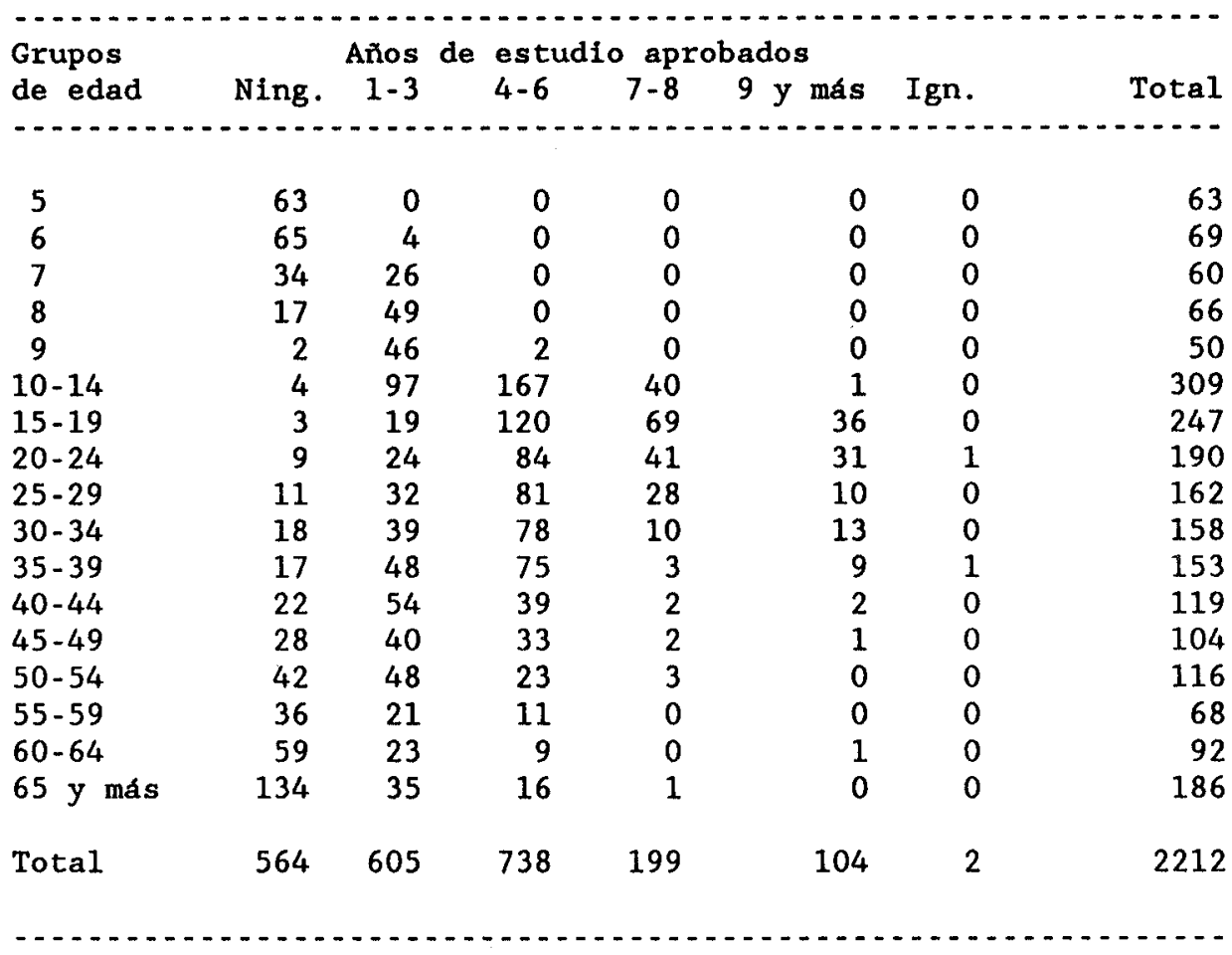

Fuente: Tabulados especiales Censo de 1988. 
ANEXO 2

REDUCCIONES INDIGENAS SELECCIONADAS: DISTRIBUCION REIATIVA DE LA POBLACION DE 5 AÑOS Y MAS DE EDAD POR AÑOS DE ESTUDIO APROBADOS, SEGUN SEXO Y GRUPOS DE EDAD, AGRUPADOS POR DISTRITO. CENSO DE 1988

LABRANZA

MOLCO

Sexo y grupos de edad

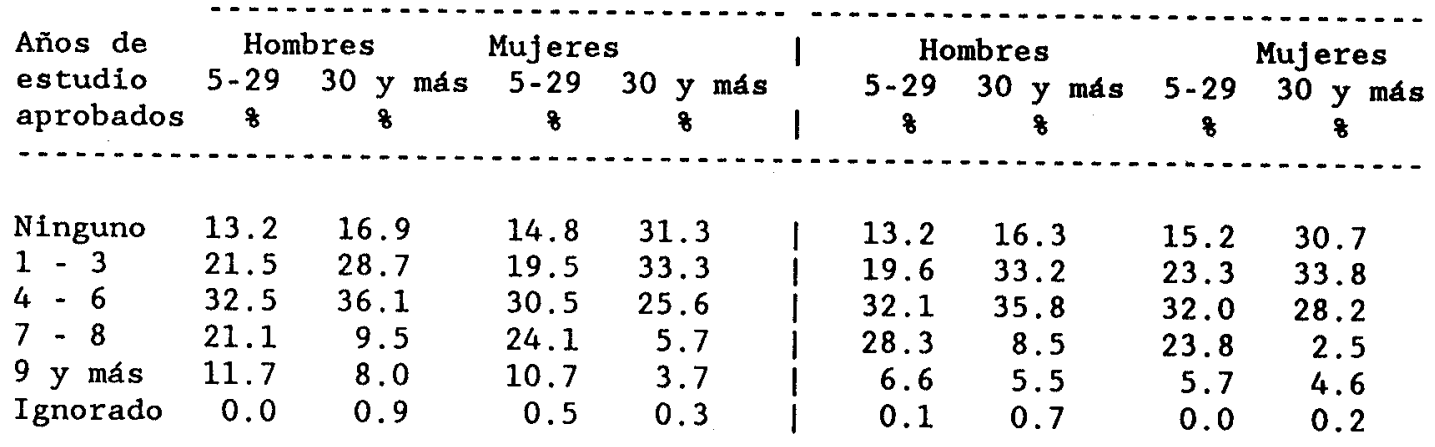

MAQUEHUE

METRENCO

Sexo y grupos de edad

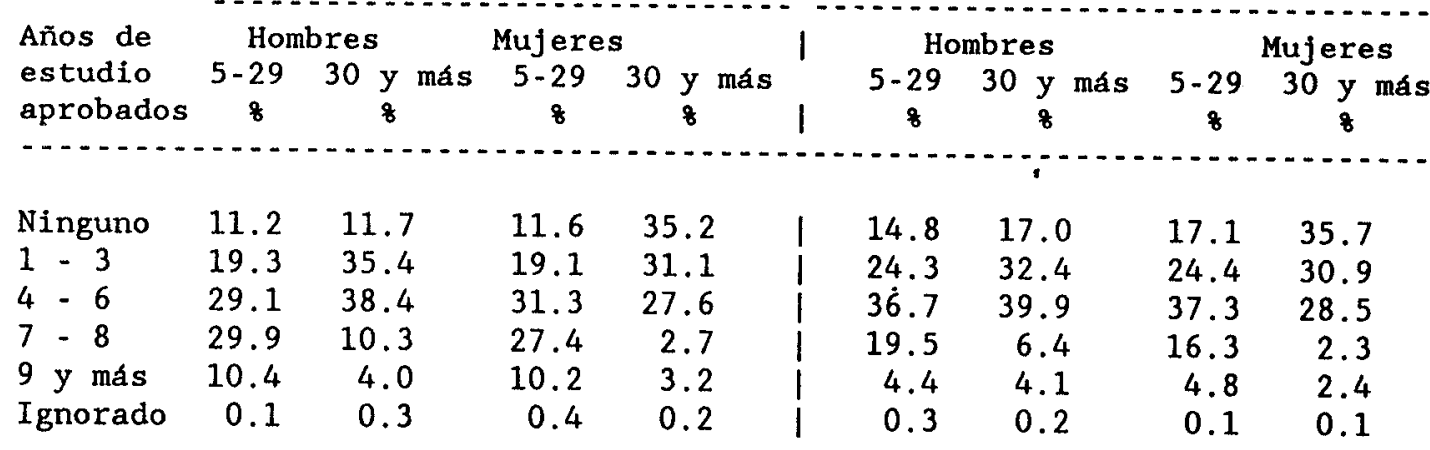

Fuente: Tabulados especiales Censo de 1988. 
ANEXO 3-A

REDUCCIONES INDIGENAS SELECCIONADAS: DISTRIBUCION RELATIVA DE LA POBLACION DE 5 AÑOS Y MAS DE EDAD POR AÑOS DE ESTUDIO APROBADOS, SEGUN LENGUA HABLADA Y GRUPOS DE EDAD. CENSO DE 1988

AMBOS SEXOS

Lengua hablada y grupos de edad

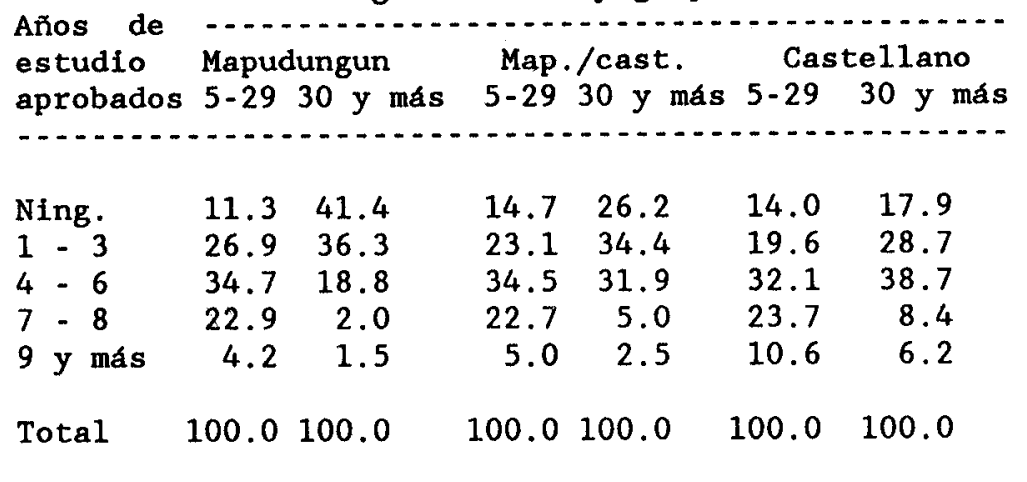

HOMBRES

Lengua hablada y grupos de edad

Años de Mapudungun Map./cast. Castellano

aprobados 5-29 30 y más 5-29 30 y más 5-29 30 y más

\begin{tabular}{|c|c|c|c|c|c|c|}
\hline Ning. & 7.0 & 25.4 & 12.8 & 15.5 & 15.3 & 12.8 \\
\hline $1-3$ & 28.4 & 43.3 & 22.7 & 35.3 & 19.2 & 27.1 \\
\hline $4-6$ & 36.2 & 25.0 & 34.3 & 38.2 & 31.4 & 41.9 \\
\hline $7-8$ & 23.7 & 3.4 & 24.8 & 8.0 & 23.8 & 11.3 \\
\hline 9 y más & 4.7 & 3.0 & 5.4 & 3.0 & 10.3 & 6.9 \\
\hline Tot & 100.0 & 100.0 & 100.0 & 100.0 & 100.0 & 100.0 \\
\hline Promedio & 4.6 & 2.7 & 4.6 & 3.6 & 5.1 & 4.4 \\
\hline Mediana & 4.8 & 2.1 & 4.8 & 30 & 5.0 & 4.5 \\
\hline
\end{tabular}




\section{MUJERES}

Lengua hablada y grupos de edad

Años de

Map./cast.

Castellano

aprobados 5-29 30 y más 5-29 30 y más 5-29 30 y más

Ning. $\quad \begin{array}{llllll}16.1 & 56.3 & 16.9 & 36.8 & 12.6 & 23.2\end{array}$

$\begin{array}{lllllll}1-3 & 24.7 & 30.0 & 23.6 & 33.6 & 20.1 & 30.5\end{array}$

$\begin{array}{lllllll}4-6 & 32.3 & 13.0 & 34.8 & 25.6 & 32.9 & 35.5\end{array}$

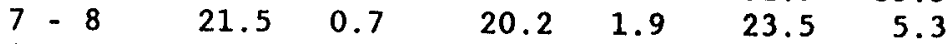

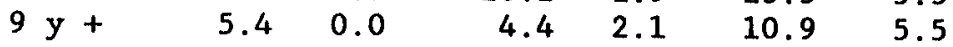

$\begin{array}{llllll}\text { Total } 100.0 & 100.0 & 100.0 & 100.0 & 100.0 & 100.0\end{array}$

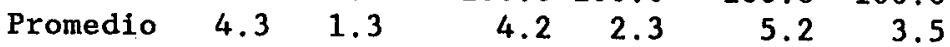

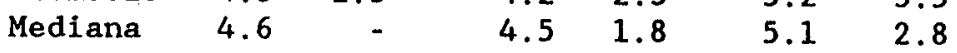

Fuente: Tabulados especiales Censo de 1988. 
ANEXO 3-B

DISTRITO LABRANZA: DISTRIBUCTON DE LA POBLACTON DE 5 AÑOS Y MAS DE EDAD POR SEXO, LENGUA HABLADA MAS FRECUENTEMENTE EN EL HOGAR Y GRUPOS DE EDAD, SEGUN AÑOS DE ESTUDIO APROBADOS. CENSO DE 1988

Sexo, lengua
y edad
ning. $1-3 \quad 4-6 \quad 7-8$ años de estudio aprobados
9 y más s.i. Total

HOMBRES

MAPUCHE

$\begin{array}{lrrrrrrr}5-29 & 0 & 6 & 7 & 3 & 1 & 0 & 17 \\ 30 \text { y más } & 9 & 12 & 5 & 0 & 1 & 1 & 28 \\ \text { Ignox. } & 0 & 0 & 0 & 0 & 0 & 0 & 0\end{array}$

MAPU-CASTE

$\begin{array}{lrrrrrrr}5-29 & 30 & 39 & 75 & 38 & 17 & 0 & 199 \\ 30 \text { y más } & 27 & 51 & 59 & 10 & 8 & 0 & 155 \\ \text { Ignor. } & 0 & 0 & 0 & 0 & 0 & 0 & 0\end{array}$

CASTELLANO

$\begin{array}{lrrrrrrr}5-29 & 29 & 51 & 63 & 53 & 34 & 0 & 230 \\ 30 \text { y más } & 23 & 37 & 62 & 24 & 18 & 2 & 166 \\ \text { Ignor. } & 0 & 0 & 0 & 0 & 0 & 0 & 0\end{array}$

MUJERES

MAPUCHE

$\begin{array}{lrrrrrrr}5-29 & 1 & 3 & 7 & 3 & 0 & 0 & 14 \\ 30 \text { y más } & 17 & 11 & 4 & 1 & 0 & 0 & 33 \\ \text { Ignor. } & 0 & 0 & 0 & 0 & 0 & 0 & 0\end{array}$

MAPU-CASTE

$\begin{array}{lrrrrrrr}5-29 & 29 & 38 & 55 & 36 & 10 & 1 & 169 \\ 30 \text { y más } & 58 & 54 & 34 & 3 & 1 & 1 & 151 \\ \text { Ignor. } & 0 & 0 & 0 & 0 & 0 & 0 & 0\end{array}$

CASTELLANO

$\begin{array}{lrrrrrrr}5-29 & 32 & 41 & 66 & 62 & 35 & 1 & 237 \\ 30 \text { y más } & 35 & 52 & 52 & 17 & 11 & 0 & 167 \\ \text { Ignor. } & 0 & 0 & 0 & 0 & 0 & 0 & 0\end{array}$

Fuente: Tabulados especiales Censo de 1988 . 
ANEXO 3-C

DISTRITO MOLCO: DISTRIBUCION DE LA POBLACION DE 5 AÑOS Y MAS DE EDAD POR SEXO, LENGUA HABLADA MAS FRECUENTEMENTE EN EL HOGAR Y GRUPOS DE EDAD, SEGUN AÑOS DE ESTUDIO APROBADOS. CENSO DE 1988

Sexo, lengua $\quad$ Años de estudio aprobados
y edad $\quad$ ning. $1-3 \quad 4-6 \quad 7-8$ y más s.i. Total

HOMBRES

MAPUCHE

$\begin{array}{lrrrrrrr}5-29 & 0 & 12 & 20 & 17 & 2 & 0 & 51 \\ 30 \text { y más } & 14 & 23 & 17 & 1 & 2 & 0 & 57 \\ \text { Ignor. } & 0 & 0 & 0 & 0 & 0 & 0 & 0\end{array}$

MAPU : CASTE

$\begin{array}{lrrrrrrr}5-29 & 46 & 78 & 134 & 131 & 24 & 0 & 413 \\ 30 \text { y más } & 52 & 102 & 126 & 34 & 10 & 3 & 327 \\ \text { Ignor. } & 0 & 0 & 0 & 0 & 0 & 0 & 0\end{array}$

\section{CASTELLANO}

$\begin{array}{lrrrrrrr}5-29 & 54 & 58 & 89 & 66 & 24 & 1 & 292 \\ 30 \text { y más } & 28 & 67 & 64 & 18 & 16 & 1 & 194 \\ \text { Ignor. } & 0 & 0 & 0 & 0 & 0 & 0 & 0\end{array}$

MUJERES

MAPUCHE

$\begin{array}{lrrrrrrr}5-29 & 3 & 10 & 8 & 11 & 1 & 0 & 33 \\ 30 \text { y más } & 37 & 14 & 4 & 1 & 0 & 0 & 55 \\ \text { Ignor. } & 1 & 0 & 0 & 0 & 0 & 0 & 1\end{array}$

MAPU-CASTE

$\begin{array}{lrrrrrrr}5-29 & 50 & 75 & 112 & 80 & 17 & 0 & 334 \\ 30 \text { y más } & 94 & 102 & 93 & 5 & 7 & 0 & 301 \\ \text { Ignor. } & 0 & 0 & 0 & 0 & 0 & 0 & 0\end{array}$

CASTELIANO

$\begin{array}{lrrrrrrr}5-29 & 36 & 51 & 67 & 48 & 15 & 0 & 217 \\ 30 \text { y más } & 29 & 61 & 51 & 9 & 16 & 1 & 167 \\ \text { Ignor. } & 0 & 0 & 0 & 0 & 0 & 0 & 0\end{array}$

Fuente: Tabulados especiales Censo de 1988. 
ANEXO 3-D

DISTRITO MAQUEHUE: DISTRIBUCION DE LA POBLACION DE 5 AÑOS Y MAS DE EDAD POR SEXO, LENGUA HABLADA MAS FRECUENTEMENTE EN EL HOGAR Y GRUPOS DE EDAD, SEGUN AÑOS DE ESTUDIO APROBADOS. CENSO DE 1988

Sexo, lengua y edad ning. 1-3

\section{Años de estudio aprobados}

4-6 7-8 9 y más s.i. Total

\section{HOMBRES}

MAPUCHE

$\begin{array}{lrrrrrrr}5-29 & 3 & 18 & 26 & 18 & 7 & 0 & 72 \\ 30 \text { y más } & 19 & 32 & 18 & 4 & 1 & 0 & 74 \\ \text { Ignor. } & 0 & 0 & 0 & 0 & 0 & 0 & 0\end{array}$

MAPU-CASTE

$\begin{array}{lrrrrrrr}5-29 & 51 & 100 & 133 & 139 & 31 & 0 & 454 \\ 30 \text { y más } & 39 & 129 & 127 & 36 & 6 & 1 & 338 \\ \text { Ignor. } & 0 & 0 & 0 & 0 & 0 & 0 & 0\end{array}$

CASTELILANO

$\begin{array}{lrrrrrrr}5-29 & 45 & 52 & 97 & 106 & 54 & 1 & 355 \\ 30 \text { y más } & 19 & 72 & 108 & 31 & 16 & 1 & 247 \\ \text { Ignor. } & 0 & 0 & 0 & 0 & 0 & 0 & 0\end{array}$

MUJERES

MAPUCHE

$\begin{array}{lrrrrrrr}5-29 & 9 & 10 & 21 & 21 & 4 & 0 & 65 \\ 30 \text { y más } & 42 & 25 & 14 & 1 & 0 & 0 & 82 \\ \text { Ignor. } & 0 & 0 & 0 & 0 & 0 & 0 & 0\end{array}$

MAPU-CASTE

$\begin{array}{lrrrrrrr}5-29 & 53 & 77 & 112 & 96 & 24 & 2 & 364 \\ 30 \text { y más } & 124 & 110 & 79 & 7 & 10 & 0 & 330 \\ \text { Ignor. } & 2 & 0 & 0 & 0 & 0 & 0 & 2\end{array}$

CASTELLANO

$\begin{array}{lrrrrrrr}5-29 & 28 & 61 & 109 & 95 & 51 & 1 & 345 \\ 30 \text { y más } & 63 & 69 & 88 & 11 & 10 & 1 & 242 \\ \text { Ignor. } & 0 & 0 & 0 & 0 & 0 & 0 & 0\end{array}$

Fuente: Tabulados especiales Censo de 1988. 
ANEXO 3-E

DISTRITO METRENCO: DISTRIBUCION DE LA POBLACION DE 5 AÑOS Y MAS DE EDAD POR SEXO, LENGUA HABLADA MAS FRECUENTEMENTE EN EL HOGAR Y GRUPOS DE EDAD, SEGUN AÑOS DE ESTUDIO APROBADOS. CENSO DE 1988

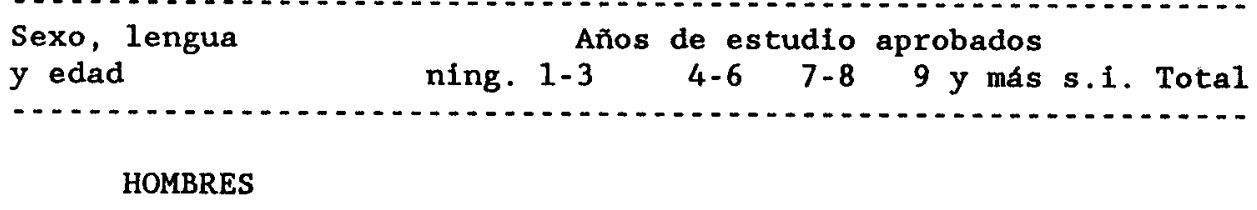

MAPUCHE

$\begin{array}{lrrrrrrr}5-29 & 15 & 37 & 40 & 23 & 2 & 1 & 118 \\ 30 \text { y más } & 26 & 49 & 27 & 4 & 4 & 0 & 110 \\ \text { Ignor. } & 0 & 0 & 0 & 0 & 0 & 0 & 0\end{array}$

MAPU-CASTE

$\begin{array}{lrrrrrrr}5-29 & 106 & 195 & 280 & 141 & 26 & 1 & 749 \\ 30 \text { y más } & 84 & 177 & 185 & 24 & 15 & 2 & 487 \\ \text { Ignor. } & 0 & 0 & 0 & 0 & 0 & 0 & 0\end{array}$

CASTELIANO

$\begin{array}{lrrrrrrr}5-29 & 86 & 108 & 192 & 109 & 33 & 2 & 530 \\ 30 \text { y más } & 56 & 90 & 177 & 38 & 18 & 0 & 379 \\ \text { Ignor. } & 0 & 0 & 0 & 0 & 0 & 0 & 0\end{array}$

MUJERES

MAPUCHE

$\begin{array}{lrrrrrrr}5-29 & 23 & 32 & 36 & 13 & 3 & 0 & 107 \\ 30 \text { y más } & 61 & 31 & 13 & 0 & 0 & 1 & 106 \\ \text { Ignor. } & 0 & 0 & 0 & 0 & 0 & 0 & 0\end{array}$

MAPU-CASTE

$\begin{array}{lrrrrrrr}5-29 & 116 & 156 & 231 & 83 & 14 & 1 & 601 \\ 30 \text { y más } & 203 & 172 & 128 & 10 & 9 & 0 & 522 \\ \text { Ignor. } & 0 & 0 & 0 & 0 & 0 & 0 & 0\end{array}$

CASTELLANO

$\begin{array}{lrrrrrrr}5-29 & 69 & 109 & 187 & 102 & 41 & 0 & 508 \\ 30 \text { y más } & 92 & 105 & 143 & 13 & 15 & 0 & 368 \\ \text { Ignor. } & 0 & 0 & 0 & 0 & 0 & 0 & 0\end{array}$

Fuente: Tabulados especiales Censo de 1988. 
ANEXO 4

REDUCCIONES INDIGENAS SELECCIONADAS: JEFES DE HOGAR POR GRUPOS DE EDAD, SEGUN AÑOS DE ESTUDIO APROBADOS. CENSO DE 1988

HOMBRES

$\begin{array}{lrrrrrrr}\begin{array}{l}\text { Grupos } \\ \text { de edad }\end{array} & \text { Ning. } & 1-3 & 4-6 & 7-8 & 9 \text { y más Ign. } & \text { Total } \\ -15-19 & 0 & 0 & 2 & 2 & 1 & 0 & 5 \\ 20-29 & 3 & 24 & 100 & 67 & 20 & 1 & 215 \\ 30-39 & 9 & 103 & 253 & 85 & 38 & 2 & 490 \\ 40-49 & 48 & 182 & 231 & 24 & 18 & 1 & 504 \\ 50-59 & 75 & 186 & 149 & 18 & 12 & 1 & 441 \\ 60-64 & 53 & 73 & 57 & 1 & 5 & 2 & 191 \\ 65 \text { y más } & 131 & 160 & 109 & 12 & 8 & 1 & 421 \\ & & & & & & & \\ \text { Total } & 319 & 728 & 901 & 209 & 102 & 8 & 2267\end{array}$

MUJERES

\begin{tabular}{lrrrrrrr} 
Grupos & \multicolumn{6}{c}{ Años de estudio aprobados } \\
de edad & Ning. & $1-3$ & $4-6$ & $7-8$ & 9 y más Ign. & Total \\
\hdashline $5-19$ & 0 & 0 & 0 & 1 & 0 & 0 & 1 \\
$20-29$ & 1 & 1 & 6 & 1 & 1 & 0 & 10 \\
$30-39$ & 2 & 16 & 8 & 0 & 1 & 1 & 28 \\
$40-49$ & 14 & 23 & 15 & 0 & 0 & 0 & 52 \\
$50-59$ & 49 & 42 & 15 & 1 & 1 & 0 & 108 \\
$60-64$ & 41 & 18 & 8 & 1 & 0 & 0 & 68 \\
65 y más & 124 & 35 & 19 & 0 & 0 & 0 & 178 \\
Ignorado & 2 & 0 & 0 & 0 & 0 & 0 & 2 \\
Total & 233 & 135 & 71 & 4 & 3 & 1 & 447
\end{tabular}

Fuente: Tabulados especiales Censo de 1988. 


\section{ANEXO 5}

COMUNA DE TEMUCO Y DISTRITOS DE LABRANZA, MOLCO, MAQUEHUE Y METRENCO: ANTECEDENTES SOBRE EDUCACION RURAL SEGUN EL SECTOR QUE LA IMPARTE. 1988

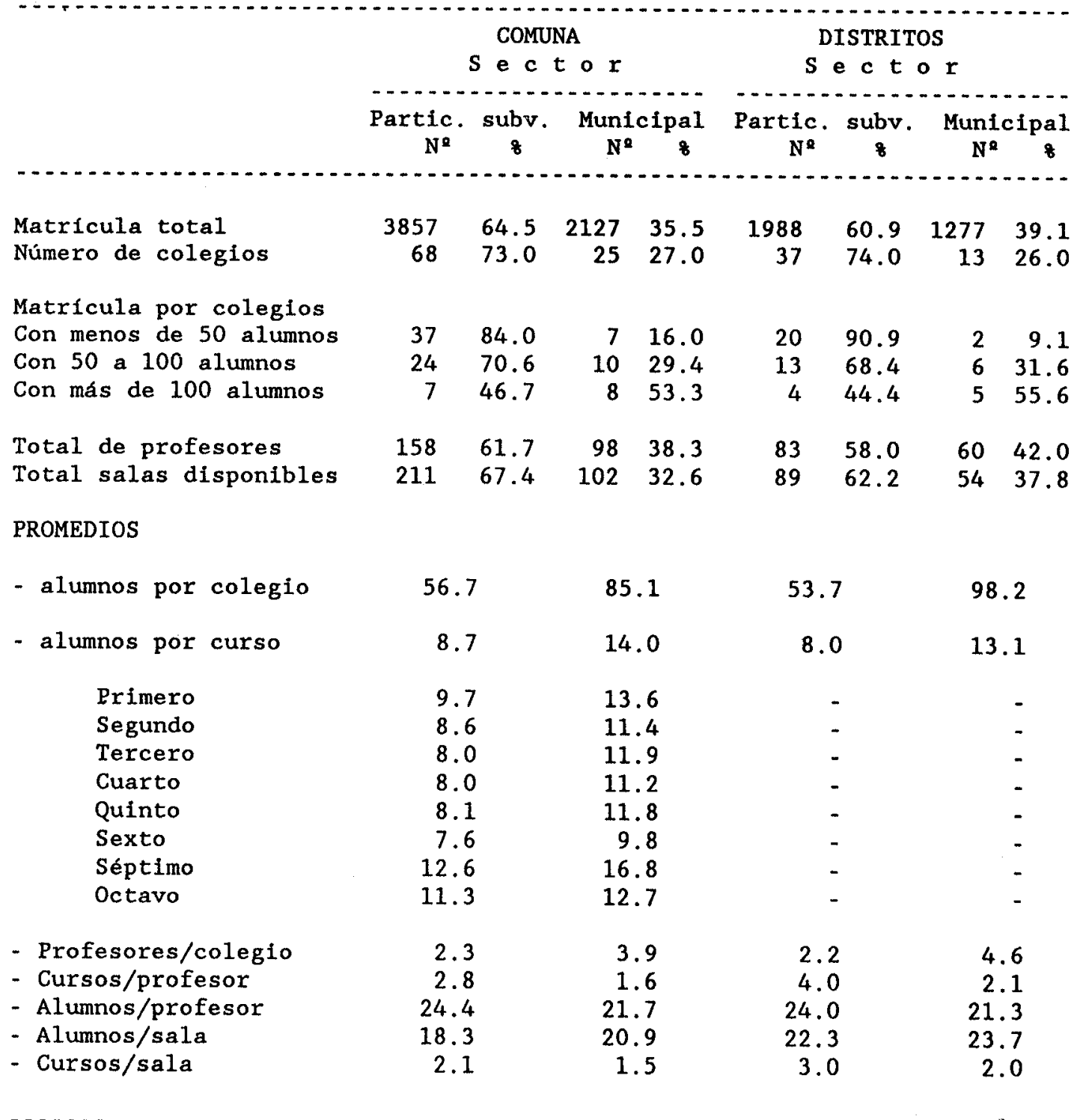

Fuente: Directorio de Establecimientos de Educación, Secretaria Regional Ministerial de Educación, IX Región, 1988. 


\title{
IV. CARACTERISTICAS ECONOMICAS
}

\author{
Gabriela Pérez* \\ Jorge Martinez
}

\section{Introducción}

En este capitulo se examinan las caracteristicas económicas de la población de las reducciones indigenas censadas en 1988, pertenecientes a los distritos de Labranza, Molco, Maquehue y Metrenco, de la Comuna de Temuco, Provincia de Cautín, en la IX Región.

La información que se analizará se refiere a dos aspectos básicos, el grado de participación de la población en la actividad económica y las caracteristicas ocupacionales de la población económicamente activa. Con respecto al primer punto, se distinguirá el comportamiento según el sexo y la edad de las personas, junto con otros rasgos especfficos, tales como $1 a$ participación de la población femenina y de los jefes de hogar, as 1 como la descripción del estado civil y del nivel de instrucción de la fuerza de trabajo de las reducciones seleccionadas. Con relación al segundo punto, se describirán las modalidades de inserción de la fuerza de trabajo en la estructura productiva, a través de las ocupaciones y categorías ocupacionales, en conjunto con el sexo y la edad de las personas activas.

En la descripción de algunos de estos aspectos se establecerán comparaciones de las caracteristicas económicas de la población estudiada entre los cuatro distritos señalados. En esta línea, se realizarán también

\footnotetext{
Universidad de La Frontera, Temuco.

Centro Latinoamericano de Demografía.
} 
comparaciones con indicadores del pals, de la IX Región y del total de reducciones indígenas de ésta, sobre la base de los datos del Censo Nacional de 1982. Por último, a lo largo de las secciones se presentarán ciertas generalidades sobre las condiciones económicas de los mapuches, de manera de contar con referentes sobre su contexto geográfico y sociroconómico.

E1 propósito esencial es entregar elementos que permitan contribuir al conocimiento de la organización e inserción económica de la población que reside en las reducciones seleccionadas, a través del diagnóstico de su participación en las actividades productivas según los aspectos mencionados.

\section{La economía de los mapuches}

En América Latina, la mayoria de los grupos étnicos aborigenes vive en condiciones de extrema pobreza (Masferrer, 1983). Dentro de la estructura socia1 nacional, el grupo mapuche que vive en reducciones indígenas es uno de los más pobres y su situación de subsistencia se ha expresado junto a un comportamiento que ha sido característico desde la creación de las reducciones: la migración temporal o definitiva (Bengoa, 1983).'

La condición de pobreza de los mapuches se vincula actualmente, en forma notoria, con la escasez de tierras en las reducciones. E1 tamaño de las propiedades familiares es, en promedio, inferior a una hectárea por persona, 1o que sumado a la baja calidad de los terrenos, la falta de riego y la carencia de medios adecuados para una buena explotación, apenas permite satisfacer las necesidades básicas de alimentación del grupo familiar. Junto con estas caracteristicas, las comunidades presentan desigualdades en la distribución de los recursos, tales como el tamaño de la propiedad y la cantidad de animales, situacíon que agrava todavia más la precaria condición de actividad de algunas familias.

Como efecto de 10 anterior, también se presentan diferencias en la vinculación que establecen los grupos famfliares con la estructura económica nacional. Tales diferenclas internas, si bien parecen haber sido latentes en

En 1886 se dicta la Ley de Reducciones Indigenas. 
la historia del pueblo mapuche, podrian haberse desarrollado en los últimos años, producto de la división de las comunidades y la entrega de titulos de propiedad individual. ${ }^{2}$

Es un hecho conocido que para el mapuche, la tierra tiene un valor fundamental que va más allá del valor económico, ya que sobre la base de ella organiza su vida; la tierra representa la posibilidad de constituir una familia, es la base de su seguridad, su estilo de vida, su forma de conectarse con el mundo (Borsotti, 1984). El campesino mapuche seria un trabajador sin cultura agraria de minifundio, ya que su situación de pequeño agricultor es consecuencia de la Ley de Reducciones Indigenas que lo obliga a sedentarizarse ("reducirse") en un terreno limitado (Stuchlik, 1974).

La mayor parte de la población que vive en las reducciones indigenas de la Comuna de Temuco depende de la actividad agricola para subsistir. La economia mapuche es, en términos generales, una economía de subsistencia basada en la agricultura intensiva y en la crianza de ganado y aves. El tipo de cultivos depende de la extensión, calidad y ubicación de los terrenos, y de la demanda y posibilidades de comercialización existentes. La mayor parte de la producción agricola se destina a satisfacer las necesidades de autoconsumo, y está dada fundamentalmente por el cultivo de trigo, legumbres, papas y hortalizas. otra parte de esta producción se comercializa y la producción que se destina exlusivamente al mercado se relaciona con cultivos orientados a la industria (raps, remolacha, lupino).

La crianza de animales, principalmente vacunos, ovejas, cerdos y aves de corral se destina tanto al autoconsumo como a la venta, constituyendo una especie de reserva financiera o inversión (Stuchlik, 1974).

La base de la economia desarrollada en las reducciones sigue siendo el trabajo de toda la familia. Por lo general, el padre es quien asume el trabajo de la tierra y la comercialización de su producción; la mujer, además de estar a cargo de las tareas del hogar y de la producción para autosubsistencla, se dedica también al cultivo de la huerta y a la crianza de ganado menor, a tejer y a ayudar en las tareas agricolas de la producción destinada a la venta.

La Ley $\mathrm{N}^{\circ} 2568$ dictada el año 1979, determina por medio de la división de reservas, la propiedad legal e individual de la tierra en las comunidades mapuches. 
Los niños se incorporan a temprana edad en las actividades productivas del grupo familiar; de acuerdo con ella, van asumiendo distintas responsabilidades: ayudan en el acarreo de agua y leña; cuidan de los animales y los sembrados; cuando están más grandes ayudan en la preparación de la tierra, en la siembra y en la comercialización de los productos, labores que combinan con las actividades escolares. E1 trabajo de la mujer y de los ninos es de gran importancia y su grado de colaboración está determinado por la necesidad de fuerza de trabajo que exista en el predio.

E1 campesino mapuche, afectado por la situación de pobreza, el cese del sistema tradicional de tenencia de la tierra y debido a los cambios que ha experimentado el sector agricola nacional, ha tenido que desarrollar y reforzar diversas estrategias para sobrevivir, determinadas por las caracteristicas particulares de su organización social y del medio geográfico, social y económico en que se inserta. Entre ellas, se puede señalar al cultivo de tierras y crianza de animales en medieria; la proletarización y subproletarización temporal o definitiva de hombres y mujeres (no sólo en el sector agrícola tradicional, sino también en actividades del sector servicios e industrial); el desarrollo de actividades por cuenta propia en el sector informal de la economfa en ocupaciones de baja calificación; y la migración definitiva o temporal de parte importante de su población en edad activa, que se incorpora a los sectores laborales, sociales y económicos más postergados de las principales áreas urbanas o a las áreas rurales que demandan estacionalmente abundante mano de obra.

El largo contacto con la sociedad chilena, los intentos de asimilación cultural y los cambios económicos que amenazan su permanencia como pueblo, han provocado transformaciones en su modo de vida y un desarraigo cultural. Sin embargo, en términos generales, siguen manteniendo algunas caracteristicas económicas, sociales y culturales tradicionales, tales como el uso de su propia lengua, costumbres y ceremonias religiosas, que los identifican como grupo étnico.

La modernización de un sector de la agricultura con empleo de alta tecnologia y los cambios que ha experimentado la economla nacional, producto de las crísis de los años 1975 y 1982, han contribuido a empeorar la situación de los grupos sociales más pobres de la población y, dentro de éstos, la del sector campesino mapuche. Este ha experimentado una baja en su poder adquisitivo y una reducción en sus fuentes de trabajo en los fundos, debiendo competir con las grandes industrias agropecuarias en condiciones desventajosas (bajo rendimiento y calidad de su producción, altos costos de transporte y bajos precios). Como 
se ha señalado, esta situación contribuye a una fuerte emigración de la fuerza de trabajo de las reducciones, ya sea temporal (en labores agricolas estacionales) o permanente (fundamentalmente hacia las áreas urbanas). ${ }^{3}$

\section{Definición y medición de las caracteristicas económicas}

E1 examen de las caracteristicas económicas de la población de las reducciones seleccionadas se basa en los datos recogidos en el Censo de 1988, referidos a tres aspectos básicos:

- la condición de actividad de la población

- la categoria de la ocupación

- la ocupación principal

La población económicamente activa (PEA), se definió como aquellos individuos de 12 años y más de edad que declararon tener trabajo (remunerado o no), estar cesantes o que buscaban trabajo por primera vez en la semana anterior al censo.' La razón para fijar este límite de edad se debe, como ya se ha mencionado, a que en las reducciones se desarrolla una economia agricola de subsistencia, basada en la mano de obra familiar, donde los niños se incorporan a edades tempranas a las labores productivas.

Al establecer el limite en los 15 años de edad, como en el Censo Nacional de 1982, y no incluir a parte de la población en edad escolar que contribuye a la actividad económica, se pensó que podria haber una importante subestimación de la PEA, situación que se trató de aminorar registrando a quienes respondieron "trabaja y estudia" dentro de la fuerza de trabajo.

Cabe destacar que el periodo de referencia de las preguntas sobre actividad oculta parte de los mecanismos a los que la población recurre para subsistir, debido al carácter estacional y diversificado de las economias campesinas. Por otra parte, dado que generalmente el tamaño de la propiedad no logra satisfacer las necesidades minimas, es frecuente que se recurra al trabajo temporal fuera del predio, por lo que la persona alterna a lo largo del año ocupaciones y categorias de ocupación diferentes (CEPAL, 1984).

Al respecto, se ha detectado una importante emigración durante la década del 80 en el caso de las reducciones seleccionadas en el Censo de 1988 (ver Capitulo Caracteristicas Demográficas).

Definiciones utilizadas por el Instituto Nacional de Estadisticas (INE) en el Censo Nacional de 1982, salvo el límite de edad. 
Dentro de las categorfas de actividad (ocupado, cesante, busca trabajo por primera vez, no activo), se agregó la categorfa "dueña de casa y trabaja", con el objeto de determinar con mayor exactitud la PEA femenina. Al respecto, se sabe que es frecuente que una parte importante de dueñas de casa se declare inactiva aun cuando realice alguna actividad remunerada, parcial o temporalmente, con la que contribuye al mantenimiento de los hogares (CEPAL, 1989). s $^{3}$

Al interrogar por la categoria ocupacional, se buscó determinar la proporción de población que trabaja en forma independiente o como asalariada, $y$ aquella que forma parte de la fuerza de trabajo familiar no remunerada.

Finalmente, con relación a la ocupación desempeñada, se buscó conocer el grado de adscripción de la población económicamente activa a las labores agricolas $u$ otras labores importantes relacionadas con distintos sectores de la actividad económica.

\section{La participación de la población en la actividad económica}

La población de las reducciones estudiadas está constituida por 12952 personas, de las cuales casi el 75 por ciento es población en edad de trabajar (9 502 personas de 12 años y más de edad). Con relación a la condición de actividad, la PEA representa el 31 por ciento de la población total, en tanto la población no activa alcanza al 43 por ciento (gráfico 1). Como se aprecia en el cuadro 1, el 42 por clento (3 993 personas) de la población en edad de trabajar es población económicamente activa.

De acuerdo con estas cifras, en las reducciones seleccionadas existe una alta proporción de población económicamente dependiente (69 por ciento), 10 que significa que por cada persona que trabaja, otras 2.2 dependen económicamente de ella. Sin embargo, esta relación sobreestima la dependencia real, ocultando la complejidad de las economias campesinas indigenas, en donde la unidad económica funciona sobre la base del trabajo de todo el grupo familiar, siendo de gran importancia la contribución informal de la mujer y de los ninos.

Cabe destacar que por razones de comparabilidad de la información, no serán siempre incluidas en el análisis como parte de la población económicamente activa. 
En el cuadro 1 se aprecia que las tres cuartas partes de los hombres de 12 años y más de edad forma parte de la PEA y prácticamente el 100 por ciento declaró encontrarse ocupado. Esto es de esperar en zonas rurales, ya que es dificil que existan desocupados absolutos, aunque es muy posible que se presente una desocupación disfrazada a través del subempleo de los recursos humanos, como consecuencia de la escasa capacitación laboral y de la falta de asistencia tecnológica y crediticia. En cualquier caso, la medición de esta situación es dificil de lograr.

CUADRO 1

REDUCCIONES INDIGENAS SELECCIONADAS:

DISTRIBUCION RELATIVA DE IA POBLACION DE 12 AÑOS Y MAS DE EDAD POR CONDICION DE ACTIVIDAD, SEGUN SEXO. CENSO DE 1988

\begin{tabular}{|c|c|c|c|}
\hline $\begin{array}{l}\text { Condición de } \\
\text { actividad }\end{array}$ & $\begin{array}{c}\text { Hombres } \\
8\end{array}$ & $\underset{8}{\text { Mujeres }}$ & $\begin{array}{c}\text { Ambos sexo } \\
8\end{array}$ \\
\hline \multicolumn{4}{|l|}{ PEA } \\
\hline Ocupado & 74.0 & 5.5 & 41.5 \\
\hline $\begin{array}{l}\text { Cesante } \\
\text { Busca trabajo por }\end{array}$ & 0.6 & 0.2 & 0. \\
\hline primera vez & 0.2 & 0.1 & 0.2 \\
\hline Subtotal PEA & $\begin{array}{r}74.8 \\
(3732)\end{array}$ & $\begin{array}{r}5.8 \\
(261)\end{array}$ & $\begin{array}{r}42.0 \\
(3993)\end{array}$ \\
\hline
\end{tabular}

Población no activa

$\begin{array}{lrrr}\text { Dueña de casa } & 0.4 & 66.2 & 31.7 \\ \begin{array}{l}\text { Dueña de casa } \\ \text { y trabaja }\end{array} & - & 3.9 & \\ \text { Estudiante } & 14.6 & 13.7 & 1.9 \\ \text { Pensionado } & 8.2 & 9.4 & 14.2 \\ \text { Otro no activo } & 1.8 & 1.0 & 8.8 \\ \text { Subtotal pob. no activa } 25.1 & 94.2 & 1.4 \\ & (1253) & (4254) & (5507) \\ \text { Total pob.12 años y más } 100.0 & 100.0 & 100.0 \\ & (4986) & (4516) & (9502)\end{array}$

Fuente: Anexo 1 . 


\section{Gráfico 1 \\ REDUCCIONES INDIGENAS SELECCIONADAS: \\ POBLACION TOTAL POR CONDICION DE ACTIVIDAD \\ $Y$ MENOR DE 12 ANNOS DE EDAD. CENSO DE 1988}

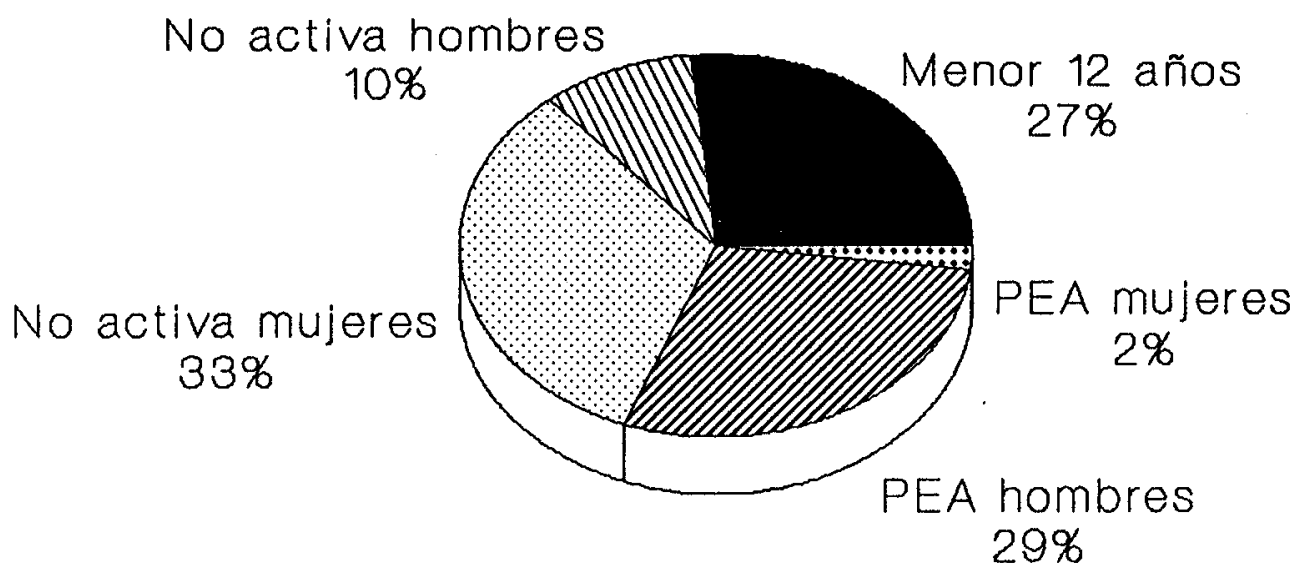

Fuente: Guadro 1 
La mujer, por su lado, casi en su totalidad forma parte de 1o que tradicionalmente se denomina población no activa ( 94 por ciento), concentrándose en la categoria "dueña de casa", donde se ubica el 66 por ciento de la población femenina de 12 años y más de edad.

Estas cifras indicarian que, en términos generales, al hombre se le asigna el trabajo productivo y a la mujer las tareas del hogar. Cabe señalar que, por 1o general, estas labores exceden el ámbito del hogar en áreas rurales, debido a la participación de la mujer en los trabajos del huerto familiar, en la crianza de ganado menor e incluso en actividades vinculadas con la comercialización. Esto permite concluir que es diffcil conocer en su real dimensión la organización de las familias rurales para su subsistencia.

\subsection{Diferencias entre distritos}

Es importante examinar el comportamiento de $1 a$ participación de $1 a$ población en la actividad económica según los distritos, ya que se descubren algunas peculiaridades que llaman la atención y que podrian dar cuenta de algún grado de diferenciación interna en cuanto a las caracteristicas económicas.

E1 análisis de la condición de actividad en cada distrito muestra un comportamiento muy homogéneo para los hombres, lo que no se advierte entre las mujeres (anexo 2). Maquehue es el distrito que posee la más alta participación laboral femenina, lo que podria deberse a una mayor integración con Temuco y a una mayor diversidad en cuanto a las fuentes de trabajo, especialmente en los servicios (hospital, escuelas, iglesias, industrias, restaurantes y moteles). La menor participación en Molco podria asociarse con el hecho de que en el sector no hay otras fuentes de trabajo aparte de las escuelas; sólo existen caminos de tierra y sus limites abarcan solamente a otras reducciones.

\subsection{Diferencias con el contexto nacional y regional}

E1 análisis del grado de participación de la población de las reducciones seleccionadas en la actividad económica, comparada con la de otras áreas, muestra interesantes resultados.

Por medio del porcentaje de PEA (de 15 años y más de edad) sobre la población total, se observa que no existen grandes diferencias entre la participación económica de la población estudiada y la participación que mostraban la IX Región y el pais en 1982, como se aprecia en el cuadro 2 . Sin 
embargo, al considerar el sexo de las personas, se descubre que la participación femenina en 1a PEA de las reducciones estudiadas es notablemente inferior a la de estas áreas, 10 que se verifica también para el total de reducciones censadas en 1982 .

\section{CUADRO 2}

PARTICIPACION DE LA POBLACION DE 15 AÑOS Y MAS DE EDAD EN LA ACTIVIDAD ECONOMICA POR AREA, SEGUN SEXO. CENSOS DE 1982 Y 1988 (por cien)

\begin{tabular}{|c|c|c|c|c|c|c|}
\hline \multirow[b]{2}{*}{ Area } & \multicolumn{3}{|c|}{ PEA/poblac. total } & \multicolumn{3}{|c|}{ PEA/poblac. 15 y más } \\
\hline & Hombres & Mujeres & $\begin{array}{l}\text { Ambos } \\
\text { sexos }\end{array}$ & Hombres & Mujeres & $\begin{array}{l}\text { Ambos } \\
\text { sexos }\end{array}$ \\
\hline Pais 1982 (1) & 49.0 & 16.6 & 32.5 & 73.5 & 24.2 & 47.9 \\
\hline IX Región 1982 (2) & 47.0 & 12.5 & 29.7 & 73.5 & 19.2 & 46.0 \\
\hline $\begin{array}{l}\text { Total reducciones } \\
1982 \text { (2) }\end{array}$ & 49.3 & 4.9 & 28.0 & 80.2 & 8.2 & 46.2 \\
\hline $\begin{array}{l}\text { Reducciones } \\
\text { seleccionadas } \\
\text { Censo de } 1988 \text { (3) }\end{array}$ & 55.2 & 4.2 & 30.8 & 82.4 & 6.4 & 46.3 \\
\hline
\end{tabular}

Fuente: (1) INE (1987a).

(2) Oyarce, Romaggi y Vidal (1989).

(3) Anexo 1.

En las reducciones seleccionadas, como se observa en el cuadro 2, la participación de los hombres es catorce veces superior a la de las mujeres, diferencia algo mayor que la encontrada en el total de reducciones del Censo Nacional de 1982. Estas discrepancias superan largamente a las detectadas para la región y el pais.

Al eliminar el efecto que pudieran tener las diferentes estructuras etarias, es decir, por medio de la estimación del porcentaje de PEA sobre 1a población de 15 años y más de edad, en general, se confirma 10 señalado.

Cabe agregar finalmente que la medición del grado de participación de la población estudiada en las actividades económicas, no ha considerado que existen actividades estacionales que involucran diferentes ocupaciones, que pueden 
aumentar la participación de la PEA. Al respecto, es necesario destacar que dada la creciente subdivision de las tierras, muchos estudiantes, dueñas de casa, trabajadores familiares y algunos trabajadores por cuenta propia se emplean como temporeros en ciertas épocas del año en que hay oferta de trabajo, ya sea en lugares cercanos a las reducciones o fuera de ellas, como por ejemplo, en época de recolección de frutas en la zona central del pais, en faenas forestales, y en lugares cercanos para la aporca y cosecha de remolacha. Sobre este punto se volverá en el análisis de las caracteristicas ocupacionales.

\subsection{Participación femenina}

De los antecedentes que se han ido presentando, se podria señalar que, formalmente, el peso de la actividad económica en las reducciones indigenas seleccionadas parece recaer en los hombres. Sin embargo, el trabajo que realiza la mujer en el hogar (principalmente en los estratos socioeconómicos bajos de las áreas rurales), tiene un carácter tan importante como el del varón, al cumplir, además de las funciones reproductivas y de mantención de la familia, una significativa participación en las labores de producción y comercialización (CEPAL, 1984).

Muchas mujeres, especialmente dueñas de casa, no se reconocen como activas en encuestas o censos aun cuando realizan también alguna actividad remunerada. Varios factores intervienen en esta situación, como por ejemplo, el hecho de que las ocupaciones que desempeñan son una prolongación del trabajo doméstico (el que no es valorado); no tienen regularidad; son de jornada parcial; no se realizan en lugares estables o no tienen un horario fijo.

Cabe destacar que no resulta fácil incorporar estas actividades dentro de la PEA, ya que implicaria redefinir la población activa y, además, se perderia la posibilidad de establecer comparaciones con otras realidades. En el Censo de 1988 se ha buscado abordar parcialmente este problema, a través de la inclusión de la categoría "dueña de casa y trabaja" definida por una contribución directa o indirecta con ingresos al grupo familiar. Sin embargo, a la luz de los resultados, pareciera prevalecer una restricción en lo que la mujer tiende a considerar como contribución al ingreso, en el sentido de excluir actividades 
tales como la crianza de aves y animales menores, y actividades agricolas y artesanales destinadas al autoconsumo y a la venta, que en no pocos casos suelen ser de responsabilidad exclusiva de la mujer."

Es asi como en las reducciones estudiadas, las mujeres dueñas de casa que declaran que trabajan representan apenas el 3.9 por ciento del total de mujeres en edad de trabajar (cuadro 1). No obstante, si se suma esta categoria a las mujeres de la PEA, la participación femenina en la PEA total asciende desde 6.5 (anexo 1) a 10.5 por ciento (cuadro 3), y la PEA sobre la población femenina en edad de trabajar sube de 5.8 a 9.7 por ciento (cuadro 4).

\section{CUADRO 3}

REDUCCIONES INDIGENAS SELECCIONADAS: POBLACION ECONOMICAMENTE ACTIVA

POR SEXO. CENSO DE 1988

(incluyendo "dueña de casa que trabaja")

\begin{tabular}{|c|c|c|}
\hline Sexo & $\begin{array}{c}\text { Total } \\
\text { PEA }\end{array}$ & 8 \\
\hline $\begin{array}{l}\text { Hombres } \\
\text { Mujeres }\end{array}$ & $\begin{array}{r}3732 \\
438\end{array}$ & $\begin{array}{l}89.5 \\
10.5\end{array}$ \\
\hline Ambos sexos & 4170 & 100.0 \\
\hline
\end{tabular}

Fuente: Anexo 1

La tendencia observada en la participación de la mujer no se modifica al sumar 1a PEA y las dueñas de casa que trabajan en cada distrito, y compararlas con el total de mujeres en edad de trabajar. Maquehue es el distrito que mantiene una mayor participación laboral femenina y Molco la menor, aunque esto ocurre se considere o no a las dueñas de casa que trabajan (cuadro 4).

Este aspecto requiere profundizarse y discutirse, con el objeto de probar nueva metodologias para captar la participación femenina con mayor exactitud, sin perder de vista las posibilidades de operacionalización y comparación de la información. 
REDUCCIONES INDIGENAS SELECCIONADAS:

PORCENTAJE DE MUJERES QUE TRABAJAN SOBRE LA POBLACION FEMENINA DE 12 AÑOS Y MAS DE EDAD POR DISTRITO, SEGUN CONDICION DE ACTIVIDAD. CENSO DE 1988

\begin{tabular}{|c|c|c|c|}
\hline \multirow{2}{*}{ Distrito } & \multicolumn{3}{|c|}{ de actividad } \\
\hline & PEA & $\begin{array}{l}\text { Dueña de casa } \\
\text { y trabaja }\end{array}$ & local \\
\hline Labranza & 4.9 & 3.3 & 8.2 \\
\hline Molco & 3.4 & 2.4 & 5.8 \\
\hline Maquehue & 8.1 & 3.9 & 12.0 \\
\hline Metrenco & 5.7 & 4.9 & 10.6 \\
\hline Total & $\begin{array}{r}5.8 \\
(261 / \\
4516)\end{array}$ & $\begin{array}{r}3.9 \\
(177 / \\
4516)\end{array}$ & $\begin{array}{r}9.7 \\
(438 / \\
4516)\end{array}$ \\
\hline
\end{tabular}

Fuente: Anexo 3.

En Maquehue, como se ha señalado, hay una serie de factores que estarian determinando una mayor participación relativa de la población femenina en la fuerza de trabajo. Metrenco reúne similares caracteristicas en cuanto a la disponibilidad de medios de locomoción; fácil acceso a la carretera y a caminos secundarios pavimentados; mayores fuentes de trabajo en fundos y parcelas; y cercanía a centros poblados con servicios públicos. En todo caso, debe advertirse que en ambos distritos estas ventajas se reducen a determinadas áreas.

En sintesis, puede señalarse que a pesar de la probable subestimación de la fuerza de trabajo femenina, es indudable que en las reducciones indigenas, donde predomina la actividad agricola, se privilegia el trabajo masculino. Esto explicaria el hecho de que las familias suelen retener a una parte de los hijos varones para que ayuden al padre o jefe de hogar en las labores productivas de la unidad familiar y, para que más tarde, se hagan cargo de ella. Es posible que otra parte de la familia, entre las que pueden incluirse muchas mujeres, deba emigrar o buscar trabajo fuera de la reducción. La importancia de este fenómeno es que se generan mecanismos que permitirian mantener un cierto equilibrio entre propiedad y población, evitando la subdivisión de la propiedad al concentrar los derechos de herencia en la persona que permanece en el hogar. Al respecto, Bengoa (1987) destaca que la escasez de tierras impedia el reconocimiento 
efectivo de los derechos legales de los demás hijos, situación que seguramente se ha visto afectada con la Ley $N^{2} 2568$ del año 1979.

\subsection{Jefes de hogar}

La condición de actividad del jefe de hogar guarda estrecha relación con la organización económica de las familias, siendo de especial relevancia la situación de las mujeres jefas de hogar. E1 cuadro 5 muestra que el 71 por ciento de las personas registradas como jefes de hogar corresponde a PEA, los que se declararon ocupados casi en su totalidad.

CUADRO 5

REDUCCIONES INDIGENAS SELECCIONADAS:

DISTRIBUCION RELATIVA DE YEFES DE HOGAR POR CONDICYON DE ACTTVIDAD, SEGUN GEXO. CENSO DE 1988

\begin{tabular}{|c|c|c|c|}
\hline \multirow{2}{*}{$\begin{array}{l}\text { Condición } \\
\text { de } \\
\text { actividad }\end{array}$} & \multicolumn{3}{|c|}{ Jefes de hogar } \\
\hline & $\begin{array}{c}\text { Hombres } \\
q\end{array}$ & $\underset{8}{\text { Mujeres }}$ & Ambos sexos \\
\hline PEA & 83.1 & 7.6 & 70.6 \\
\hline No activo & & & \\
\hline Dueña de casa & 0.2 & 47.4 & 8.0 \\
\hline $\begin{array}{l}\text { Duena de casa } y \\
\text { trabaja }\end{array}$ & - & 7.8 & 1.3 \\
\hline Pensionado & 14.7 & 36.3 & 18.3 \\
\hline otro no activo & 1.9 & 0.9 & 1.8 \\
\hline Total & $\begin{array}{r}100.0 \\
(2267)\end{array}$ & $\begin{array}{l}100.0 \\
(447)\end{array}$ & $\begin{array}{r}100.0 \\
(2714)\end{array}$ \\
\hline
\end{tabular}

Fuente: Anexo 4.

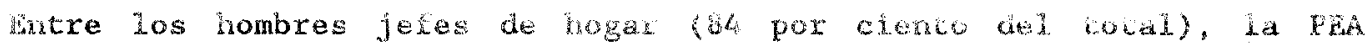

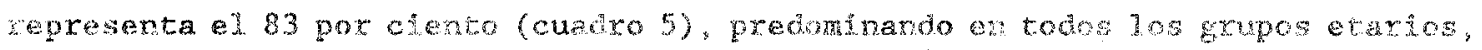
salvo entre los mayores de 59 años de edad, donde la representación es compartida con los pensionados (anexo 4 ).

Como se aprecia, las mujeres jefas de hogar presentan una situación radicalmente diferente, ya que se encuentran mayoritariamente dentro de la 
población no activa (92 por ciento); casi la mitad de ellas son dueñas de casa $y$, en menor proporción, pensionadas. Al igual que los hombres jefes de hogar que trabajan, las jefas de hogar registradas como dueñas de casa predominan en todos los grupos etarios, excepto entre los de 60 años y más de edad (anexo 4).

En el grupo de los pensionados, la importancia relativa de las mujeres es bastante mayor que la de los jefes de hogar varones, posiblemente porque éstos permanecen en actividad aun a edades avanzadas (en todo caso, e1 67 por ciento de los pensionados jefes de hogar son varones).

Dentro de las mujeres jefas de hogar, las que trabajan ( 8 por ciento), constituyen una proporción ligeramente superior a la PEA femenina (6 por ciento: cuadro 1), hecho que indicaria que su ingreso al mercado de trabajo responde más bien a la necesidad de mantener una familla. La jefa de hogar que es dueña de casa y trabaja tiene la misma importancia relativa que la que declaró que sólo trabaja; por lo tanto, al sumar ambas categorlas, la proporción de jefas de hogar en actividad se duplica.

La importancia relativa de los jefes de hogar económicamente activos va disminuyendo con la edad y se van perfilando como jefes de hogar los pensionados y las dueñas de casa. La situación descrita parece indicar que la mujer que asume la jefatura de hogar se ve obligada a trabajar por necesidad, cuando hay ausencia de un varón en edad de trabajar en el hogar, debido a viudez, separación o migración por causas laborales."

\section{Caracteristicas demográficas de 1a pEA}

Las modalidades de participación de la población en las actividades económicas están asocjadas, además del sexo, con la edad de las personas y con otxos rasgos espectficos. Para conocer este comportamiento se examinarán las características del sexo y la edad, junto con el estado civil y el nivel de instrucción de la PEA.

\subsection{Sexo y edad}

El grado de participación de hombres y mujeres en la actividad económica es difererte, comn st ha visto, pexo también lo es en conjunto con la edad de las personas. Por lo general, entre los hombres la participación es más baja en los menores de 20 años de edad, sube a cerca del 100 por ciento en las edades 
centrales y luego decrece a partir de los 60 años de edad. Entre las mujeres, el grado de participación en la actividad económica es variable, especialmente entre áreas urbanas (donde es mayor) y áreas rurales.

En las reducciones indigenas seleccionadas se confirma lo señalado, ya que, además, las tasas especificas de actividad (porcentaje de PEA sobre población de cada grupo de edad), son mayores entre los hombres. El cuadro 6 muestra que las tasas especificas de actividad femenina alcanzan sus mayores valores entre los 15-29 años de edad, mientras la población masculina mantiene un comportamiento relativamente parejo desde los 20 hasta los 59 años de edad.

La situación que afecta a la población femenina podria estar asociada con los cambios en el estado civil que se producen con el aumento de la edad, y con las diferentes etapas del ciclo de vida de la mujer.

CUADRO 6

REDUCCIONES INDIGENAS SELECCIONADAS:

TASAS ESPECIFICAS DE ACTIVIDAD DE LA POBLACION DE 12 AÑOS Y MAS DE EDAD POR GRUPOS QUINQUENALES DE EDAD, SEGUN SEXO. CENSO DE 1988 * (por cien)

\begin{tabular}{lrrr}
$\begin{array}{l}\text { Grupos } \\
\text { de edad }\end{array}$ & Hombres & Mujeres & $\begin{array}{r}\text { Ambos } \\
\text { sexos }\end{array}$ \\
\hdashline $2-14$ & 9.3 & 0.4 & 5.1 \\
$15-19$ & 65.2 & 9.2 & 39.4 \\
$20-24$ & 93.9 & 10.2 & 58.8 \\
$25-29$ & 97.2 & 9.9 & 58.8 \\
$30-34$ & 97.8 & 5.3 & 54.2 \\
$35-39$ & 96.8 & .4 .2 & 51.1 \\
$40-44$ & 96.9 & 7.8 & 51.9 \\
$45-49$ & 91.5 & 6.5 & 53.0 \\
$50-54$ & 89.1 & 5.4 & 46.0 \\
$55-59$ & 89.5 & 5.5 & 48.5 \\
60 y más & 46.7 & 1.2 & 23.0
\end{tabular}

Fuente: Anexo 1 .

*: (PEA/población grupo de edad) * 100 .

Por su parte, la participación de los hombres menores de 20 años de edad es significativa, aunque la PEA menor de 15 años representa sólo el 1.3 por ciento del total de hombres activos, ya que la gran mayoria de estas personas 
(90 por ciento) corresponde a la categoria estudiantes (anexo 1). Es probable que, dado el carácter del trabajo que realiza la mayor parte de los jóvenes como trabajador familiar no remunerado, la declaración de actividad esté subestimada. Al no percibir remuneración y al ejecutar labores de las que son responsables desde la niñez, esta población no se consideraría económicamente activa mientras permanece en el sistema educativo.

Con respecto a la participación de las mujeres dueñas de casa que declaran que trabajan, ésta se mantiene relativamente pareja desde los 15 a los 59 años de edad (ver anexo 1), lo que podría relacionarse, como ya se mencionó, con 1a necesidad de trabajar por ser jefa de hogar. Este grupo, por lo general, se ocupa en actividades que se pueden realizar en el hogar y que no obligan a cumplir un horario fijo de trabajo.

Tal como se hizo anteriormente con la participación del total de población, al comparar la participación en la actividad económica de hombres y mujeres por grupos de edad, registrada a partir del Censo Nacional de 1982 (IX Región y total de reducciones de la región), con la obtenida en las reducciones del Censo de 1988, se aprecia que la participación masculina en las reducciones seleccionadas es ligeramente superior a la de la IX Región y bastante más elevada que la del total de reducciones de ésta, lo que aconteceria prácticamente en todas las edades. Las mujeres, en cambio, presentan tasas inferiores a las regionales y similares a las del total de reducciones indigenas de la región, según la información del Censo Nacional de 1982 (gráficos 2 y 3).

Entre los hombres de las reducciones censadas en 1988, las categorías de edades extremas, 15-19 y mayores de 59 años de edad, presentan tasas de actividad superiores al promedio de la IX Región. Esto se debe al hecho de que en las economfas campesinas la incorporación al trabajo se produce a edades más tempranas y el retiro a edades más tardías.

La incorporación temprana de la población rural a la fuerza de trabajo obedecería a que los jóvenes del campo se ven obligados a contribuir a la subsistencia familiar, a lo que se agrega el que muchos de ellos no siguen estudiando al no contar con establecimientos que ofrezcan cursos de niveles avanzados en su área de residencia. Por su parte, la prolongación en grado importante de la participación de la población de 60 años y más de edad, puede estar vinculada con razones culturales, asi como con el hecho de que es indispensable su permanencia en el trabajo para asegurar la subsistencia, ya que por ejemplo, se conoce que no todos los ancianos reciben pensión de vejez - jubilación y para quienes la reciben, su monto suele ser insuficiente. 
Gritioo 2

IX REGION Y REDUCCIONES INDIGENAG.

TASAS ESP ECIFICAS DE ACTIVIDAD MASCULINA POR GRUPOS

QUINQUENALES DE EDAD. CEN9OS DE 1982 Y 1988

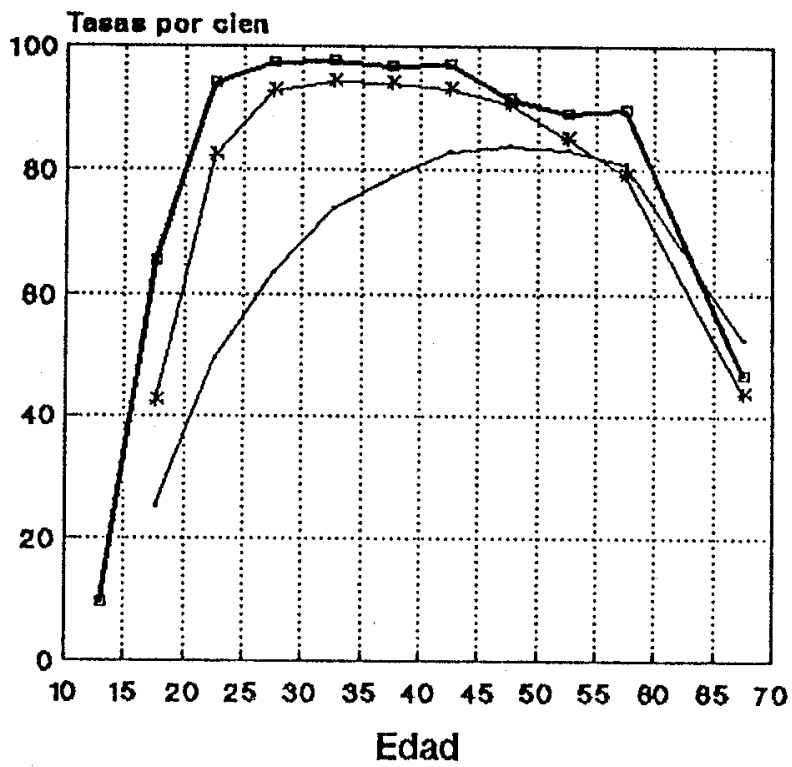

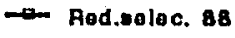

- Total rod.Ind. 82

* IX Aog. 82

Fuente: Guadro 6 y Anexo 5

Erifloo a

IX REGION Y REDUCCIONEE INDIGENAE, TASAS ESPECIFICAS DE ACTIVIDAD FEMENINA POR GAUPOE QUINQUENALES DE EDAD. CENEOE DE 1982 \% 1980

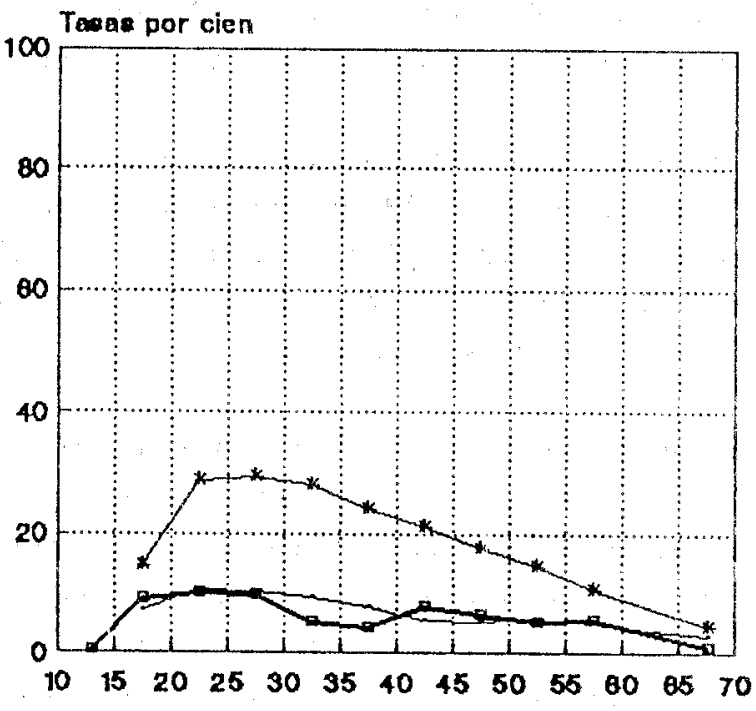

Edad

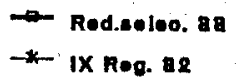

Tutal red.Ind. 82

Fuente: Cuadro o Y Anexo 6 


\subsection{Estado civil}

E1 análisis del estado civil de la fuerza de trabajo, según el sexo y $1 a$ edad de las personas, muestra algunas particularidades que permiten conocer mejor las modalidades de su participación en la actividad económica.

Entre la población femenina, más del 60 por ciento de las activas son solteras, lo que se explicaria por un lado, por el patrón tradicional de división de roles sexuales entre los mapuches, en que la mayoria de las solteras no tendrian la responsabilidad directa en las tareas del hogar, como acontece con las mujeres casadas. Por otro lado, la necesidad de subsistir y aportar con ingresos al grupo familiar ayudaria a explicar la presencia de las mujeres solteras en la PEA, de modo que el comportamiento de éstas contribuye decisivamente a definir el perfil de la mujer que trabaja, el cual, además, se puede describir por una mayor participación relativa entre las edades 20-29 años.

Como se observa en el cuadro 7, la participación económica de las mujeres que tienen relación de pareja es bastante inferior a la de las mujeres viudas, separadas y solteras, 10 que en parte confirmaria la persistencia del patrón de comportamiento tradicional de los mapuches, en el que a estas mujeres les corresponde asumir las labores relacionadas con la reproducción y mantención de la familia. Probablemente, cuando se asume la jefatura del hogar, la situación puede cambiar, como 10 indicaria la mayor participación relativa de las separadas.

Finalmente, entre los hombres, con tasas especificas de actividad económica mucho más elevadas, se observa un comportamiento que es independiente del estado civil y de la edad, excepto entre los solteros menores de 15 años, quienes en su mayoria son aun estudiantes. 
CUADRO 7

REDUCCIONES INDIGENAS SELECCIONADAS:

TASAS ESPECIFICAS DE ACTIVIDAD DE LA POBLACION DE 12 AÑOS Y MAS DE EDAD POR SEXO Y GRUPOS DE EDAD, SEGUN ESTADO CIVIL. CENSO DE 1988 * (por cien)

\begin{tabular}{lrrrr}
$\begin{array}{l}\text { Sexo y } \\
\text { grupos } \\
\text { de edad }\end{array}$ & \multicolumn{3}{c}{ Estado civil PEA } \\
& casado & viudo & separ. soltero \\
Hombres & & & & \\
$12-14$ & & & & \\
$15-19$ & 100.0 & - & - & 64.9 \\
$20-29$ & 99.3 & - & 75.0 & 94.1 \\
$30-39$ & 98.5 & 100.0 & 88.9 & 94.8 \\
$40-49$ & 95.9 & 87.5 & 92.9 & 86.9 \\
$50-59$ & 91.2 & 97.3 & 66.7 & 79.0 \\
60 y más & 52.2 & 24.2 & 63.6 & 56.1 \\
& & & & \\
Total hombres & 87.0 & 43.1 & 78.0 & 67.1 \\
& $(1840)$ & $(88)$ & $(39)$ & $(1764)$
\end{tabular}

Mujeres

$\begin{array}{lrrrr}12-14 & - & - & - & 0.4 \\ 15-19 & - & - & - & 10.1 \\ 20-29 & 3.4 & - & - & 16.6 \\ 30-39 & 2.0 & 16.7 & 25.0 & 12.6 \\ 40-49 & 5.3 & 20.0 & 16.7 & 10.4 \\ 50-59 & 3.9 & 7.6 & 6.3 & 11.4 \\ 60 \text { y más } & 0.6 & 1.4 & 5.0 & 2.2 \\ & & & & \\ \text { Total mujeres } & 3.0 & 4.0 & 11.0 & 9.1 \\ & (63) & (16) & (8) & (174)\end{array}$

Fuente: Anexo 6.

*: (PEA por estado civil/población grupo de edad por estado civil) * 100 .

4.3. Nivel de instrucción de 1 a fuerza de trabajo

E1 nivel de instrucción de la fuerza de trabajo, medido a través del número de años de estudio aprobados por las personas activas, otorga importantes elementos de juicio para conocer el grado de capacitación de la fuerza de 
trabajo, as como la relación entre la inserción económica y la condición social de la población estudiada.

Como se aprecia en el cuadro 8 , en general, el nivel de instrucción de $1 a$ PEA es bajo, aunque varia en forma inversa con la edad.

\section{CUADRO 8}

REDUCCIONES INDIGENAS SELECCIONADAS:

DISTRIBUCION RELATIVA DE LA POBLACION ECONOMICAMENTE ACTIVA POR SEXO Y GRUPOS DE EDAD, SEGUN AÑOS DE ESTUDIO APROBADOS. CENSO DE 1988

\begin{tabular}{|c|c|c|c|c|c|c|c|c|}
\hline \multirow{2}{*}{$\begin{array}{l}\text { Sexo y } \\
\text { grupos } \\
\text { de edad }\end{array}$} & \multicolumn{8}{|c|}{ Años de estudio aprobados } \\
\hline & 0 & $1-3$ & $4-6$ & $7-8$ & 9 y más & Tot & & edio \\
\hline \multicolumn{9}{|l|}{ Hombres } \\
\hline $12-14$ & 2.1 & 16.7 & 50.0 & 31.3 & - & 100.0 & (48) & 5.2 \\
\hline $15-19$ & 1.0 & 8.8 & 39.0 & 44.4 & 6.4 & 100.0 & (487) & 6.3 \\
\hline $20-24$ & 2.1 & 8.2 & 34.2 & 40.9 & 14.5 & 100.0 & (609) & 6.8 \\
\hline $25-29$ & 1.4 & 11.3 & 40.9 & 34.3 & 11.7 & 100.0 & (487) & 6.4 \\
\hline $30-34$ & 0.8 & 13.6 & 46.2 & 28.3 & 10.9 & 100.0 & $(396)$ & 6.1 \\
\hline 35 y más & 14.2 & 36.3 & 40.2 & 5.2 & 4.1 & 100.0 & (1694) & 3.7 \\
\hline \multicolumn{9}{|l|}{ Mujeres } \\
\hline $12-14$ & - & - & 50.0 & 50.0 & - & 100.0 & (2) & 6.3 \\
\hline $15-19$ & - & 7.1 & 37.5 & 50.0 & 5.4 & 100.0 & (56) & 6.5 \\
\hline $20-24$ & - & 13.0 & 21.7 & 30.4 & 34.8 & 100.0 & (46) & 8.2 \\
\hline $25-29$ & 2.6 & 15.4 & 28.2 & 20.5 & 33.3 & 100.0 & (39) & 7.6 \\
\hline $30-34$ & 5.3 & 31.6 & 36.8 & 10.5 & 15.8 & 100.0 & (19) & 5.3 \\
\hline 35 y más & 22.6 & 34.4 & 31.2 & 1.1 & 10.7 & 100.0 & (93) & 3.7 \\
\hline
\end{tabular}

Fuente: Anexo 7.

En efecto, se observa que la escolaridad es superior entre los menores de 35 años de edad, entre quienes el promedio de años de estudio aumenta gradualmente hasta el grupo 20-24 años de edad, como consecuencia de la expansión del sistema educacional en las últimas décadas y el cambio de conducta experimentado por la sociedad mapuche en su largo y creciente contacto con la sociedad chilena, asi como por efecto de las mayores exigencias hacia la fuerza laboral.

Al considerar el sexo de las personas activas, se aprecia que las mujeres registran promedios superiores de años de estudios a los de los hombres en los 
grupos de menores de 30 años de edad. Esto hace que entre la población femenina activa y el total de mujeres de 15 años y más de edad existan fuertes diferencias en la escolaridad: entre las mujeres que se encuentran en el mercado laboral el analfabetismo es más de dos veces inferior al que corresponde al total de la población femenina $y$, además, ellas alcanzan una mayor participación relativa en los niveles educacionales más altos (cuadro 9)."

\section{CUADRO 9}

REDUCCIONES INDIGENAS SELECCIONADAS :

DISTRIBUCION RELATIVA DE LA POBLACION ECONOMICAMENTE ACTIVA Y DE 15 AÑOS $Y$ MAS DE EDAD POR AÑOS DE ESTUDIO APROBADOS, SEGUN SEXO. CENSO DE 1988

\begin{tabular}{|c|c|c|c|c|c|c|}
\hline \multirow{4}{*}{$\begin{array}{l}\text { Años de } \\
\text { estudio } \\
\text { aprobados }\end{array}$} & \multicolumn{2}{|c|}{ Hombres } & \multicolumn{2}{|c|}{ Mujeres } & \multicolumn{2}{|c|}{ Ambos sexc } \\
\hline & $\cdots$ & . & $\ldots$ & $\ldots$ & $\ldots$ & $\ldots$ \\
\hline & PEA & $\begin{array}{l}\text { Pobl. } \\
15 \text { y más }\end{array}$ & PEA & $\begin{array}{l}\text { Pobl. } \\
15 \text { y más }\end{array}$ & PEA & $\begin{array}{r}\text { Pol } \\
15 \mathrm{y}\end{array}$ \\
\hline & 8 & 8 & 8 & 8 & 8 & 8 \\
\hline Ninguno & 7.2 & 9.7 & 9.0 & 22.0 & 7.3 & 15.5 \\
\hline $1-3$ & 22.1 & 22.4 & 21.2 & 23.5 & 22.0 & 22.9 \\
\hline $4-6$ & 39.8 & 37.2 & 31.0 & 31.9 & 39.2 & 34.7 \\
\hline 7 y más & 30.5 & 30.3 & 38.1 & 22.3 & 31.0 & 26.6 \\
\hline Total & 100.0 & 100.0 & 100.0 & 100.0 & 100.0 & 100.0 \\
\hline
\end{tabular}

Fuente: Anexo 7 y tabulados especiales Censo de 1988.

En sintesis, el nivel educacional de la PEA, en promedio, no supera el nivel básico. E1lo podria estar asociado con los bajos requerimientos de capacitación en el desarrollo de las actividades productivas que se realizan principalmente en la propiedad familiar, asi como en las relaciones entre comunidades. Estas actividades obedecen a un conocimiento que es parte del proceso de educación informal, que se obtiene a través de la observación y la práctica en la participación con los padres y familiares en las tareas económicas $y$ domésticas de la unidad familiar.

Aunque en el Censo de 1988 la PEA abarca población desde los 12 años de edad, el bajo número de casos incluidos en esos grupos etarios no influye mayormente en la comparación con la población total de 15 años y más de edad. 
Es probable que se requiera un mayor grado de instrucción en el desarrollo de las actividades económicas (asociación positiva) cuando se trata del trabajo fuera de las reducciones, en las relaciones comerciales y en las relaciones con instituciones estatales y privadas.' La mayor escolaridad de las mujeres activas se relacionaria con su participacion en algunas de estas actividades, ejerciendo un rol de vinculación con la sociedad nacional a través de la introducción de nuevos valores y pautas culturales, tales como las aspiraciones de consumo y el comportamiento reproductivo.

\section{Caracteristicas ecupacionales}

E1 análisis de las ocupaciones y categorfas ocupacionales de la población activa de las reducciones seleccionadas, constituye otro aspecto fundamental en el conocimiento de su inserción en la estructura productiva.

Debido al carácter de pequeños propietarios de la mayoria de la población (52 por ciento trabaja por cuenta propia), más del 80 por ciento de la PEA se ocupa en actividades agropecuarlas, las que están orientadas al cultivo de cereales, chacareria, crianza de animales y actividades forestales, entre otras. Las cifras del cuadro 10 muestran que, con relación a la categoría ocupacional, el 53 por ciento de los hombres de la PEA trabaja por cuenta propia, en tanto que entre las mujeres, el 51 por ciento se desempeña como asalariada.

Con respecto a la ocupación, el 87 por ciento de los hombres se ocupa en actividades agropecuarias, mientras que entre las mujeres se observa una cierta diversificación ocupacional, donde las principales ocupaciones guardan relación con los servicios personales y ocupaciones afines ( 37 por ciento), ${ }^{10}$ y con actividades agropecuarias (22 por ciento).

Algo de ello puede apreciarse al observar los datos del anexo 8-A, donde destaca la mayor escolaridad relativa de las mujeres que trabajan en ocupaciones relactonadas con los servicios personales.

En estas ocupaciones el número de mujeres es superior al de los hombres. 
REDUCCIONES INDIGENAS SELECCIONADAS:

DISTRIBUCION RELATIVA DE LA POBLACION ECONOMICAMENTE

ACTIVA POR SEXO Y OCUPACION PRINCIPAL, SEGUN CATEGORIA OCUPACIONAL. CENSO DE 1988

\begin{tabular}{|c|c|c|c|c|c|}
\hline Sexo & Cat & gorla o & pacional & & \\
\hline $\begin{array}{l}\text { y } \\
\text { ocupación } \\
\text { principal. }\end{array}$ & Cta.propia & $\underset{8}{A}$ & Trab.fam. & Patrón & $\begin{array}{c}\text { Total } \\
8\end{array}$ \\
\hline Hombres & & & & & \\
\hline Profesionales & 0.1 & 1.3 & - & - & \\
\hline Directivos & 0.1 & - & - & - & \\
\hline Empleados ofic. & 0.1 & 0.6 & - & - & 0 . \\
\hline Vendedores & 2.6 & 1.3 & 0.5 & - & 1. \\
\hline Agricultores & 94.5 & 58.8 & 98.7 & 54.5 & 86.9 \\
\hline Conductores & - & 0.7 & - & 9.1 & 0. \\
\hline Artesanos & 0.8 & 7.5 & 0.6 & 9.1 & 2. \\
\hline Otros artesanos & 1.6 & 10.7 & 0.1 & 27.3 & 3 . \\
\hline Otros obreros & 0.1 & 15.9 & 0.1 & - & 3. \\
\hline Servicios pers. & 0.2 & 2.9 & - & - & 0 . \\
\hline Ignorado & - & 0.5 & - & - & 0 . \\
\hline Total hombres & $\begin{array}{r}100.0 \\
(1969)\end{array}$ & $\begin{array}{l}100.0 \\
(876)\end{array}$ & $\begin{array}{l}100.0 \\
(864)\end{array}$ & $\begin{array}{r}100.0 \\
(11)\end{array}$ & $\begin{array}{r}100.0 \\
(3720)\end{array}$ \\
\hline
\end{tabular}

Mujeres

\begin{tabular}{|c|c|c|c|c|c|}
\hline Profesionales & - & 10.1 & - & - & 5.1 \\
\hline Empleadas ofic. & - & 3.1 & - & - & 1.6 \\
\hline Vendedoras & 27.5 & 2.3 & 11.4 & - & 12.6 \\
\hline Agricultoras & 19.8 & 9.3 & 77.1 & - & 22. \\
\hline Artesanas & 47.3 & 1.6 & 11.4 & - & 19.2 \\
\hline Otras artesanas & 4.4 & 0.8 & - & - & 2. \\
\hline Otras obreras & - & 0.8 & - & - & 0. \\
\hline Servicios pers. & - & 72.1 & - & - & 36. \\
\hline Ignoradas & 1.1 & - & - & - & 0.2 \\
\hline Total mujeres & $\begin{array}{r}100.0 \\
(91)\end{array}$ & $\begin{array}{l}100.0 \\
(129)\end{array}$ & $\begin{array}{r}100.0 \\
(35)\end{array}$ & - & $\begin{array}{l}100 . \\
(255\end{array}$ \\
\hline
\end{tabular}

Fuente: Anexo 9. Para detalle de los grupos de ocupación, consultar anexo 8-B. 
Las actividades agropecuarias predominan en todas las categorfas de ocupación masculina. Entre las mujeres, en cambio, las asalariadas corresponden principalmente a los servicios personales, actividades que se realizan fuera de la reducción en ocupaciones tales como empleada doméstica, lavandera y planchadora a domicilio;" en tanto que otras ocupaciones se realizan en escuelas y restaurantes cercanos (por ejemplo, cocinera). Las trabajadoras por cuenta propia, que constituyen el 36 por ciento de la PEA femenina, se desempenan fundamentalmente en actividades artesanales de tejidos a telar (alfombras, bolsos, lamas, mantas) y a palillo (calcetas, chalecos de lana cruda, gorros), producción que es llevada a cabo en todas sus etapas (esquilado, lavado, hilado y tejido) dentro de la unidad famillar. Las mujeres dueñas de casa que trabajan 10 hacen principalmente en este tipo de ocupaciones artesanales (anexo 10).

Finalmente, se observa que existe una relación entre edad y categoria de ocupación. Entre los jóvenes, ésta adquiere una modalidad que es distinta entre hombres y mujeres: los primeros se desempeñan preferentemente como trabajadores familiares, en tanto las mujeres jovenes 10 hacen como asalariadas. Este comportamiento se modifica en ambos sexos a partir de 10525 años, en donde las personas pasan a desempeñarse, de preferencia, como trabajadores por cuenta propia, lo que podria estar relacionado con la constitución de la familia (anexo 11). Cabe destacar, por último, que la condición de trabajadores familiares entre los hombres jóvenes parece estar asociada con los métodos alternativos para evitar la extrema subdivisión de la tierra y apoyar la cohesión de la familia, como ha destacado Bunster (1968).

\subsection{Diferencias entre distritos}

E1 análisis de las caracteristicas ocupacionales de la población de los cuatro distritos incluidos en el estudio muestra que no existe una homogeneidad, hecho que se relaciona con otros aspectos ya analizados, como 10 es el diferente grado de participación femenina en la fuerza de trabajo.

En todos los distritos estudiados se detecta que la ocupación principal de los hombres se relaciona claramente con el trabajo agricola, situación que es más acentuada en Molco (anexo 12). Entre las mujeres, las actividades ligadas a los servicios personales son las principales, pero la importancia de las trabajan en el servicio doméstico en la ciudad de Temuco serían campesinas mapuches. 
ocupaciones varia según el distrito, destacando las actividades de venta en Labranza y las de artesania en Metrenco (anexo 12). Cabe señalar que las actividades de comercialización de productos artesanales $y$ de consumo (chacareria, frutas, leche, huevos, aves), suelen realizarse en forma directa en las ciudades cercanas; casa por casa; en ferias; en calles; o en puestos instalados en las orillas de los caminos principales.

Un análisis de la categoria de la ocupación (anexo 13), revela que aun cuando la actividad por cuenta propia es la principal en todos los distritos, el perfil es varlable. Entre los hombres, el distrito de Molco, que parece ser el más representativo de una economía agricola de subsistencia, tiene la más alta proporción de trabajadores por cuenta propia y de trabajadores familiares no remunerados. Las razones por las cuales este distrito no presenta las caracteristicas de ocupación de los otros, parecen estar vinculadas con su mayor aislamiento relativo (está rodeado exclusivamente por otras reducciones), con la menor disponibilidad de vias de comunicación con los centros urbanos y con el hecho de que no ha sido penetrado en la misma medida por personas no mapuches, ya que en el área no existen parcelas ni fundos, lo que determina que existan menores posibilidades de venta de su fuerza de trabajo.

Los distritos de Labranza y Metrenco presentan una importante proporción de asalariados ( 28 y 31 por ciento, respectivamente), y una menor representación de trabajadores familiares (cerca de 20 por ciento), asomando como áreas cuya economia tiende a desarrollarse fuera de los limites de la reducción o a proletarizarse, al contar con fuentes de trabajo en fundos y parcelas, y una mayor articulación con Temuco. ${ }^{12}$

Finalmente, Maquehue, en cuyo perfil de categoria ocupacional los trabajadores familiares no remunerados tienen la segunda importancia (28 por ciento), representaria un contexto de una economia intermedia o en transición, en la cual las unidades económicas probablemente tendrian una cierta capacidad para retener a parte de su población activa.

En el caso de las mujeres, haciendo presente el bajo número de casos y la limitación que ello significa para el análisis, el perfil de la categorfa ocupacional en los distritos es menos uniforme (anexo 13). La categoria de

A juzgar por un reconocimiento general de la zona estudiada, el nivel socioeconómico de ambos distritos parece ser inferior al de los otros dos, 1o que en el caso de Metrenco parece confirmarse, por el menor nivel de escolaridad que presenta su población. 
trabajadoras asalariadas se mantiene como la más importante para todos ellos, pero su peso relativo es diferente, obedeciendo a la diversidad de ocupaciones que se orientan preferentemente a trabajos fuera del distrito.

Molco es el distrito que tiene la más alta proporción de trabajadoras asalariadas (69 por ciento), el que presenta la mayor proporción de trabajadoras familiares (21 por ciento), y el que posee la más baja representación de trabajadoras independientes ( 10 por ciento). Debe recordarse que este distrito presenta la menor participación de su población femenina en la actividad económica (cuadro 4).

La tendencia en los distritos de Labranza, Maquehue (éste, con la mayor participación femenina en la PEA) y Metrenco, es la de igualar la Importancia de las trabajadoras asalariadas con las mujeres que trabajan por cuenta propia, aunque Maquehue y Metrenco mantienen una importante representación de trabajadoras familiares (cerca de 15 por ciento).

En sintesis, siendo la población masculina la más representativa de las caracteristicas ocupacionales de la población económicamente activa de los cuatro distritos, se advierten diferencias que podrian estar relacionadas con una inserción económica determinada por la localización y características geográficas del distrito, por la diversificación de las fuentes de trabajo y por una mayor - menor subdivisión de la tierra.

\subsection{Comparación entre las reducciones seleccionadas y las reducciones de la IX Región}

Como localidades rurales, en las reducciones indigenas censadas tanto en el Censo de 1988 (seleccionadas) como en el Censo Nacional de 1982 (total de reducciones de la IX Región), la ocupación principal de los hombres se relaciona con las actividades agricolas. Sin embargo, en las mujeres, los servicios personales compartian importancia con las actividades agricolas en la totalidad de reducciones del Censo Nacional de 1982 (Oyarce, Romaggi y Vidal, 1989).

Al establecer estas comparaciones conviene tener presente que es probable que por su cercania a Temuco, las reducciones de los cuatro distritos presentaban diferencias en 1982 con respecto al total de reducciones de la región, las cuales se habrian mantenido en 1988. Esto significa que no es posible inferir tendencias para las reducciones seleccionadas al comparar la información en uno y otro momento. 
Los datos disponibles muestran, en todo caso, que la autogestión es una caracteristica común a las reducciones indigenas (cuadro 11). La importancia relativa de los trabajadores por cuenta propia y de los trabajadores familiares alcanzaba a un 68 por ciento en las reducciones de la IX Región en 1982, en tanto representa un 74 por ciento de la PEA en 1988 en las reducciones estudiadas. Si las diferencias se han mantenido, ello obedeceria a las distintas estrategias desarrolladas para insertarse en el mercado laboral, para suplir la falta de tierra, la escasa productividad, la falta de fuentes de trabajo y el bajo poder adquisitivo.

\section{CUADRO 11}

REDUCCIONES INDIGENAS :

DISTRIBUCION RELATIVA DE LA POBLACION ECONOMICAMENTE ACTIVA POR CATEGORIA OCUPACIONAL. CENSOS DE 1982 Y 1988

$\begin{array}{lcc}\begin{array}{l}\text { Categoria } \\ \text { ocupacional }\end{array} & \begin{array}{c}\text { Retal } 1982(1) \\ 8\end{array} & \begin{array}{c}\text { Selecc. } \\ \text { Tog8 }\end{array} \\ \text { Asalariado } & 30.8 & 25.3 \\ \text { Cuenta propia } & 43.1 & 51.8 \\ \text { Trabaj. familiar } & 25.1 & 22.6 \\ \text { Patrón o empleador } & 0.8 & 0.3 \\ \text { Total } & 100.0 & 100.0 \\ & (38265) & (3976)\end{array}$

Fuente: (1) Oyarce, Romaggi y Vidal (1989).

(2) Anexo 9.

La alta proporción de trabajadores por cuenta propia y de trabajadores familiares no remunerados expresa el carácter de economía agrícola de subsistencia desarrollada por la población de las reducciones indigenas seleccionadas. Sin embargo, el hecho de que una cuarta parte de la fuerza de trabajo se desempeña como asalariada demuestra la necesidad de buscar empleo fuera de las reducciones. Al respecto, debe destacarse la existencia del acceso a empleos en algunas épocas del año en zonas rurales de uso intensivo de mano 
de obra (actividades agrícolas en general, y fruticolas y forestales en particular), tanto al interior de 1 a IX Región como fuera de ella. ${ }^{13}$

13 Babarovic et al. (1987), en un estudio sobre cerca de 300 hogares campesinos mapuches, realizado en las provincias de Cautín y Malleco entre 1981 y 1982, encontraron que los destinos principales de los trabajadores temporales eran las áreas rurales, tanto de la IX Región como de otras regiones. 


\section{Conclusiones}

El análisis de la información obtenida en el Censo de 1988 con respecto a las caracteristicas económicas de la población de las reducciones seleccionadas, muestra que la organización de la actividad económica aparece marcada por una clara división sexual, ya que el hombre es el principal componente de la población que se declara económicamente activa, la cual representa casi un tercio de la población total.

La participación de la mujer es reducida y bastante inferior a la de la IX Región y el pais en su conjunto. Sin embargo, es probable que esta participación aparezca subestimada por la metodologla empleada para recabar la información o por factores culturales a través de los cuales la mujer se percibe sólo como dueña de casa, debido al carácter informal y esporádico de su trabajo, aun cuando sus actividades constituyan un aporte regular e importante al ingreso familiar. Las mujeres que trabajan son en su mayoria jóvenes, entre 20-29 años de edad, hecho que parece asociarse con el estado civil y la constitución de una familia. Otro grupo de mujeres que trabajan 10 hacen por su condición de jefas de hogar, debido a la ausencla del cónyuge o viudez.

Por otra parte, los antecedentes han permitido conocer que la población se incorpora a la fuerza de trabajo a temprana edad, manteniendo el hombre una alta participación hasta edad avanzada. La población menor de 15 años de edad que declara que trabaja tiene poca gravitación en la PEA, pese a que los niños desde pequeños, tienen responsabilidades en actividades productivas, las que deben combinar con las actividades escolares.

Con respecto al nivel de instrucción de la $\mathrm{PEA}$, éste es superior al del total de la población, a pesar de que, en promedio, no supera el nivel básico. Los trabajadores jóvenes, en particular las mujeres, tienen una mayor escolaridad, lo que sugiere que podria existir una relación positiva entre actividad económica y educación formal, cuando se realiza un trabajo fuera de las reducciones y en las relaciones comerciales y administrativas con la sociedad nacional.

Con relación a las caracteristicas ocupacionales, las actividades agropecuarias son las más importantes en estas reducciones, lo que se corresponde con la mayor gravitación de los trabajadores por cuenta propia y trabajadores familiares no remunerados ( 74 por ciento), hecho que caracteriza a las economias campesinas de subsistencia. Sin embargo, la participación de los asalariados 
(25 por ciento) representa una de las estrateglas de sobrevivencia en economias que no son capaces de dar empleo productivo a su fuerza de trabajo o de completar el ingreso familiar.

E1 perfil ocupacional es distinto según el sexo. Entre los hombres, e1 80 por ciento de la PEA se ocupa en la agricultura, mientras que entre las mujeres la mayoría se ocupa en servicios personales ( 37 por ciento) y en actividades agropecuarias (22 por ciento).

Las diferencias encontradas en el grado de participación en la actividad económica y en los perfiles ocupacionales de los cuatro distritos estudiados muestran las diferencias de los contextos en que éstas se desenvuelven, dependiendo del mayor o menor grado de integración con Temuco y de la existencia de fuentes de trabajo; asi también, sugieren la presencia de distintas estrategias de inserción en el mercado laboral y de alguna forma de diferenciación social al interior de la población.

Puede concluirse que la población de las reducciones indigenas seleccionadas presenta las caracteristicas de una economia campesina de subsistencia parcialmente orientada al mercado, donde la familia es la unidad básica de producción y de consumo, en un contexto de limitada disponibilidad de recursos productivos. 


\section{Bibliografia}

Babarovic, Ivo; Campaña, Pilar; Dlaz, Cecilia y Durán, Esteban (1987), Campesinado mapuche y procesos socio-económicos reglonales. Grupo de Investigaciones Agrarias, Santiago, AHC, Serie Docs. de Trabajo $N^{2} 34$, agosto.

Bengoa, José (1983), El campesinade chileno después de la Reforma Agraria. Ediciones Sur, Santiago.

Bengoa, José (1987), Historia del pueblo mapuche. Ediciones Sur, Santiago.

Borsotti, Carlos A. (1984), Sociedad rural educación y escuela en América Latina. Ed. Kapelusz, UNESCO-CEPAL-PNUD, Serie/Educación y Sociedad.

Bunster, Ximena (1968), Adaptation in mapuche life: natural and directed. Columbia University, Michigan, Ph. D. Anthropology.

Comisión Económica para América Latina (CEPAL) (1984), La mujer rural de América Latina: un actor social del último decenio (1975-1984). Santiago.

Comisión Económica para América Latina (CEPAL) (1989), Transformación ocupacional $y$ crisis social en América Latina. Santiago.

Instituto Nacional de Estadisticas (INE) (1987a), Total pais. Población XV Censo Nacional de Población y IV de Vivienda - Chile 1982. INE, Santiago, Tomo I, mayo.

Instituto Nacional de Estadísticas (INE) (1987b), IX Región de La Araucania, Población XV Censo Nacional de Población y IV de Vivienda - Chile 1982. INE, Santiago, Tomo II, julio.

Masferrer K., Elio (1983), La situación social de los grupos indigenas de América Latina.

Oyarce, Ana M.; Romaggi, Marisabel y Vidal, Aldo (1989), Cómoviven los mapuches. Análisis del Censo de Población de Chile de 1982. PAESMI, Santiago, Serie Docs. de Trabajo $\mathrm{N}^{2} 01$, enero.

Stuchlik, Milan (1974), Rasgos de la sociedad mapuche contemporánea. Ed. Nueva Universidad, Santiago.

Zambrano N., Mireya (1989), "Experienclas educativas en Chile". En D'Emilio, A. L. (comp.), Mujer indigena y educación en América Latina, UNESCO-OREALC, Santiago, junio, pp. 339-369. 
Anexos 
ANEXO 1

REDUCCIONES INDIGENAS SELECCIONADAS: POBLACION DE 12 AÑOS Y MAS DE EDAD POR SEXO Y GRUPOS QUINQUENALES DE EDAD, SEGUN CONDICION DE ACTIVIDAD. CENSO DE 1988

\section{HOMBRES}

\begin{tabular}{|c|c|c|c|c|c|c|c|c|c|c|}
\hline \multirow{5}{*}{$\begin{array}{l}\text { Grupos } \\
\text { de } \\
\text { edad }\end{array}$} & \multicolumn{9}{|c|}{ Condición de actividad } & \multirow{5}{*}{ Total } \\
\hline & \multicolumn{9}{|c|}{$\begin{array}{l}\text { PEA } \\
\text { Población no activa }\end{array}$} & \\
\hline & \multirow{3}{*}{\multicolumn{3}{|c|}{$\begin{array}{l}\text { Busca } \\
\text { prim. } \\
\text { Ocup. Ces. vez }\end{array}$}} & \multirow{3}{*}{\multicolumn{6}{|c|}{$\begin{array}{ll}\begin{array}{l}\text { y } \\
\text { y }\end{array} & \text { Dueño } \\
\text { trab. Pens. casa Estu. Otro Ign. }\end{array}$}} & \\
\hline & & & & & & & & & & \\
\hline & & & & & & & & & & \\
\hline $12-14$ & 48 & 0 & 0 & & 1 & 2 & 460 & 2 & 1 & 514 \\
\hline $15-19$ & 481 & 6 & 6 & & 0 & 7 & 245 & 11 & 0 & 756 \\
\hline $20-24$ & 601 & 8 & 3 & & 3 & 1 & 22 & 14 & 0 & 652 \\
\hline $25-29$ & 481 & 6 & 1 & & 8 & 1 & 2 & 3 & 0 & 502 \\
\hline $30-34$ & 393 & 3 & 1 & & 6 & 0 & 0 & 3 & 0 & 406 \\
\hline $35-39$ & 356 & 2 & 0 & & 8 & 1 & 8 & 3 & 0 & 370 \\
\hline $40-44$ & 278 & 2 & 0 & & 7 & 1 & 0 & 1 & 0 & 289 \\
\hline $45-49$ & 287 & 2 & 0 & & $0 \quad 19$ & 1 & 0 & 7 & 0 & 316 \\
\hline $50-54$ & 230 & 0 & 0 & & $0 \quad 20$ & 3 & 0 & 5 & 0 & 258 \\
\hline $55-59$ & 221 & 1 & 0 & & 113 & 2 & 0 & 10 & 0 & 248 \\
\hline 60 y más & 315 & 0 & 0 & & 0325 & 3 & 0 & 32 & 0 & 675 \\
\hline Total hombres & 3691 & 30 & 11 & & 1410 & 22 & 729 & 91 & 1 & 498 \\
\hline
\end{tabular}




\section{MUJERES}

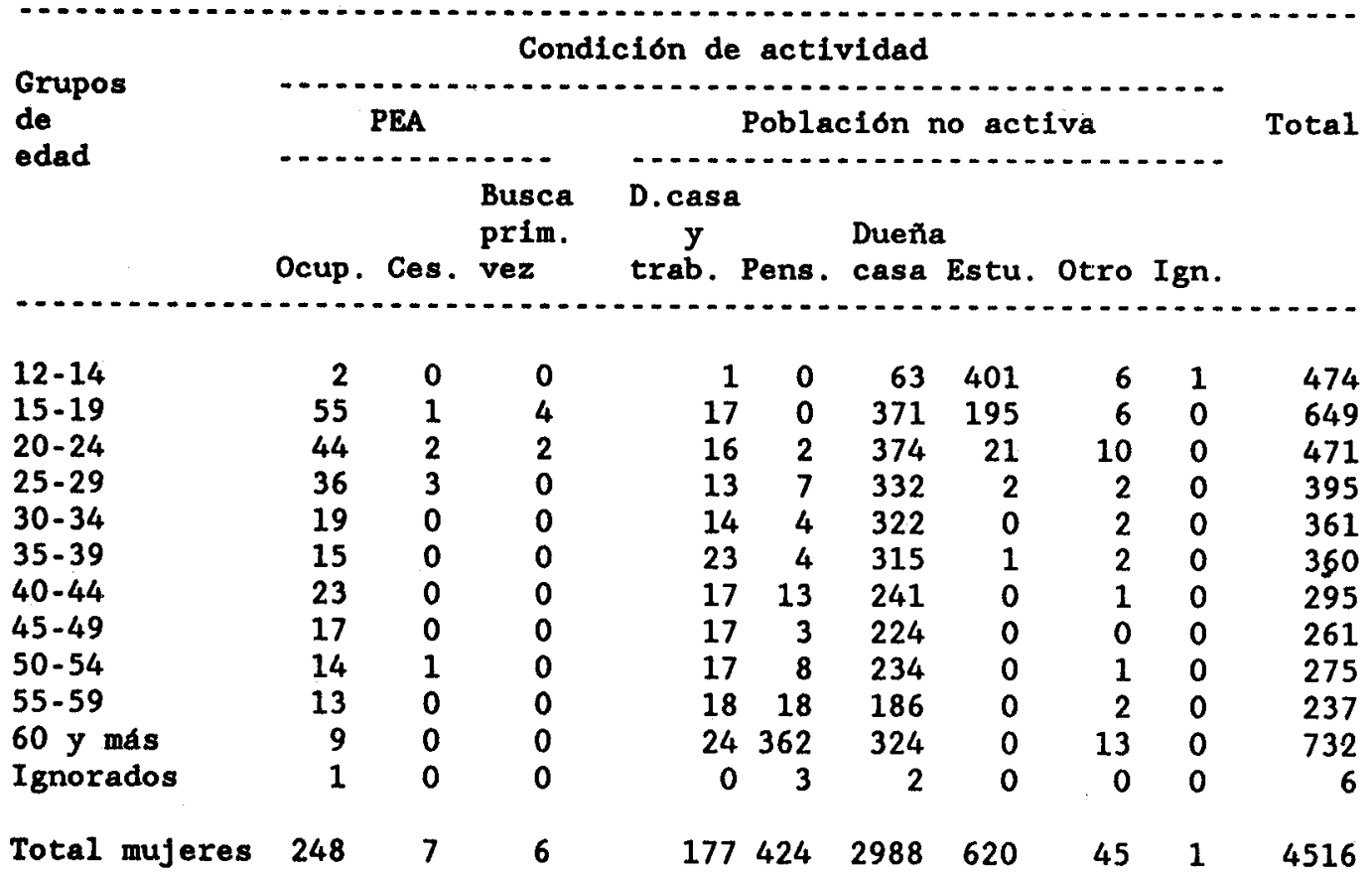

Fuente: Tabulados especiales Censo de 1988. 
ANEXO 2

REDUCCIONES INDIGENAS SELECCIONADAS: DISTRIBUCION RELATIVA DE LA POBLACION ECONOMICAMENTE ACTIVA POR CONDICION DE ACTIVIDAD, SEGUN DISTRITO Y S.EXO. CENSO DE 1988

\begin{tabular}{|c|c|c|c|c|c|c|c|c|}
\hline \multirow[b]{2}{*}{$\begin{array}{l}\text { Condición } \\
\text { de } \\
\text { actividad }\end{array}$} & \multicolumn{8}{|c|}{ Distrito y sexo } \\
\hline & $\begin{array}{c}\text { Lab } \\
\begin{array}{c}\text { Homb } \\
8\end{array}\end{array}$ & ranza & $\begin{array}{c}\text { Mo } \\
\text { Homb } \\
8\end{array}$ & $\begin{array}{l}1 \mathrm{co} \\
\cdot \underset{\mathrm{guj}}{\mathrm{Muj}} .\end{array}$ & $\begin{array}{c}\text { Maqu } \\
\text { Homb } \\
8\end{array}$ & $\begin{array}{c}\text { uehue } \\
\\
8 u j\end{array}$ & $\begin{array}{c}\text { Metr } \\
\text { Homb } \\
8\end{array}$ & 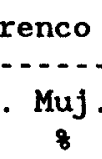 \\
\hline \multicolumn{9}{|l|}{ Activos } \\
\hline Ocupado & 73.2 & 4.6 & 74.7 & 2.9 & 72.0 & 7.7 & 75.3 & 5.6 \\
\hline Cesante & 0.4 & 0.3 & 0.6 & 0.5 & 2.1 & 0.4 & 0.3 & 0.1 \\
\hline D. de casa/trabaj & a 0.0 & 3.3 & 0.0 & 2.4 & 0.0 & 3.9 & 0.1 & 4.9 \\
\hline \multicolumn{9}{|l|}{ No activos } \\
\hline Pensionado (a) & 8.5 & 10.8 & 7.9 & 9.4 & 8.7 & 8.9 & 8.0 & 9.2 \\
\hline Tareas de casa & 0.6 & 63.2 & 0.0 & 71.4 & 1.1 & 63.0 & 0.2 & 66.9 \\
\hline Estudiante & 15.6 & 16.9 & 15.5 & 12.4 & 13.8 & 15.2 & 14.3 & 12.3 \\
\hline Otro no activo & 1.6 & 0.9 & 1.3 & 1.1 & 2.3 & 0.9 & 1.9 & 1.0 \\
\hline Total & $\begin{array}{l}100.0 \\
(667)\end{array}$ & $\begin{array}{l}100.0 \\
(646)(\end{array}$ & $\begin{array}{l}100.0 \\
1088)\end{array}$ & $\begin{array}{l}100.0 \\
(887)(\end{array}$ & $\begin{array}{l}100.01 \\
1297)(1\end{array}$ & $\begin{array}{l}100.0 \\
1199)(\end{array}$ & $\begin{array}{l}100.01 \\
1933)(1\end{array}$ & $\begin{array}{l}100.0 \\
1783)\end{array}$ \\
\hline
\end{tabular}

Fuente: Tabulados especiales Censo de 1988. 
ANEXO 3

REDUCCIONES INDIGENAS SELECCIONADAS: POBLACION FEMENINA DE 12 ANTOS Y MAS DE EDAD QUE TRABAJA POR DISTRITO, SEGUN CONDICION DE ACTIVIDAD. CENSO DE 1988

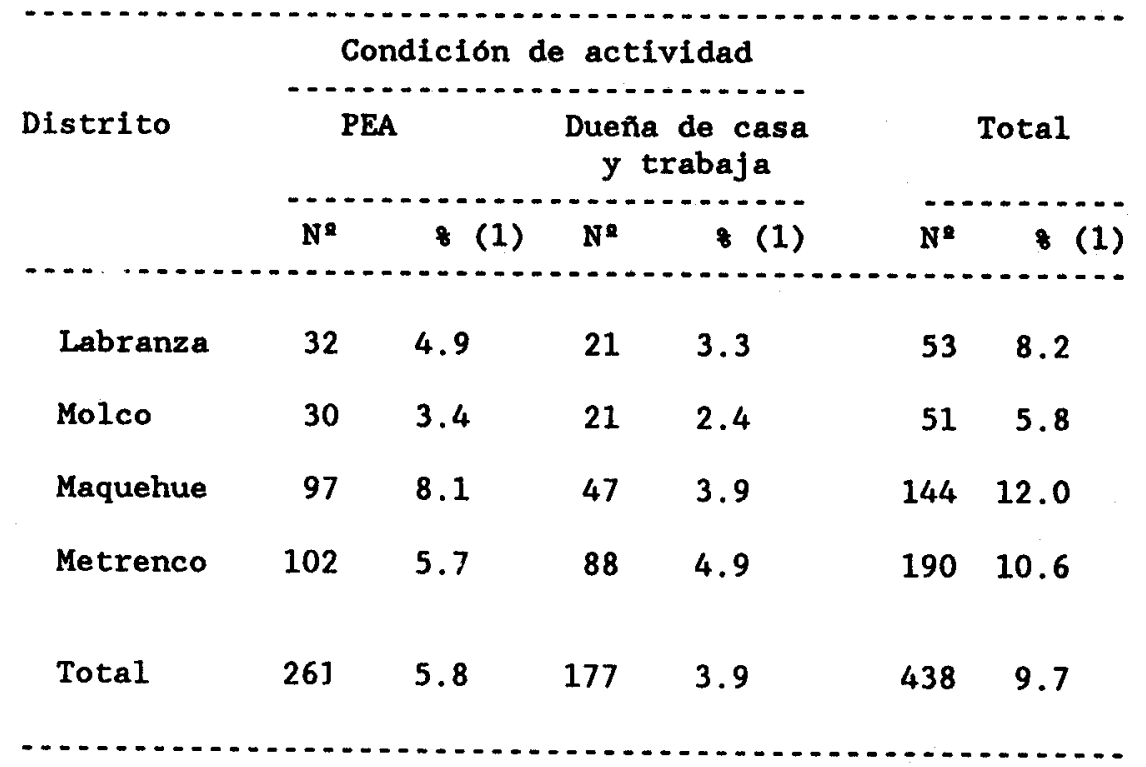

Fuente: Tabulados especiales Censo de 1988.

(1): Porcentaje sobre población femenina de 12 años y más de edad. 
ANEXO 4

REDUCCIONES INDIGENAS SELECCIONADAS: DISTRIBUCION DE LOS JEFES DE HOGAR POR SEXO Y GRUPOS DE EDAD, SEGUN CONDICION DE ACTIVIDAD. CENSO DE 1988

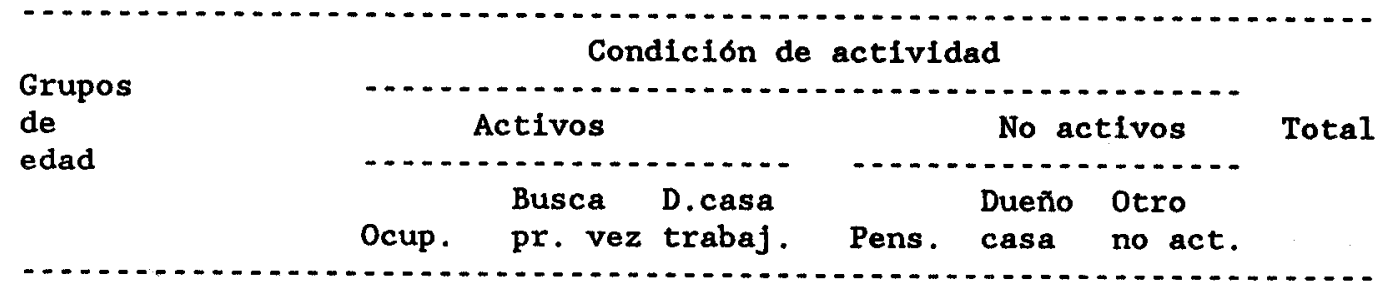

\section{HOMBRES}

$\begin{array}{lrllrlrr}15-19 & 5 & 0 & 0 & 0 & 0 & 0 & 5 \\ 20-29 & 213 & 1 & 0 & 1 & 0 & 0 & 215 \\ 30-39 & 483 & 2 & 0 & 3 & 0 & 2 & 490 \\ 40-49 & 478 & 3 & 0 & 18 & 0 & 5 & 504 \\ 50-59 & 405 & 1 & 1 & 22 & 3 & 9 & 441 \\ 60 \text { y más } & 292 & 0 & 0 & 290 & 2 & 28 & 612 \\ \text { Total hombres } & 1876 & 7 & 1 & 334 & 5 & 44 & 2267\end{array}$

MUJERES

$\begin{array}{lrrrrrrr}15-19 & 0 & 0 & 0 & 0 & 0 & 0 & 0 \\ 20-29 & 4 & 0 & 1 & 1 & 4 & 0 & 10 \\ 30-39 & 5 & 0 & 5 & 2 & 16 & 0 & 28 \\ 40-49 & 9 & 0 & 4 & 3 & 36 & 0 & 52 \\ 50-59 & 9 & 0 & 14 & 15 & 69 & 1 & 108 \\ 60 \text { y más } & 7 & 0 & 11 & 141 & 84 & 3 & 246 \\ \text { Ignorado } & 0 & 0 & 0 & 0 & 2 & 0 & 2 \\ \text { Total mujeres } & 34 & 0 & 35 & 162 & 212 & 4 & 447\end{array}$

Fuente: Tabulados especiales Censo de 1988. 
ANEXO 5

IX REGION Y REDUCCIONES INDIGENAS: POBLACION ECONOMICAMENTE ACTIVA Y TOTAL DE 15 AÑOS Y MAS DE EDAD POR SEXO Y GRUPOS QUINQUENALES DE EDAD. CENSO NACIONAL DE 1982

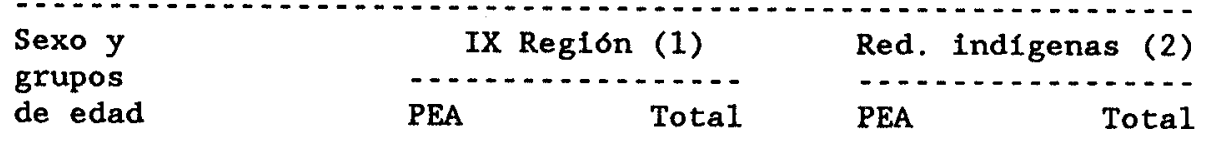

Hombres

$\begin{array}{lrrrl}15-19 & 17807 & 41940 & 2035 & 8190 \\ 20-24 & 26429 & 32164 & 2993 & 6029 \\ 25-29 & 22177 & 23915 & 2778 & 4384 \\ 30-34 & 18825 & 19976 & 2684 & 3640 \\ 35-39 & 16458 & 17510 & 2675 & 3393 \\ 40-44 & 15269 & 16418 & 2762 & 3345 \\ 45-49 & 12228 & 13513 & 2418 & 2886 \\ 50-54 & 11654 & 13727 & 2395 & 2879 \\ 55-59 & 8758 & 11071 & 2021 & 2500 \\ 60-64 & 6969 & 9775 & 1728 & 2250 \\ 65 \text { y más } & 7080 & 22559 & 2023 & 4898\end{array}$

Mujeres

$\begin{array}{lrrrr}15-19 & 5989 & 40655 & 476 & 6523 \\ 20-24 & 9146 & 31872 & 496 & 4639 \\ 25-29 & 7189 & 24481 & 386 & 3716 \\ 30-34 & 5782 & 20576 & 313 & 3273 \\ 35-39 & 4451 & 18481 & 249 & 3167 \\ 40-44 & 3544 & 16818 & 180 & 3188 \\ 45-49 & 2583 & 14627 & 152 & 2925 \\ 50-54 & 2109 & 14141 & 164 & 2683 \\ 55-59 & 1294 & 11733 & 125 & 2538 \\ 60-64 & 730 & 10288 & 94 & 2187 \\ 65 \text { y más } & 902 & 24076 & 113 & 4805\end{array}$

Fuente: (1) INE (1987b).

(2) Oyarce, Romaggi y Vidal (1989). Total de reducciones de la región. 
ANEXO 6

REDUCCIONES INDIGENAS SELECCIONADAS: POBLACION ECONOMICAMENTE ACTIVA POR SEXO Y GRUPOS DE EDAD, SEGUN ESTADO CIVIL. CENSO DE 1988

Sexo y
grupos
de

Hombres

$\begin{array}{lrrrrrrrr}12-14 & 0 & 0 & 0 & 0 & 0 & 48 & 0 & 48 \\ 15-19 & 6 & 1 & 0 & 0 & 0 & 486 & 0 & 493 \\ 20-29 & 89 & 190 & 1 & 0 & 3 & 817 & 0 & 1100 \\ 30-39 & 69 & 457 & 0 & 2 & 8 & 219 & 0 & 755 \\ 40-49 & 29 & 419 & 0 & 14 & 13 & 93 & 1 & 569 \\ 50-59 & 31 & 312 & 1 & 36 & 8 & 64 & 0 & 452 \\ 60-64 & 8 & 125 & 1 & 16 & 4 & 24 & 0 & 178 \\ 65 \text { y más } & 7 & 94 & 0 & 20 & 3 & 13 & 0 & 137 \\ & & & & & & & & 3732\end{array}$

Mujeres

$\begin{array}{lrrrrrrrr}12-14 & 0 & 0 & 0 & 0 & 0 & 2 & 0 & 2 \\ 15-19 & 0 & 0 & 0 & 0 & 0 & 60 & 0 & 60 \\ 20-29 & 4 & 10 & 0 & 0 & 3 & 73 & 0 & 73 \\ 30-39 & 0 & 11 & 0 & 1 & 4 & 18 & 0 & 34 \\ 40-49 & 5 & 17 & 0 & 6 & 2 & 10 & 0 & 40 \\ 50-59 & 1 & 13 & 0 & 5 & 1 & 8 & 0 & 28 \\ 60-64 & 0 & 2 & 0 & 3 & 0 & 2 & 0 & 7 \\ 65 \text { y más } & 0 & 0 & 0 & 1 & 1 & 0 & 0 & 2 \\ \text { Ignorado } & 0 & 0 & 0 & 0 & 0 & 1 & 0 & 1 \\ & & & & & & & & \end{array}$

Fuente: Tabulados especiales Censo de 1988. 
ANEXO 7

REDUCCIONES INDIGENAS SELECCIONADAS: POBLACION ECONOMICAMENTE ACTIVA POR SEXO $Y$ GRUPOS QUINQUENALES DE EDAD, SEGUN AÑOS DE ESTUDIO APROBADOS. CENSO DE 1988

Sexo y

Años de estudio aprobados

grupos

Anos de estudio aprobados

de edad

Ning. 1 a $3 \quad 4$ a $6 \quad 7$ a $8 \quad 9$ y más Ign. Total

Hombres

$\begin{array}{lrrrrrrr}12-14 & 1 & 8 & 24 & 15 & 0 & 0 & 48 \\ 15-19 & 5 & 43 & 190 & 216 & 31 & 2 & 487 \\ 20-24 & 13 & 50 & 208 & 249 & 88 & 1 & 609 \\ 25-29 & 7 & 55 & 199 & 167 & 57 & 2 & 487 \\ 30-34 & 3 & 54 & 183 & 112 & 43 & 1 & 396 \\ 35-39 & 11 & 99 & 178 & 45 & 23 & 2 & 358 \\ 40-44 & 20 & 93 & 138 & 15 & 12 & 2 & 280 \\ 45-49 & 32 & 115 & 120 & 12 & 8 & 2 & 289 \\ 50-54 & 39 & 93 & 80 & 5 & 12 & 1 & 230 \\ 55-59 & 45 & 97 & 69 & 7 & 4 & 0 & 222 \\ 60-64 & 54 & 63 & 53 & 0 & 6 & 2 & 178 \\ 65 \text { y más } & 39 & 51 & 39 & 4 & 4 & 0 & 137 \\ & & & & & & & \\ \text { Total hombres } & 269 & 821 & 1481 & 847 & 288 & 15 & 3721\end{array}$

Mujeres

\begin{tabular}{|c|c|c|c|c|c|c|c|}
\hline $12-14$ & 0 & 0 & 1 & 1 & 0 & 0 & 2 \\
\hline $15-19$ & 0 & 4 & 28 & 21 & 3 & 0 & 56 \\
\hline $20-24$ & 0 & 6 & 10 & 14 & 16 & 0 & 46 \\
\hline $25-29$ & 1 & 6 & 11 & 8 & 13 & 0 & 39 \\
\hline $30-34$ & 1 & 6 & 7 & 2 & 3 & 0 & 19 \\
\hline $35-39$ & 1 & 4 & 5 & 0 & 4 & 1 & 15 \\
\hline $40-44$ & 2 & 8 & 9 & 1 & 2 & 1 & 23 \\
\hline $45-49$ & 5 & 5 & 6 & 0 & 1 & 0 & 17 \\
\hline $50-54$ & 3 & 7 & 5 & 0 & 0 & 0 & 15 \\
\hline $55-59$ & 5 & 6 & 2 & 0 & 0 & 0 & 13 \\
\hline $60-64$ & 3 & 1 & 2 & 0 & 1 & 0 & 7 \\
\hline 65 y más & 2 & 1 & 0 & 0 & $\overline{0}$ & 0 & 3 \\
\hline Total mujeres & 23 & 54 & 79 & 54 & 43 & 2 & 255 \\
\hline
\end{tabular}

Fuente: Tabulados especiales Censo de 1988. 
ANEXO 8-A

REDUCCIONES INDIGENAS SELECCIONADAS: POBLACION ECONOMICAMENTE ACTIVA POR SEXO Y OCUPACION PRINCIPAL, SEGUN AÑOS DE ESTUDIO APROBADOS.

CENSO DE 1988

Sexo y

ocupación

principal

(1)
Años de estudio aprobados

Ning. 1 a $3 \quad 4$ a $6 \quad 7$ a $8 \quad 9$ y más Ign. Total

Hombres

$\begin{array}{lrrrrrrr}0 & 0 & 2 & 2 & 0 & 9 & 0 & 13 \\ 1 & 0 & 0 & 1 & 0 & 0 & 0 & 1 \\ 2 & 0 & 0 & 0 & 4 & 2 & 0 & 6 \\ 3 & 2 & 12 & 19 & 28 & 5 & 0 & 66 \\ 4 & 245 & 737 & 1294 & 733 & 211 & 15 & 3225 \\ 5 & 0 & 0 & 5 & 0 & 2 & 0 & 7 \\ 6 & 3 & 10 & 27 & 26 & 22 & 0 & 88 \\ 7 & 13 & 26 & 66 & 16 & 9 & 0 & 130 \\ 8 & 5 & 28 & 58 & 29 & 22 & 0 & 142 \\ 9 & 1 & 4 & 8 & 10 & 5 & 0 & 28 \\ \text { Ignor. } & 0 & 2 & 1 & 1 & 1 & 0 & 5 \\ & & & & & & & 3721\end{array}$

Mujeres

\begin{tabular}{|c|c|c|c|c|c|c|c|}
\hline 0 & 0 & 0 & 0 & 0 & 13 & 0 & 13 \\
\hline 1 & 0 & 0 & 0 & 0 & 0 & 0 & 0 \\
\hline 2 & 0 & 0 & 0 & 0 & 4 & 0 & 4 \\
\hline 3 & 6 & 9 & 6 & 4 & 6 & 1 & 32 \\
\hline 4 & 5 & 11 & 22 & 17 & 2 & 0 & 57 \\
\hline 5 & 0 & 0 & 0 & 0 & 0 & 0 & 0 \\
\hline 6 & 4 & 20 & 16 & 6 & 2 & 1 & 49 \\
\hline 7 & 2 & 2 & 0 & 1 & 0 & 0 & \\
\hline 8 & 0 & 0 & 1 & 0 & 0 & 0 & \\
\hline 9 & 6 & 11 & 34 & 26 & 16 & 0 & 93 \\
\hline Ignor. & 0 & 1 & 0 & 0 & 0 & 0 & \\
\hline tal mujeres & 23 & 54 & 79 & 54 & 43 & 2 & \\
\hline
\end{tabular}

Fuente: Tabulados especiales Censo de 1988.

(1): Grupos principales de ocupación: ver anexo 8-B. 
ANEXO 8-B

GRUPOS PRINCIPALES DE OCUPACION

0: Profesionales, técnicos y personas en ocupaciones afines

1: Gerentes, administradores y funcionarios de categoria directiva

2: Empleados de oficina y personas en ocupaciones afines

3: Vendedores y personas en ocupaciones afines

4: Agricultores, ganaderos, pescadores, cazadores, madereros y personas en ocupaciones afines

5: Conductores de medios de transporte y personas en ocupaciones afines

6: Artesanos y operarios en ocupaciones relacionadas con la hilanderia, la confección de vestuario y calzado, la carpinteria, la industria de la construcción, la mecánica y las artes gráficas

7: $\quad$ Otros artesanos y operarios

8: Obreros y jornaleros no especificados en otras categorias

9: Trabajadores en servicios personales $y$ en ocupaciones afines

$\mathrm{X}$ : Trabajadores en ocupaciones no identificables y otros trabajadores no especificados en otras categorias (estos casos se incluyen en la categoria "ignorados")

Fuente: Clasificación Ocupacional COTA-70, revisada para el Programa del XV Censo Nacional de Población y IV de Vivienda de Chile - 1982. 
ANEXO 9

REDUCCIONES INDIGENAS SELECCIONADAS: POBLACION ECONOMICAMENTE ACTIVA

POR SEXO Y OCUPACION PRINCIPAL, SEGUN CATEGORIA OCUPACIONAL. CENSO DE 1988

Sexo y

ocupación

principal

(1)
Categorla ocupacional

Cta.prop. Asalar. Trab.fam. Patrón Ign. Total

Hombres

$\begin{array}{lrrrllr}0 & 2 & 11 & 0 & 0 & 0 & 13 \\ 1 & 1 & 0 & 0 & 0 & 0 & 1 \\ 2 & 1 & 5 & 0 & 0 & 0 & 6 \\ 3 & 51 & 11 & 4 & 0 & 0 & 66 \\ 4 & 1861 & 515 & 853 & 6 & 0 & 3235 \\ 5 & 0 & 6 & 0 & 1 & 0 & 7 \\ 6 & 16 & 66 & 5 & 1 & 0 & 88 \\ 7 & 32 & 94 & 1 & 3 & 0 & 130 \\ 8 & 2 & 139 & 1 & 0 & 0 & 142 \\ 9 & 3 & 25 & 0 & 0 & 0 & 28 \\ \text { Ignor. } & 0 & 4 & 0 & 0 & 1 & 5\end{array}$

Total

hombres 1969

$876 \quad 864$

11

$1 \quad 3721$

Mujeres

$\begin{array}{lrrrllr}0 & 0 & 13 & 0 & 0 & 0 & 13 \\ 1 & 0 & 0 & 0 & 0 & 0 & 0 \\ 2 & 0 & 4 & 0 & 0 & 0 & 4 \\ 3 & 25 & 3 & 4 & 0 & 0 & 32 \\ 4 & 18 & 12 & 27 & 0 & 0 & 57 \\ 5 & 0 & 0 & 0 & 0 & 0 & 0 \\ 6 & 43 & 2 & 4 & 0 & 0 & 49 \\ 7 & 4 & 1 & 0 & 0 & 0 & 5 \\ 8 & 0 & 1 & 0 & 0 & 0 & 1 \\ 9 & 0 & 93 & 0 & 0 & 0 & 93 \\ \text { Ignor. } & 1 & 0 & 0 & 0 & 0 & 1\end{array}$

Total

mujeres

91

129

35

0

255

Fuente: Tabulados especiales Censo de 1988 .

(1): Grupos principales de ocupación: ver anexo 8-B. 
ANEXO 10

REDUCCIONES INDIGENAS SELECCIONADAS: DISTRIBUCION RELATIVA DE MUJERES DUEÑAS DE CASA QUE TRABAJAN POR OCUPACION PRINCIPAL, SEGUN CATEGORIA OCUPACIONAL. CENSO DE 1988

\begin{tabular}{|c|c|c|c|c|c|c|}
\hline $\begin{array}{l}\text { Grupos } \\
\text { de } \\
\text { ocupación } \\
\text { principal } \\
\text { (1) }\end{array}$ & Cta. prop & $\begin{array}{c}\text { gorla o } \\
\text { Asalar. } \\
8\end{array}$ & $\begin{array}{l}\text { sacional } \\
\text { T. fam. }\end{array}$ & Patrón & \multicolumn{2}{|c|}{ Total } \\
\hline 0 & 0.0 & 13.0 & 0.0 & 0.0 & 1.1 & (2) \\
\hline 1 & 0.0 & 0.0 & 0.0 & 100.0 & 0.6 & (1) \\
\hline 3 & 24.8 & 6.3 & 7.4 & 0.0 & 20.3 & (36) \\
\hline 4 & 13.5 & 12.5 & 70.3 & 0.0 & 22.0 & (39) \\
\hline 6 & 54.9 & 6.3 & 22.2 & 0.0 & 45.2 & $(80)$ \\
\hline 7 & 0.8 & 0.0 & 0.0 & 0.0 & 0.6 & (1) \\
\hline 9 & 4.5 & 62.5 & 0.0 & 0.0 & 9.0 & (16) \\
\hline Ignor. & 1.5 & 0.0 & 0.0 & 0.0 & 1.1 & (2) \\
\hline
\end{tabular}

Total dueñas de casa que trabajan

$\begin{array}{rrrrr}100.0 & 100.0 & 100.0 & 100.0 & 100.0 \\ (133) & (16) & (27) & (1) & (177)\end{array}$

Fuente: Tabulados especiales Censo de 1988.

(1): Grupos principales de ocupación: ver anexo 8-B. 
ANEXO 11

REDUCCIONES INDIGENAS SELECCIONADAS: POBLACION ECONOMICAMENTE ACTIVA POR SEXO Y GRUPOS QUINQUENALES DE EDAD, SEGUN CATEGORIA OCUPACTONAL. CENSO DE 1988

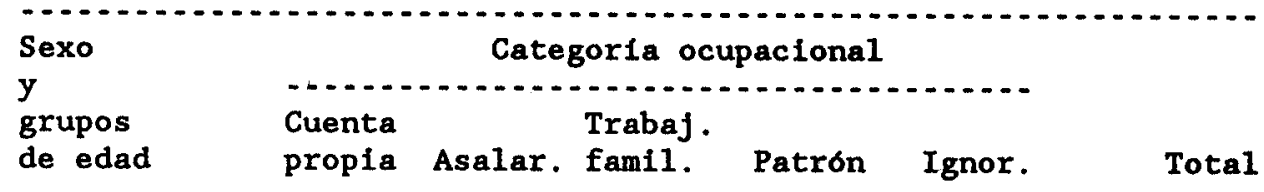

Hombres

$\begin{array}{lrrrrrr}12-14 & 0 & 15 & 33 & 0 & 0 & 48 \\ 15-19 & 35 & 149 & 303 & 0 & 0 & 487 \\ 20-24 & 122 & 205 & 280 & 1 & 1 & 609 \\ 25-29 & 203 & 161 & 123 & 0 & 0 & 487 \\ 30-34 & 242 & 94 & 59 & 1 & 0 & 396 \\ 35-39 & 251 & 76 & 30 & 1 & 0 & 358 \\ 40-44 & 217 & 51 & 9 & 3 & 0 & 280 \\ 45-49 & 230 & 53 & 4 & 2 & 0 & 289 \\ 50-54 & 195 & 27 & 8 & 0 & 0 & 230 \\ 55-59 & 195 & 19 & 7 & 1 & 0 & 222 \\ 60 \text { y más } & 279 & 26 & 8 & 2 & 0 & 315 \\ \text { Total hombres } & 1969 & 876 & 864 & 11 & 1 & 3721\end{array}$

Mujeres

$\begin{array}{lrrrllr}12-14 & 0 & 2 & 0 & 0 & 0 & 2 \\ 15-19 & 7 & 34 & 15 & 0 & 0 & 56 \\ 20-24 & 7 & 30 & 9 & 0 & 0 & 46 \\ 25-29 & 10 & 25 & 4 & 0 & 0 & 39 \\ 30-34 & 7 & 12 & 0 & 0 & 0 & 19 \\ 35-39 & 11 & 4 & 0 & 0 & 0 & 15 \\ 40-44 & 11 & 11 & 1 & 0 & 0 & 23 \\ 45-49 & 9 & 5 & 3 & 0 & 0 & 17 \\ 50-54 & 10 & 4 & 1 & 0 & 0 & 15 \\ 55-59 & 11 & 1 & 1 & 0 & 0 & 13 \\ 60 \text { y más } & 8 & 1 & 0 & 0 & 0 & 1 \\ \text { Ignorado } & 0 & 0 & 1 & 0 & 0 & 255 \\ \text { Total mujeres } & 91 & 129 & 35 & 0 & 0 & \end{array}$

Fuente: Tabulados especiales Censo de 1988. 
ANEXO 12

REDUCCIONES INDIGENAS SELECCIONADAS: DISTRIBUCION RELATIVA DE LA POBLACION ECONOMICAMENTE ACTIVA POR SEXO Y OCUPACION PRINCIPAL, SEGUN DISTRITO. CENSO DE 1988

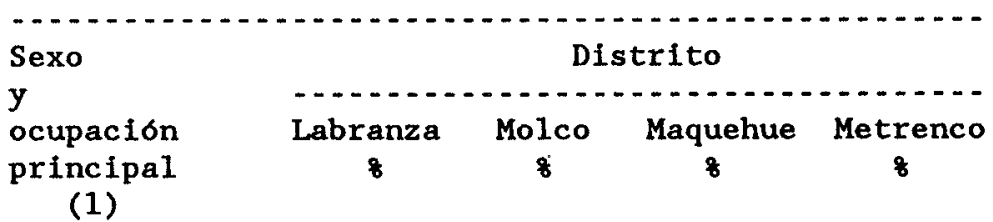

(1)

Hombres

$\begin{array}{lrrrr}0 & 0.2 & 0.9 & 0.2 & 0.2 \\ 1 & 0.0 & 0.0 & 0.1 & 0.0 \\ 2 & 0.4 & 0.1 & 0.2 & 0.1 \\ 3 & 2.2 & 1.7 & 2.9 & 0.9 \\ 4 & 91.4 & 93.9 & 82.4 & 84.5 \\ 5 & 0.4 & 0.1 & 0.3 & 0.1 \\ 6 & 1.2 & 1.2 & 5.2 & 1.5 \\ 7 & 1.2 & 0.7 & 0.9 & 7.5 \\ 8 & 1.4 & 1.1 & 6.4 & 4.5 \\ 9 & 0.8 & 0.2 & 1.3 & 0.7 \\ \text { Ignor. } & 0.6 & 0.0 & 0.0 & 0.1\end{array}$

Total hombres $100.0 \quad 100.0 \quad 100.0 \quad 100.0$ (491) (815) (957) (1458)

Mujeres

$\begin{array}{lrrrr}0 & 3.1 & 24.1 & 3.2 & 2.0 \\ 1 & 0.0 & 0.0 & 0.0 & 0.0 \\ 2 & 3.1 & 0.0 & 2.1 & 1.0 \\ 3 & 28.1 & 6.9 & 19.1 & 3.0 \\ 4 & 25.0 & 24.1 & 13.8 & 29.0 \\ 5 & 0.0 & 0.0 & 0.0 & 0.0 \\ 6 & 3.1 & 3.4 & 19.1 & 29.0 \\ 7 & 6.3 & 0.0 & 0.0 & 3.0 \\ 8 & 0.0 & 0.0 & 0.0 & 1.0 \\ 9 & 31.3 & 41.4 & 42.6 & 31.0 \\ \text { Ignor. } & 0.0 & 0.0 & 1.0 & 1.0 \\ \text { mujeres } & 100.0 & 100.0 & 100.0 & 100.0 \\ & (32) & (29) & (94) & (100) \\ & & & & \\ & & & & \end{array}$

Fuente: Tabulados especiales Censo de 1988.

(1): Grupos principales de ocupación: ver anexo 8-B. 
ANEXO 13

REDUCCIONES INDIGENAS SELECCIONADAS: POBLACION ECONOMICAMENTE ACTIVA POR SEXO Y CATEGORIA OCUPACIONAL, SEGUN DISTRITO. CENSO DE 1988

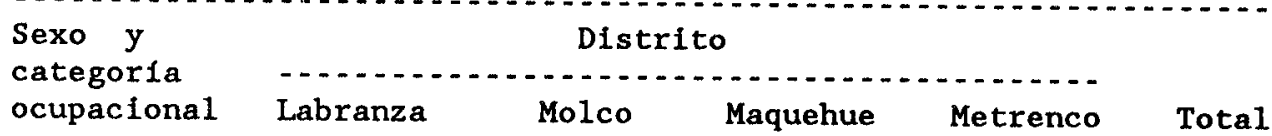

Hombres

$\begin{array}{lrrrrr}\text { Cuenta propia } & 254 & 495 & 497 & 723 & 1969 \\ \text { Asalariado } & 138 & 91 & 190 & 457 & 876 \\ \text { T. familiar } & 99 & 227 & 266 & 272 & 864 \\ \text { Empleador } & 0 & 2 & 4 & 5 & 11 \\ \text { Total hombres } & 491 & 815 & 957 & 1457 & 3720\end{array}$

Mujeres

$\begin{array}{lrrrrr}\text { Cuenta propia } & 13 & 3 & 33 & 42 & 91 \\ \text { Asalariado } & 18 & 20 & 47 & 44 & 129 \\ \text { T. familiar } & 1 & 6 & 14 & 14 & 352 \\ \text { Total mujeres } & 32 & 29 & 94 & 100 & 255\end{array}$

Fuente: Tabulados especiales Censo de 1988. 


\title{
V. VIVIENDA, HOGAR Y FAMILIA
}

\author{
Ana M. Oyarce*
}

\section{Introducción}

En este capitulo se aborda el análisis de los aspectos de vivienda, hogar y familia, correspondientes a la población de las reducciones indigenas seleccionadas que fueron censadas en 1988 en los distritos de Labranza, Molco, Maquehue y Metrenco, pertenecientes a la Comuna de Temuco en la IX Región. El propósito fundamental es contribuir al conocimiento de las condiciones de vida y de algunas características culturales de la población.

Los temas están ordenados en cuatro secciones. La primera guarda relación con la vivienda y el hogar, considerando aspectos como los tipos de vivienda existentes y sus caracteristicas, as 1 como el tamaño de los hogares y el grado de hacinamiento existente en ellos. La segunda sección hace alusión a las caracteristicas de saneamiento ambiental, donde se describen las fuentes de obtención de agua de consumo y los sistemas empleados para la eliminación de excretas. La tercera sección recoge los aspectos relativos a la familia, en términos de los tipos encontrados y su composición, entre algunos aspectos. Como cuarta sección, se presenta un análisis desde el punto de vista de la cultura, a través de la lengua hablada en el hogar y del apego al modo de vida tradicional mapuche, sobre la base de los antecedentes anteriores. Por último, se exponen algunas conclusiones sobre los resultados más relevantes.

Cabe consignar que a lo largo de este capitulo se presentarán frecuentes comparaciones con la información correspondiente al total de reducciones

Programa de Apoyo y Extensión en Salud Materno Infantil y Universidad de La Frontera, Temuco. 
indigenas de la IX Región que fueron censadas en 1982, si bien hay que considerar que en el Censo de 1988 se incluye sólo un 10 por ciento del total de población indigena detectada en el Censo Nacional de $1982 \mathrm{y}$, además, la población estudiada presenta el sesgo de estar ubicada en reducciones cercanas al principal centro urbano regional. Sólo en algunos casos especificos se procederá a establecer comparaciones con la información correspondiente a las mismas reducciones indigenas en 1982 .

Finalmente, junto al análisis de los datos se irán presentando algunos antecedentes sobre el conocimiento de los temas tratados como una forma de permitir una mejor comprensión de ellos.

\section{Vivienda y hogar}

En esta sección se describen los tipos de vivienda, sus caracteristicas en cuanto al material del piso de los dormitorios, asi como la disponibilidad de éstos, de piezas en general y de pieza de cocina en particular. Se analiza también el tamaño de los hogares, el grado de hacinamiento existente en ellos y la lengua hablada con más frecuencia. Previamente, se presentan las definiciones utilizadas para la recolección y manejo de la información de vivienda y hogar.

\subsection{Definiciones de las categorias de vivienda y hogar}

Es importante conocer el estado y calidad de la vivienda, asi como su equipamiento sanitario, por su estrecha relación con la salud de los individuos que la habitan $y$ por la información que se obtiene sobre la situación y disponibilidad económica de las personas que la habitan (CELADE, 1987). Sin embargo, el análisis de la vivienda debe realizarse desde una perspectiva integral, ya que como respuesta de organización del espacio la vivienda cumple funciones sociales, culturales, fisiológicas y biológicas. Dicho de otro modo, toda sociedad ha diseñado e implementado su propio tipo de vivienda, la que se relaciona directamente con la necesidad y recursos del medio ambiente natural y social (Quilapi, 1976).

En el Censo Nacional de 1982 se defíníb la vivienda como "un lugar separado e independiente construido, convertido o dispuesto para el alojamiento permanente - temporal". Las viviendas permanentes fueron clasificadas en "casa, departamento y conventillo", y las semipermanentes se las clasificó en "rancho, ruca o choza; mejora, emergencla, marginal y callampa" (INE, 1987a). Para 1a recolección de la información sobre este aspecto, en el Censo de las Reducciones 
Indigenas Seleccionadas (1988) se hicieron algunos cambios, con el objetivo de describir mejor las particularidades de la vivienda de la población de las reducciones y asi lograr relacionarlas con la mortalidad infantil y materna, dado que se supone una estrecha relación de la salud con las condiciones y calidad de la vivienda. De acuerdo con lo antexior, se han realizado tres modificaciones:

- Se abrió la categoria denominada "mejora", dado que el conocimiento del área de estudio hacia pensar que algunas de las viviendas categorizadas como "casas" se asemejaban más a ésta que a una casa propiamente tal (al respecto, hay que tenex presente que en el Censo Nacional de 1982 la categorla "mejora" fue sólo considerada para el medio urbano).

- Se separó la categoría "ruca" de "rancho", dada la necesidad de conocer y estimar la importancia relativa de la vivienda autóctona teóricamente asociada con los patrones de vida tradicionales.

- Se crearon dos categorias de viviendas mixtas, "ruca-casa" y "ruca-mejora", puesto que se sabia que actualmente un porcentaje relativamente importante de familias posee, además de la "ruca", una "casa" o una "mejora".

Estas adecuaciones en las categorias con que se recogió la información, que fueron propuestas por Oyarce, Romaggi y Vidal (1989), hacen posible caracterizar mejor la población en estudio, pero como se desprende, no permiten la comparación con la información recogida con las categorfas del Censo Nacional de 1982 .

Con respecto a los conceptos de vivienda y hogar, debe señalarse que ellos corresponden a categorfas diferentes. En efecto, se ha definido como hogar a "un grupo de personas con o sin vínculos familiares, que hacen vida en común compartiendo un mismo techo y la misma comida". El criterio básico para separar una vivienda de un hogar es que en estos últimos las personas proveen por separado su alimentación. De lo anterior, se deduce que podría haber más de un hogar en una vivienda.

\subsection{Tipos de vivienda}

En el Censo de 1988 se identificaron 2714 hogares y 2691 viviendas, 10 que significa que el número de viviendas donde existe más de un hogar es muy bajo. Es asi que en los datos que aquí se exponen las viviendas con más de un hogar alcanzan a sólo un 1 por ciento, por lo que el análisis se realizará como 
si fueran una misma entidad, es decir, considerando como total el número de hogares, ya que la mayoría de la información relevante está recogida tomando como base esta categoría.

Si se toma el total de hogares encuestados, el distrito de Metrenco representa un 40 por ciento del total; Maquehue posee el 25 por ciento; Molco el 21 por ciento y Labranza el 14 por ciento.

Las viviendas han sido agrupadas en tradicionales ("ruca"); mixtas ("rucacasa" y "ruca-mejora") y no tradicionales ("casa" y "mejora")." La vivienda tradicional mapuche se denomina "ruka" en la lengua vernácula. Antiguamente parece haber sido de grandes dimensiones, con superficles que variaban entre 120 y 140 metros cuadrados, algunas con hasta 100 personas en su interior (Aldunate, 1986; Bengoa y Valenzuela, 1984). E1 tamaño dependía de la posición y rango del jefe de hogar, generalmente poligamo. La "ruca" es una vivienda de forma ovalada, sin divisiones internas ni ventanas; su estructura está formada por postes y varas a modo de entramado con distintos tipos de fibra vegetal en la cubierta y paredes. E1 piso es de tierra apisonada.

Sobre la funcionalidad de la ruca hay numerosos testimonios y estudios (Aldunate, 1986; Bunster, 1970; Quilapi, 1976), y todos ellos refieren que las paredes de fibra vegetal impermeabilizadas por la acción constante del humo del fogón hacen que sea más abrigada y temperada en el invierno y más fresca en el verano que la mejora y la casa rural. Actualmente la forma y función de la ruca ha permanecido, pero su tamaño ha disminuido notablemente.

En el cuadro 1 y gráfico 1 se puede observar que las viviendas preponderantes son las no tradicionales. En primer lugar está la "casa", alcanzando a un 40 por ciento del total y le sigue en importancia la "mejora", con un 28 por ciento. Estas dos categorias de vivienda no tradicional o no mapuche alcanzan al 68 por ciento del total.

En importancia decreciente siguen las viviendas mixtas del tipo "rucacasa" y "ruca-mejora", con un 13 por ciento cada una. Por último, la vivienda tradicional o "ruca" exclusiva alcanza solo a un 7 por ciento. En esta

Las definiciones de los tipos de vivienda son las siguientes: ruca: construcción rural de material ligero (varas, coligüe y paja) y piso de tierra; casa: construcción permanente, separada e independiente, con techo $y$ paredes forradas o cubiertas interiormente; mejora: construcción de paredes de madera $y$ techo de fonolita, sin cubierta interior; ruca-casa: construcción mixta; ruca-mejora: construcción mixta (UFRo et a1., 1989). 
categorla, como se verá luego, pueden encontrarse aquellos hogares que habitan en más de una ruca, por ejemplo, "ruca-cocina" y "ruca-dormitorio".

\section{CUADRO 1}

REDUCCIONES INDIGENAS SELECCIONADAS: DISTRIBUCION RELATIVA DE LOS HOGARES POR TIPO DE VIVIENDA, SEGUN DISTRITO. CENSO DE 1988

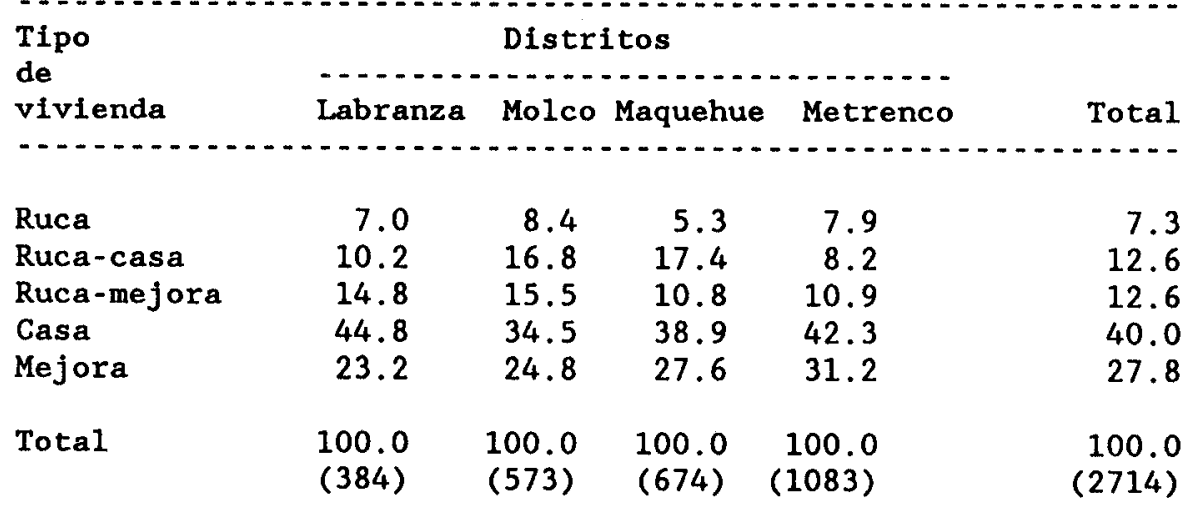

Fuente: Anexo 1

Desde otro punto de vista, al agrupar aquellas viviendas que presentan al menos una construcción tradicional, que en el caso de las viviendas mixtas corresponderfa fundamentalmente al tipo "ruca-cocina", se tiene que éstas alcanzan a un 33 por ciento.

En el cuadro 1 se advierte que en todos los distritos la vivienda más importante, en términos relativos, es la "casa", con valores que van desde un 45 por ciento en Labranza hasta un 35 por ciento en Molco. La construcción tradicional o "ruca" exclusiva es la de menor importancia relativa en todos los distritos y varía desde un 8 por ciento en Molco hasta un 5 por ciento en Maquehue.

La escasa importancia relativa que posee la construcción tradicional exclusiva podria estar asociada con factores tales como transformaciones en el ecosistema, que han hecho cada vez más dificil disponer de material para la construcción de las rucas (principalmente de las distintas fibras vegetales). Asi también, puede señalarse a la pérdida y desdibujamiento de formas de trabajo 


\section{Gráfico 1 \\ REDUCCIONES INDIGENAS SELECCIONADAS: DISTRIBUCION RELATIVA DE LOS HOGARES POR TIPO DE VIVIENDA. CENSO DE 1988}

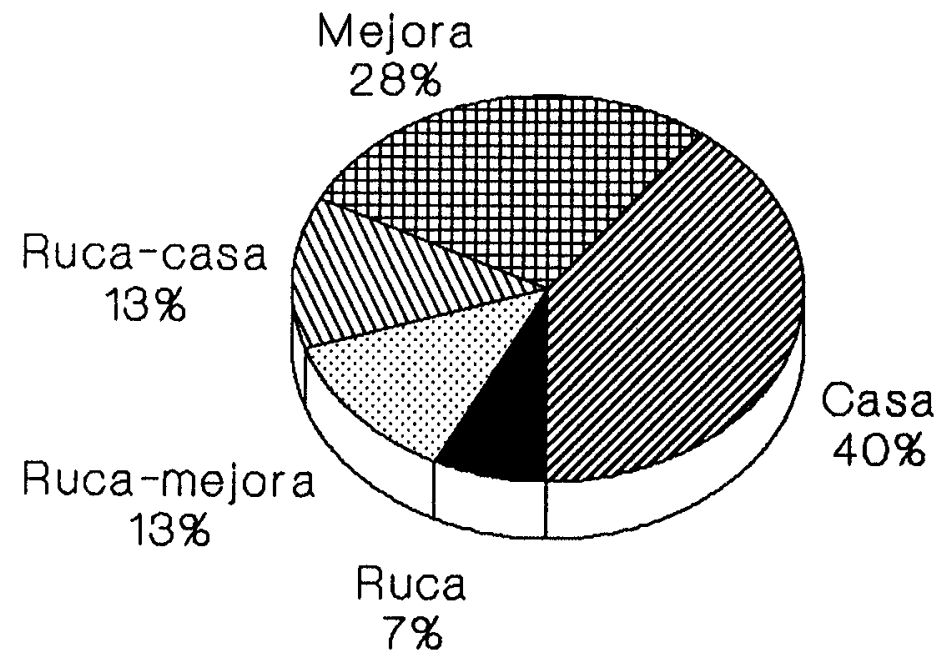

Fuente: Guadro 1 
comunitario como el rukan, que permitian aportar la mano de obra extrafamiliar necesaria para la construcción. Sin embargo, un tercio de las viviendas cuenta al menos con una construcción tradicional, lo que sugiere que la valoracion sobre su utilidad coexiste con probables cambios en las expectativas de 10 que es una vivienda deseable, debicio al mayor status que daria poseer una vivienda de tipo occidental o no tradicional. Es posible que por razones económicas 0 , simplemente, por lo que se ha denominado "conducta pragmática" (Oyarce, 1989), los mapuches han accedido a los programas estatales que les han proporcionado viviendas de tipo occidental, aun cuando se seguiria reconociendo la funcionalidad de la ruca con respecto al uso del espacio, el almacenamiento y conservación de alimentos y la protección contra la humedad y el frio (Bunster, 1970).

Finalmente, hay que destacar que la "mejora", que constituye una vivienda de emergencia en las áreas urbanas, está presente en un 41 por ciento de las viviendas (sola y combinada con "ruca"). Esto significarfa que las viviendas pobres de las areas urbanas tendrian su representación en las reducciones seleccionadas. Aunque esto no quiere decir que los hogares registren similares caracteristicas socioeconómicas entre estas áreas, es indudable que se trata de viviendas precarias que inciden en desfavorables condiciones de vida.

\subsection{Caracteristicas de la vivienda}

\subsubsection{Material del piso de los dormitorios}

Un indicador de las condiciones materiales de la vivienda es el material predominante en el piso de los dormitorios. En el cuadro 2 se aprecia que cerca de un 45 por ciento de los hogares reside en viviendas con piso de "madera" en el dormitorio. Por su parte, los hogares que residen en viviendas que cuentan con piso de "entablado" y de "tierra" constituyen el 54 por ciento del total."

Al considerar los tipos de vivienda, el gráfico 2 muestra que la vivienda tipo "casa" consta en un 83 por ciento de los casos con piso de "madera". En la categoria "mejora", se advierte que un 46 por ciento de las viviendas que quedan consignadas bajo esta denominación presenta piso de "entablado" en los dormitorios y un 39 por clento posee piso de "tlerra". Esto último parece importante de destacar, pues con la definición tradicional habrian quedado consignadas como "casa" un número importante de viviendas que tienen tablas o tablones separados; madera: piso de maderas ensambladas (UFRO et al. , 1989). 
predominantemente piso de "tierra" en sus dormitorios. Esta situación permite afirmar que la "mejora" es una vivienda precarla, ya que el 85 por ciento de ellas posee piso de "entablado" o de "tierra" en sus dormitorios.

\section{CUADRO 2}

REDUCCIONES INDIGENAS SELECCIONADAS: DISTRIBUCION RELATIVA DE LOS HOGARES POR MATERTAL DEL PISO DE LOS DORMITORIOS, SEGUN TIPO DE VIVIENDA. CENSO DE 1988

\begin{tabular}{|c|c|c|c|c|c|c|}
\hline $\begin{array}{l}\text { Material } \\
\text { del piso } \\
\text { de los } \\
\text { dormitorios }\end{array}$ & Ruca & $\begin{array}{r}\text { Tipo } \\
\text { Ruca-casa }\end{array}$ & $\begin{array}{l}\text { de vivienda } \\
\text { Ruca-mejora }\end{array}$ & Casa & Mejora & Total \\
\hline Entablado & 1.5 & 26.7 & 35.6 & 13.7 & 46.0 & 26.2 \\
\hline Madera & 0.5 & 60.4 & 7.1 & 82.6 & 13.9 & 45.3 \\
\hline Tierra & 98.0 & 12.9 & 56.4 & 2.7 & 38.6 & 27.5 \\
\hline Otro & - & - & 0.6 & 0.7 & 1.5 & 0.8 \\
\hline Ignorado & - & - & 0.3 & 0.3 & - & 0.2 \\
\hline Total & $\begin{array}{l}100.0 \\
(197)\end{array}$ & $\begin{array}{l}100.0 \\
(341)\end{array}$ & $\begin{array}{l}100.0 \\
(337)\end{array}$ & $\begin{array}{r}100.0 \\
(1085)\end{array}$ & $\begin{array}{l}100.0 \\
(754)\end{array}$ & $\begin{array}{r}100.0 \\
(2714)\end{array}$ \\
\hline
\end{tabular}

Fuente: Anexo 2.

Por su parte, en las categorias "ruca" y "ruca-mejora" más de la mitad de las viviendas tiene piso de "tierra" en los dormitorios.

En las viviendas mixtas de1 tipo "ruca-casa" se presenta un 60 por ciento de los casos con piso de "madera" y un 13 por clento posee piso de "tierra" en los dormitorios. Esto estarla evidenciando que, como por definición la "ruca" tiene piso de "tierra", se estarla confirmando que cuando se sigue el patrón "ruca-casa", la primera haria de cocina y la "casa" poseería los dormitorios. 
Gráfico 2

REDUCCIONES INDIGENAS SELECCIONADAS: DISTRIBUCION RELATIVA DE LOS HOGARES POR MATERIAL DEL PISO DE LOS DORMITORIOS, SEGUN TIPO DE VIVIENDA. CENSO DE 1988
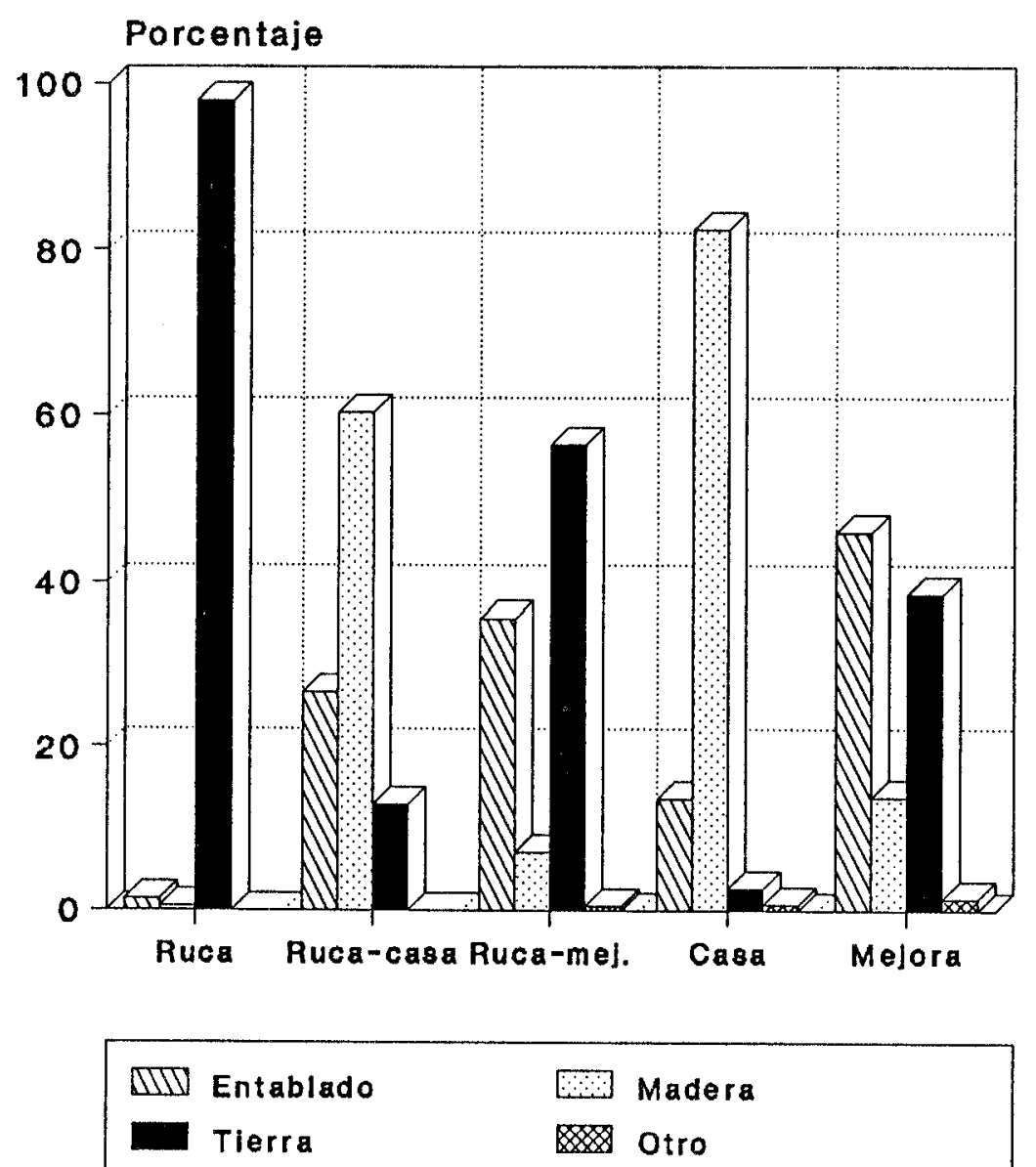

Fuente: Cuadro 2 
E1 comportamiento por distrito muestra que las viviendas con piso de "madera" son las de mayor importancia en todos ellos. El piso de "entablado" en los dormitorios es el segundo en importancia, excepto en Molco, en el cual el 33 por ciento de las viviendas posee piso de "tierra" en los dormitorios (anexos $3,4,5$ y 6)..$^{3}$

En sintesis, puede decirse que el material predominante del piso de los dormitorios, como indicador de las condiciones de la vivienda, señala que una mayoria de los hogares reside en viviendas que cuentan con pisos asociados con situaciones de insalubridad, hecho que es más notorio en las viviendas tipo "ruca", "ruca-mejora" y "mejora", con el agravante que esta última no cuenta con la funcionalidad de la vivienda tradicional.

\subsubsection{Disponibilidad de dormitorios}

Con respecto al número total de dormitorios, en el cuadro 3 se observa que la mayor importancia relativa la tienen los hogares con 2 a 3 piezas de dormitorio, los que constituyen más de la mitad del total de hogares. Sin embargo, llama la atención que un 38 por ciento de los hogares sólo tengan 1 dormitorio, porcentaje mucho más alto que el encontrado en el año 1982 para las mismas reducciones indigenas, en donde un 20 por ciento de las viviendas tenfa 1 dormitorio." En todo caso, es probable que la cifra de 38 por ciento contenga también aquellos hogares que no cuentan con pieza exclusiva de dormitorios, ya que en el Censo de 1988 los encuestadores debieron considerar la existencia de dormitorio aun en aquellos hogares con una pieza.

Según el tipo de vivienda, en el mismo cuadro se aprecia que en la "ruca" se presenta la mayor importancia relativa de las viviendas con una pieza de dormitorio, con un 89 por ciento, 10 que es esperable, ya que como se dijo, la vivienda tradicional es de una habitación. Junto a ésta, las viviendas que presentan menor número de dormitorios son la "mejora" y la "ruca-mejora", ya que poseen, en términos relativos, casi la mitad de sus viviendas con 1 dormitorio. Por el contrario, 1a "casa" y la "ruca-casa" son las únicas en que 1a mayor importancia relativa la tienen las viviendas con 2 a 3 dormitorios.

La información sobre el material del piso de los dormitorios no es posible compararla con la que corresponde al total de reducciones de la IX Región, según el Censo Nacional de 1982, pues los datos respectivos están subsumidos en un indicador de calidad de la vivienda. 


\section{CUADRO 3}

REDUCCIONES INDIGENAS SELECCIONADAS: DISTRIBUCION RELATIVA DE LOS HOGARES POR NUMERO DE DORMITORIOS, SEGUN TIPO DE VIVIENDA. CENSO DE 1988

\begin{tabular}{|c|c|c|c|c|c|c|}
\hline $\begin{array}{l}\text { Número } \\
\text { de } \\
\text { dormitorios }\end{array}$ & Ruca & $\begin{array}{r}\text { Tip } \\
\text { Ruca-casa }\end{array}$ & $\begin{array}{c}\text { de vivienda } \\
\text { Ruca-mejora }\end{array}$ & Casa & Mejora & Total \\
\hline 1 & 88.8 & 21.4 & 48.4 & 15.8 & 57.7 & 37.5 \\
\hline $2-3$ & 10.7 & 63.6 & 45.4 & 66.2 & 36.7 & 51.1 \\
\hline $4-5$ & 0.5 & 14.4 & 6.2 & 16.7 & 5.4 & 10.8 \\
\hline $6-8$ & - & 0.6 & - & 1.2 & 0.2 & 0.6 \\
\hline 9 y más & - & - & - & 0.1 & - & - \\
\hline otal & $\begin{array}{l}100.0 \\
(197)\end{array}$ & $\begin{array}{l}100.0 \\
(341)\end{array}$ & $\begin{array}{l}100.0 \\
(337)\end{array}$ & $\begin{array}{r}100.0 \\
(1085)\end{array}$ & $\begin{array}{l}100.0 \\
(754)\end{array}$ & $\begin{array}{r}100.0 \\
(2714)\end{array}$ \\
\hline
\end{tabular}

Fuente: Anexo 7.

Finalmente, hay que destacar que un 11 por ciento de las viviendas posee más de 3 dormitorios, situación que está bastante alejada de 10 que se supone es el patrón tradicional, representando además, un valor idéntico al encontrado para las mismas reducciones indigenas en 1982.5

\subsubsection{Disponibilidad de piezas}

Según el número total de piezas, en el cuadro 4 se observa una situación parecida a la anteriormente descrita, ya que la mayor importancia relativa la tienen las viviendas de 2 piezas, con un 24 por ciento. Sin embargo, las viviendas de 4 piezas alcanzan a un 23 por ciento y las viviendas con más de 4 piezas son el 26 por ciento.

Si se analiza la información según el tipo de vivienda, se puede observar en dicho cuadro que entre las viviendas que cuentan con una pieza, dentro de las "rucas", éstas alcanzan un 46 por ciento. 
Lo que más llama la atención en las otras viviendas es que 1a "casa" adquiere caracteristicas bastante distintas, ya que un tercio de ellas tiene 4 piezas y un 44 por ciento tiene 4 y más piezas. La "ruca-casa", por su parte, presenta una situación algo similar.

\section{CUADRO 4}

REDUCCIONES INDIGENAS SELECCIONADAS: DISTRIBUCION RELATIVA DE LOS HOGARES POR NUMERO TOTAL DE PIEZAS, SEGUN TIPO DE VIVIENDA. CENSO DE 1988

\begin{tabular}{lrrrrrr}
$\begin{array}{l}\text { Número } \\
\text { total de } \\
\text { piezas }\end{array}$ & \multicolumn{1}{c}{ Ruca } & Ruca-casa & Ruca-mejora & Casa & Mejora & Total \\
\hline & & & & & & \\
1 & 46.2 & 0.3 & 1.5 & 0.8 & 13.7 & 7.7 \\
2 & 44.2 & 14.7 & 45.4 & 7.1 & 39.3 & 24.4 \\
3 & 8.1 & 22.6 & 31.2 & 14.4 & 23.7 & 19.6 \\
4 & 0.5 & 32.6 & 11.3 & 33.3 & 13.3 & 22.5 \\
5 & 1.0 & 20.2 & 8.6 & 25.7 & 6.6 & 15.8 \\
6 & - & 6.5 & 1.2 & 9.0 & 2.9 & 5.4 \\
7 y más & - & 3.1 & 0.9 & 9.7 & 0.5 & 4.5 \\
& 100.0 & 100.0 & 100.0 & 100.0 & 100.0 & 100.0 \\
Total & $(197)$ & $(341)$ & $(337)$ & $(1085)$ & $(754)$ & $(2714)$
\end{tabular}

Fuente: Anexo 8 .

Al comparar la información del número de dormitorios y piezas entre las reducciones seleccionadas censadas en 1988 con la información correspondiente a las mismas reducciones censadas en 1982, se descubre que en la población estudiada en el Censo de 1988 se presentaria una mejor situación en cuanto a la disponibilidad de piezas y de dormitorios en las viviendas. Esto puede advertirse en los datos que se presentan en el cuadro 5, donde se aprecian diferencias marcadas en algunas categorias."

En el Censo Nacional se preguntó por pieza exclusiva de dormitorio; en el Censo de 1988 se preguntó por el número de piezas que se usan para dormir, aun cuando también se destinen a otro uso. Sin embargo, se puede asumir que al menos en aquellas viviendas de una pieza (209 casos), no hay pieza exclusiva de dormitorio (anexo 8). 
CUADRO 5

REDUCCIONES INDIGENAS SELECCIONADAS: DISTRIBUCION RELATIVA DE LAS VIVIENDAS POR NUMERO DE PIEZAS, SEGUN TOTAL DE PIEZAS Y DORMITORIOS. CENSOS DE 1982 Y 1988

\begin{tabular}{|c|c|c|c|c|}
\hline \multirow{2}{*}{$\begin{array}{l}\text { Número } \\
\text { de } \\
\text { piezas }\end{array}$} & \multicolumn{2}{|c|}{1982 (1) } & \multicolumn{2}{|c|}{1988 (2) } \\
\hline & $\begin{array}{l}\text { Total } \\
\text { piezas }\end{array}$ & Dormit. & $\begin{array}{l}\text { Total } \\
\text { piezas }\end{array}$ & Dormit. \\
\hline 0 & - & 27.4 & - & 7.7 \\
\hline 1 & 25.2 & 19.8 & 7.7 & 29.8 \\
\hline 2 & 29.6 & 27.8 & 24.4 & 33.7 \\
\hline 3 & 16.9 & 14.3 & 19.6 & 17.4 \\
\hline 4 & 16.9 & 8.6 & 22.5 & 9.2 \\
\hline 5 & 5.9 & 1.2 & 15.8 & 1.6 \\
\hline & 2.7 & 0.6 & 5.4 & 0.3 \\
\hline 7 y más & 2.9 & 0.2 & 4.5 & 0.3 \\
\hline Total & $\begin{array}{r}100.0 \\
(2882)\end{array}$ & $\begin{array}{r}100.0 \\
(2882)\end{array}$ & $\begin{array}{r}100.0 \\
(2714)\end{array}$ & $\begin{array}{r}100.0 \\
(2714)\end{array}$ \\
\hline
\end{tabular}

Fuente: (1) Tabulados especiales Censo Nacional de 1982. (2) Anexos 8 y 9 .

\subsubsection{Disponibilidad de pieza de cocina}

Al considerar la disponibilidad de pieza de cocina, se observa que la gran mayoria de los hogares y viviendas cuenta con una pieza exclusiva para este fin (91 por ciento; anexo 7), lo que evidenciarla un aspecto positivo en las caracteristicas de éstas. Con respecto al tipo de vivienda, se observa que la "casa" y la "mejora" cuentan mayoritariamente con una pieza de cocina (99 por ciento y 85 por ciento, respectivamente; anexo 7). Por su parte, las viviendas mixtas "ruca-casa" y "ruca-mejora", presentan también valores relativos importantes, ya que en un 99 y 95 por ciento cuentan con pieza de cocina, función que la cumpliria generalmente la "ruca" (anexo 7).

Llama la atención que poco más de la mitad de las "rucas" cuenta con pieza exclusiva de cocina, lo que estaria apoyando la hipotesis de que en esta categoría habría viviendas con más de una construcción tipo "ruca" (anexo 7). 
El porcentaje de hogares que dispone de pieza de cocina en las reducciones estudiadas en 1988 es superior al de las mismas reducciones según el Censo Nacional de 1982 ( 79 por ciento). ${ }^{7}$ La presencia de una pieza exclusiva de cocina estaria indicando una tendencia hacia la conformación de un modelo occidental de organización de la vivienda, lo que podria estar asociado con modificaciones en otras costumbres tradicionales.

\subsection{Tamaño de los hogares}

Una de las caracteristicas más importantes de conocer es el número de personas por hogar, ya que permite una aproximación al efecto que pudieran tener las tendencias en el comportamiento demográfico de la población estudiada. Por otro lado, en las economias familiares campesinas el tamaño del hogar es fundamental, pues se relaciona directamente con la mano de obra que se dispone. No existen estimaciones del promedio de personas por hogar para los pueblos indoamericanos, aunque se ha hablado indistintamente de 4 a 7 personas por familia (Hidalgo, 1972). Sin embargo, para el caso de los mapuches, que eran polfgamos, este promedio es bajo. Los cronistas (siglos XVI a XIX) hablan de familias muy numerosas y de que vivian todos juntos en enormes rucas. Es probable que durante el periodo de guerra posterior, el tamaño de los hogares y familias disminuyera (en el caso de los incas el promedio de personas baja de 6 a 2.5 ; Hidalgo, 1972), aunque cabe destacar que en un estudio realizado a fines del. siglo XIX se encontraron jefes de hogar con dieciocho, veinte y hasta veinticuatro esposas, todas en una sola vivienda, si bien con su propio hogar y puerta (Guevara, 1913).'

E1 promedio de personas por hogar en las reducciones estudiadas es de 4.8. Como se aprecia en el cuadro 6, los hogares con 2 a 4 personas poseen la mayor importancia relativa entre la población de las reducciones indfgenas seleccionadas, los que alcanzan a casi la mitad del total de hogares. No obstante, 1lama la atención que casi un 40 por ciento de los hogares tiene entre 5 y 7 personas y que los grupos de 8 y más personas, tamaño considerado más cercano al patrón tradicional, sólo alcanzan a un 12 por ciento. Es indudable que estas caracteristicas guardan estrecha relación con las tendencias demográficas advertidas, esto es, una fuerte emigración de personas y una fecundidad en descenso, aunque todavia alta.

Información correspondiente a tabulados especiales Censo Nacional de 1982 .

Esto correspondería a la definición de varios hogares en una vivienda. 
CUADRO 6

REDUCCIONES INDIGENAS SELECCIONADAS: DISTRIBUCION RELATIVA DE LOS HOGARES POR NUMERO DE PERSONAS, SEGUN TIPO DE VIVIENDA.

CENSO DE 1988

\begin{tabular}{lrrrrrr}
$\begin{array}{l}\text { Número } \\
\text { de personas } \\
\text { en el hogar }\end{array}$ & \multicolumn{1}{c}{ Ruca } & \multicolumn{1}{c}{ Ruca-casa } & Ruca-mejora & Casa & Mejora & Total \\
\hline & & & & & & \\
1 & 18.3 & 2.6 & 3.9 & 4.0 & 7.8 & 5.9 \\
$2-4$ & 46.2 & 35.2 & 46.9 & 38.1 & 50.3 & 42.8 \\
$5-7$ & 25.9 & 44.9 & 35.0 & 44.9 & 34.0 & 39.2 \\
$8-10$ & 8.6 & 13.2 & 14.2 & 11.8 & 6.9 & 10.7 \\
11 y más & 1.0 & 4.1 & & 1.2 & 1.0 & 1.4 \\
& & & & & & \\
Total & 100.0 & 100.0 & 100.0 & 100.0 & 100.0 & 100.0 \\
& $(197)$ & $(341)$ & $(337)$ & $(1085)$ & $(754)$ & $(2714)$
\end{tabular}

Fuente: Anexo 10.

De los estudios realizados en épocas recientes, se puede citar al de Stuchlik (1974), que muestra un promedio bastante bajo ( 4.8 personas) con relación a lo tradicional, pero que es idéntico al encontrado en el Censo de 1988. Este hecho llama la atención, ya que se trata de un trabajo realizado hace casi dos décadas y en una zona más alejada de los centros urbanos que los distritos estudiados en 1988. Por otra parte, el estudio de Bengoa (1987), encontró en 200 hogares un promedio de 6.2 personas por familla. Este autor atribuye el aumento a una baja en la mortalidad infantil y a un descenso en la migración, a pesar que los promedios encontrados en el Censo Nacional de 1982 ( 5.1 ; según Oyarce, Romaggi y Vidal, 1989) y los de 1988 más bien parecen sugerir que en el trabajo de Bengoa el promedio más alto puede deberse al tamaño de la muestra.

En sintesis, el promedio de personas por hogar en las reducciones seleccionadas (4.8) representa un valor levemente inferior que el encontrado para todas las reducciones identificadas en el Censo Nacional de 1982 (5.1). Hay que destacar que en la IX Región en 1982 los promedios de personas por hogar eran de 4.8 (4.7 para las áreas urbanas y 5.0 para las áreas rurales; según INE, 1985 y 1987b), lo que significaria un acercamiento en el tamaño de los hogares de las reducciones estudiadas en 1988 con el que presentaba la IX Región en 1982. 
Respecto a este punto, Bengoa (1987) encontró una relación entre el tamaño de los hogares y el tamaño del predio. A mayor cantidad de hectáreas, la familla es más numerosa. Sin embargo, también podria pensarse que las familias con más recursos poseen mayores expectativas de educación para sus hijos y que también en esas familias se presenta una alta emigración.

Con relación al tipo de vivienda y número de personas, la "ruca-casa" y la "casa" son las que poseen hogares de mayor tamaño relativo, ya que un 62 por ciento de los hogares de las "ruca-casas" y un 58 por ciento de los hogares de las "casas" tienen 5 y más personas. En el otro extremo, la "ruca" posee hogares de menor tamaño, ya que un 65 por ciento de ellos posee 4 o menos personas (gráfico 3). Este hecho es un poco contradictorio y merecerla estudiarse en profundidad, ya que en teorfa, las familias que viven en viviendas tradicionales deberían ser las más numerosas, en el sentido de estar más ligadas al tamaño tradicional y, sobre todo, de no limitar el número de hijos. Sin embargo, los datos parecen mostrar que en estas viviendas se concentran los hogares de menor tamaño y los unipersonales. Un factor que podrla relacionarse con 10 anterior es que en estas viviendas se mantendrian las personas mayores, los "troncos" de grandes familias, cuyos hijos al casarse se construyen una vivienda de tipo occidental en un lugar contiguo al de la ruca paterna (que obviamente quedará consignada como otra vivienda). Un aspecto que podría estar influyendo, si bien habria que comprobar con estudios especificos, es que ante la dictación de la Ley 2568 los hijos mayores han pedido el terreno que les corresponde en herencia, aun cuando los padres estén vivos. 
Gráfico 3

REDUCCIONES INDIGENAS SELECCIONADAS: DISTRIBUCION RELATIVA DE LOS HOGARES POR NUMERO DE PERSONAS EN EL HOGAR, SEGUN TIPO DE VIVIENDA. CENSO DE 1988

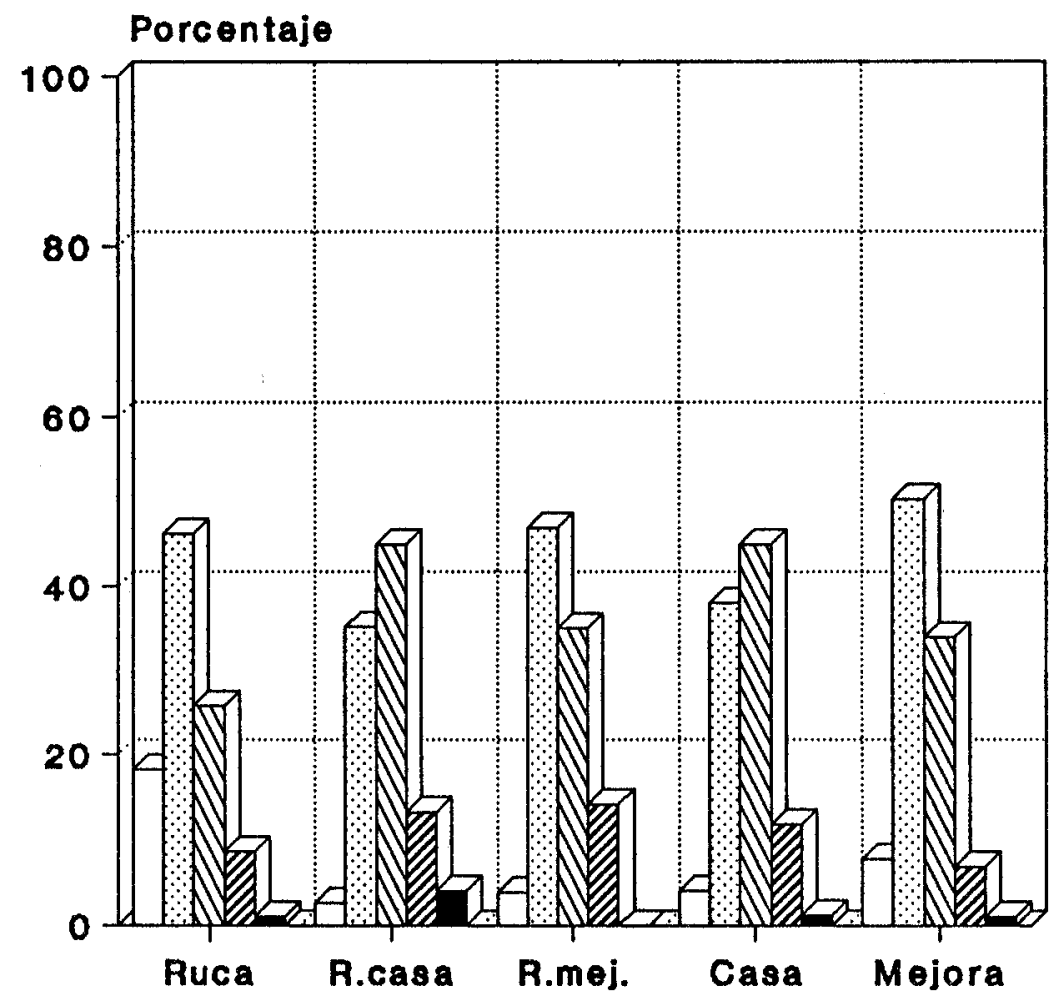

1 pere. $2-4$ pers. $\square$ 6IV 6-7 pers. WIIA 8-10 pers. W 11 y más pers.

Fuente: Cuadro 6 


\subsection{Grado de hacinamiento}

Es importante conocer si existe hacinamiento en las viviendas, ya que las condiciones de insalubridad suelen estar asociadas con altos indices de hacinamiento. El análisis de la información del número de personas por pieza muestra el grado de hacinamiento que afecta a la población. El indicador respectivo se construyo considerando el promedio de personas por hogar (4.8), partiendo del supuesto que las viviendas deberian contar con un minimo de 3 piezas para desarrollar con normalidad el total de las actividades propias del hogar. E1 indicador se basó en las sigulentes categorias:

- Sin hacinamiento: 2 o menos personas por pieza

- Hacinamiento leve: 2.1 a 2.5 personas por pieza

- Hacinamiento medio: 2.6 a 3 personas por pieza

- Hacinamiento alto: 3 y más personas por pieza

E1 gráfico 4 muestra que el 74 por ciento de la población de las reducciones indigenas seleccionadas no presentaria situación de hacinamiento, según el indicador utilizado. Esto parecerıa confirmado, además, por la fuerte presencia de viviendas de 3 y más piezas (cuadro 4).

Solo un 10 por ciento de la población y un 7 por ciento de los hogares presentaria un nivel "alto" de hacinamiento. Con relación al hacinamiento encontrado para el total de reducciones de la IX Región en 1982, éste era bastante más elevado, ya que alcanzó a un 30 por ciento de los hogares en situación de "alto" hacinamiento (Oyarce, Romaggi y Vidal, 1989).'

De estas cifras globales, puede señalarse que los problemas de calidad de la vivienda no se expresarian en un hacinamiento, lo que motiva conocer otras caracteristicas, tales como la disponibilidad de saneamiento.

En rigor, la comparación debe hacerse considerando los valores de las categorias de hacinamiento "medio" y "alto" utilizadas en el análisis del Censo de 1988 (12 por ciento de los hogares), contrastándolos con el valor equivalente a la categoria "alto" empleada en el análisis del Censo Nacional de 1982 (30 por ciento de los hogares). 


\section{Gráfico 4 \\ REDUCCIONES INDIGENAS SELECCIONADAS: DISTRIBUCION RELATIVA DE LA POBLACION Y DE LOS HOGARES SEGUN GRADO DE HACINAMIENTO. CENSO DE 1988}

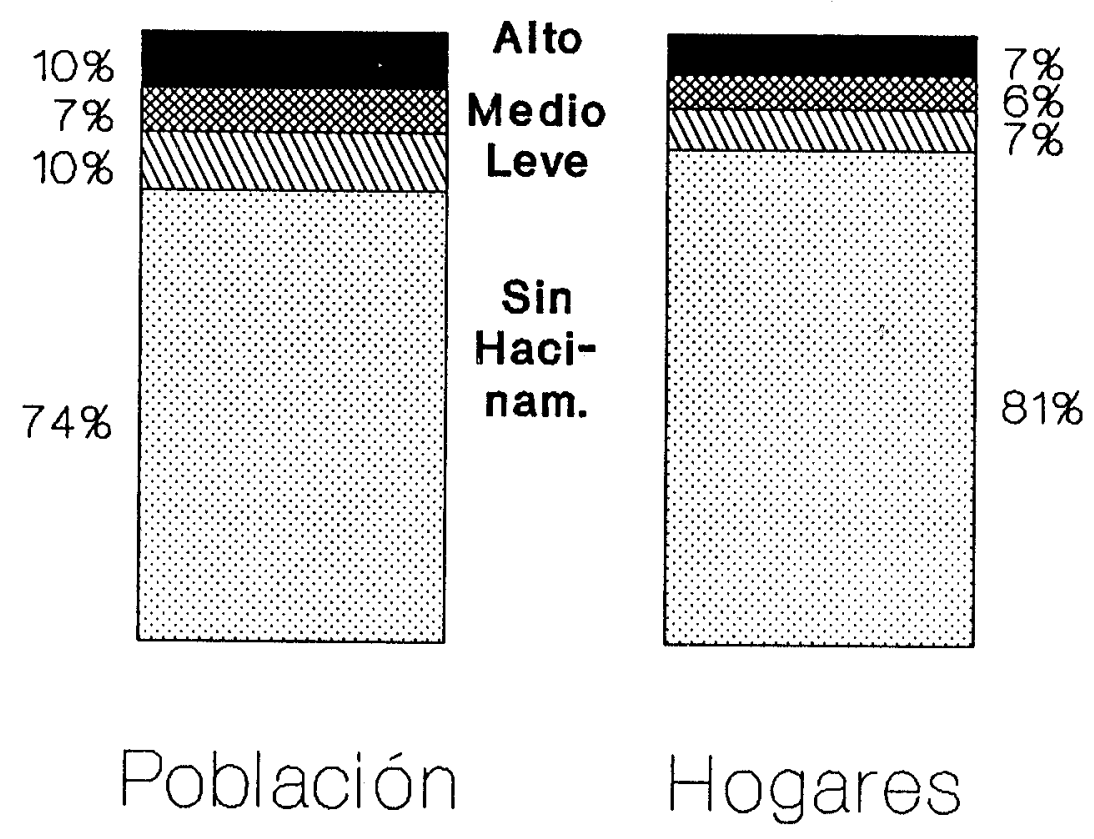

Fuente: Anexo 11 


\section{Caracteristicas de saneamiento ambiental}

En esta área interesa conocer algunas caracteristicas ambientales que están directamente vinculadas con las condiciones de vida -entre ellas, las de salud-, tales como el sistema de obtención de agua que se consume en el hogar y el sistema de eliminación de excretas. Para este fin, se emplearon categorias que miden saneamiento básico, consideradas como las más adecuadas a la realidad en estudio, de acuerdo con el análisis de los datos del Censo Nacional de 1982, correspondientes a la totalidad de reducciones indigenas de la IX Región (Oyarce, Romaggi y Vidal, 1989).

Con relación a la procedencia o las fuentes de obtención de agua de consumo, se discriminó más en la categoria "pozo", que fue la de mayor importancia relativa en todas las reducciones de la región en 1982, quedando las siguientes categorias: "pozo descubierto", "pozo protegido sin bomba", "pozo protegido con bomba", "vertiente", "rio o arroyo" y "otro". Para los sistemas de eliminación de excretas o tipo de baño se consideraron las categorias: "cajón sobre pozo negro", "letrina sanitaria", "baño dentro de la casa" y "no tiene" (campo abierto).

\subsection{Procedencia del agua de consumo}

Como es esperable en el sector rural, no existe agua potable en los hogares de las reducciones indigenas seleccionadas. Si se suman todos los hogares que presentan "pozos", sin considerar sus condiciones, se encuentra que el 89 por ciento tiene esta fuente de obtención de agua (cuadro 7 y gráfíco 5). Este porcentaje es bastante más alto que el que correspondia a todas las reducciones de la región, según el Censo Nacional de 1982, donde un 61 por ciento de los hogares tenía este sistema de obtención de agua (Oyarce, Romaggi y Vidal, 1989).

Si se consideran todos los "pozos", más de la mitad está "protegido", aunque en su mayoria no poseen bomba. Al sumar las categorfas que expresan las condiciones más deficientes, se aprecia que el 46 por ciento de las viviendas cuenta con "pozo descubierto", "vertiente" y "rfo o arroyo". 
CUADRO 7

REDUCCIONES INDIGENAS SELECCIONADAS: DISTRIBUCION RELATIVA DE LOS HOGARES POR SISTEMA DE PROCEDENCIA DEL AGUA, SEGUN TIPO DE VIVIENDA. CENSO DE 1988

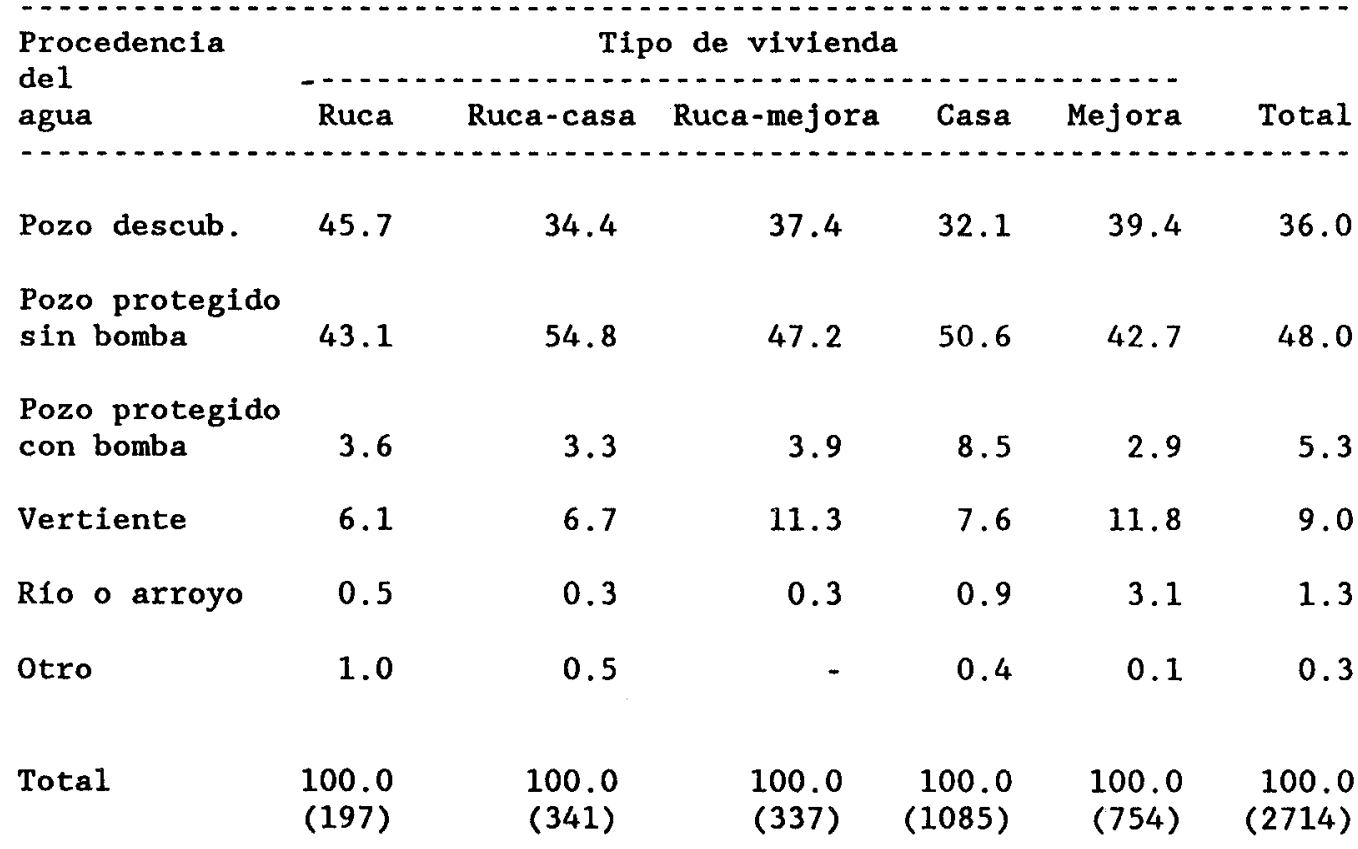

Fuente: Anexo 16.

Con respecto a los distritos, en general se mantienen las tendencias señaladas, encontrándose la mayoria de los hogares con "pozo protegido", exceptuando Maquehue, donde alcanza mayor gravitación el sistema de "pozo descubierto" como el más frecuente sistema de obtención de agua (anexos 12, 13, 14 y 15 ).

Al considerar los tipos de vivienda se observa que la "casa" y la "rucacasa" presentan una mejor situación relativa en cuanto a los sistemas de obtención de agua (más del 55 por ciento con "pozo protegido"). Llama la atención que la "mejora" y la "ruca-mejora" presentan la mayor participación relativa de la "vertiente" como fuente de obtención de agua (sobre 11 por ciento). El caso de la "mejora" adquiere singular relevancia si se tiene en cuenta que un 54 por ciento de estas viviendas posee "pozo descubierto", 
"vertiente" y "rio o arroyo", proporción que incluso supera a la que corresponde
a la "ruca" exclusiva en estos tipos de obtención de agua.

\subsection{Sistema de eliminación de excretas}

Con relación al sistema de eliminación de excretas, categorizado como tipo de baño, en el cuadro 8 y gráfico 6 se aprecia que el 90 por ciento de los hogares tiene "cajón sobre pozo negro" y un 9 por ciento no dispone de ningún sistema. Cabe señalar que en la cotalidad de reducciones de la IX Región, según el Censo Nacional de 1982, un 96 por ciento de los hogares contaba con "cajón sobre pozo negro" (Oyarce, Romaggi y Vidal, 1989). 10

\section{CUADRO 8}

REDUCCIONES INDIGENAS SELECCIONADAS: DISTRIBUCION RELATIVA DE LOS HOGARES POR SISTEMA DE ELIMINACION DE EXCRETAS, SEGUN TIPO DE VIVIENDA. CENSO DE 1988

\begin{tabular}{|c|c|c|c|c|c|c|}
\hline $\begin{array}{l}\text { Sistema } \\
\text { de eliminación } \\
\text { de excretas }\end{array}$ & Ruca & $\begin{array}{r}\text { Tip } \\
\text { Ruca-casa }\end{array}$ & $\begin{array}{c}\text { o de vivienda } \\
\text { Ruca-mejora }\end{array}$ & Casa & Mejora & Total \\
\hline $\begin{array}{l}\text { Cajón sobre } \\
\text { pozo negro }\end{array}$ & 70.1 & 91.5 & 84.0 & 96.9 & 88.1 & 90.2 \\
\hline $\begin{array}{l}\text { Letrina } \\
\text { sanitaria }\end{array}$ & 0.5 & - & 0.3 & 0.8 & 0.3 & 0.5 \\
\hline $\begin{array}{l}\text { Baño dentro } \\
\text { de la casa }\end{array}$ & - & - & - & 0.4 & - & 0.2 \\
\hline No tiene & 29.4 & 8.5 & 15.7 & 1.9 & 11.5 & 9.1 \\
\hline Ignorado & - & - & - & - & 0.1 & 0.0 \\
\hline Total & $\begin{array}{l}100.0 \\
(197)\end{array}$ & $\begin{array}{l}100.0 \\
(341)\end{array}$ & $\begin{array}{l}100.0 \\
(337)\end{array}$ & $\begin{array}{r}100.0 \\
(1085)\end{array}$ & $\begin{array}{l}100.0 \\
(754)\end{array}$ & $\begin{array}{l}100.0 \\
(2714)\end{array}$ \\
\hline
\end{tabular}

Fuente: Anexo 17.

10 En el Censo Nacional de 1982 no se pudo estimar el número de hogares que no disponia de baño o no contaba con algún sistema de elíminación de excretas, pues no se considero esa posibilidad. Por lo tanto, la cantidad de pozos negros probablemente estaria sobreestimada en ese año. 


\section{Gráfico 5 \\ REDUCCIONES INDIGENAS SELECCIONADAS: DISTRIBUCION RELATIVA DE LOS HOGARES POR SISTEMA DE PROCEDENCIA DEL AGUA. \\ CENSO DE 1988}

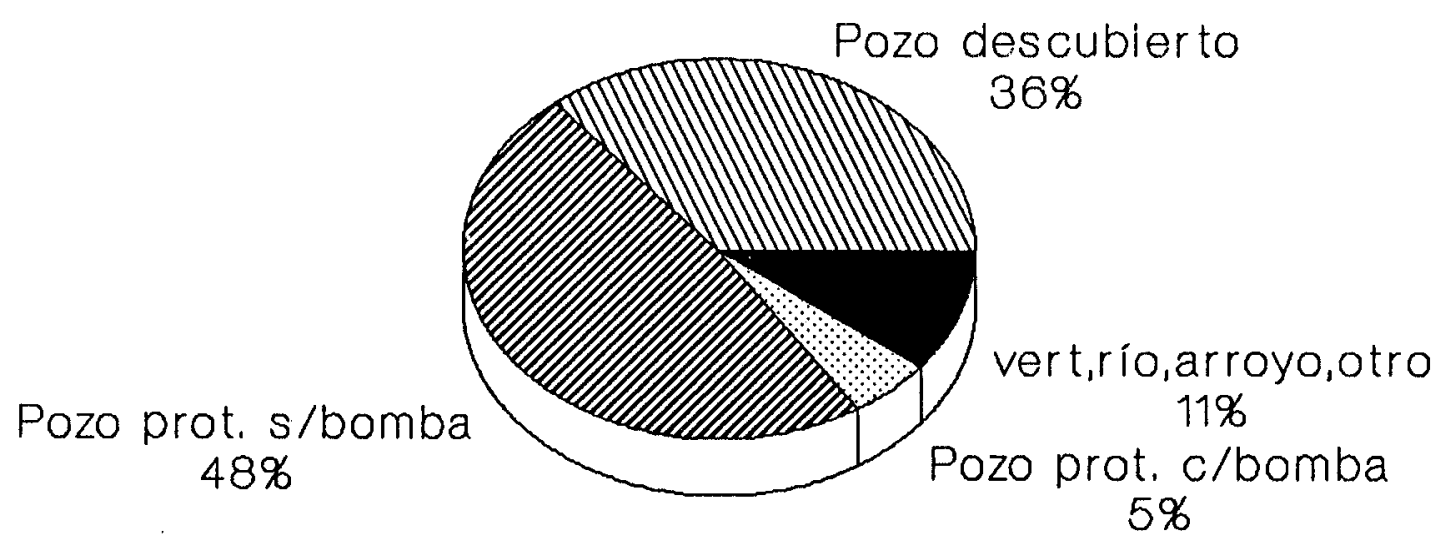

Fuente: Cuadro 7 


\section{Gráfico 6 \\ REDUCCIONES INDIGENAS SELECCIONADAS: DISTRIBUCION RELATIVA DE LOS HOGARES POR SISTEMA DE ELIMINACION DE EXCRETAS. \\ CENSO DE 1988}

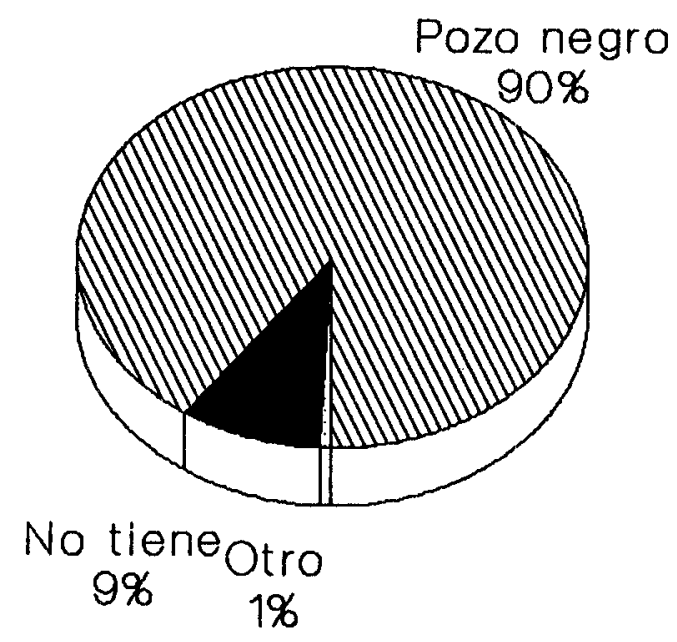

Fuente: Cuadro 8 
La situación entre los distritos es bastante homogénea, aunque Maquehue y Labranza presentan un porcentaje de cerca del 11 por ciento de hogares cuyas viviendas no cuentan con sistema de eliminación de excretas (anexos 18, 19, 20 y 21). Debe recordarse que Maquehue presenta en el sistema de obtención de agua 1a mayor frecuencia de "pozos descubiertos".

Según el tipo de vivienda, si bien la tendencia general se mantiene para todas las categorias, la "ruca" exclusiva evidencia la situación más deficiente, ya que aproximadamente un 30 por ciento de este tipo de viviendas no cuenta con ningún sistema de eliminación de excretas (cuadro 8 ).

En sintesis, con relación a las caracteristicas de saneamiento ambiental de la población de las reducciones indigenas seleccionadas, se observa que la situación es más bien precaria, ya que lo más frecuente es la presencia de "cajón sobre pozo negro" como sistema de eliminación de excretas, y de "pozo protegido sin bomba" como fuente de obtención de agua. Como se aprecia en el cuadro 9, poco menos de la mitad de los hogares se encuentra en esta situación, siguiéndole en importancia el mismo tipo de baño combinado con "pozo descubierto", donde se encuentra casi un tercio de los hogares. 
CUADRO 9

REDUCCIONES INDIGENAS SELECCIONADAS: DISTRIBUCION RELATIVA DE

LOS HOGARES POR TIPO DE BAÑO, SEGUN PROCEDENCIA DEL AGUA.

CENSO DE 1988

Tipo

de

baño

\section{Procedencia del agua}

\section{Pozo desc. Pozo prot. Pozo prot. Vert. Rio o Otro Total} sin bomba con bomba arroyo

Fuente: Anexo 22.

\section{Familia}

Los tipos de familia, asi como su composición y las caracteristicas del jefe de hogar, constituyen importantes aspectos de conocer en el análisis de las tendencias que sigue la organización social de la población estudiada. En el caso de las sociedades Ilamadas simples o no tecnificadas, como la de los mapuches, el estudio de los sistemas de parentesco y de las familias es de crucial importancia, pues con frecuencia éstos son la base de la estructura social, cumpliendo además una pluralidad de funciones en otros ámbitos que van más allá de las relaciones y alianzas por parentesco (Foester, 1980). 
La información sobre la familia se ha recogido preguntando por la relación de parentesco de cada persona del hogar, con la persona que fue reconocida como jefe del mismo.

\subsection{Tipos de familia}

Para comprender las caracteristicas actuales de la familia mapuche es necesario conocer el patrón tradicional de organización social mapuche." En términos generales, la estructura social mapuche a la conquista de los españoles se basaba en los lazos de parentesco; no existian otras instituciones de poder politico ni económico centralizado. Los grupos de parientes llamados linajes establecian relaciones de parentesco con otros linajes mediante el intercambio de esposas, ya que eran exógamos. Esta situación creaba alianzas duraderas que regulaban los conflictos y servian para desarrollar trabajos y acciones colectivas como el rukan, mingako y eventos de tipo religioso, politico, económico y militar. Cada linaje o grupo doméstico amplio era una unidad sociopolitica autónoma (Bengoa y Valenzuela, 1984; Foester, 1980; Stuchlik, 1974). De lo anterior se desprende la importancia que le otorgaban a las relaciones de parentesco, y se decia que mientras más esposas, hijos y parientes tenia un hombre, más rico era.

Los linajes eran de descendencia patrilineal y con residencia patrilocal; el matrimonio era poligámico, del tipo poliginico (un hombre con varias mujeres), generalmente con prácticas de sororato (las esposas eran hermanas entre $s 1$ ) y levirato (a la muerte del jefe de hogar su hijo mayor o hermano heredaba sus esposas, excluyendo a la madre biológica). Otra práctica matrimonial preferencial era el matrimonio con la prima cruzada matrilateral. Todo esto significa que las relaciones de parentesco establecfan verdaderas redes de organización social, constituyendo la base de la estructura social mapuche.

La información existente sobre los patrones tradicionales de vida de los mapuches proviene básicamente de los escritos de los cronistas (siglos XVI hasta mediados del siglo XIX). Aun cuando es innegable que el modo de vida mapuche sufrio transformaciones durante el largo y cruento periodo de enfrentamiento sostenido con el invasor español, historiadores y antropólogos afirman que los cambios más drásticos se produjeron desde la 1lamada "Pacificación de La Araucania" y fundamentalmente con la radicación en reducciones (aproximadamente entre 1860-1920). Para efectos de este análisis se considerará como patrón tradicional el modo de vida mapuche que existia hasta fines de ese periodo (Oyarce, 1989). 
Cada grupo de parentesco estaba encabezado por un jefe o longko que tenfa autoridad por ser miembro de la generación anterior. Esta persona administraba los terrenos comunes al linaje y aseguraba los campos a las nuevas familias (Stuchlik, 1974).

Los grupos de parentesco se regian por un cuerpo de costumbres, una especie de ley indigena, llamado ad mapu. En el aspecto religioso el chaman, conocido como el o la machi, era el encargado de mantener el equilibrio entre la vida natural, social y sobrenatural.

Durante el primer periodo de la colonización (1536-1641) los mapuches no sucumbieron a los españoles, quienes se vieron obligados a reconocer al río Bio Bío como limite norte del territorio mapuche independiente. En términos de su estructura de parentesco, los mapuches continuaron con sus preferencias por el intercambio matrimonial entre grupos familiares, lo que favoreció la mantención de relaciones de alianza entre los grupos. Al respecto, existen numerosos testimonios de la guerra que señalan que el grupo de parientes funcionaba como una unidad polftica y militar. Dos siglos más tarde, en 1866, el gobierno chileno dictó una ley en la cual se reservan sectores de la frontera como reducciones para los mapuches. En 1880, cuando las tropas chilenas mantenian una guerra con los paises vecinos de Perú y Bolivia, los mapuches se alzaron en armas, pero fueron aplastados en 1882 por el ejército. Como consecuencia de su derrota, el gobierno readecuó la ley de reducciones: a cada grupo local se le asignó una determinada cantidad de tierras en tenencia común por medio de un documento llamado Título de Merced (se otorgaron alrededor de 3000 ).

La radicación de los mapuches trajo como consecuencia un cambio drástico en la organización social: como el jefe no podia asignar nuevas tierras, el linaje o grupo como un todo perdió importancia y el grupo local de parentesco se fue desintegrando, lo que condujo a una mayor gravitación de la familia individual (Stuchlik, 1974).

Actualmente, si bien las relaciones de parentesco siguen regulando algunas esferas de la vida al interior de las reducciones, las prácticas de la poliginia, sororato y levirato prácticamente han desaparecido, aun cuando se mantiene, en cierta medida, 1a práctica del matrimonio preferencial (Foester, 1980; Oyarce, 1989).

Para el análisis de los tipos de familia según la información del Censo de 1988, se han considerado cinco categorias de familia. Las tres primeras se 
relacionan con las categorías de los miembros que la componen y las dos últimas se basan en la presencia o ausencia del cónyuge del jefe de hogar:

- Nuclear: formada por el jefe de hogar, cónyuge e hijos.

- Extensa: formada por el jefe de hogar, cónyuge, hijos y otros parientes.

- Compuesta: formada por el jefe de hogar, cónyuge, hijos, otros parientes y otros no parientes.

- Completa: aquella en donde está el jefe de hogar más el cónyuge.

- Incompleta: aquella donde el o la jefe de hogar está sin cónyuge.

Como se observa en el cuadro 10, la familia más frecuente entre la población estudiada es la de tipo "nuclear", con el 62 por ciento de los hogares correspondientes a este tipo de familia. Este porcentaje es más alto que el encontrado en el Censo Nacional de 1982 para todas las reducciones indigenas identificadas en la IX Región, ya que la cifra era de un 54 por ciento, e incluso es más elevado que el promedio regional para el mismo año, que alcanzaba a 56 por clento (Oyarce, Romaggi y Vidal, 1989). Esto evidencia que en las reducciones estudiadas en 1988 se estarian produclendo transformaciones en la estructura social mapuche con relación al patrón tradicional, situación ya detectada en 1982 en el total de reducciones indigenas de la IX Región.

La familia "extensa" mantiene una cierta importancia relativa, con un 33 por ciento de los hogares (cuadro 10). La familia "compuesta", por su parte, presenta un porcentaje muy bajo, con casi un 7 por ciento de los hogares, porcentaje muy similar al encontrado en 1982 en todas las reducciones de la región (Oyarce, Romaggi y Vidal, 1989), lo que evidenciaria una mantención de la pauta de organización mapuche basada en el parentesco. ${ }^{12}$

Según la presencia o ausencia del cónyuge del jefe de hogar, en las reducciones se observa un número alto de familias "completas", con un 70 por ciento del total de hogares (anexo 23), cifra levemente menor que la encontrada para todas las reducciones de la región en 1982, que era de 66 por ciento (Oyarce, Romaggi y Vidal, 1989). Este fenómeno puede estar relacionado con una fuerte emigración, pero además con un modelo matrimonial bastante tardio para una población indrgena campesina.

12 Hay que recordar que la familia "compuesta" incluye personas no parientes, caracteristica que parece relacionarse más con el fenomeno de los allegados en las áreas urbanas. 
CUADRO 10

REDUCCIONES INDIGENAS SELECCIONADAS: DISTRIBUCION RELATIVA DE LOS HOGARES Y DE LA POBLACION POR TIPO DE FAMILIA, SEGUN PRESENCIA O AUSENCIA DEL CONYUGE DEL JEFE DE HOGAR. CENSO DE 1988

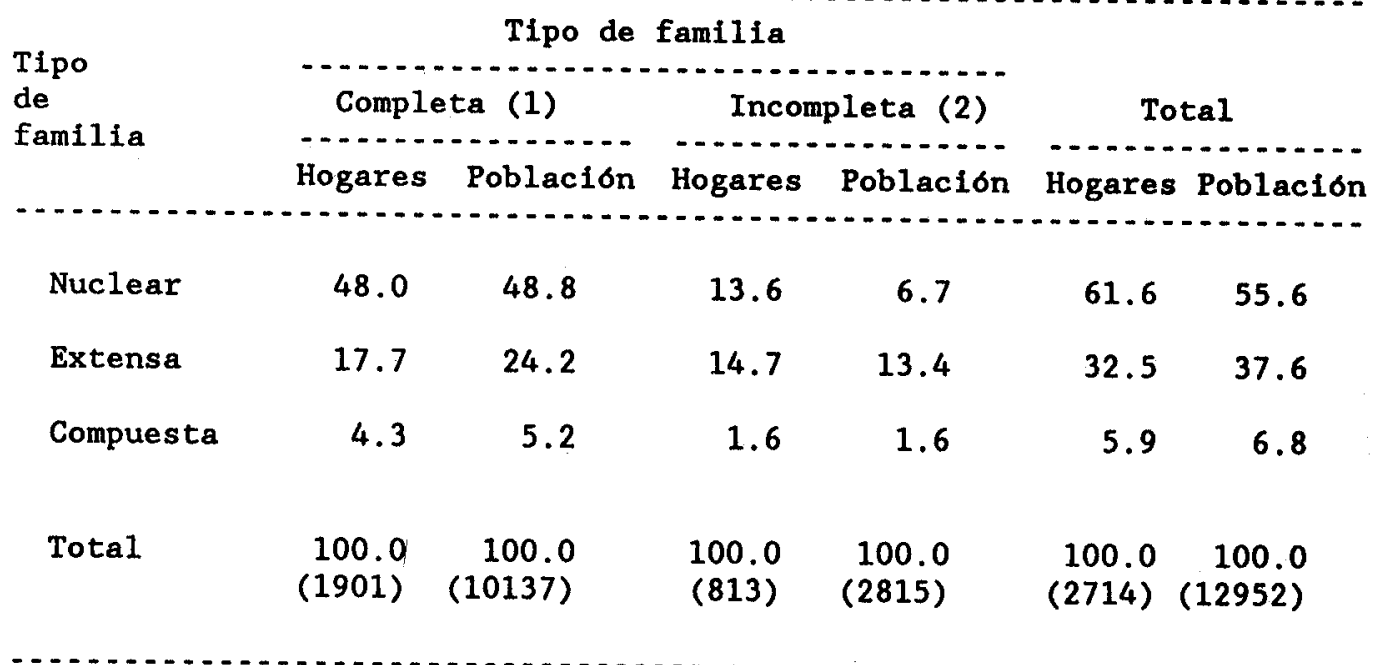

Fuente: Anexo 23.

(1): Presencia del cónyuge del jefe de hogar.

(2): Ausencia del cónyuge del jefe de hogar.

En el cuadro 10 se muestra también la distribución de la población por tipos de familia, observándose que ésta sigue el patrón observado en los hogares, aunque con una leve disminución de la frecuencia de la familia "nuclear".

Si se analiza la información relacionando el tipo de familia según su estructura y según la presencia o ausencia del o de la cónyuge del jefe de hogar, el mismo cuadro 10 indica que casi la mitad de los hogares y de la población corresponde a familias "nucleares completas". Es decir, de cada 10 hogares, 5 estarian constituidos por el jefe de hogar, el cónyuge y los hijos. Esta situación es relativamente similar a la encontrada en la totalidad de reducciones de la región, según el Censo Nacional de 1982, aun cuando en ese año el porcentaje bordeaba el 40 por ciento (Oyarce, Romaggi y Vidal, 1989). El grafico 7 muestra también el comportamiento para la población en ambos censos. 
REDUCCIONES INDIGENAS:

PROMEDIO DE PERSONAS POR HOGAR,

SEGUN TIPO DE FAMILIA. CENSOS DE 1982 Y 1988

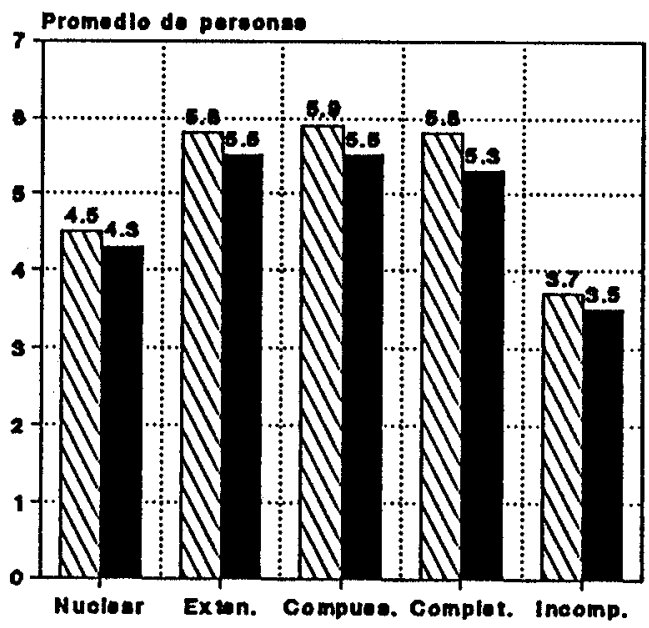

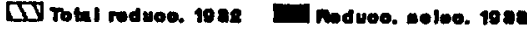

Fuente: Anexo 23 y Oyarce, Romaggl y Vidal (1989)

Grafloo 10

REDUCCIONES INDIGENAS:

PROMEDIO DE PERSONAS EN EI HOGAR POR TIPO DE FAMILIA, SEGUN FAMILIA COMPLETA $O$ INCOMPLETA. CENSOS DE 1982 Y 1988

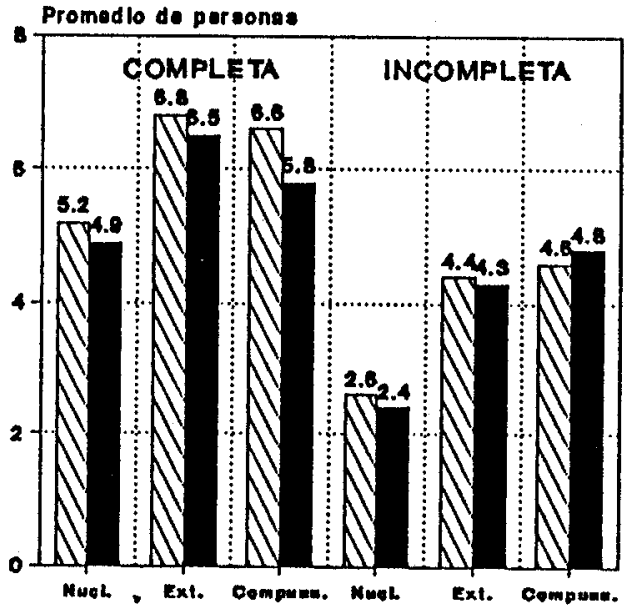

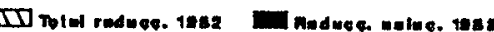

Fuente, Anexo 23 y Oyarce, Romagol y Vidal (1988) 
Dentro de cada tipo de familia, el gráfico 8 muestra que en las famillas "nucleares" y las "compuestas", cerca de las tres cuartas partes son "completas". En cambio, poco menos de la mitad de los hogares de las familias "extensas" corresponde a familias "incompletas", es decir el o la jefe de hogar está sin su cónyuge.

En sintesis, en la población de las reducciones indigenas seleccionadas estudiada en 1988 se observa que la familia "nuclear completa" es la más importante en términos relativos, teniendo una participación mayor que la detectada en 1982 para el total de reducciones de la IX Región. Sin embargo, debe advertirse que no se conoce la dinámica de este proceso al interior de estas reducciones desde 1982 a 1988, as 1 como hay que recordar que el Censo de 1988 incluye a algo menos del 10 por ciento de la población de las reducciones indígenas de la IX Región.

\subsubsection{Tamaño de las familias}

E1 tamaño de las familias es un aspecto que ya se mencionó al analizar el tamaño de los hogares y los datos mostraron que éstos tienen un tamaño bastante bajo para una población rural indigena. El promedio de personas en el hogar por tipos de familia arroja diferencias entre éstos, evidentemente, donde las familias "extensas completas" registran una cifra de 6.5 personas como el mayor valor (hay que recordar que en esta situación está casi una cuarta parte de la población). Llama la atención que, en total, las familias "extensas" y "compuestas" poseen hogares de igual tamaño promedio, esto es, 5.5 personas, a pesar que, como se verá más adelante, presentan una composición diferente. Los gráficos 9 y 10 muestran este comportamiento, asi como para el total de reducciones de la IX Región en 1982 .

Los hogares de las familias "completas" poseen un promedio de 5.3 personas, en tanto que en las familias "Incompletas" registran 3.5 personas.

La comparación entre los dos censos muestra que, en general, en todos los tipos de familia se presentan hogares con tamaños promedios más bajos en las reducciones seleccionadas en 1988, excepto en las familias "compuestas incompletas". E1 único tipo de familia que se asemeja al patrón tradicional, con respecto al número de personas, es la familia "extensa completa" (6.5 personas ). 
Gráfico 8

REDUCCIONES INDIGENAS SELECCIONADAS: DISTRIBUCION RELATIVA DE LOS HOGARES POR TIPO DE FAMILIA. CENSO DE 1988

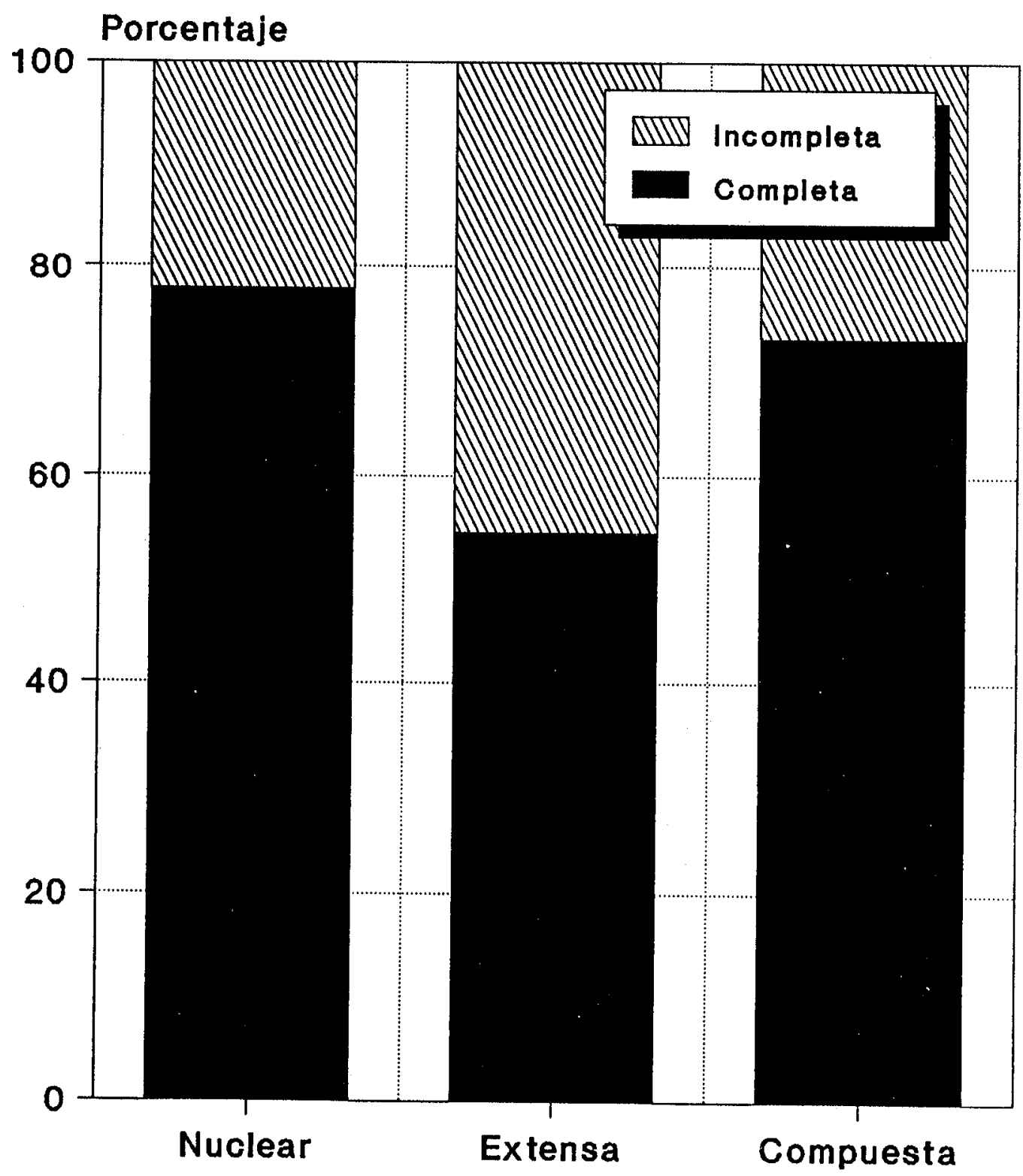

Fuente: Anexo 23 
Gráfico 7

REDUCCIONES INDIGENAS: DISTRIBUCION RELATIVA DE LA POBLACION POR TIPO DE FAMILIA.

CENSOS DE 1982 Y 1988

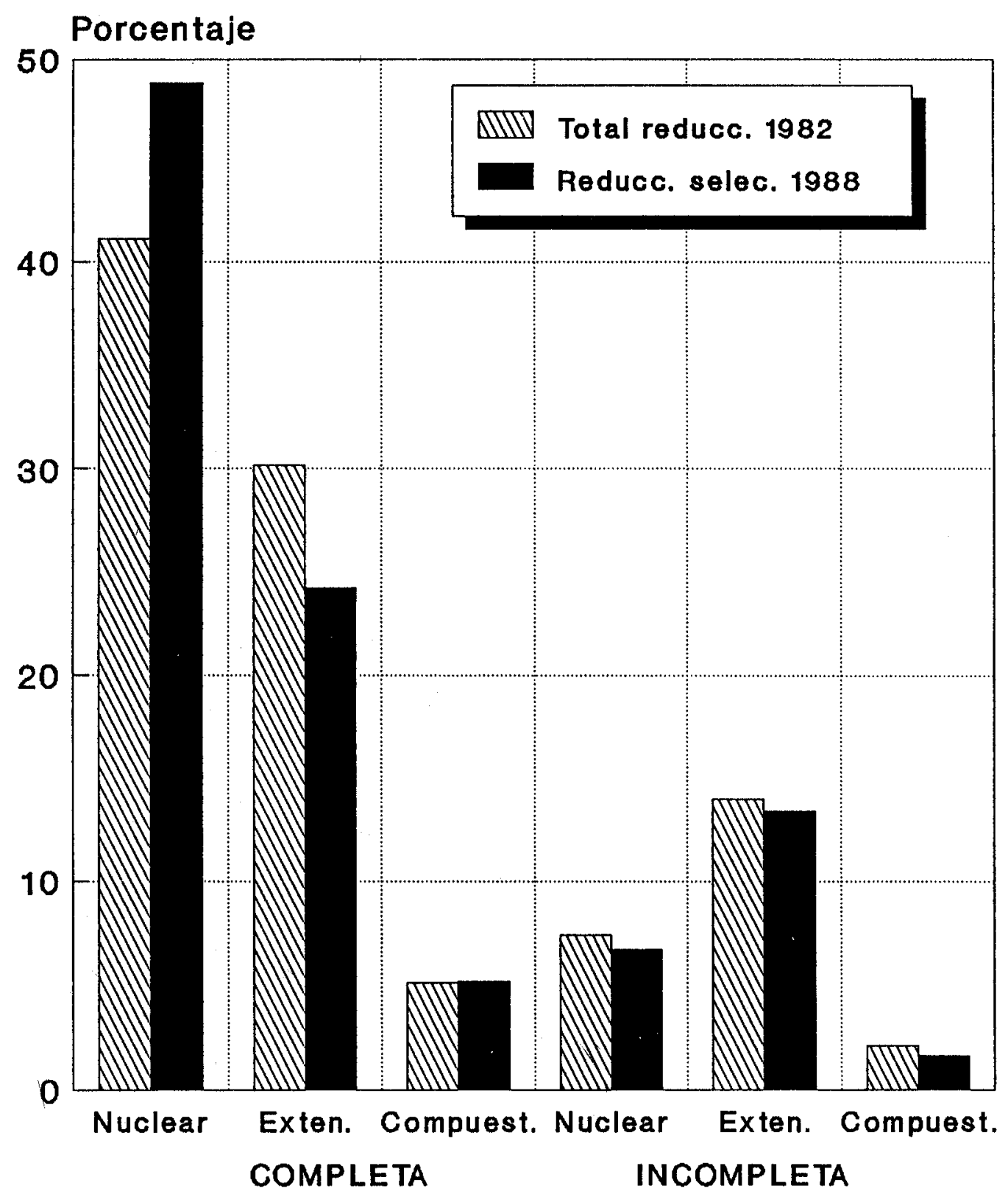

Fuente: Anexo 23 y Oyarce, Romaggi y Vidal (1989) 
E1 posible descenso en el número promedio de personas por familia, con relación al patrón tradicional de no limitar el número de hijos, sumado al hecho de que la familia "nuclear" estaria aumentando su preponderancia, permite afirmar que en las reducciones indigenas estudiadas en el Censo de 1988 se muestran en forma más acentuada los cambios detectados en el Censo Nacional de 1982 para el total de las reducciones indigenas de la región. Si bien se desconoce exactamente cómo ha sido el proceso desde 1982 hasta la fecha del Censo de 1988 en las reducciones seleccionadas, es importante destacar que la población indigena estudiada en el año 1982 presentaba un bajo número medio de personas en el hogar, asi como una fecundidad muy inferior en comparación con otros grupos indigenas de América Latina $\mathrm{y}$ con los mapuches de Argentina alrededor de esa fecha, cuyo nivel de fecundidad era de más de 7 hijos por mujer (Somoza, 1985)..13 No obstante 10 anterior, en términos generales, el promedio de personas por familia (4.8) es idéntico al encontrado en 1968 en un estudio sobre familias del valle central en Chol Chol, Provincia de Cautin (Stuchlik, 1974).

Además de la fecundidad en descenso, existen otros factores que podrian estar incidiendo en el cambio del patrón de familia que existió en la sociedad mapuche hasta antes del establecimiento en reducciones. Sin embargo, un probable factor desencadenante pareciera ser la creciente escasez del recurso suelo, producida por la radicación en reducciones, con el resultado de una fuerte presión demográfica sobre la tierra que habria privilegiado la emigración femenina (realidad conocida). También es posible que la deteriorada situación económica que caracteriza a los mapuches haya provocado una tendencia a dividir a la familia "extensa", por cambios en la pauta de residencia matrimonial (1a nueva pareja ya no se instala en la casa paterna, sino que la patrilocalidad se mantiene a nivel de la reducción), lo que además explicaria que en las viviendas más tradicionales el número de personas sea relativamente menor.

Los cambios anotados revelarian que se han estado produciendo algunas importantes modificaciones en el sistema social mapuche, en el cual la familia se asemejaría cada vez más al patrón urbano de familia "nuclear" relativamente pequeña. En todo caso, no debe olvidarse que la información que se maneja está es de cerca de 4 hijos (ver Capitulo Caracteristicas Demográficas). 
recogida en cuatro distritos que están a menos de 30 kilómetros de la capital de la IX Región y donde la sociedad nacional ha introducido más instituciones que en otras áreas, tales como escuelas, postas y misiones, que muy probablemente, han permitido una fuerte irradiación de las pautas y modelos externos a la sociedad mapuche.

\subsection{Estructura y composición de la familia}

\subsubsection{Sexo}

Con relación a la composición por sexo de las familias, de acuerdo al cuadro 11, es posible advertir que los hombres predominan en casi todos los tipos de familia, especialmente entre las familias "nucleares incompletas" (58 por ciento). La única excepción se presenta en las familias "extensas incompletas" (donde constituyen el 49 por ciento).

Las relaciones de masculinidad indican que, en general, las famillas "nucleares" poseen los indices más altos, seguidas en orden decreciente por las familias "compuestas". En las familias "extensas", por su lado, se observa una similar participación en el número de hombres y mujeres.

Los valores extremos de las relaciones de masculinidad corresponden a las familias "nucleares incompletas", donde se registran 138 hombres por cada 100 mujeres (valor más elevado), en tanto que entre las familias "extensas incompletas" existen 96 hombres por cada 100 mujeres (valor más bajo; cuadro 11).

Estos resultados presentan un comportamiento muy parecido al encontrado en la totalidad de las reducciones indigenas de la IX Región en 1982, ya que, como se aprecia en el cuadro 11 y gráfico 11, también en éstas el indice de masculinidad más alto correspondia a las familias "nucleares incompletas" y el más bajo a las familias "extensas incompletas"."

La presencia de los indices de masculinidad más altos en las familias "nucleares incompletas" y los más bajos en las familias "extensas incompletas" parecerfa indicar que se está frente a un patrón de migración que serfa necesario estudiar con mayor profundidad, relacionando estas familias con su estructura por sexo y edad, relaciones de parentesco con el jefe cie hogar y condición de actividad de los miembros. 0tros elementos fundamentales que seria necesario conocer es el tamano del predio y las reglas de herencia de él. 
El hecho de que en las familias "nucleares" se presente la mayor superioridad relativa de hombres sobre mujeres, estaria dando cuenta que es en estas familias donde se produciria fundamentalmente el proceso emigratorio femenino. Dicho de otro modo más general, el carácter de familia "nuclear" podría estar asociado, entre otros factores, con la marcada emigración que pareciera afectar a algunos grupos familiares.

La presencia y mantención de los altos indices de masculinidad, como apoyo a la idea de una estabilización de la emigración, ya ha sido planteada en otros estudios (Bengoa y Valenzuela, 1984) y también ha sido descrita en el Capitulo Caracteristicas Demográficas.

CUADRO 11

REDUCCIONES INDIGENAS: DISTRIBUCION RELATIVA DE LA POBLACION POR TIPO DE FAMILIA, SEGUN SEXO E INDICES DE MASCULINIDAD. CENSOS DE 1982 Y 1988

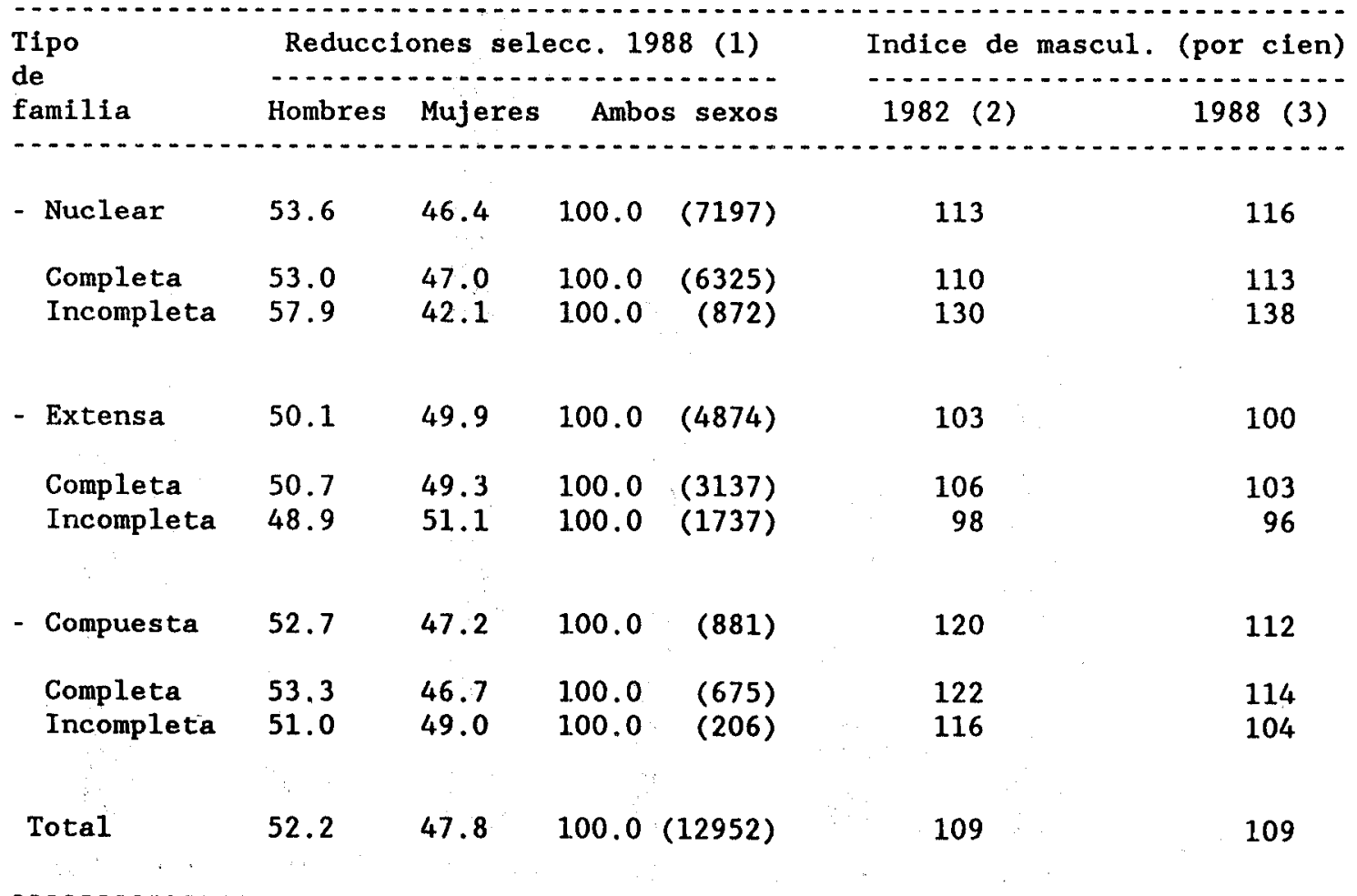

Fuente: (1) y (3) Anexo 23.

(2) Oyarce, Romaggi y Vidal (1989). La información corresponde al total de reducciones de la IX Región. 


\section{Grafico 11}

REDUCCIONES INDIGENAS:

INDICES DE MASCULINIDAD POR TIPO DE FAMILIA. CENSOS DE 1982 Y 1988
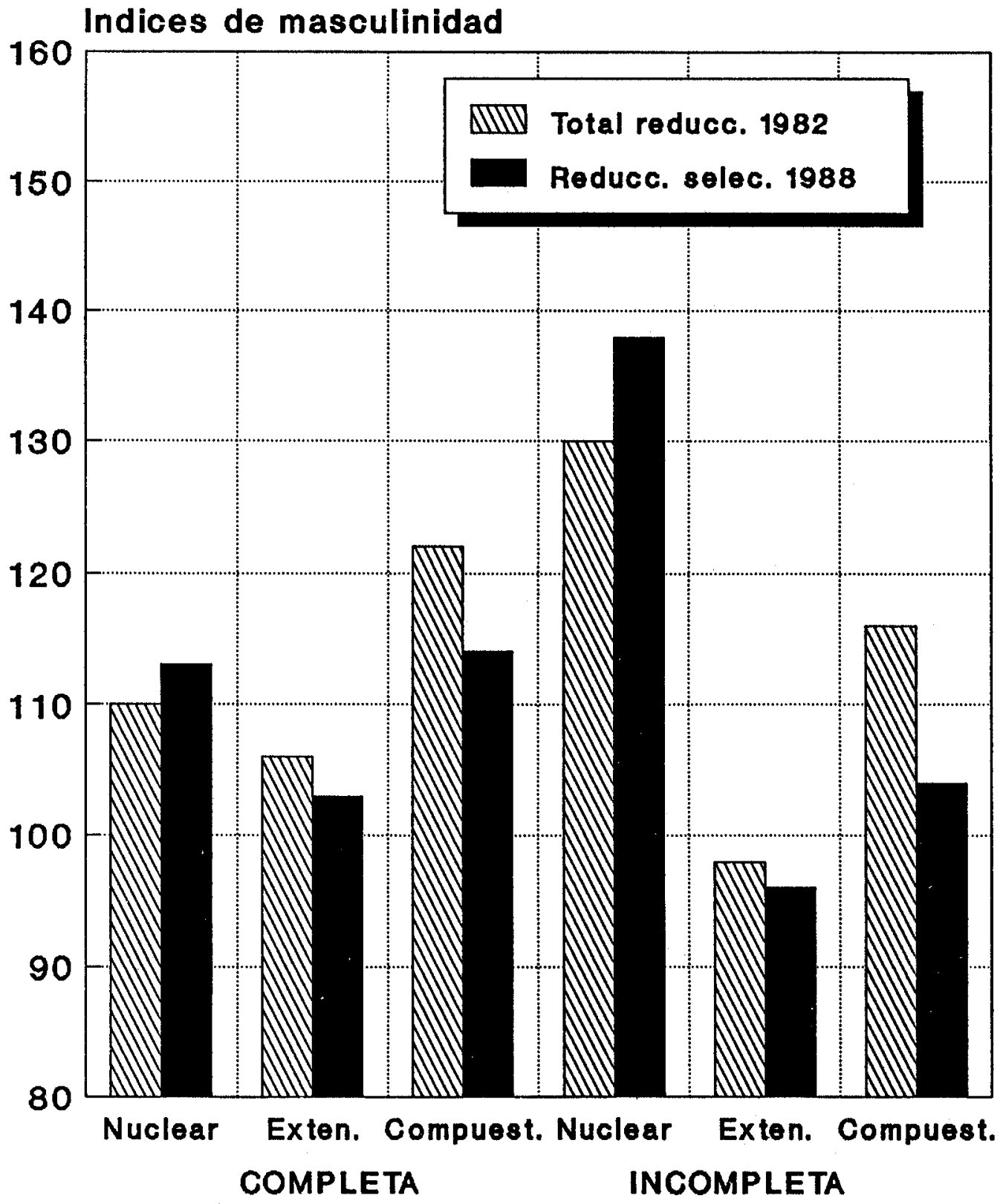

Fuente: Cuadro 11 


\subsubsection{Edad}

E1 promedio de edad según tipo de familia, como se observa en el gráfico 12, muestra que las familias "nucleares" son las más jóvenes (27 años), situación que es similar a la encontrada en el Censo Nacional de 1982 para la totalidad de reducciones indigenas de la IX Región (25 años).

Por otra parte, llama la atención el envejecimiento que afectaría a las familias "compuestas", cuyo promedio de edad supera $10 s 38$ años en las reducciones seleccionadas, después de haber alcanzado $10 s 31$ años en 1982 en el total de reducciones de la región.

Con relación a la estructura por grupos de edad, en el cuadro 12 y gráfico 13 se observa que en las familias "extensas" de las reducciones estudiadas a partir del Censo de 1988, existe la mayor presencia relativa de las personas de 60 años y más de edad, donde alcanzan a un 16 por ciento. Por otro lado, en las familias "nucleares" se presenta la mayor importancia relativa de las personas menores de 15 años de edad, quienes 1legan a abarcar un 37 por ciento.

Finalmente, una observación importante es que, como se aprecia en el cuadro 12, existen fuertes diferencias entre la representación de hombres y mujeres en las edades 15-29 años. Alli, el predominio masculino se presenta en todos los tipos de familia. 


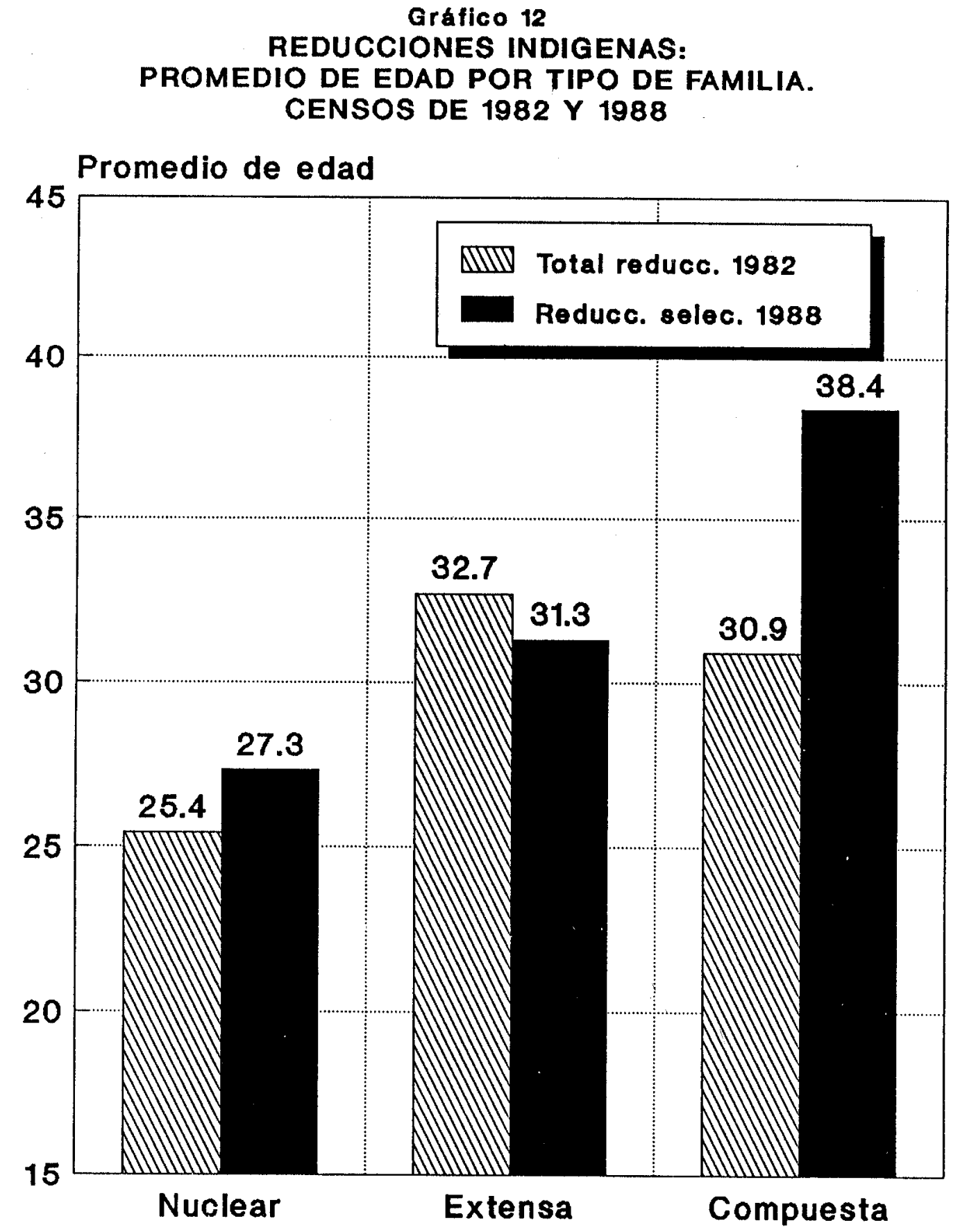

Fuente: Anexo 24 y Oyarce, Romaggi y Vidal (1989) 


\section{CUADRO 12}

REDUCCIONES INDIGENAS SELECCIONADAS: DISTRIBUCION RELATIVA DE LA POBLACION POR SEXO Y TIPO DE FAMILIA, SEGUN GRUPOS DE EDAD.

\section{CENSO DE 1988}

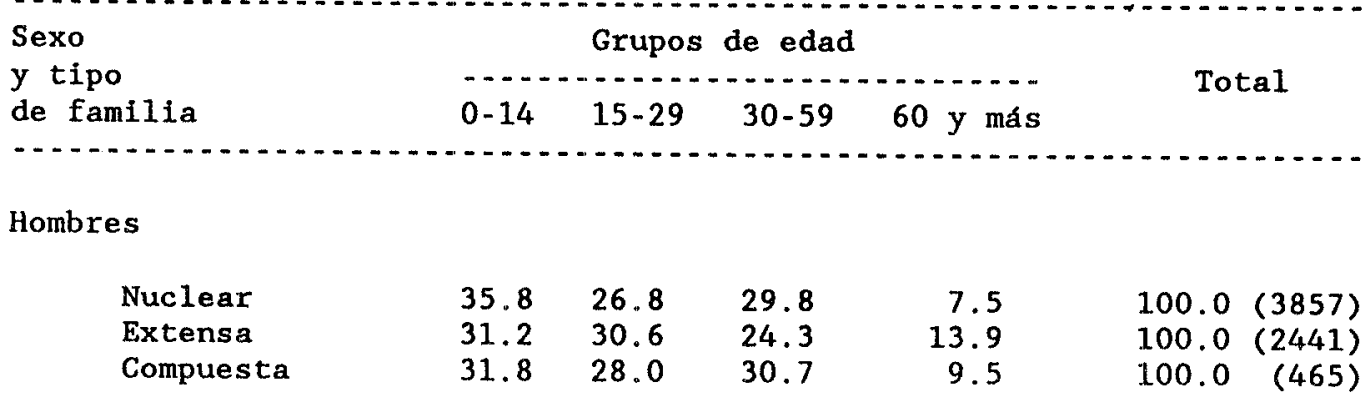

Mujeres

$\begin{array}{lrrrrrr}\text { Nuclear } & 38.1 & 23.9 & 30.6 & 7.3 & 100.0(3340) \\ \text { Extensa } & 30.3 & 25.7 & 26.0 & 18.0 & 100.0(2433) \\ \text { Compuesta } & 32.9 & 21.9 & 32.0 & 13.2 & 100.0 & (416)\end{array}$

Ambos sexos

$\begin{array}{lrrrrr}\text { Nuclear } & 36.9 & 25.5 & 30.2 & 7.4 & 100.0(7197) \\ \text { Extensa } & 30.7 & 28.1 & 25.2 & 16.0 & 100.0(4874) \\ \text { Compuesta } & 32.4 & 25.1 & 31.3 & 11.2 & 100.0(881) \\ & & & & & (12952)\end{array}$

Fuente: Anexo 24. 
Grafico 13

REDUCCIONES INDIGENAS SELECCIONADAS: DISTRIBUCION RELATIVA DE LA POBLACION POR GRUPOS DE EDAD, SEGUN TIPO DE FAMILIA. CENSO DE 1988

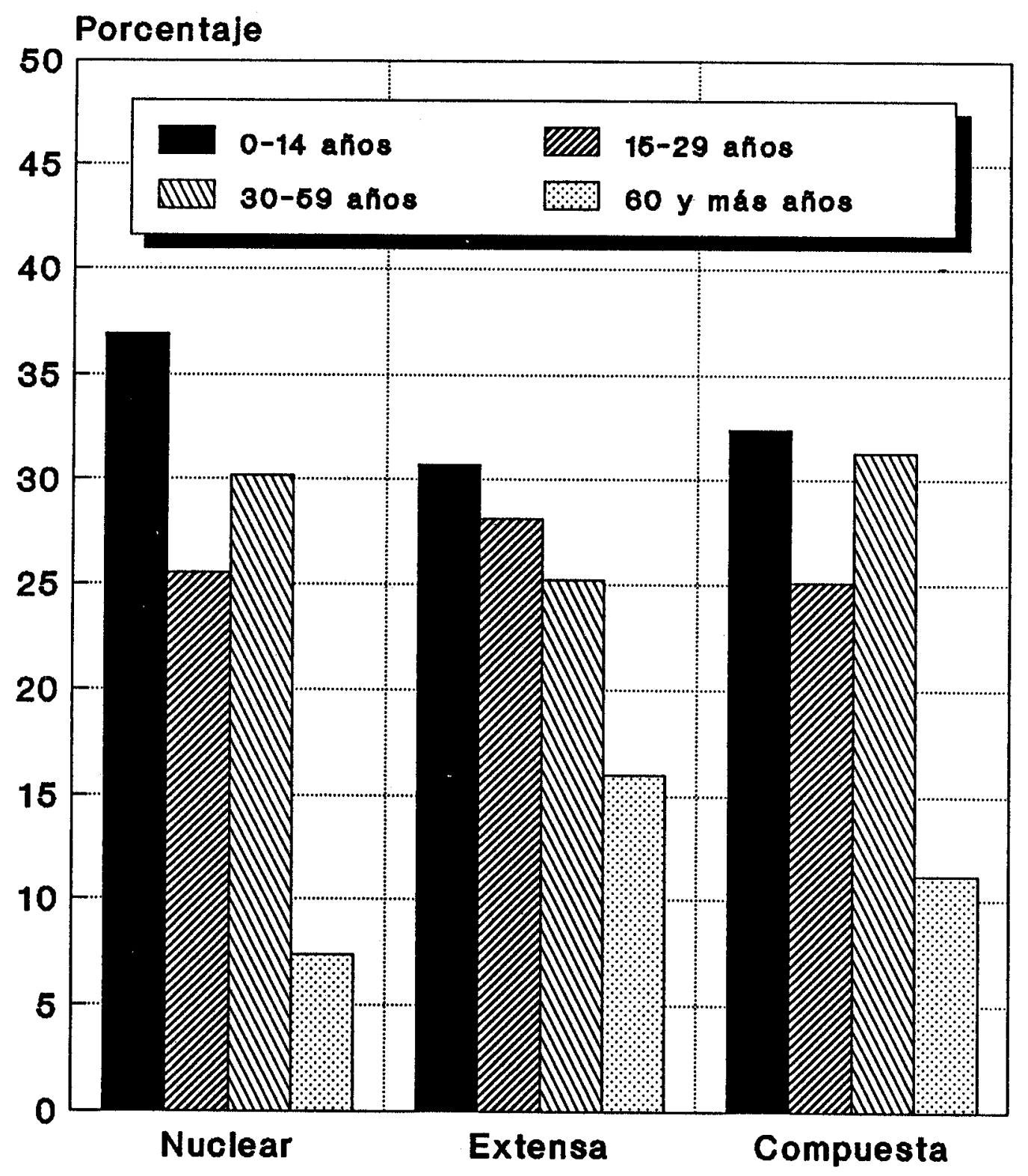

Fuente: Cuadro 12 


\subsubsection{Composición de la familia}

La composición de las familias es distinta según el tipo que se considere. Si bien no es posible reconstituir familias de acuerdo a su composición en forma exacta, se puede realizar el ejercicio de estimar el peso relativo de los miembros en cada tipo de familia, con el fin de construir modelos o tipos ideales de familias. ${ }^{15}$

De acuerdo con los datos del cuadro 13, podrla decirse que en las reducciones seleccionadas en 1988, en una familia "nuclear" de 4.3 miembros, 2.5 de ellos serian hijos. Con relación al total de reducciones de la IX Región, según el Censo Nacional de 1982, se aprecia un descenso en el número teórico de hijos en este tipo de familia, pasando desde un valor de 2.8 a 2.5 hijos.

Estos modelos de composición de las familias permiten plantear como hipótesis la creciente variabilidad y complejidad de la estructura familiar mapuche contemporánea (Quesne1, 1989). Si se piensa que se trata de un grupo indigena, con prácticas tradicionales de poliginia sororal y levirato, en el que probablemente no existian jefes de hogar y personas sin cónyuge, los modelos muestran un drástico y profundo cambio que debe relacionarse fundamentalmente con la migración.

Al analizar la información se observa que en ninguno de los tipos de familia está presente en su totalidad el cónyuge del jefe de hogar, ni aun en las familias "nucleares". También es llamativo que la categoria "otros parientes" tiene tres veces más peso que el cónyuge en las familias "extensas" y el mismo peso en la familias "compuestas". Lo anterior debe entenderse como un proceso de variabilidad y complejidad de la composición y estructura familiar mapuche, fenomeno que se relaciona directamente con una fuerte emigración (fundamentalmente femenina); una nupcialidad bastante tardia para una sociedad indigena rural (en el total de reducciones en 1982 la edad promedio de la primera unión fue de 28.7 años para los hombres y 24.2 para las mujeres; Oyarce, Romaggi y Vidal, 1989); una inestabilidad en el mercado matrimonial (el 55 por ciento de los hombres y el 34 por ciento de las mujeres menores de 30 años de edad son

Para lograr esto, se multiplicó el promedio de personas en cada tipo de familia por la distribución relativa de la población según grado de parentesco con el jefe de hogar en ese mismo tipo de familia. Similar procedimiento se planteo en el analisis de la información del Censo Nacional de 1982 para las reducciones de la IX Región (Oyarce, Romaggi y Vidal, 1989). 
solteros) y, finalmente, el fenomeno se asociarla con una baja posibilidad de contraer matrimonio al interior de estas reducciones.

Con relación a este último punto, Bengoa y Valenzuela (1984) muestran que de cinco familias sólo una tiene la posibilidad de intercambiar mujeres con otra reducción (el resto de mujeres emigra). Esta dificultad para reproducir las condiciones de vida de la familia mapuche representa un cambio dramático que permite vislumbrar no sólo la probabilidad de un fuerte proceso de desaparición cultural, sino que, de mantenerse las tendencias de alta emigración y descenso en la fecundidad, permite admitir la factibilidad de la desaparición biológica, hecho que por lo demás, ya ha sido planteado (Vidal, 1989).

CUADRO 1.3

REDUCCIONES INDIGENAS: COMPOSICION MODELO POR TIPO DE FAMILIA, SEGUN NUMERO DE MIEMBROS. CENSOS DE 1982 Y 1988 *

Tipo
de
familia

Total reduc.

IX Región 1982

(1)

$\begin{array}{llllrrr}\text { Nuclear } & 1.0 & 0.7 & 2.8 & - & - & 4.5 \\ \text { Extensa } & 1.0 & 0.6 & 2.2 & 2.0 & - & 5.8 \\ \text { Compuesta } & 1.0 & 0.6 & 1.8 & 1.1 & 1.4 & 5.9\end{array}$

Reducciones

selec. 1988

(2)

$\begin{array}{llllrrr}\text { Nuclear } & 1.0 & 0.8 & 2.5 & - & - & 4.3 \\ \text { Extensa } & 1.0 & 0.5 & 2.1 & 1.9 & - & 5.5 \\ \text { Compuesta } & 1.0 & 0.7 & 1.7 & 0.7 & 1.4 & 5.5\end{array}$

Fuente: (1) Oyarce, Romaggi y Vidal (1989).

(2) Anexos 23 y 25.

*: Composición estimada a partir del tamaño promedio de cada tipo de familia multiplicado por el porcentaje de miembros en cada tipo de familia respectiva. 
Finalmente, en los datos que se han presentado, las famillas "extensas" y las "compuestas", si bien presentan un tamaño similar, difleren en los criterios de inclusión de sus miembros y es llamativo el hecho de que en estas últimas la categoria "no parientes" tiene más peso que la de "otros parientes". Un factor que puede estar relacionado con lo anterior es que no es infrecuente que uno de los cónyuges aporte hijos de otro progenitor; en el caso de la mujer y por presentar un tipo de residencia patrilocal, estos hijos quedan consignados como "no parientes".

\subsection{Caracteristicas del jefe de hogar}

La condición de jefe de hogar es distinta según el sexo, el tipo de familia, el estado civil y la edad. El jefe de hogar se consideró aquel miembro reconocido como tal y, en caso de duda, quien tiene la responsabilidad económica del hogar o, en última instancia, la persona de mayor edad (UFRo et al., 1989).

Con relación a la variable sexo, lo primero que destaca es que un 84 por ciento de los jefes de hogar son varones, valor muy similar al encontrado en el Censo Nacional de 1982 para todas las reducciones de la región, en que un 83 por ciento de los hogares tenia como jefe a un hombre (Oyarce, Romaggi y Vidal, 1989).

Como se aprecia en el cuadro 14, según el tipo de familia, los hombres muestran un fuerte predominio en la función de jefe de hogar en las familias "completas". La mujer, en cambio, asume esta función en forma mayoritaria en las familias "incompletas", donde alcanza un 53 por ciento. Esto vendria a demostrar que la mujer asume las funciones de jefa de hogar fundamentalmente cuando está sola, sin su cónyuge o pareja. 
CUADRO 14

REDUCCIONES INDIGENAS SELECCIONADAS: DISTRIBUCION RELATIVA DE LOS JEFES DE HOGAR POR TIPO DE FAMILIA, SEGUN SEXO. CENSO DE 1988

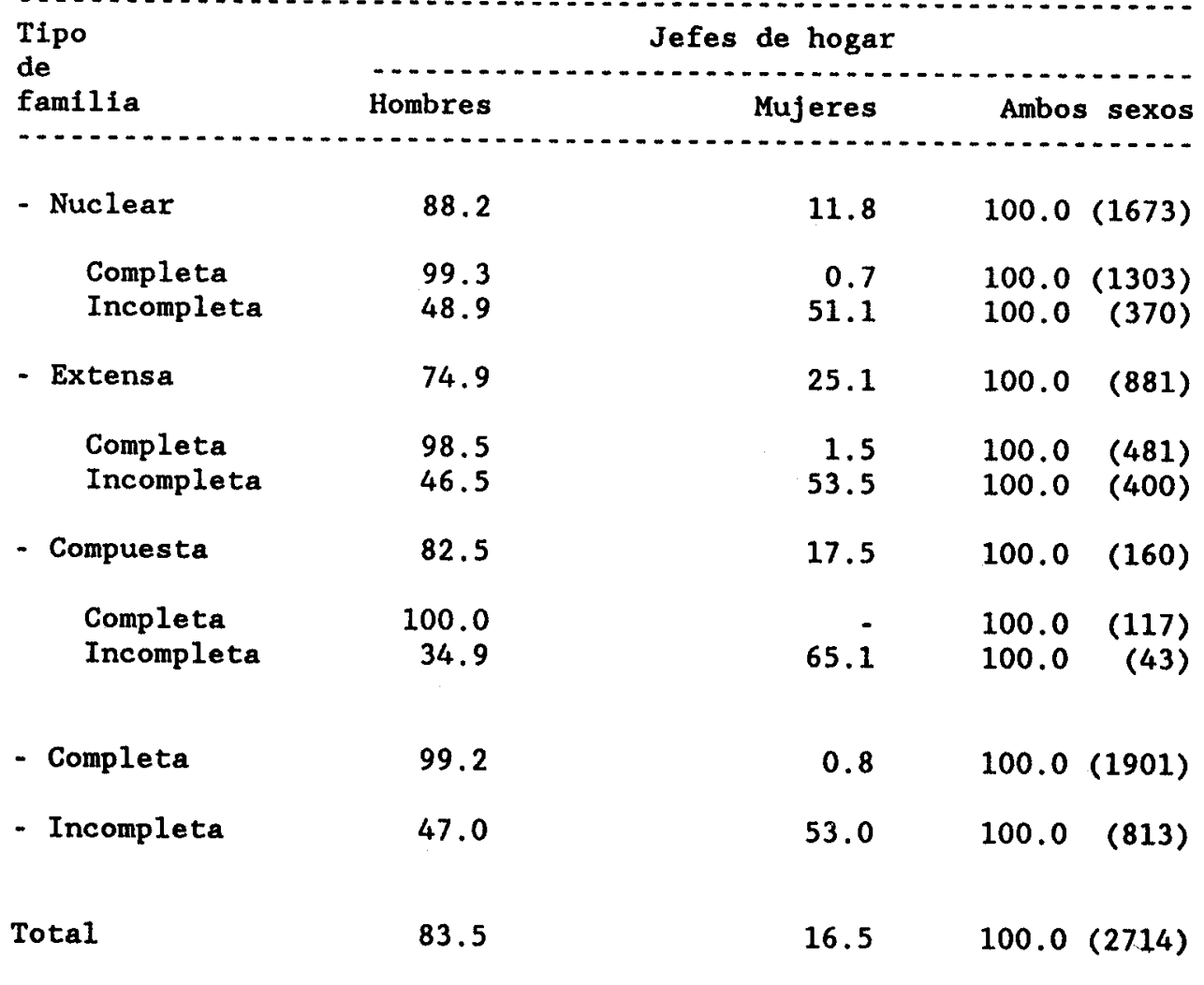

Fuente: Anexo 26. 
La tendencia descrita es simflar a la encontrada en el Censo Nacional de 1982 para todas las reducciones de la IX Región (Oyarce, Romaggi y Vidal, 1989) y pareciera confirmar que el hecho de que la mujer asuma la función de jefa de hogar estarla asociado principalmente con la muerte del cónyuge $y$, en menor medida, con la condición de soltera y de separada. Esta situación se evidencia en el cuadro 15, donde se representa la distribución relativa de los jefes de hogar por estado civil.

CUADRO 15

REDUCCIONES INDIGENAS SELECCIONADAS: DISTRIBUCION RELATIVA DE LOS JEFES DE HOGAR POR ESTADO CIVIL, SEGUN SEXO.

CENSO DE 1988

\begin{tabular}{|c|c|c|c|}
\hline \multirow[t]{2}{*}{$\begin{array}{l}\text { Es tado } \\
\text { civil }\end{array}$} & \multicolumn{3}{|c|}{ Jefes de hogar } \\
\hline & Hombres & Mujeres & A. sexos \\
\hline Conviviente & 7.7 & 2.9 & 6.9 \\
\hline Casado por civil & 75.9 & 4.0 & 64.0 \\
\hline Casado mapuche & 0.1 & 0.2 & 0.1 \\
\hline Viudo & 7.7 & 59.7 & 16.3 \\
\hline Separado & 1.2 & 7.7 & 2.2 \\
\hline Soltero & 7.4 & 25.5 & 10. \\
\hline Total & $\begin{array}{r}100.0 \\
(2267)\end{array}$ & $\begin{array}{l}100.0 \\
(447)\end{array}$ & $\begin{array}{r}100.0 \\
(2714)\end{array}$ \\
\hline
\end{tabular}

Fuente: Anexo 27. 
En efecto, la mayor parte de las mujeres jefas de hogar son viudas (60 por ciento) y solteras (26 por ciento), mientras que el 76 por ciento de 10 s hombres jefes de hogar son casados. Algo similar se encontró en todas las reducciones de la región, según el Censo Nacional de 1982, salvo la mayor participación relativa de las mujeres casadas (Oyarce, Romaggi y Vidal, 1989)."16

Al relacionar la información sobre la edad del jefe de hogar (cuadro 16), llama la atención que la mayor importancia relativa la tengan los jefes de hogar mayores de 64 años ( 22 por ciento) y que casi un tercio sean personas de 60 años y más de edad, al igual que sucedia en todas las reducciones de la IX Región en 1982 (Oyarce, Romaggi y Vidal, 1989). Este es un hecho de importancia en la planificación de cualquier programa de salud que se desee implementar en esta población, ya que es muy probable que sean estas personas quienes adopten o influyan en las decisiones y conductas terapeúticas de los demás miembros de la familia.

En todo caso, al considerar los tipos de familia, se observa que las familias "nucleares" presentan casi la mitad de los jefes de hogar entre los 30-49 años de edad.

Al analizar la información sobre jefes de hogar según estado civil hay que señalar que, en general, la confiabilidad de la información es dudosa. Si bien en el Censo de 1988 se preguntó por el "matrimonio tradicional mapuche", las respuestas fueron minimas, debido a que cuando se contestaron las dos formas de matrimonio ("mapuche" y "civil"), se registró esta úlima. Por otra parte, la categoria "conviviente" puede estar. sobreenumerada, debido a que algunos entrevistados pudieron haber respondido esta forma de unión en circunstancias que son casados "a 10 mapuche", en razón de su percepción sobre lo que la sociedad nacional considera como uniones consensuales. Al respecto, es probable que buena parte de los "matrimonios tradicionales" estén subsumidos en los matrimonios legales, porque la mayoria de las parejas se casaria primero "a lo mapuche" y después, cuando nacen los hijos, se casaria en el Registro Civil (Oyarce, 1989), as 1 como se conoce que el "matrimonio mapuche" es bastante duradero y estable. Finalmente, independiente de estas consideraciones, Llama la atención que esta población indigena, con sus propias formas y estilos de contraer matrimonio, contraiga en un porcentaje tan alto, matrimonio por la ley civil chilena, en un comportamiento que ya ha sido descrito y mencionado en otros trabajos y que parece corresponder a una actitud pragmática frente a la sociedad nacional (Oyarce, 1989). 
CUADRO 16

REDUCCIONES INDIGENAS SELECCIONADAS: DISTRIBUCION RELATIVA

DE LOS JEFES DE HOGAR POR TIPO DE FAMILIA, SEGUN GRUPOS DE EDAD.

CENSO DE 1988

$\begin{array}{lccccccccc}\begin{array}{l}\text { Tipo } \\ \text { de } \\ \text { familia }\end{array} & 15-19 & 20-29 & 30-39 & 40.49 & 50-59 & 60-64 & 65 & \text { y más } & \text { Total } \\ \text { Nuclear } & 0.1 & 10.4 & 23.6 & 23.3 & 19.6 & 7.0 & 15.9 & 100.0 & (1673) \\ \text { Extensa } & 0.3 & 4.8 & 9.7 & 14.9 & 22.4 & 14.8 & 33.3 & 100.0 & (881) \\ \text { Compuesta } & 0.6 & 5.6 & 23.8 & 21.9 & 15.0 & 7.5 & 25.6 & 100.0 & (160) \\ & & & & & & & & & \\ \text { Total } & 0.2 & 8.3 & 19.1 & 20.5 & 20.2 & 9.5 & 22.1 & 100.0 & (2714)\end{array}$

Fuente: Anexo 28.

\section{Hogares y lengua hablada}

Se considera importante analizar una variable de carácter cultural, a la luz de los resultados que se han ido presentando y que indicarian la existencia de un proceso creciente de aculturación entre la población de las reducciones indigenas seleccionadas. Una de las variables especificamente culturales sobre la cual se recogió información en el Censo de 1988 fue la lengua hablada. Se preguntó cuál era la lengua usada más frecuentemente en el hogar, partiendo del supuesto que es en éste donde se realiza el proceso de transmisión de la cultura - socialización y donde se toman, además, las decisiones más importantes referentes tanto a la salud como al resto de las actividades o áreas de la vida. La mantención de la lengua materna, en este caso, el "mapudungun" (también llamado "mapuche"), reflejaria también la mantención de la cosmovisión indigena $y$, como postulan algunos lingüistas y estudiosos, el hablar en mapuche determinaria en gran medida e1 "ser mapuche". 
La lengua vernácula de los mapuches significa literalmente "habla de la tierra" o "habla del pais". Se considera que el uso del mapudungun es la marca más objetiva de su identidad sociocultural (Salas, 1984). Esta lengua es hablada fundamentalmente en los contextos socioculturales mapuches, siendo el castellano la lengua del contacto con el resto de la socledad global.

En general, se acepta que los mapuches son bilingües, aunque el castellano que hablan está intervenido de tal manera por la lengua materna, que algunos lingüistas postulan que, más que un sociolecto, el castellano mapuchizado que hablan constituiría una tercera lengua.

E1 estudio cientifico del mapudungun es relativamente reciente y en la actualidad se sabe que presenta al menos tres dialectos. Su estructura-central y más compleja es el verbo; su sistema fonológico consta de seis vocales y dieciocho consonantes. Es una lengua de tradición oral, si bien hace alrededor de una década mapuches y lingüistas han desarrollado serios intentos por lograr un alfabeto adecuado (Sociedad Chilena de Lingüistica, 1989). ${ }^{17}$

Para el mapuche hablar en castellano es más que una opción, una necesidad. Sin embargo, el proceso en que aprende el idfoma hispano (fundamentalmente en la escuela) lo lleva a la pérdida paulatina de su lengua y trae tamblén como resultado el perder sus formas de vida tradicional y el reemplazarlas por las occidentales (Durán y Ramos, 1988).

Según el cuadro 17, aproximadamente en la mitad de los hogares se habla "mapudungun y castellano" con más frecuencia ("bilingües"), E1 "castellano" se habla más frecuentemente en el 41 por ciento de los hogares y el "mapudungun" sólo en el 10 por clento. Cabe señalar que se desconoce el número de hablantes monolingües, ya que se pregunta por la lengua que se habla en el hogax. Al respecto, es probable que en los hogares donde se usa frecuentemente el "mapudungun", se emplee el "castellano" en otras esferas, como sucederia en instanclas de carácter comercial y laboral. Relacionado con 10 anterior, es interesante destacar que en un mismo hogar y, dado el grado de transición hacia la cultura occidental, es posible que las personas de 60 años y más de edad hablen más frecuentemente el "mapudungun", que los adultos jóvenes sean "bilingües" y que los menores de 15 años de edad hablen con más frecuencia el innovación curricular o biculturalmente orientados (Fundación Instituto Indigena, 1989). 
"castellano". Este es un importante aspecto que habria que profundizar y que conviene tener presente en el momento de derivar conclusiones a partir de los resultados.

CUADRO 17

REDUCCIONES INDIGENAS SELECCIONADAS: DISTRIBUCION RELATIVA DE LOS HOGARES POR LENGUA HABLADA MAS FRECUENTEMENTE, SEGUN TIPO DE VIVIENDA.

CENSO DE 1988

\begin{tabular}{|c|c|c|c|c|c|c|}
\hline $\begin{array}{l}\text { Lengua hablada } \\
\text { con más frecuencia } \\
\text { en el hogar }\end{array}$ & Ruca & $\begin{array}{r}\text { Tip } \\
\text { Ruca-casa }\end{array}$ & $\begin{array}{l}\text { de vivienda } \\
\text { Ruca-mejora }\end{array}$ & Casa & Mejora & Total \\
\hline apuche & 11.7 & 10.6 & 20.5 & 6.9 & 9.3 & 10.1 \\
\hline $\begin{array}{l}\text { Mapuche y } \\
\text { castellano }\end{array}$ & 59.4 & 60.4 & 56.4 & 42.8 & 45.9 & 48.7 \\
\hline Castellano & 28.9 & 29.0 & 23.1 & 50.3 & 44.8 & 41.2 \\
\hline otal & $\begin{array}{l}100.0 \\
(197)\end{array}$ & $\begin{array}{l}100.0 \\
(341)\end{array}$ & $\begin{array}{l}100.0 \\
(337)\end{array}$ & $\begin{array}{r}100.0 \\
(1085)\end{array}$ & $\begin{array}{l}100.0 \\
(754)\end{array}$ & $\begin{array}{l}100.0 \\
(2714)\end{array}$ \\
\hline
\end{tabular}

Fuente: Anexo 29.

E1 cuadro anterior muestra que al agrupar las categorfas de hablantes de "mapuche y castellano" y la de hablantes de "mapuche", en casi un 60 por ciento de los hogares se habla, en mayor o menor medida, la lengua materna. Este cuadro indica también que esta situación se presenta en forma notoria en las viviendas que cuentan al menos con una vivienda tradicional, lo que expresarla una asociación entre la mantención del uso de la lengua materna y el tipo de vivienda tradicional. Sin embargo, una asociación como la descrita es más bien válida para la lengua hablada y el tipo de vivienda en general, puesto que si se considera la situación opuesta, se descubre que en un 90 por ciento de los hogares se habla, en mayor o menor medida, el "castellano", lo que es más marcado entre los hogares de las "casas" y de las "mejoras", que son viviendas no tradicionales. 
Según distrito, la situación es bastante homogénea y se mantiene la tendencia central, aunque s6lo en Labranza la categorfa de los hogares que hablan "castellano" con mayor frecuencia es relativamente superior (anexos 30, 31, 32 y 33).

Otra de las observaciones importantes de establecer es la que guarda relación con el tamaño que tienen los hogares según la lengua que se habla con más frecuencia en ellos. El cuadro 18 muestra que aquellos hogares donde se mantiene el uso frecuente del "mapudungun" son los más pequeños (4 personas en promedio). Al respecto, no debe olvidarse que estos hogares solo constituyen el 10 por ciento del total y representan al 9 por ciento de la población.

CUADRO 18

REDUCCIONES INDIGENAS SELECCIONADAS: DISTRIBUCION DE HOGARES Y POBLACION $Y$ TAMAÑO DE LOS HOGARES POR LENGUA HABLADA MAS FRECUENTEMENTE. CENSO DE 1988

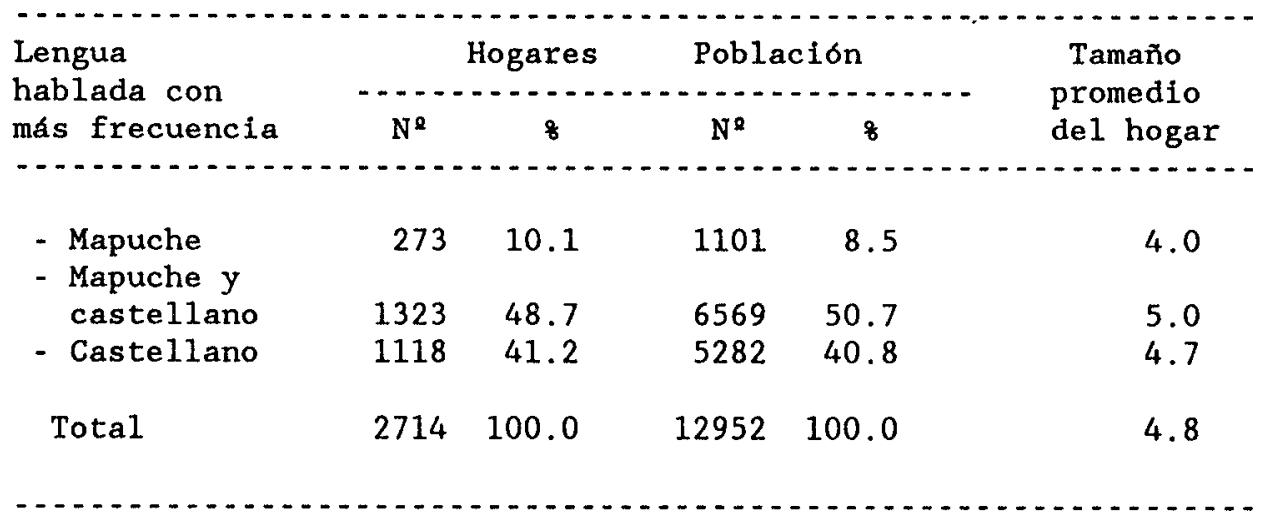

Fuente: Anexos 29 y 34 .

Llama también la atención que los hogares "bilingües" presentan el mayor tamaño relativo, por sobre el promedio general. Esta situación se contradice con el hecho de que los hogares que tienen un número mayor de personas -patrón tradicional- es donde se esperaria que hubiera una tendencia a hablar con mayor frecuencia el idioma materno. En todo caso, es probable que en los hogares más numerosos se hable preferentemente el "castellano" por la necesidad de la participación de los niños en el sistema escolar monolingüe de castellano y e1 mayor contacto con la sociedad nacional en el plano de las relaciones sociales y económicas que establecerian los miembros de estos hogares. Este hallazgo mereceria estudiarse en profundidad, porque apreciado desde otro punto de vista, 
los hogares más pequeños, donde se habla "mapudungun" en forma frecuente (mantención de tradiciones), registran una menor fecundidad (patrón occidental). Una explicación de su menor tamaño podria estar asociada con el cambio en la pauta residencial; los hijos si bien siguen habitando en las tierras paternas ya no lo hacen en la misma vivienda. Sin embargo, la menor fecundidad de las mujeres no puede explicarse por esta situación, lo que motivaria estudiar estos hogares.

En las viviendas más tradicionales, tanto en la construcción como en la lengua hablada por las personas que las habitan, se concentrarian entonces las familias más envejecidas y con menos personas. Se puede plantear como hipótesis que esta tendencia se irfa acentuando en las próximas décadas por la asignación de títulos de dominio individual.

Debe señalarse, finalmente, que el análisis de los datos sobre la lengua hablada es de crucial importancia para entender las tendencias de cambio hacia las formas y valores occidentales. Hay estudios que muestran que el principal vehiculo de aculturación en la población mapuche ha sido, precisamente, la adopción de la lengua castellana (Durán y Ramos, 1988). En esta perspectiva, se construyó un indicador de apego al modo de vida tradicional mapuche, basado en la lengua hablada, el tipo de vivienda y el tipo de familia, aspecto sobre el que se presentarán los resultados a continuación.

\subsection{E1 apego al modo de vida tradicional mapuche}

Como se ha podido apreciar, en las reducciones estudiadas reside una cierta proporción de población que, aparentemente, no posee lo que son algunas de las caracteristicas culturales del mapuche. Si bien se admitia con cierta probabilidad que la población estudiada manifestase un fuerte contacto con la sociedad nacional, por el hecho de que las reducciones se localizan cerca del principal centro urbano (Temuco), el número de hogares que no presenta ninguna de las caracteristicas tradicionales que se han ido exponiendo, es más alto que el esperado.

Por la razón anterior, y sobre la base de los antecedentes con que se cuenta, se procedió a la elaboración de un indicador que pudiera categorizar y distinguir aquellas familias más apegadas al modo de vida tradicional mapuche, de aquellas fámilias más occidentalizadas o menos apegadas a determinadas costumbres. Con este fin, se eligieron tres variables que, se supone, suelen ser consideradas por los mapuches como discriminatorias del apego a la cultura tradicional: la lengua hablada, la vivienda y la familia. Como este es un primer 
intento de medir variables culturales, este indicador puede dar un aproximación al complejo fenómeno del mantenimiento 0 del cambio de los patrones tradicionales. ${ }^{18}$

De acuerdo con el indicador de apego al modo de vida tradicional -basado principalmente en la lengua hablada- en el cuadro 19 y gráfico 14 se aprecia que la mayor importancia relativa la tendrian los hogares "moderadamente tradicionales", con un 39 por ciento del total de hogares (en todos ellos se hablan las dos lenguas con igual frecuencia; viven principalmente en viviendas no tradicionales; y se trata de familias "nucleares"). Le siguen en importancia los hogares clasificados como "no tradicionales", con un 23 por ciento (en todos ellos se habla "castellano" más frecuentemente; viven en viviendas no tradicionales; y se trata de familias en su mayorfa "nucleares").

Para la construcción del indicador se pidió la opinión de seis antropólogos conocedores del modo de vida tradicional mapuche, entendiendo como tal el patrón cultural que existio hasta el periodo de la radicación en reducciones (Oyarce, 1989): A estos antropólogos se les entregó el 1istado de variables con sus respectivas categorias, a las que debian asignar un puntaje entre 1 y 5 , en que el valor menor era para el mayor apego al modo de vida tradicional. Las variables debian puntuarse de acuerdo con $1 a$ importancia que le asignara cada especialista. Las categorias debian puntuarse por variables, bajo el mismo criterio de a menor puntaje, mayor apego al modo de vida tradicional. Para la selección de las combinaciones de puntaje se consideró como primera prioridad aquella que se repitiera - que fuera la más frecuente (moda). A partir de la combinación seleccionada, quedaron los siguientes valores: lengua: 1 , vivienda: 4 y familia: 5. Dentro de cada variable los puntajes fueron:

Para la lengua: mapuche $=1$; mapuche y castellano $-2 ;$ y castellano -5 . Para 1a vivienda: ruca - 1; ruca y otra construcción - 2; y casa y mejora - 3. Para la familia: extensa $=1$; nuclear $=3$; y compuesta $=4$.

La ponderación de las variables se tomó a partir de los inversos de los puntajes, de tal manera que la variable lengua alcanzó una ponderación del 69 por ciento, la vivienda un 17 por ciento y la familia un 14 por ciento. Finalmente las categorias quedaron del modo que sigue:

\section{Grado de apego}

Muy tradicional Tradiciona1

Tradicional moderado: Poco tradicional No tradicional

\section{Valores}

: mayor o igual a 1.00 ; menor o igual a 1.44

: mayor o igual a 1.45 ; menor o igual a 1.99

mayor o igual a 2.00; menor o igual a 2.49

: mayor o igual a 2.50 ; menor o igual a 4.35

mayor o igual a 4.36 
CUADRO 19

REDUCCIONES INDIGENAS SELECCIONADAS: DISTRIBUCION DE LOS HOGARES POR

TIPO DE VIVIENDA Y FAMILIA, SEGUN LENGUA HABLADA MAS FRECUENTEMENTE E INDICADOR DE APEGO AL MODO DE VIDA TRADICIONAL MAPUCHE (IA). CENSO DE 1988

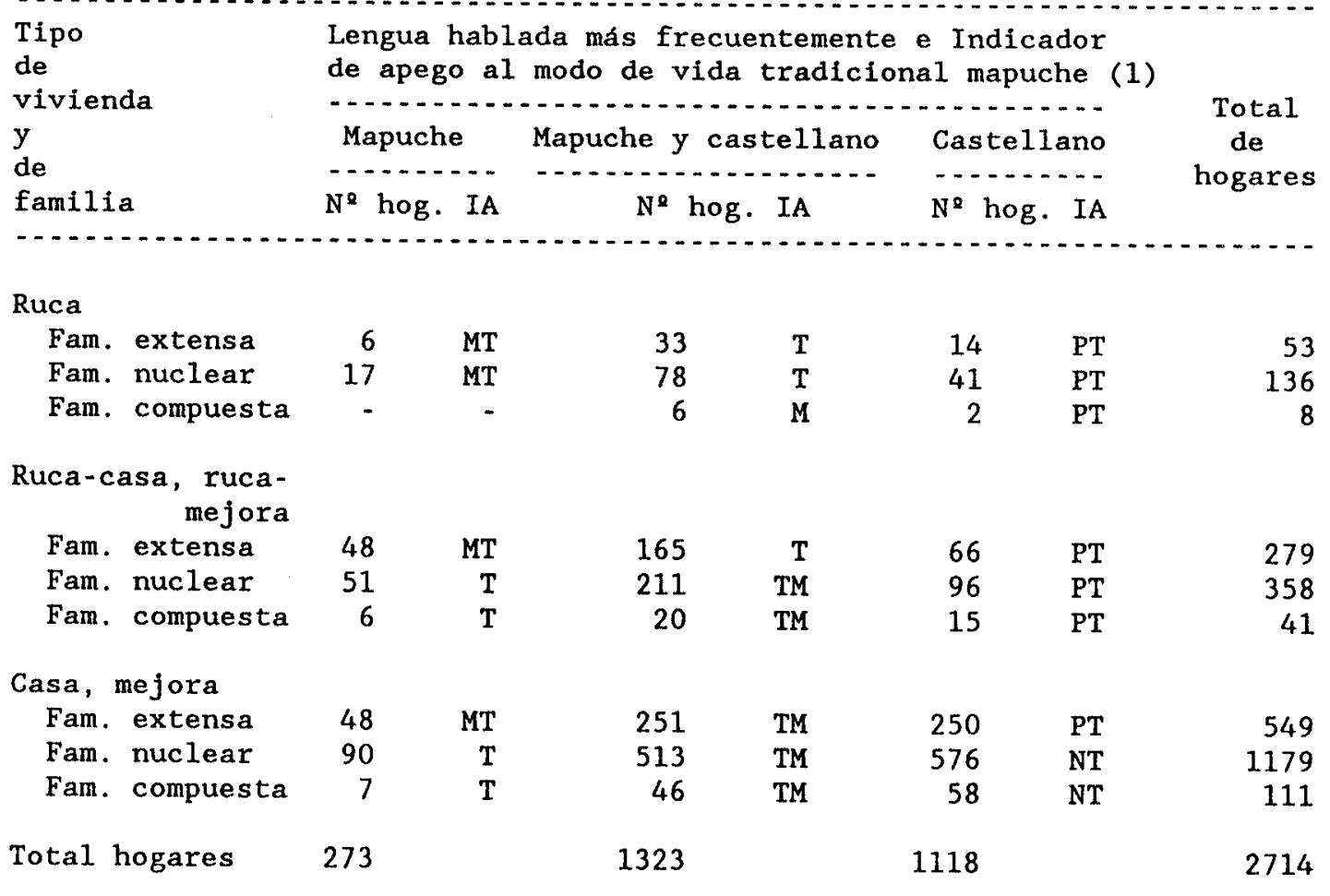

Fuente: Anexo 35 .

(1): MT: muy tradicional $T$ : tradicional $T M$ : tradicional moderado PT: poco tradicional NT: no tradicional.

Llama la atención que los hogares "muy tradicionales" sólo alcanzan a un 4 por ciento del total de hogares (en todos ellos se habla "mapuche" con más frecuencia; habitan en viviendas tradicionales, mixtas y no tradicionales; y en su mayoria se trata de familias "extensas")." Ello podria significar que en

En la categoria "muy tradicional" quedaron incluidas viviendas que no son tradicionales. Sin embargo, esto se basa en la propia opinión de los mapuches, según la cual se puede ser "netamente mapuche" (expresión con que se refieren al modo de vida tradicional) y vivir en "casa" o "mejora". 
Gráfico 14

REDUCCIONES INDIGENAS SELECCIONADAS: DISTRIBUCION RELATIVA DE LOS HOGARES POR GRADO DE APEGO AL MODO DE VIDA TRADICIONAL MAPUCHE. CENSO DE 1988

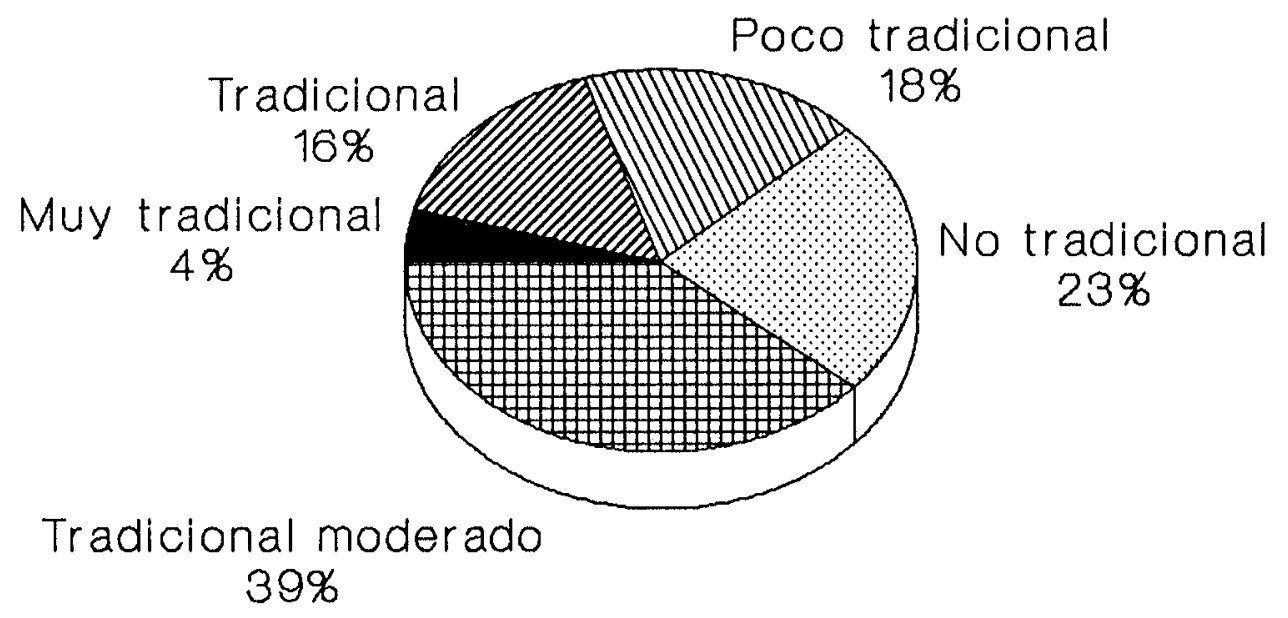

Fuente: Cuadro 20 
las reducciones seleccionadas habria un número significativo de mapuches aparentemente más aculturizados y también, quizás, de personas no mapuches. ${ }^{\star 0}$

El fenómeno de la aculturación es muy complejo y ofrece grandes dificultades no sólo para su medición, sino también para la definición de las caracteristicas de un grupo que se van a considerar como indicadores de la aculturación. En este sentido y como se conoce el patrón tradiclonal, se ha denominado al indicador como de "apego al modo de vida" y no de aculturación.

Es evidente que el mapuche que encontro el conquistador y el de hoy hay grandes diferencias causadas, por sobre todo, por casi 500 años de contacto bélico y pacffico. Sin embargo, a pesar que existe un proceso de chilenización y una gran presion de la sociedad global, los mapuches siguen manteniendo su identidad sociocultural. Por ello, no es posible explicar todos los cambios como un proceso aculturativo, ya que seria simplificar el fenómeno (Faron, 1969).

Desde otro punto de vista, si se acepta que el grado de aculturación está directamente relacionado con el grado de contacto entre las culturas involucradas en el proceso, se puede sugerir como hipotesis que las reducciones de Labranza, Molco, Maquehue y Metrenco presentan una situación de aculturación más acentuada que otras reducciones ubicadas a mayor distancia del principal centro urbano de la región. E1 indicador de apego al modo de vida tradicional pareceria apoyar la idea anterior.

Finalmente, si se analiza la información sobre el indicador (grado) de apego al modo de vida tradicional según distrito, que se presenta en el cuadro 20 , se advierte que en todos ellos la situación es muy parecida, manteniéndose la tendencia general. Al ordenar los distritos en un continuo de más tradicional a más occidental, se tendria en primer lugar a Molco, en segundo lugar a Maquehue y a Metrenco y, finalmente, a Labranza.

Esta situación podria deberse a matrimonios con personas no mapuches o a la venta de las tierras, que en todo caso, se realizaría únicamente mediante resquicios legales, ya que desde el punto de vista jurfdico son inalienables $y$ no enajenables. 
CUADRO 20

REDUCCIONES INDIGENAS SELECCIONADAS: DISTRIBUCION RELATIVA DE LOS HOGARES POR GRADO DE APEGO AL MODO DE VIDA TRADICIONAL MAPUCHE, SEGUN DISTRITOS. CENSO DE 1988

\begin{tabular}{|c|c|c|c|c|c|}
\hline $\begin{array}{l}\text { Grado de } \\
\text { apego al modo } \\
\text { de vida } \\
\text { tradicional }\end{array}$ & Labranza & $\begin{array}{r}\text { Dis } \\
\text { Molco }\end{array}$ & Itos & Metrenco & Total \\
\hline Muy tradicional & 2.1 & 3.8 & 6.1 & 4.4 & 4.4 \\
\hline Tradicional & 16.2 & 18.0 & 14.5 & 15.4 & 15.8 \\
\hline Tradicional moderado & 33.3 & 41.0 & 38.4 & 39.2 & 38.7 \\
\hline Poco tradicional & 19.8 & 19.6 & 20.0 & 14.8 & 17.8 \\
\hline No tradicional & 28.7 & 17.6 & 20.9 & 26.1 & 23.4 \\
\hline Total & $\begin{array}{l}100.0 \\
(384)\end{array}$ & $\begin{array}{l}100.0 \\
(573)\end{array}$ & $\begin{array}{l}100.0 \\
(674)\end{array}$ & $\begin{array}{r}100.0 \\
(1083)\end{array}$ & $\begin{array}{r}100.0 \\
(2714)\end{array}$ \\
\hline
\end{tabular}

Fuente: Anexo 36. 


\section{Conclusiones}

El análisis de la información obtenida en el Censo de 1988 indica que en las reducciones indigenas de los distritos de Labranza, Maquehue, Molco y Metrenco, se presentan en forma acentuada las caracteristicas ya observadas, en parte, en el estudio de todas las reducciones de la IX Región, realizado sobre la base de los datos del Censo Nacional de 1982. Puede decirse que, en sintesis, las caracteristicas relativas a las condiciones materiales de vida y a la organización social evidenciarian un proceso de adopción de formas y modelos de la sociedad occidental, aun cuando también se conservan algunos rasgos de la estructura social tradicional mapuche. Cabe destacar que este proceso no parece ser homogéneo al interior de las reducciones e incluso puede no serlo dentro de cada familia.

Con relación a los aspectos de vivienda y hogar, el Censo de 1988 ha permitido describir la realidad habitacional y de saneamiento ambiental de la población, destacándose dos aspectos. En primer término, coexisten viviendas de tipo tradicional, viviendas mixtas y viviendas no tradicionales, aunque una mayoria de ellas corresponde a estas últimas ("casas" y "mejoras"; 68 por ciento). En segundo término, relacionado con lo anterior, si bien las viviendas presentan en su mayor parte caracteristicas que determinan un bajo grado de hacinamiento, en general, se presentan condiciones de deficiencia sanitaria y precariedad ambiental, debido a la existencia de rústicos sistemas de obtención de agua $y$ de eliminación de excretas, así como de un número importante de viviendas que cuentan con pisos de "entablado" y de "tierra" en sus dormitorios. La conclusión fundamental que surge de estos antecedentes es la presencia de una población que en algunas dimensiones vive en condiciones homogéneamente pobres, pero que en otros aspectos, como es el caso del tipo de vivienda habitada, exhibe una heterogeneidad relativa, que estarfa interrelacionada con un fenómeno de diferenciación no sólo cultural, sino también económica (por ejemplo, debido a la presencia de la "mejora"). Este hallazgo, por su importancia, mereceria estudiarse mediante investigaciones especificas.

Con respecto a la familia, el análisis de los datos muestra que en esta esfera se estarian produciendo los cambios más drásticos, tal como se evidencia en el aumento progresivo del número de familias "nucleares", típicas de la sociedad occidental (más de la mitad de la población vive en este tipo de familias en las reducciones estudiadas). E1 aumento de estas familias ya ha sido descrito en varios estudios (Bengoa y Valenzuela, 1984; Foester, 1980; Stuch1ik, 1974) y es un resultado del proceso de radicación en reducciones. Es esperable 
que con la Ley 2568 que otorga titulos de propiedad individual, este proceso se agudice, situación que podria explicar la fragmentación de las familias "extensas" que se dividen cada vez más, quedando en la vivienda paterna sólo los "troncos" o parejas más ancianas (1o que se relaciona además con el menor tamaño de los hogares de las "rucas" y de aquellos donde se mantiene el uso frecuente de la lengua materna), mientras los hijos, principalmente hombres, piden el predio que les corresponde en herencia y construyen alli una nueva vivienda. Este proceso de creciente individualismo es reconocido también por los mapuches.

A pesar de todas estas tendencias, perduran algunos rasgos de la estructura social tradicional mapuche, tales como la familia "extensa" (cerca de un 40 por ciento de la población vive en este tipo de familias); el parentesco como condicionante en la composición de la familia; y el fuerte predominio del jefe de hogar varón.

Un aspecto particularmente importante es el que dice relación con la lengua hablada en los hogares. Sólo en una pequeña fracción de éstos se mantiene el uso frecuente del "mapudungun" (hogares que son los de menor tamaño), por lo que en una gran mayoria de hogares se habla, en mayor o menor medida, la lengua hispana. Esta situación sería uno de los principales desencadenantes del proceso de aculturación al interior de las reducciones y se muestra claramente a través del grado de apego al modo de vida tradicional, cuyo indicador ha permitido establecer que los hogares se distribuyen según distintos grados de apego a la cultura y que casi una cuarta parte de ellos no posee la lengua, la vivienda ni el tipo de familia tradicional.

En sintesis, en las reducciones estudiadas según el Censo de 1988, se aprecia un creciente proceso de adopción de pautas y valores occidentales, que se refleja no sólo en los aspectos de la cultura material como la vivienda, sino sobre todo, en aspectos ideológicos y sociales tales como el cambio en la estructura y tamaño de la familia y la incorporación del empleo frecuente de la lengua hispana en los hogares. Esta tendencia no parece significar, necesariamente, una mejoria en las condiciones objetivas de vida de la población, ya que se detectan situaciones fuertemente deficientes, dadas por ejemplo, por la presencia de viviendas precarias introducidas como las "mejoras" que, por 10 demás, son típicas de las zonas de pobreza urbana.

E1 proceso de pérdida de los rasgos tradicionales y de incorporación de patrones occidentales puede estar asociado con la cercania de las reducciones de los cuatro distritos a la capital de la IX Región y con el hecho de que se trata de un área en que la sociedad nacional ha mantenido, desde principios de 
siglo, focos importantes de irradiación de la cultura occidental, principalmente por medio de misiones religiosas, escuelas y, posteriormente, centros de salud. Sin embargo, el factor que parece ser decisivo en este proceso es la adopción del castellano, ya que refleja no sólo adquirir la lengua hispana, sino que con alguna probabilidad, significa también la incorporación de valores y patrones de la sociedad global, como la vivienda, el tipo de familia y la expectativa con respecto al número de hijos. Lo anterior demuestra que el proceso de cambio o continuidad cultural es muy complejo y que todos los aspectos materiales y sociales están interrelacionados, 1o que tiene una influencia directa en los cambios demográficos y de la organización social.

Finalmente, para la superación de las precarias condiciones de vida de esta población se deberian considerar medidas que no atenten contra sus tradiciones culturales. La cultura que ellos viven no es algo abstracto, es un complejo de hechos, relaciones, conceptos y valores con coherencia interna, como señala stuchlik (1974), que influyen directamente en sus actitudes hacia los cambios externos. 


\section{Bibliografia}

Aldunate, Carlos (1986), Cultura mapuche. Serie Patrimonio Cultural Chileno, Colección Culturas Aborigenes, Segunda Edicion.

Bengoa, José (1987), Historla del pueblo mapuche. Ediclones Sur, Santiago.

Bengoa, José y Valenzuela, Eduardo (1984), Economfa mapuche. Pobreza y susbsistencla en la sociedad contemporánea. PAS, Santiago.

Bunster, Ximena (1970), "Algunas consideraciones en torno a la dependencia cultural y cambio entre los mapuches". En II Semana Indigenista, Pontificia Univ. Católica de Temuco, pp. 13-27.

Centro Latinoamericano de Demografia (CELADE) (1987), Costa Rica: los grupos sociales de riesgo para la sobrevida infantil 1960-1984. CELADE, San José, Serie A, N² 1049 .

Durán, Teresa y Ramos, Nelly (1988), "Castellanización formal en La Araucanfa a través de la escuela". En Lenguas Modernas, Univ. de Chile, $\mathrm{N}^{2} 15, \mathrm{pp}$. $131-154$.

Faron, Louis (1969), Los mapuches, Su estructura social. Instituto Indigenista Interamericano, México.

Foester, Rolf (1980), Estructura y funciones del parentesco mapuche: su pasado y su presente. Univ. de Chile, Facultad de Ciencias Humanas, Depto. de Antropologia, Tesis para optar al Grado de Licenciado en Antropologia Social.

Fundación Instituto Indigena (1989), Resúmenes, Jornadas de Educación Indigena. Pontificia Univ. Católica de Temuco, 10-14 julio.

Guevara, Tomás (1913), Las últimas familias y costumbres araucanas. Imprenta Barcelona, Santiago.

Hidalgo, Jorge (1972), "Algunas notas sobre los mapuches protohistóricos". En II Semana Indigenista, Pontificia Univ. Católica de Temuco, pp. 25-42.

Instituto Nacional de Estadisticas (INE) (1985), IX Región de La Araucania, Localidades pobladas XV Censo Nacional de Población y IV de Vivienda Chile 1982. INE, Santiago, Tomo II, septiembre.

Instituto Nacional de Estadisticas (INE) (1987a), Total pais, Población XV Censo Nacional de Población y IV de Vivienda - Chile 1982. INE, Santiago, Tomo I, mayo.

Instituto Nacional de Estadisticas (INE) (1987b), IX Región de La Araucania, Población XV Censo Nacional de Población y IV de Vivienda - Chile 1982. INE, Santiago, Tomo I, julio. 
Oyarce P., Ana M. (1989), Conocimientos, creenclas y prácticas en torno al cicle vital en una comunidad mapuche de la IX Región de Chile. PAESMI, Santiago, Serie Docs. de Trabajo No. 2, mayo.

Oyarce, Ana M.; Romaggi, Marisabel y Vidal, Aldo (1989), Cómo viven les mapuches. Análisis del Censo de Población de Chile de 1982. PAESMI, Santiago, Serie Docs. de Trabajo $\mathrm{N}^{2} 01$, enero.

Quesne1, Andre (1989), Propuestas para una estrategia de investigación de las condiciones de salud materno infantil mapuche. Temuco, (inédito).

Quilapi, Edith (1976), La vivienda mapuche. Univ. de Concepción, Tesis para optar al Grado de Licenciado en Antropologia.

Salas, Adalberto (1984), Textos orales en mapuche o araucano. Ed. Universitaria de Concepción, Colección Lenguas Vernáculas de Chile, $\mathrm{N}^{2} 1$.

Sociedad Chilena de Lingüfstica (1989), Uso del alfabeto unificado. Pontificia Univ. Católica de Temuco.

Somoza, Jorge L. (1985), Condiciones socioeconomicas de comunidades rurales. CELADE, Santiago, Serie OI $\mathrm{N}^{2} 36$, marzo.

Stuchlik, Milan (1974), Rasgos de la sociedad mapuche contemporánea. Ed. Nueva Universidad, Santiago.

Universidad de La Frontera (UFRO); Instituto Nacional de Estadisticas (INE); Fundación Instituto Indigena (FII); Programa de Apoyo y Extensión en Salud Materno Infantil (PAESMI) y Centro Latinoamericano de Demografia (CELADE) (1989), Censo Experimental de Reducciones Indigenas Seleccionadas Cautin Chile. 1988. Tabulaciones básicas. Imprenta INE, Santiago, diciembre.

Vidal, Aldo (1989), "Indicadores sociodemográficos de la población mapuche rural ¿crisis de la reproducción societal?. En Resistencia y cambio cultural en la sociedad mapuche actual. CIIDE, Edit. Sociedad Longko Kilapan, Temuco, (en prensa). 
Anexos 
ANEXO 1

REDUCCIONES INDIGENAS SELECCIONADAS: DISTRIBUCION DE LOS HOGARES POR TIPO DE VIVIENDA, SEGUN DISTRITO. CENSO DE 1988

\begin{tabular}{|c|c|c|c|c|c|}
\hline \multirow{2}{*}{$\begin{array}{l}\text { Tipo } \\
\text { de } \\
\text { vivienda }\end{array}$} & \multicolumn{4}{|c|}{ Distritos } & \multirow[b]{2}{*}{ Total } \\
\hline & Labranza & Molco & Maquehue & Metrenco & \\
\hline $4 \mathrm{Ca}$ & & & & & \\
\hline $\begin{array}{l}\text { Ruca } \\
\text { Ruca-csesa }\end{array}$ & 27 & 48 & 36 & 86 & 197 \\
\hline Ruca-casa & 39 & 96 & 117 & 89 & 341 \\
\hline Ruca-mejora & 57 & 89 & 73 & 118 & 337 \\
\hline Casa & 172 & 198 & 262 & 453 & 1085 \\
\hline Mejora & 89 & 142 & 186 & 337 & 754 \\
\hline otal & 384 & 573 & 674 & 1083 & 2714 \\
\hline
\end{tabular}

Fuente: Tabulados especiales Censo de 1988.

ANEXO 2

REDUCCIONES INDIGENAS SELECCIONADAS: DISTRIBUCION DE LOS HOGARES POR MATERIAL DEL PISO DE LOS DORMITORIOS, SEGUN TIPO DE VIVIENDA. CENSO DE 1988

Material

del piso

de los

dormitorios
Tipo de vivienda

Ruca Ruca-casa Ruca-mejora Casa Mejora Total

$\begin{array}{lrrrrrr}\text { Entablado } & 3 & 91 & 120 & 149 & 347 & 710 \\ \text { Madera } & 1 & 206 & 24 & 896 & 105 & 1232 \\ \text { Tierra } & 193 & 44 & 190 & 29 & 291 & 747 \\ \text { Otro } & 0 & 0 & 2 & 8 & 11 & 21 \\ \text { Ignorado } & 0 & 0 & 1 & 3 & 0 & 4 \\ \text { Total } & 197 & 341 & 337 & 1085 & 754 & 2714\end{array}$

Fuente: Tabulados especiales Censo de 1988. 
ANEXO 3

LABRANZA: DISTRIBUCION DE LOS HOGARES POR MATERIAL DEL PISO DE LOS DORIITORIOS, SEGUN TIPO DE VIVIENDA. CENSO DE 1988

\begin{tabular}{|c|c|c|c|c|c|c|}
\hline $\begin{array}{l}\text { Material } \\
\text { de1 piso } \\
\text { de los } \\
\text { dormitorios }\end{array}$ & Ruca & Tipc & $\begin{array}{l}\text { de vivienda } \\
\text { Ruca-mejora }\end{array}$ & Casa & Mejora & Total \\
\hline Entablado & 1 & 12 & 18 & 21 & 49 & 101 \\
\hline Madera & 0 & 24 & 7 & 145 & 19 & 195 \\
\hline Tierra & 26 & 3 & 32 & 6 & 20 & 7 \\
\hline otro & 0 & 0 & 0 & 0 & 1 & \\
\hline Total & 27 & 39 & 57 & 172 & 69 & 384 \\
\hline
\end{tabular}

Fuente: Tabulados especiales Censo de 1988.

ANEXO 4

MOLCO: DISTRIBUCION DE LOS HOGARES POR MATERIAL DEL PISO

DE LOS DORMITORIOS, SEGUN TIPO DE VIVIENDA. CENSO DE 1988

\begin{tabular}{|c|c|c|c|c|c|c|}
\hline $\begin{array}{l}\text { Material } \\
\text { del piso } \\
\text { de los } \\
\text { dormitorios }\end{array}$ & Ruca & Tipo & $\begin{array}{l}\text { de vivienda } \\
\text { Ruca-mejora }\end{array}$ & Casa & Mejora & Total \\
\hline 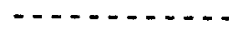 & -0 & & & & & \\
\hline Entablado & 0 & 40 & 23 & 38 & 67 & 170 \\
\hline Madera & 1 & 64 & 9 & 216 & 39 & 328 \\
\hline Tierra & 47 & 13 & 40 & 3 & 79 & 169 \\
\hline Otro & 0 & 0 & 0 & 3 & 1 & 4 \\
\hline Ignorado & 0 & 0 & 1 & 2 & 0 & 3 \\
\hline Total & 48 & 117 & 73 & 262 & 186 & 674 \\
\hline
\end{tabular}

Fuente: Tabulados especiales Censo de 1988. 
ANEXO 5

MAQUEHUE: DISTRIBUCION DE LOS HOGARES POR MATERIAL DEL PISO

DE LOS DORMITORIOS, SEGUN TIPO DE VIVIENDA. CENSO DE 1988

\begin{tabular}{|c|c|c|c|c|c|c|}
\hline $\begin{array}{l}\text { Material } \\
\text { del piso } \\
\text { de los } \\
\text { dormitorios }\end{array}$ & Ruca & $\begin{array}{r}\text { Tip } \\
\text { Ruca-casa }\end{array}$ & $\begin{array}{c}\text { de vivienda } \\
\text { Ruca-mejora }\end{array}$ & Casa & Mejora & Total \\
\hline Entablado & 2 & 40 & 23 & 38 & 67 & 170 \\
\hline Madera & 0 & 64 & 9 & 216 & 39 & 328 \\
\hline Tierra & 34 & 13 & 40 & 3 & 79 & 169 \\
\hline otro & 0 & 0 & 0 & 3 & 1 & 4 \\
\hline Ignorado & 0 & 0 & 1 & 2 & 0 & 3 \\
\hline Total & 36 & 117 & 73 & 262 & 186 & 674 \\
\hline
\end{tabular}

Fuente: Tabulados especiales Censo de 1988.

ANEXO 6

METRENCO: DISTRIBUCION DE LOS HOGARES POR MATERIAL DEL PISO

DE LOS DORMITORIOS, SEGUN TIPO DE VIVIENDA. CENSO DE 1988

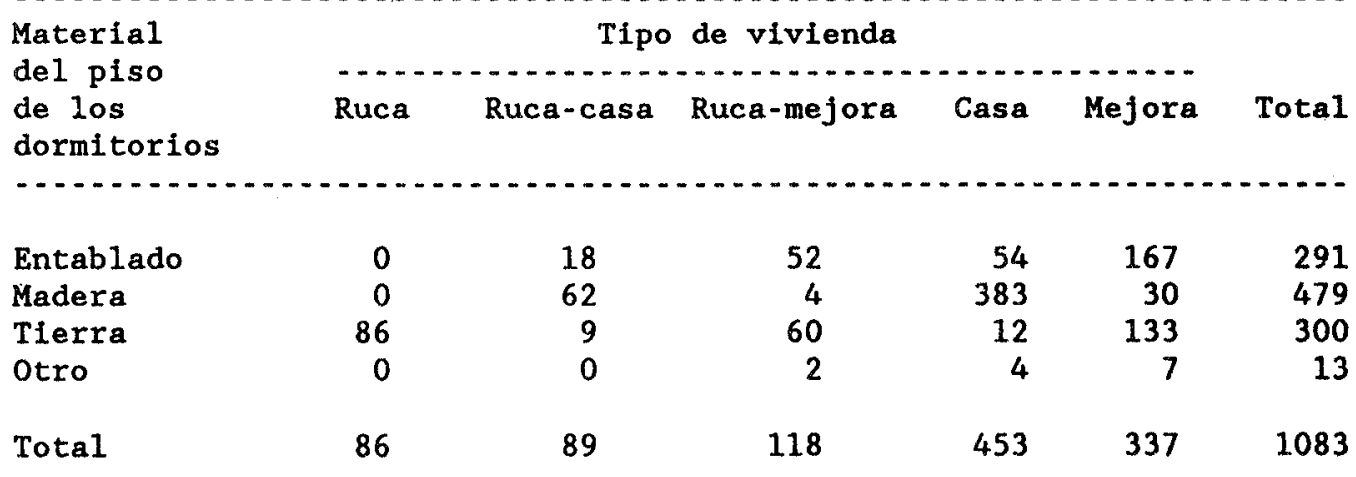

Fuente: Tabulados especiales Censo de 1988. 


\section{ANEXO 7}

REDUCCIONES INDIGENAS SELECCIONADAS: DISTRIBUCION DE LOS HOGARES

POR NUMERO DE DORMITORIOS Y DISPONIBILIDAD DE PIEZA DE COCINA

EXCLUSIVA, SEGUN TIPO DE VIVIENDA. CENSO DE 1988

\section{Número de}

dormitorios y

disponibilidad

de pieza de cocina

\section{Tipo de vivienda}

Ruca Ruca-casa Ruca-mejora Casa Mejora Total

1

Si

No

$2-3$

$\mathrm{Si}$

No

4-5

Si

No

6-8

Si

9 y más

Si

Total

Si

No

$84 \quad 72$

91

16

5

1

0

0

0

197

101

96

1

216

1

48

1

2

0
0

21
0

181

1

13

161
10

330

105

801

$\begin{array}{llll}9 & 10 & 105 & 216\end{array}$

145

8

716

2

268

1361

9

0

13

1

0

1

Fuente: Tabulados especiales Censo de 1988. 
ANEXO 8

REDUCCIONES INDIGENAS SELECCIONADAS: DISTRIBUCION DE LOS HOGARES POR NUMERO TOTAL DE PIEZAS, SEGUN TIPO DE VIVIENDA. CENSO DE 1988

$\begin{array}{lrrrrrr}\begin{array}{l}\text { Número } \\ \text { detal }\end{array} & \text { Ruca } & \text { Ruca-casa } & \text { Ruca-mejora } & \text { Casa } & \text { Mejora } & \text { Total } \\ & & & & & \\ 1 & 91 & 1 & 5 & 9 & 103 & 209 \\ 2 & 87 & 50 & 153 & 77 & 296 & 663 \\ 3 & 16 & 77 & 105 & 156 & 179 & 533 \\ 4 & 1 & 111 & 38 & 361 & 100 & 611 \\ 5 & 2 & 69 & 29 & 279 & 50 & 429 \\ 6 & 0 & 22 & 4 & 98 & 22 & 146 \\ 7 & 0 & 6 & 1 & 57 & 1 & 65 \\ 8 & 0 & 2 & 0 & 27 & 1 & 30 \\ 9 \text { y más } & 0 & 3 & 2 & 21 & 2 & 28 \\ & & & & & & \\ \text { Total } & 197 & 341 & 337 & 1085 & 754 & 2714\end{array}$

Fuente: Tabulados especiales Censo de 1988. 
ANEXO 9

REDUCCIONES INDIGENAS SELECCIONADAS: DISTRIBUCION DE LOS HOGARES POR NUMERO DE DORMITORIOS, SEGUN TIPO DE VIVIENDA. CENSO DE 1988

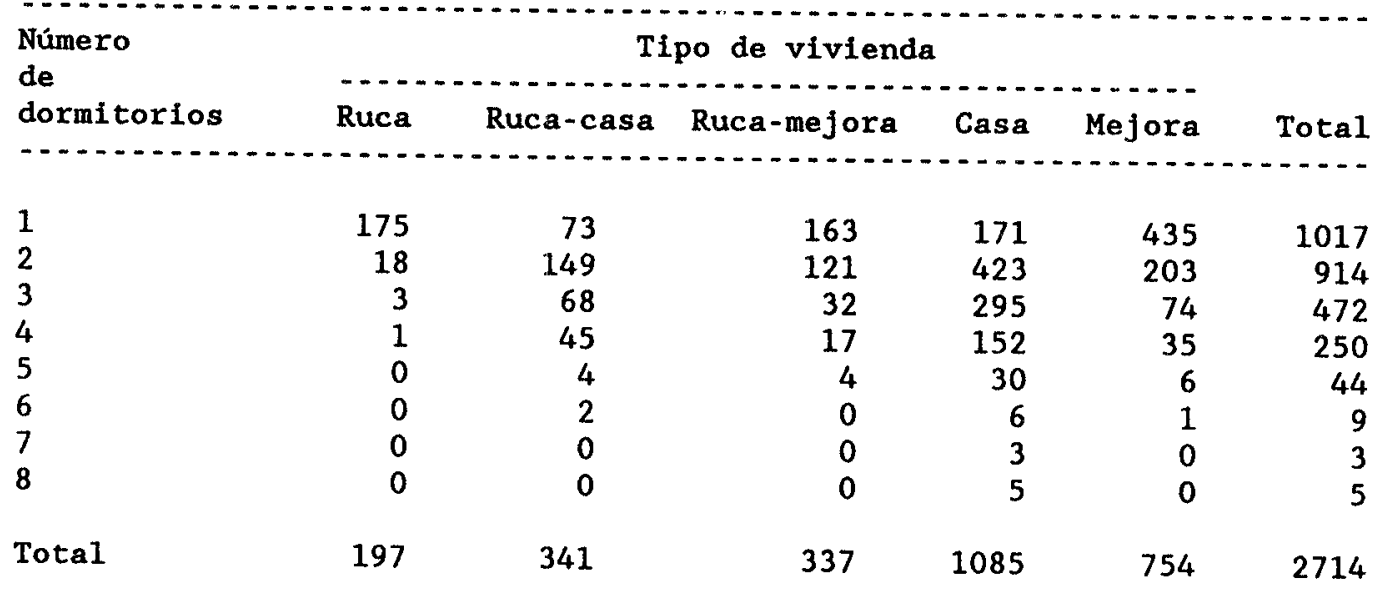

Fuente: Tabulados especiales Censo de 1988. 
ANEXO 10

REDUCCIONES INDIGENAS SELECCIONADAS: DISTRIBUCION DE LOS HOGARES POR NUMERO DE PERSONAS, SEGUN TIPO DE VIVIENDA. CENSO DE 1988

\begin{tabular}{lrrrrrr}
$\begin{array}{l}\text { Número de } \\
\text { personas on } \\
\text { el hogar }\end{array}$ & $\begin{array}{c}\text { Ruca } \\
\text { Ruca de vivienda }\end{array}$ & Ruca-casa & Ruca-mejora & Casa & Mejora & Tota1 \\
\hline 1 & & & & & & \\
$2-4$ & 36 & 9 & 13 & 44 & 59 & 161 \\
$5-7$ & 91 & 120 & 158 & 413 & 379 & 1161 \\
$8-10$ & 51 & 153 & 118 & 487 & 256 & 1065 \\
11 y más & 17 & 45 & 48 & 128 & 52 & 290 \\
& 2 & 14 & 0 & 13 & 8 & 37 \\
Total & 197 & 341 & 337 & 1085 & 754 & 2714
\end{tabular}

Fuente: Tabulados especiales Censo de 1988.

ANEXO 11

REDUCCIONES INDIGENAS SELECCIONADAS: DISTRIBUCION DE LOS HOGARES POR NUMERO TOTAL DE PIEZAS, SEGUN NUMERO DE PERSONAS EN EL HOGAR.

CENSO DE 1988

\begin{tabular}{|c|c|c|c|c|c|c|c|c|}
\hline \multirow{2}{*}{$\begin{array}{l}\text { Número } \\
\text { total de } \\
\text { piezas }\end{array}$} & \multicolumn{8}{|c|}{ Número de personas en el hogar } \\
\hline & 1 & 2 & 3 & 4 & 5 & 6 & y más & \\
\hline 1 & 57 & 22 & 42 & 38 & 26 & 12 & 12 & 209 \\
\hline 2 & 57 & 90 & 127 & 135 & 103 & 61 & 90 & 663 \\
\hline 3 & 1.9 & 65 & 98 & 113 & 93 & 60 & 85 & 533 \\
\hline 4 & 16 & 60 & 79 & 91 & 107 & 107 & 151 & 611 \\
\hline 5 & 9 & 32 & 45 & 59 & 81 & 57 & 146 & 429 \\
\hline 6 & 1 & 2 & 14 & 15 & 24 & 30 & 60 & 146 \\
\hline 7 & 1 & 4 & 4 & 12 & 7 & 11 & 26 & 65 \\
\hline 8 & 1 & 1 & 2 & 2 & 1 & 8 & 15 & 30 \\
\hline 9 & 0 & 1 & 2 & 2 & 0 & 3 & 4 & 12 \\
\hline 10 & 0 & 2 & 0 & 0 & 2 & 1 & 4 & 9 \\
\hline 11 & 0 & 0 & 0 & 2 & 0 & 0 & 2 & 4 \\
\hline 12 & 0 & 0 & 0 & 0 & 0 & 0 & 3 & 3 \\
\hline Total & 161 & 279 & 413 & 469 & 444 & 350 & 598 & 2714 \\
\hline
\end{tabular}

Fuente: Tabulados especiales Censo de 1988. 
ANEXO 12

LABRANZA: DISTRIBUCION DE LOS HOGARES POR SISTEMA DE

PROCEDENCIA DEL AGUA, SEGUN TIPO DE VIVIENDA. CENSO DE 1988

\begin{tabular}{|c|c|c|c|c|c|c|}
\hline $\begin{array}{l}\text { Procedencia } \\
\text { del }\end{array}$ & & Tipo & e vivienda & & & \\
\hline agua & Ruca & Ruca-casa & Ruca-mejora & Casa & Mejora & Total \\
\hline Pozo descub. & 16 & 14 & 33 & 64 & 33 & 160 \\
\hline $\begin{array}{l}\text { Pozo protegidd } \\
\text { sin bomba }\end{array}$ & 7 & 20 & 17 & 75 & 47 & 166 \\
\hline $\begin{array}{l}\text { Pozo protegida } \\
\text { con bomba }\end{array}$ & 4 & 4 & 4 & 23 & 2 & 37 \\
\hline Vertiente & 0 & 0 & 3 & 8 & 6 & 17 \\
\hline Rio o arroyo & 0 & 0 & 0 & 1 & 1 & 2 \\
\hline Otro & 0 & 1 & 0 & 1 & 0 & 2 \\
\hline Total & 27 & 39 & 57 & 172 & 89 & 384 \\
\hline
\end{tabular}

Fuente: Tabulados especiales Censo de 1988. 
ANEXO 13

MOLCO: DISTRIBUCION DE LOS HOGARES POR SISTEMA DE

PROCEDENCIA DEL AGUA, SEGUN TIPO DE VIVIENDA. CENSO DE 1988

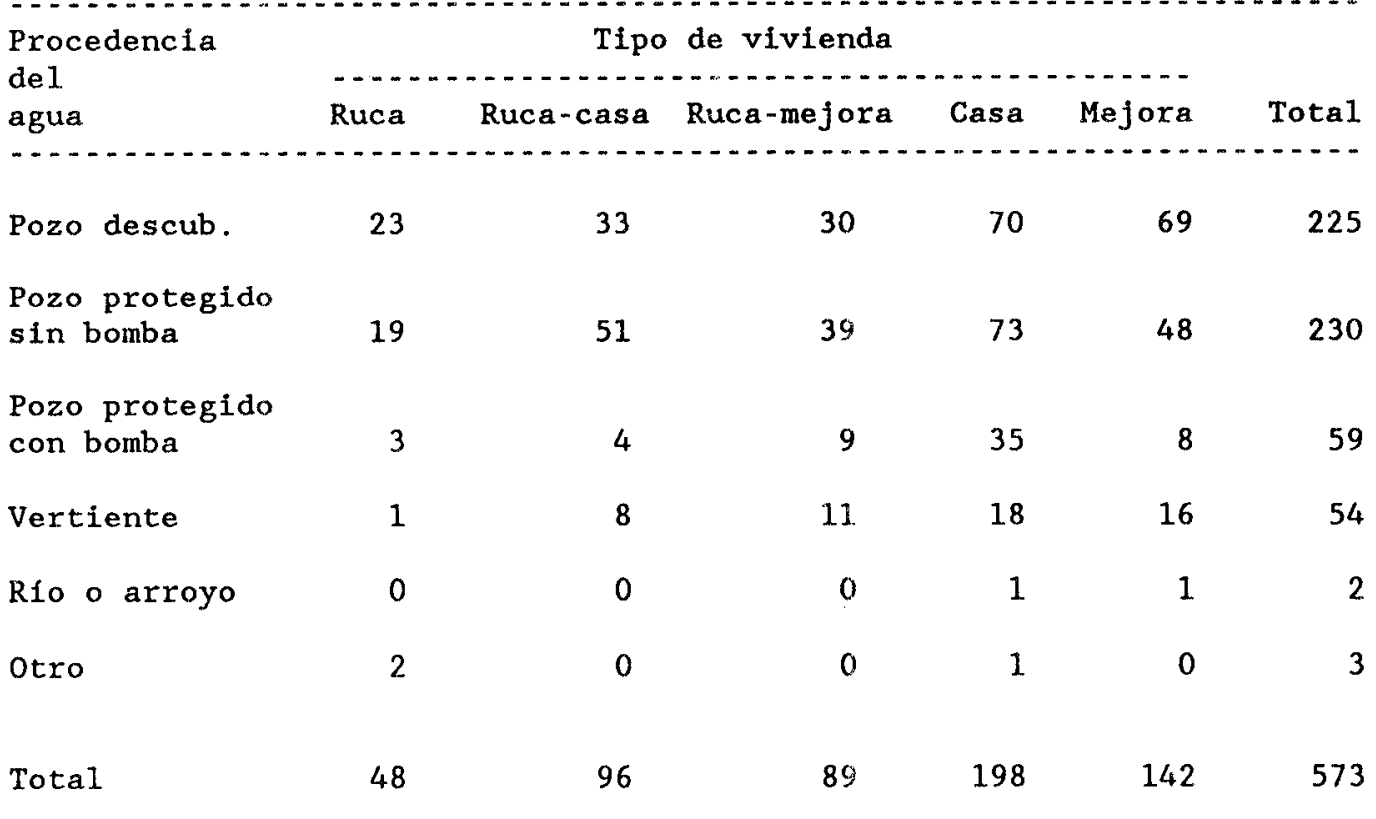

Fuente: Tabulados especiales Censo de 1988. 


\section{ANEXO 14}

MAQUEHUE: DISTRIBUCION DE LOS HOGARES POR SISTEMA DE

PROCEDENCIA DEL AGUA, SEGUN TIPO DE VIVIENDA. CENSO DE 1988

\begin{tabular}{|c|c|c|c|c|c|c|}
\hline $\begin{array}{l}\text { Procedencia } \\
\text { del } \\
\text { agua }\end{array}$ & Ruca & $\begin{array}{r}\text { Tip } \\
\text { Ruca-casa }\end{array}$ & de vivienda & Casa & Mejora & Total \\
\hline Pozo descub. & 22 & 59 & 31 & 103 & 100 & 315 \\
\hline $\begin{array}{l}\text { Pozo protegido } \\
\text { sin bomba }\end{array}$ & 8 & 44 & 27 & 112 & 54 & 245 \\
\hline $\begin{array}{l}\text { Pozo protegido } \\
\text { con bomba }\end{array}$ & 0 & 2 & 0 & 17 & 7 & 26 \\
\hline Vertiente & 6 & 11 & 14 & 27 & 24 & 82 \\
\hline Rio o arroyo & 0 & 0 & 1 & 1 & 0 & 2 \\
\hline Otro & 0 & 1 & 0 & 2 & 1 & 4 \\
\hline Total & 36 & 117 & 73 & 262 & 186 & 674 \\
\hline
\end{tabular}

Fuente: Tabulados especiales Censo de 1988. 
ANEXO 15

METRENCO: DISTRIBUCION DE LOS HOGARES POR SISTEMA DE

PROCEDENCIA DEL AGUA, SEGUN TIPO DE VIVIENDA. CENSO DE 1988

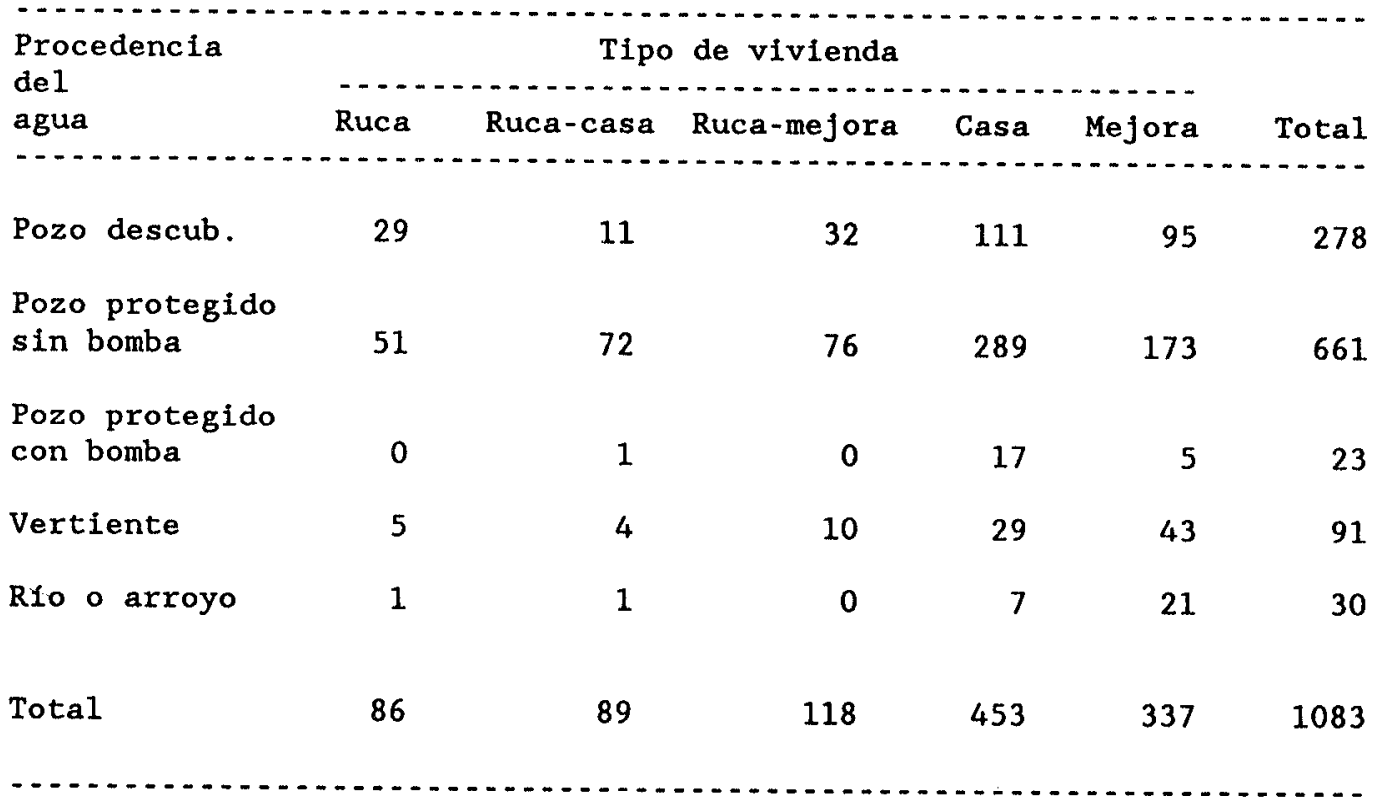

Fuente: Tabulados especiales Censo de 1988. 
ANEXO 16

REDUCCIONES INDIGENAS SELECCIONADAS: DISTRIBUCION DE LOS HOGARES POR SISTEMA DE PROCEDENCIA DEL AGUA, SEGUN TIPO DE VIVIENDA. CENSO DE 1988

\begin{tabular}{|c|c|c|c|c|c|c|}
\hline $\begin{array}{l}\text { Procedencia } \\
\text { del } \\
\text { agua }\end{array}$ & Ruca & $\begin{array}{r}\text { Tipc } \\
\text { Ruca-casa }\end{array}$ & $\begin{array}{l}\text { de vivienda } \\
\text { Ruca-mejora }\end{array}$ & Casa & Mejora & Tota1 \\
\hline Pozo descub. & 90 & 117 & 126 & 348 & 297 & 978 \\
\hline $\begin{array}{l}\text { Pozo protegido } \\
\text { sin bomba }\end{array}$ & 85 & 187 & 159 & 549 & 322 & 1302 \\
\hline $\begin{array}{l}\text { Pozo protegido } \\
\text { con bomba }\end{array}$ & 7 & 11 & 13 & 92 & 22 & 1 \\
\hline Vertiente & 12 & 23 & 38 & 82 & 89 & 244 \\
\hline Rio o arroyo & 1 & 1 & 1 & 10 & 23 & 36 \\
\hline Otro & 2 & 2 & 0 & 4 & 1 & 9 \\
\hline Total & 197 & 341 & 337 & 1085 & 754 & 27 \\
\hline
\end{tabular}

Fuente: Tabulados especiales Censo de 1988. 
ANEXO 17

REDUCCIONES INDIGENAS SELECCIONADAS: DISTRIBUCION DE LOS HOGARES POR SISTEMA DE ELIMINACION DE EXCRETAS, SEGUN TIPO DE VIVIENDA. CENSO DE 1988

\begin{tabular}{|c|c|c|c|c|c|c|}
\hline $\begin{array}{l}\text { Sistema } \\
\text { de eliminación } \\
\text { de excretas }\end{array}$ & Ruca & $\begin{array}{r}\mathrm{Ti}_{1} \\
\text { Ruca-casa }\end{array}$ & $\begin{array}{l}\text { o de viviend } \\
\text { Ruca-mejora }\end{array}$ & Casa & Mejora & Total \\
\hline $\begin{array}{l}\text { Cajón sobre } \\
\text { pozo negro }\end{array}$ & 138 & 312 & 283 & 1051 & 664 & 2448 \\
\hline $\begin{array}{l}\text { Letrina } \\
\text { sanitaria }\end{array}$ & 1 & 0 & 1 & 9 & 2 & 13 \\
\hline $\begin{array}{l}\text { Baño dentro } \\
\text { de la casa }\end{array}$ & 0 & 0 & 0 & 4 & 0 & 4 \\
\hline No tiene & 58 & 29 & 53 & 21 & 87 & 248 \\
\hline Ignorado & 0 & 0 & 0 & 0 & 1 & 1 \\
\hline Total & 197 & 341 & 337 & 1085 & 754 & 2714 \\
\hline
\end{tabular}

Fuente: Tabulados especiales Censo de 1988. 
ANEXO 18

LABRANZA: DISTRIBUCION DE LOS HOGARES POR SISTEMA DE ELIMINACION DE EXCRETAS, SEGUN TIPO DE VIVIENDA. CENSO DE 1988

\begin{tabular}{|c|c|c|c|c|c|c|}
\hline $\begin{array}{l}\text { Sistema } \\
\text { de eliminación } \\
\text { de excretas }\end{array}$ & Ruca & $\begin{array}{r}\mathrm{Ti} \\
\text { Ruca-casa }\end{array}$ & de viviend & Casa & Mejora & Total \\
\hline $\begin{array}{l}\text { Cajón sobre } \\
\text { pozo negro }\end{array}$ & 17 & 34 & 45 & 166 & 80 & 3 \\
\hline $\begin{array}{l}\text { Letrina } \\
\text { sanitaria }\end{array}$ & 0 & 0 & 0 & 1 & 0 & \\
\hline No tiene & 10 & 5 & 12 & 5 & 9 & \\
\hline Total & 27 & 39 & 57 & 172 & 89 & \\
\hline
\end{tabular}

Fuente: Tabulados especiales Censo de 1988. 
ANEXO 19

MOLCO: DISTRIBUCION DE LOS HOGARES POR SISTEMA DE ELIMINACION DE EXCRETAS, SEGUN TIPO DE VIVIENDA. CENSO DE 1988

Sistema
de eliminación
de excretas

Ruca
Tipo de vivienda

Cajón sobre

pozo negro

34

91

83

191

132

531

Letrina

sanitaria

0

0

0

1

1

2.

Baño dentro

de la casa

0

0

0

2

0

2

No tiene

14

5

6

4

9

38

Total

48

96

89

198

142

573

Fuente: Tabulados especiales Censo de 1988. 
ANEXO 20

MAQUEHUE: DISTRIBUCION DE LOS HOGARES POR SISTEMA DE ELIMINACION DE EXCRETAS, SEGUN TIPO DE VIVIENDA. CENSO DE 1988

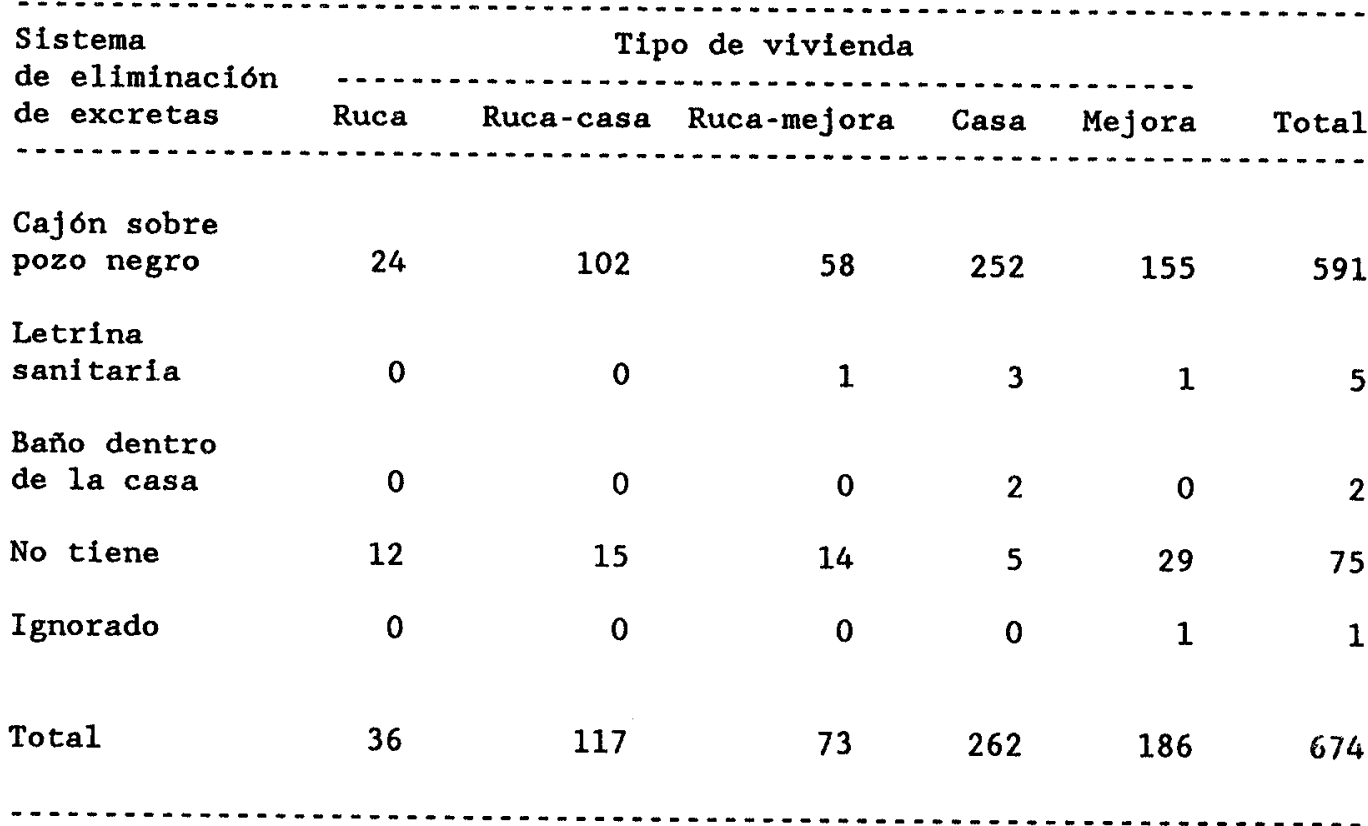

Fuente: Tabulados especiales Censo de 1988. 
ANEXO 21

METRENCO: DISTRIBUCION DE LOS HOGARES POR SISTEMA DE ELIMINACION DE EXCRETAS, SEGUN TIPO DE VIVIENDA. CENSO DE 1988

\begin{tabular}{|c|c|c|c|c|c|c|}
\hline $\begin{array}{l}\text { Sistema } \\
\text { de eliminacion } \\
\text { de excretas }\end{array}$ & Ruca & TIF & $\begin{array}{l}\text { - de viviend } \\
\text { Ruca-mejora }\end{array}$ & Casa & Mejora & Total \\
\hline $\begin{array}{l}\text { Cajón sobre } \\
\text { pozo negro }\end{array}$ & 63 & 85 & 97 & 442 & 297 & 984 \\
\hline $\begin{array}{l}\text { Letrina } \\
\text { sanitaria }\end{array}$ & 1 & 0 & 0 & 4 & 0 & 5 \\
\hline No tiene & 22 & 4 & 21 & 7 & 40 & 94 \\
\hline Total & 86 & 89 & 118 & 453 & 337 & 1083 \\
\hline
\end{tabular}

Fuente: Tabulados especiales Censo de 1988. 
ANEXO 22

REDUCCIONES INDIGENAS SELECCIONADAS: DISTRIBUCION DE LOS HOGARES POR TIPO DE BAÑO, SEGUN PROCEDENCIA DEL AGUA. CENSO DE 1988

\begin{tabular}{|c|c|c|c|c|c|c|c|}
\hline $\begin{array}{l}\text { Tipo } \\
\text { de } \\
\text { baño }\end{array}$ & Pozo desc. & $\begin{array}{l}\text { Prozo prot. } \\
\text { sin bomba }\end{array}$ & $\begin{array}{l}\text { cedencia de } \\
\text { Pozo prot. } \\
\text { con bomba }\end{array}$ & $\begin{array}{l}\text { agua } \\
\text { Vert. }\end{array}$ & $\begin{array}{l}\text { Rio o } \\
\text { arroyo }\end{array}$ & otro & Total \\
\hline $\begin{array}{l}\text { Cajón sobre } \\
\text { pozo negro }\end{array}$ & 840 & 1236 & 136 & 203 & 27 & 6 & 2448 \\
\hline $\begin{array}{l}\text { Letrina } \\
\text { sanitaria }\end{array}$ & 2 & 6 & 5 & 0 & 0 & 0 & 13 \\
\hline $\begin{array}{l}\text { Baño dentro } \\
\text { de } 1 \text { a casa }\end{array}$ & 0 & 1 & 2 & 0 & 0 & 1 & 4 \\
\hline No tiene & 135 & 59 & 2 & 41 & 9 & 2 & 248 \\
\hline Ignorado & 1 & 0 & 0 & 0 & 0 & 0 & \\
\hline Total & 978 & 1302 & 145 & 244 & 36 & 9 & 2714 \\
\hline
\end{tabular}

Fuente: Tabulados especiales Censo de 1988. 
ANEXO 23

REDUCCIONES INDIGENAS SELECCIONADAS: DISTRIBUCION DE LOS HOGARES POR TIPO DE FAMILIA SEGUN HOGARES Y POBLACION. CENSO DE 1988

\begin{tabular}{|c|c|c|c|c|c|}
\hline \multirow{2}{*}{$\begin{array}{l}\text { Tipo } \\
\text { de } \\
\text { familia }\end{array}$} & \multirow{2}{*}{ Hogares } & \multicolumn{3}{|c|}{ Población } & \multirow{2}{*}{$\begin{array}{l}\text { Personas } \\
\text { por hogar } \\
\text { (promedio) }\end{array}$} \\
\hline & & Hombres & Mujeres & A. sexos & \\
\hline Nuclear & 1673 & 3857 & 3340 & 7197 & 4.3 \\
\hline Completa & 1303 & 3352 & 2973 & 6325 & 4.9 \\
\hline Incompleta & 370 & 505 & 367 & 872 & 2.4 \\
\hline Extensa & 881 & 2441 & 2433 & 4874 & 5.5 \\
\hline Completa & 481 & 1592 & 1545 & 3137 & 6.5 \\
\hline Incompleta & 400 & 849 & 888 & 1737 & 4.3 \\
\hline Compuesta & 160 & 465 & 416 & 881 & 5.5 \\
\hline Completa & 117 & 360 & 315 & 675 & 5.8 \\
\hline Incompleta & 43 & 105 & 101 & 206 & 4.8 \\
\hline Total & 2714 & 6763 & 6189 & 12952 & 4.8 \\
\hline
\end{tabular}

Fuente: Tabulados especiales Censo de 1988. 
ANEXO 24

REDUCCIONES INDIGENAS SELECCIONADAS: DISTRIBUCION DE LA POBLACION POR TIPO DE FAMILIA Y SEXO, SEGUN GRUPOS DE EDAD. CENSO DE 1988

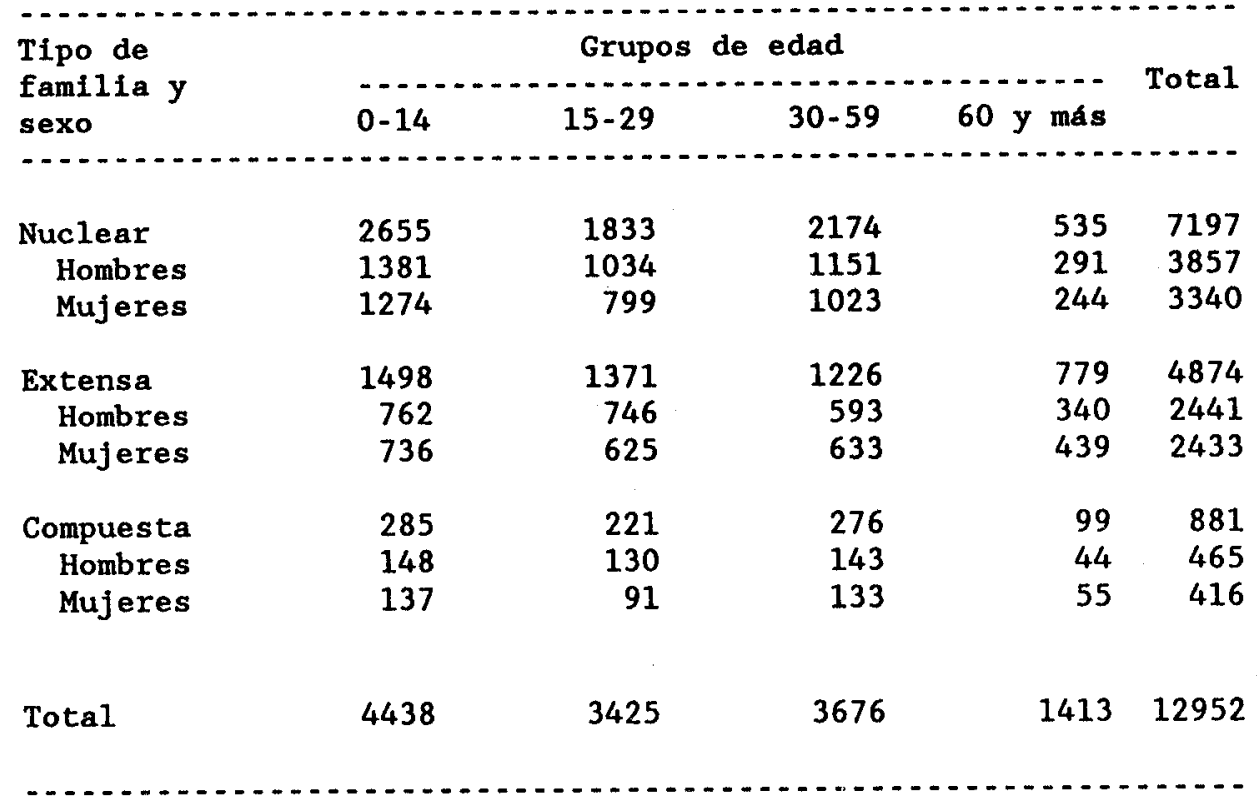

Fuente: Tabulados especiales Censo de 1988. 


\section{ANEXO 25}

REDUCCIONES INDIGENAS SELECCIONADAS: DISTRIBUCION DE LA POBLACION POR GRADO DE PARENTESCO CON EL JEFE DE HOGAR, SEGUN TIPO DE FAMILIA. CENSO DE 1988

\begin{tabular}{|c|c|c|c|c|c|c|c|c|}
\hline $\begin{array}{l}\text { Relación } \\
\text { de } \\
\text { parentesco } \\
\end{array}$ & Nuclea & \begin{tabular}{c} 
Poblac: \\
\hdashline$\quad 8$ \\
$x$
\end{tabular} & in según & $\begin{array}{c}\text { tipo } \\
8\end{array}$ & fami & La & $\mathrm{N}^{\text {To }}$ & 8 \\
\hline Jefe de hogar & 1673 & 23.3 & 881 & 18.1 & 160 & 18.2 & 2714 & 20.9 \\
\hline Conyuge & 1303 & 18.1 & 481 & 9.9 & 117 & 13.3 & 1901 & 14.7 \\
\hline Hijo (hija) & 4221 & 58.6 & 1831 & 37.6 & 264 & 30.0 & 6316 & 48.8 \\
\hline Otro pariente & 0 & - & 1681 & 34.6 & 108 & 12.2 & 1789 & 13.8 \\
\hline Otro no pariente & 0 & - & 0 & - & 232 & 26.3 & 232 & 1.9 \\
\hline Total & 7197 & 100.0 & 4874 & 100.0 & 881 & 100.0 & 12952 & 100. \\
\hline
\end{tabular}

Fuente: Tabulados especiales Censo de 1988. 


\section{ANEXO 26}

REDUCCIONES INDIGENAS SELECCIONADAS: DISTRIBUCION DE LOS JEFES DE HOGAR POR TIPO DE FAMILIA, SEGUN SEXO. CENSO DE 1988

\begin{tabular}{|c|c|c|c|}
\hline \multirow{2}{*}{$\begin{array}{l}\text { Tipo } \\
\text { de } \\
\text { familia }\end{array}$} & \multicolumn{3}{|c|}{ Jefes de hogar } \\
\hline & Hombres & Mujeres & A. sexos \\
\hline & & & \\
\hline Nuclear & 1475 & 198 & 1673 \\
\hline Completa & 1294 & 9 & 1303 \\
\hline Incompleta & 181 & 189 & 370 \\
\hline Extensa & 660 & 221 & 881 \\
\hline Completa & 474 & 7 & 481 \\
\hline Incompleta & 186 & 214 & 400 \\
\hline Compuesta & 132 & 28 & 160 \\
\hline Completa & 117 & 0 & 117 \\
\hline Incompleta & 15 & 28 & 43 \\
\hline Completa & 1885 & 16 & 1901 \\
\hline Incompleta & 382 & 431 & 813 \\
\hline Total & 2267 & 447 & 2714 \\
\hline
\end{tabular}

Fuente: Tabulados especiales Censo de 1988. 
ANEXO 27

REDUCCIONES INDIGENAS SELECCIONADAS: DISTRIBUCION DE LOS

JEFES DE HOGAR POR SEXO, SEGUN ESTADO CIVIL. CENSO DE 1988

\begin{tabular}{|c|c|c|c|c|c|c|c|}
\hline $\begin{array}{l}\text { Jefes } \\
\text { de }\end{array}$ & & 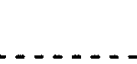 & Estado $c$ & 1 & & & \\
\hline $\begin{array}{l}\text { hogar } \\
\text { por sexo }\end{array}$ & Conviv. & $\begin{array}{l}\text { Casado } \\
\text { civil }\end{array}$ & $\begin{array}{l}\text { Casado } \\
\text { mapuche }\end{array}$ & Viudo & Separ. & Soltero & \\
\hline Hombres & 175 & 1720 & 2 & 175 & 27 & 168 & 2267 \\
\hline Mujeres & 13 & 18 & 1 & 267 & 34 & 114 & 447 \\
\hline $\begin{array}{l}\text { nbos } \\
\text { exos }\end{array}$ & 188 & 1738 & 3 & 442 & 61 & 282 & 2714 \\
\hline
\end{tabular}

Fuente: Tabulados especiales Censo de 1988.

ANEXO 28

REDUCCIONES INDIGENAS SELECCIONADAS: DISTRIBUCION DE LOS JEFES DE HOGAR POR TIPO DE FAMILIA, SEGUN GRUPOS DE EDAD. CENSO DE 1988

\begin{tabular}{|c|c|c|c|c|c|c|c|c|}
\hline $\begin{array}{l}\text { Tipo } \\
\text { de }\end{array}$ & & 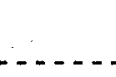 & Grup & s de ec & $\begin{array}{l}d \\
\ldots . . .\end{array}$ & - - & 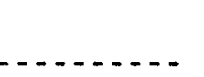 & Total \\
\hline familia & $15-19$ & $20-29$ & $30-39$ & $40-49$ & $50-59$ & $60-64$ & 65 y más & \\
\hline Nuclear & 2 & 174 & 395 & 390 & 328 & 117 & 266 & 1673 \\
\hline Extensa & 3 & 42 & 85 & 131 & 197 & 130 & 293 & 881 \\
\hline Compuesta & 1 & 9 & 38 & 35 & 24 & 12 & 41 & 160 \\
\hline Total & 6 & 225 & 519 & 556 & 549 & 259 & 600 & 2714 \\
\hline
\end{tabular}

Fuente: Tabulados especiales Censo de 1988. 
ANEXO 29

REDUCCIONES INDIGENAS SELECCIONADAS: DISTRIBUCION DE LOS HOGARES POR LENGUA HABLADA MAS FRECUENTEMENTE, SEGUN TIPO DE VIVIENDA. CENSO DE 1988

\begin{tabular}{|c|c|c|c|c|c|c|}
\hline $\begin{array}{l}\text { Lengua hablada } \\
\text { con más frecuencia } \\
\text { en el hogar }\end{array}$ & Ruca & $\begin{array}{r}\text { Tip } \\
\text { Ruca-casa }\end{array}$ & $\begin{array}{l}\text { de vivienda } \\
\text { Ruca-mejora }\end{array}$ & Casa & Mejora & Total \\
\hline Mapuche & 23 & 36 & 69 & 75 & 70 & 273 \\
\hline $\begin{array}{l}\text { Mapuche y } \\
\text { castellano }\end{array}$ & 117 & 206 & 190 & 464 & 346 & 1323 \\
\hline Castellano & 57 & 99 & 78 & 546 & 338 & 1118 \\
\hline Total & 197 & 341 & 337 & 1085 & 754 & 2714 \\
\hline
\end{tabular}

Fuente: Tabulados especiales Censo de 1988.

ANEXO 30

LABRANZA: DISTRIBUCION DE LOS HOGARES POR LENGUA HABLADA MAS FRECUENTEMENTE, SEGUN TIPO DE VIVIENDA. CENSO DE 1988

Lengua hablada con más frecuencia en el hogar en el hogar

Mapuche

Mapuche y

castellano

Castellano

Tota1
4

15

8

27
Tipo de vivienda

Ruca Ruca-casa Ruca-mejora
Casa Mejora Total

12

9

3

31

31

57

37

167

14

106

49

186

57

172

89

Fuente: Tabulados especiales Censo de 1988. 
ANEXO 31

MOLCO: DISTRIBUCION DE LOS HOGARES POR LENGUA HABLADA MAS FRECUENTEMENTE, SEGUN TIPO DE VIVIENDA. CENSO DE 1988

Lengua hablada

con más frecuencia

en el hogar

en el hogar

Mapuche

3

28

48

Mapuche y

castellano

Castellano

Total

$17 \quad 31$

Tipo de vivienda

Ruca Ruca-casa Ruca-mejora Casa Mejora Total

96

89

198

142

573

Fuente: Tabulados especiales Censo de 1988.

\section{ANEXO 32}

MAQUEHUE: DISTRIBUCION DE LOS HOGARES POR LENGUA HABLADA MAS FRECUENTEMENTE, SEGUN TIPO DE VIVIENDA. CENSO DE 1988

\begin{tabular}{|c|c|c|c|c|c|c|}
\hline $\begin{array}{l}\text { Lengua hablada } \\
\text { con más frecuencia } \\
\text { en el hogar }\end{array}$ & Ruca & $\begin{array}{r}\text { Tip } \\
\text { Ruca-casa }\end{array}$ & $\begin{array}{r}\text { de vivienda } \\
\text { Ruca-mejora }\end{array}$ & Casa & Mejora & Total \\
\hline Mapuche & 5 & 13 & 14 & 22 & 24 & 78 \\
\hline $\begin{array}{l}\text { Mapuche y } \\
\text { castellano }\end{array}$ & 20 & 65 & 35 & 111 & 89 & 320 \\
\hline Castellano & 11 & 39 & 24 & 129 & 73 & 276 \\
\hline Cota1 & 36 & 117 & 73 & 262 & 186 & 67 \\
\hline
\end{tabular}

Fuente: Tabulados especiales Censo de 1988. 
ANEXO 33

METRENCO: DISTRIBUCION DE LOS HOGARES POR LENGUA HABLADA MAS FRECUENTEMENTE, SEGUN TIPO DE VIVIENDA. CENSO DE 1988

\begin{tabular}{|c|c|c|c|c|c|c|}
\hline $\begin{array}{l}\text { Lengua hablada } \\
\text { con más frecuencia } \\
\text { en el hogar }\end{array}$ & Ruca & $\begin{array}{r}\text { Tipc } \\
\text { Ruca-casa }\end{array}$ & $\begin{array}{l}\text { de vivienda } \\
\text { Ruca-mejora }\end{array}$ & Casa & Mejora & Total \\
\hline Mapuche & 11 & 10 & 27 & 33 & 30 & 111 \\
\hline $\begin{array}{l}\text { Mapuche y } \\
\text { castellano }\end{array}$ & 54 & 59 & 71 & 194 & 151 & 529 \\
\hline Castellano & 21 & 20 & 20 & 226 & 156 & 443 \\
\hline Total & 86 & 89 & 118 & 453 & 337 & 1083 \\
\hline
\end{tabular}

Fuente: Tabulados especiales Censo de 1988.

ANEXO 34

REDUCCIONES INDIGENAS SELECCIONADAS :

DISTRIBUCION DE LA POBLACION POR LENGUA HABLADA

MAS FRECUENTEMENTE EN EL HOGAR. CENSO DE 1988

\begin{tabular}{|c|c|c|}
\hline \multirow{2}{*}{$\begin{array}{l}\text { Lengua hablada } \\
\text { con más frecuencia } \\
\text { en el hogar }\end{array}$} & \multicolumn{2}{|c|}{ Población } \\
\hline & $\mathrm{N}^{2}$ & 8 \\
\hline Mapuche & 1101 & 8.5 \\
\hline $\begin{array}{l}\text { Mapuche y } \\
\text { castellano }\end{array}$ & 6569 & 50.7 \\
\hline Castellano & 5282 & 40.8 \\
\hline Total & 12952 & 100.0 \\
\hline
\end{tabular}

Fuente: Tabulados especiales Censo de 1988. 
ANEXO 35

REDUCCIONES INDIGENAS SELECCIONADAS: DISTRIBUCION DE LOS HOGARES POR TIPO DE VIVIENDA Y FAMILIA, SEGUN LENGUA HABLADA MAS FRECUENTEMENTE

E INDICADOR DE APEGO AL MODO DE VIDA TRADICIONAL MAPUCHE (IA). CENSO DE 1988

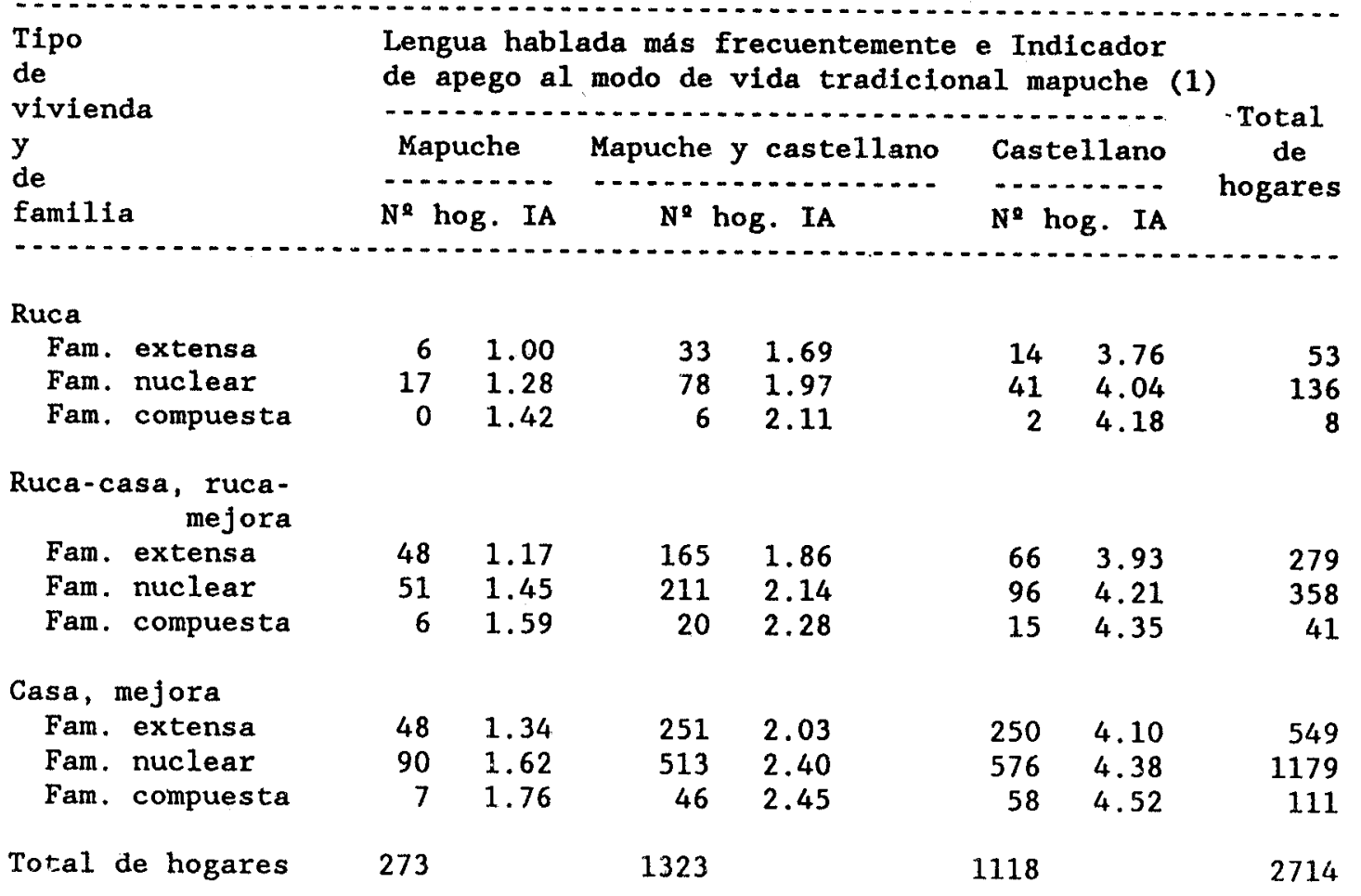

Fuente: Tabulados especiales Censo de 1988 .

(1): Grado de apego Valores

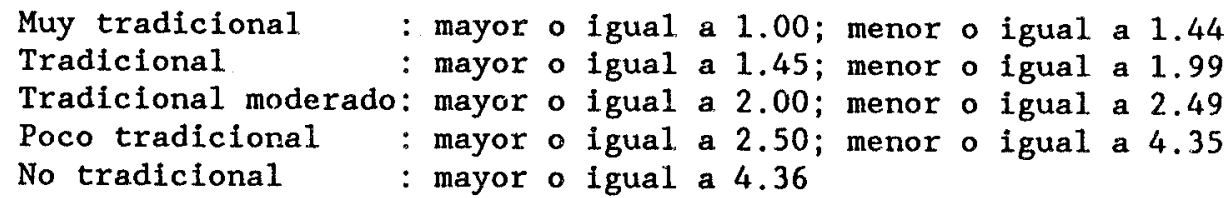


ANEXO 36

REDUCCIONES INDIGENAS SELECCIONADAS: DISTRIBUCION DE LOS

HOGARES POR GRADO DE APEGO AL MODO DE VIDA TRADICIONAL MAPUCHE, SEGUN DISTRITOS. CENSO DE 1988

\begin{tabular}{|c|c|c|c|c|c|}
\hline $\begin{array}{l}\text { Grado de } \\
\text { apego al modo } \\
\text { de vida } \\
\text { tradicional }\end{array}$ & Labranza & $\begin{array}{r}\text { Dis } \\
\text { Molco }\end{array}$ & $\begin{array}{l}\text { Itos } \\
\text { Maquehue }\end{array}$ & Metrenco & Total \\
\hline Muy tradicional & 8 & 22 & 41 & 48 & 119 \\
\hline Tradicional & 62 & 103 & 98 & 167 & 430 \\
\hline Tradicional moderado & 128 & 235 & 259 & 425 & 1047 \\
\hline Poco tradicional & 76 & 112 & 135 & 161 & 484 \\
\hline No tradicional & 110 & 101 & 141 & 282 & 634 \\
\hline Cotal & 384 & 573 & 674 & 1083 & 2714 \\
\hline
\end{tabular}

Fuente: Tabulados especiales Censo de 1988. 


\section{ANEXO 1 \\ PARTICIPANTES EN IA INVESTIGACION CENSAI.}

- Personal del Proyecto:

Coordinadores: Ronald Gebert (UFRO)

Jaime Serra (UFRO)

Fernando Muñoz (Servicio de Salud de La Araucania)

Odette Tacla (INE)

Susan Aurelius (PAESMI)

Juan Chackiel (CELADE)

Investigadores: Ana M, Oyarce

Gabriela Pérez

Susana Schkolnik

Jorge Martinez

Jorge Rodriguez

Sergio Muñoz

- Trabajo de terreno:

Coordinadora General: Cristina Niedmann

Encargado de terreno: Eugenio Acuña

Supervisores: Raúl Manzano

Sergio Yáñez

Entrevistadores: Roberto Anchio

Cristián Rivera

Sandra Anoni

Eduardo Emaldía

Luz Rojas

Ruth Gomez

Ida Ruiz

Héctor Martinez

Luis A. Ruiz

Wagner Vidal

Programación: Claudio Meza

Mauricio Osorio

- Asesores en ciertas etapas de la investigación:

\author{
Carmen Arretx \\ Jorge Garcia \\ Andre Quesnel. \\ Aldo Vidal \\ Teresa Durán \\ Mauricio Francois \\ Rodolfo Jofré \\ José Ñanco
}

\author{
César Torres \\ Jacinto Torres \\ Raú1 Caamaño \\ Bernarda Espinoza \\ Ivonne Jelves \\ Roberto Morales \\ Ne11y Ramos
}


ANEXO 2

CUESTIONARIO CENSAL

CEMSO EXPERIMENTAL DE REOUCCIONES MAPUKKES - IENUCO T98S UTRO - UCT - MAESMI - IME - CELAOE

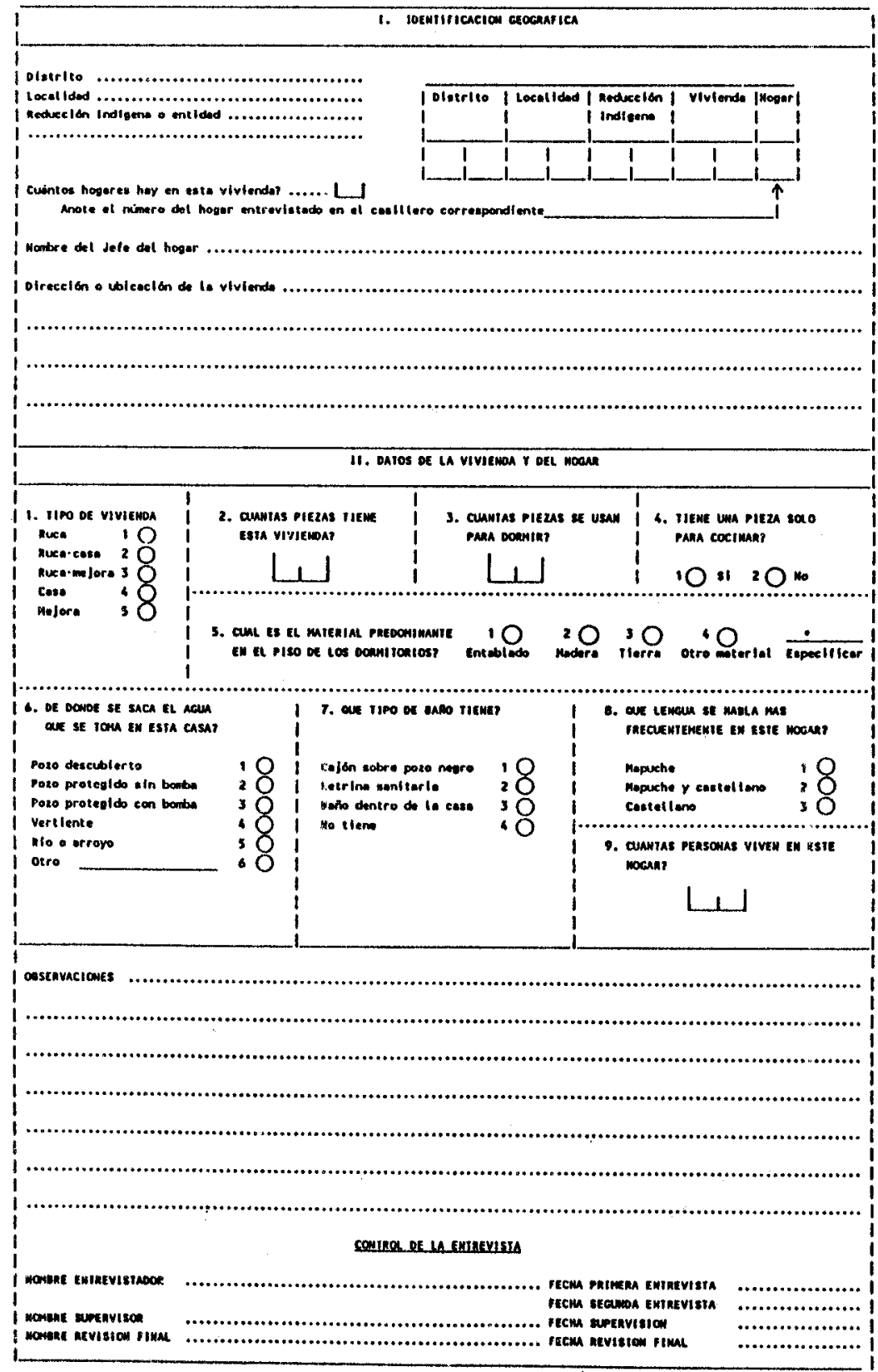




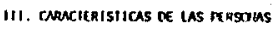

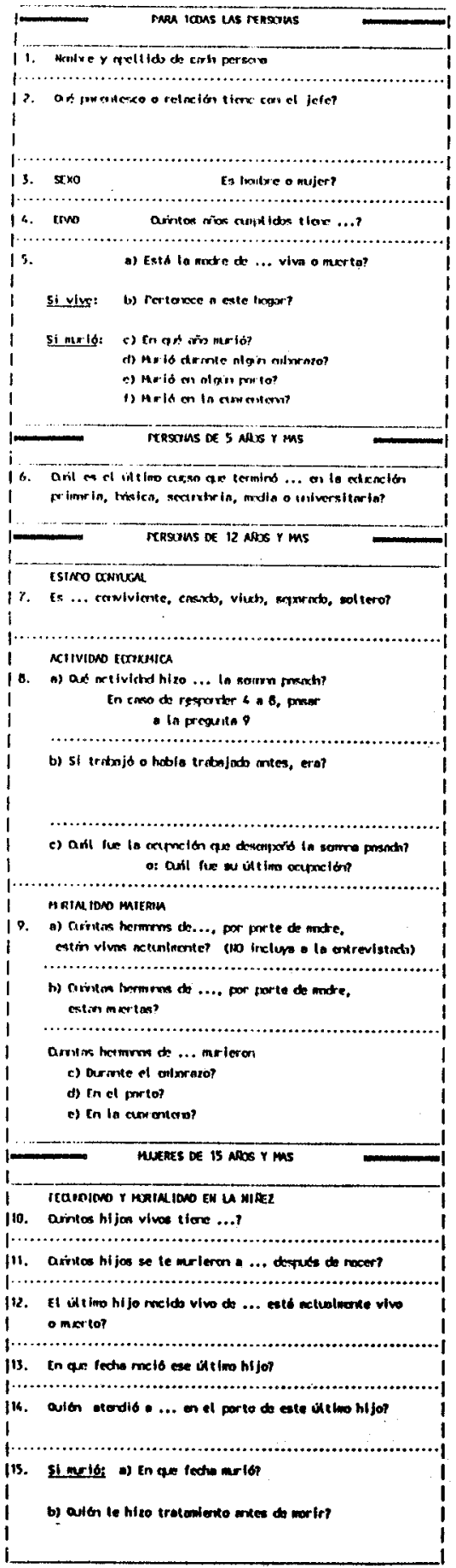

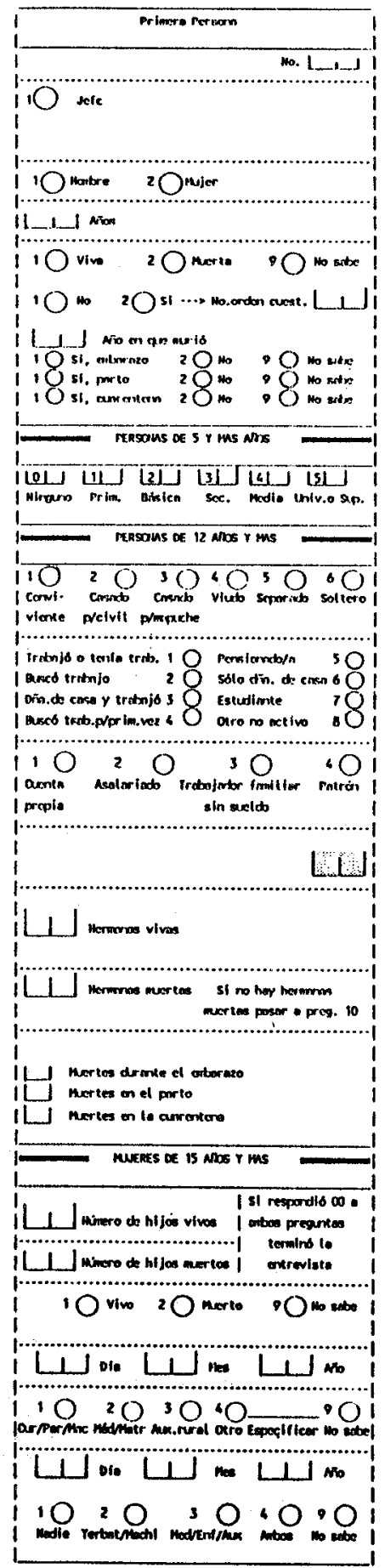

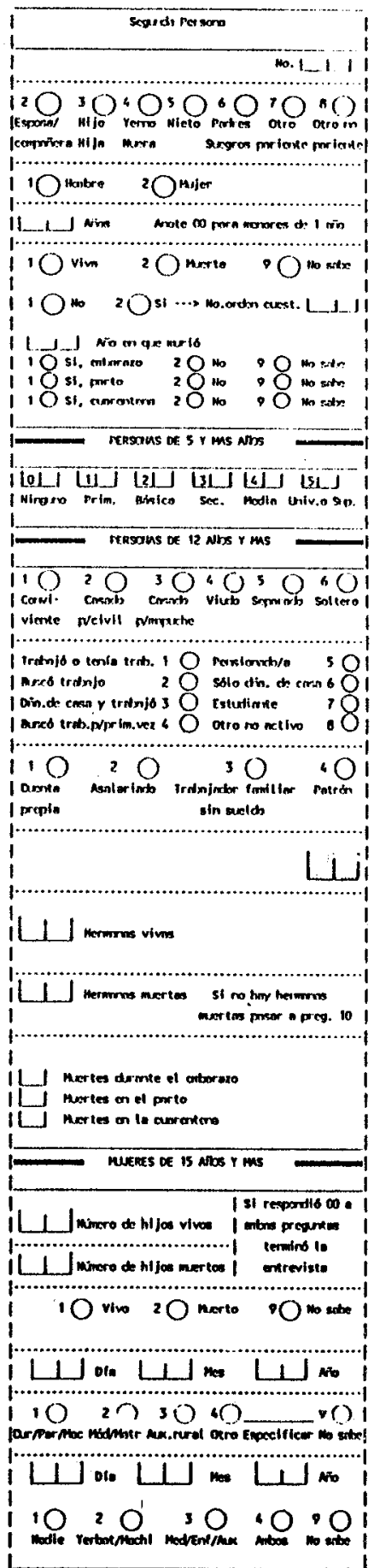

Nota: E1 cuestionario tiene columnas para nueve personas. 
El análisis de resultados está estructurado en cinco capítulos, cuyos contenidos centrales son los siguientes:

I. Características demográficas: Sc estudian los niveles aproximados de las variables demográficas (fecundidad, mortalidad y migración), junto al crecimiento y estructura por sexo y cdad de la población.

II. Mortalidad y atención de salud materno infantil: Sc analiza el nivel de la morlalidad infantil según variables socioculturales, así como se presentan órdenes de magnitud de la mortalidad materna. También se examinan la atención en el parto y la atención recibida por cl último hijo nacido vivo antes de morir.

III. Características educacionales: Se cxaminan cl analfabetismo y la situación de escolaridad de la población, asociándolos con la edad, cl sexo y la lengua hablada en el hogar.

IV. Características económicas: La información que se analiza se refiere al grado de participación de la población en la actividad cconómica y a las características ocupacionales de la población cconónicamente activa.

V. Vivienda, hogar y familia: Se presenta un análisis de las características de la vivienda, de los hogares y de las familias, describiendo otros aspectos de las condiciones materiales de vidat, así como algunos rasgos relativos a la cultura (lengua hablada en el hogar y grado de apego al modo de vida tradicional).

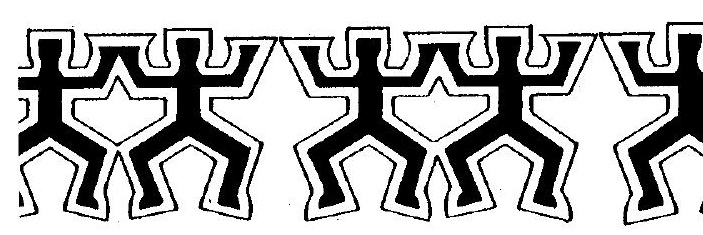

